\title{
Einfluss von Landschaftsstrukturen und landwirtschaftlicher Nutzung auf das Auftreten blattpathogener Pilze an Weizen und die genetische Diversität von Mycosphaerella graminicola (Anamorph Septoria tritici)
}

\author{
Dissertation \\ zur Erlangung des Doktorgrades \\ der Fakultät für Agrarwissenschaften \\ der Georg-August-Universität Göttingen \\ vorgelegt von \\ Julia Morzfeld \\ geboren in Bochum
}

Göttingen, Mai 2004 
1. Referent: Prof. Dr. A. von Tiedemann

2. Referent: Prof. Dr. P. Karlovsky

Tag der mündlichen Prüfung: 27.05.2004 
Für meine Familie 


\section{Inhalt}

Abkürzungen und Symbole

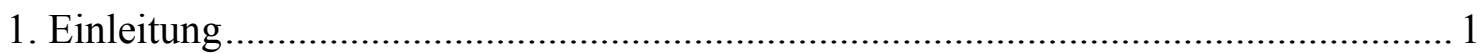

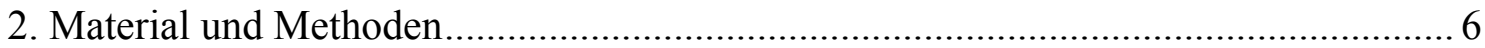

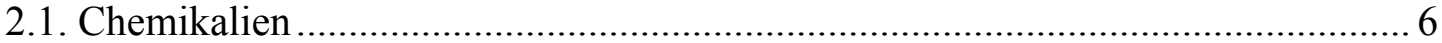

2.2. Nährmedien, Puffer und Trenngele ................................................................... 7

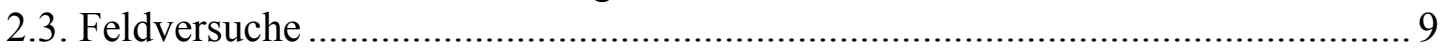

2.3.1. Landschaftsparameter der untersuchten Felder ...................................... 9

2.3.2. Bewirtschaftungsparameter der untersuchten Felder.................................. 13

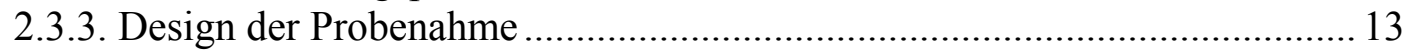

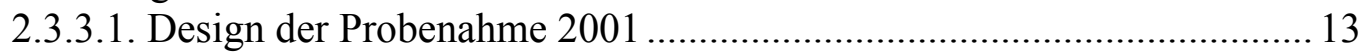

2.3.3.2. Design der Probenahme 2002 .............................................................. 14

2.3.4. Befallserhebung blattpathogener Pilze …................................................ 15

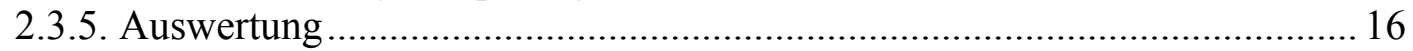

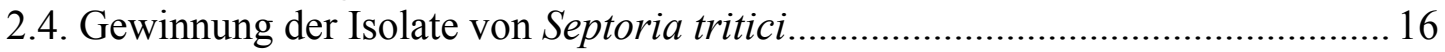

2.4.1. Bezeichnung der Isolate von Septoria tritici .................................................... 17

2.5. Untersuchungen zur Aggressivität von Septoria tritici .................................... 18

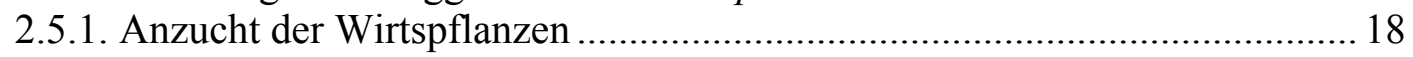

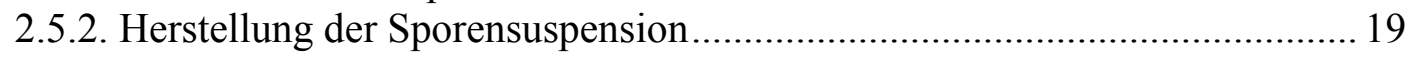

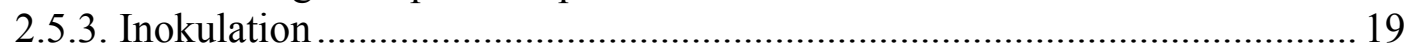

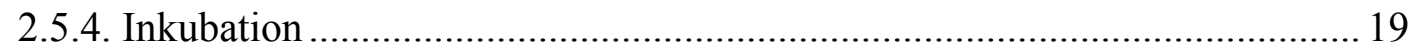

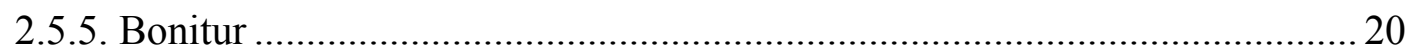

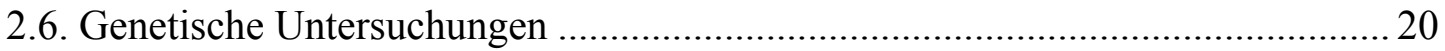

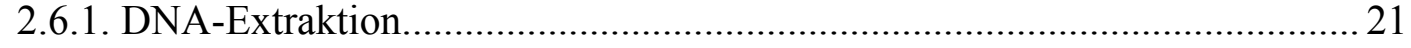

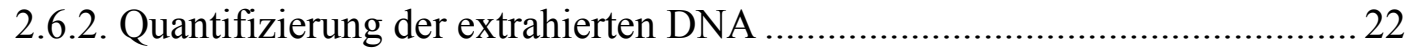

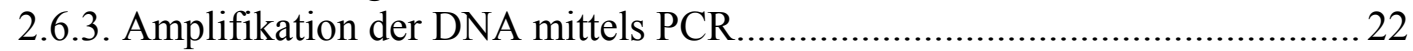

2.6.3.1. Amplifikation der DNA mittels MP-PCR …......................................... 22

2.6.3.2. Amplifikation der DNA mittels Mikrosatelliten-PCR ........................... 24

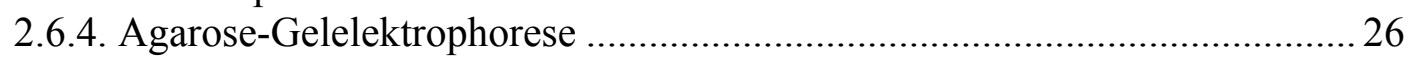

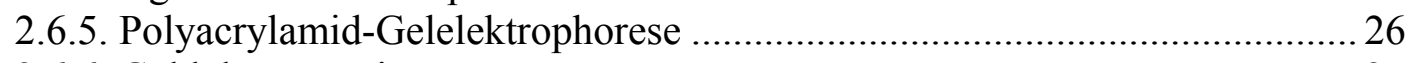

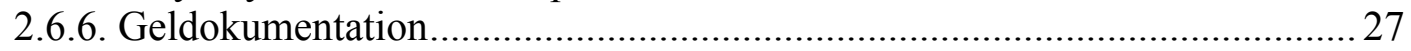

2.6.6.1. Dokumentation der Agarose-Gele .................................................... 27

2.6.6.2. Dokumentation der Polyacrylamid-Gele ............................................ 27

2.6.7. Datenerfassung und Auswertung molekularer Daten ................................. 28

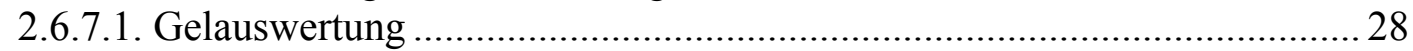

2.6.7.2. Genetische Ähnlichkeiten und multivariate Statistiken ....................... 28

2.6.7.3. Populationsgenetische Analyse von Septoria tritici ............................ 29

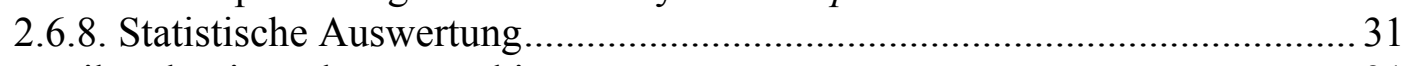

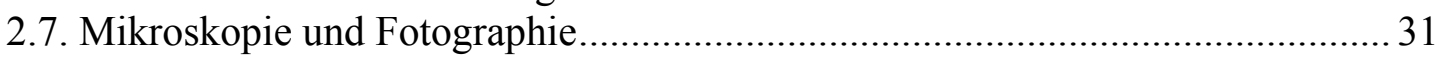




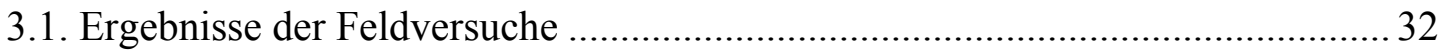

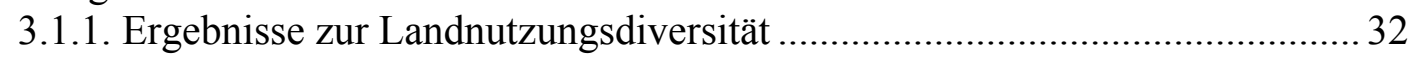

3.1.2. Unterschiede der Bewirtschaftungsweise der untersuchten Felder ................ 35

3.1.3. Auftreten blattpathogener Pilze in unterschiedlichen Landschaften ............. 41

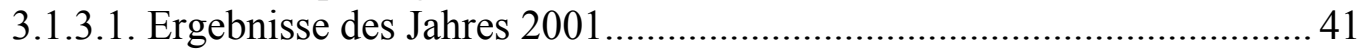

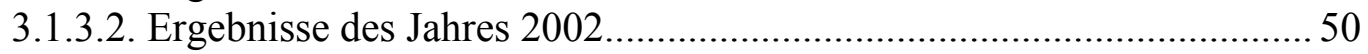

3.2. Ergebnisse der Untersuchungen zur Aggressivität von Septoria tritici.............. 61

3.2.1. Aggressivität gegenüber verschiedenen Weizensorten.................................6 61

3.2.2. Unterschiede der Aggressivität der Isolate verschiedener Felder.................. 62

3.2.3. Unterschiede der Aggressivität verschiedener Isolate von S. tritici ............. 65

3.3. Ergebnisse der genetischen Untersuchungen von Septoria tritici .......................6 67

3.3.1. Ergebnisse und Beurteilung der MP-PCR ................................................ 67

3.3.2. Genetische Diversität von Septoria tritici in Abhängigkeit von

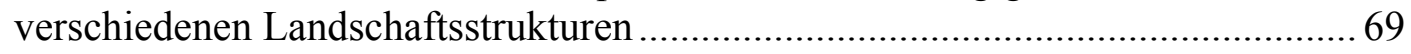

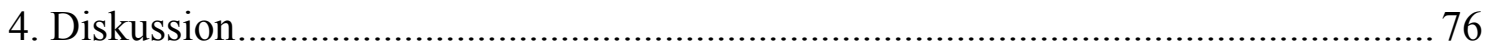

4.1. Einfluss der Landschaftsstruktur auf blattpathogene Pilze an Weizen unter Einbeziehung von Bewirtschaftungsparametern .................................................. 77

4.2. Einfluss der Landschaftsstruktur auf die Aggressivität von Septoria tritici........ 87

4.3. Einfluss der Landschaftsstruktur auf die genetische Variabilität von Septoria tritici.

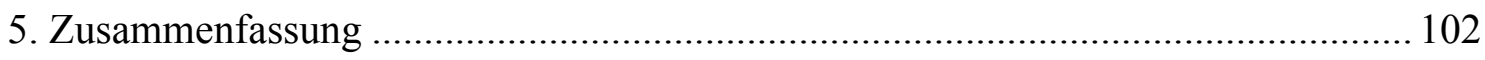

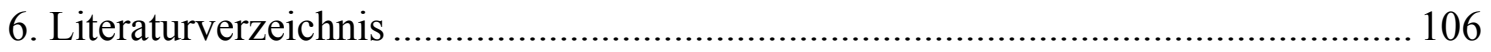

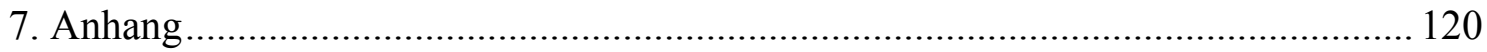

Danksagung

Lebenslauf

Erklärung 


\section{Abkürzungen und Symbole}

\begin{tabular}{|c|c|}
\hline Abb. & Abbildung \\
\hline $\mathrm{BBCH}$ & Gemeinsamer Code der Firmen BASF AG, Bayer AG, Ciba- \\
\hline & Geigy AG und Hoechst AG nach BLEIERHOLDER et. al. (1989) \\
\hline $\mathrm{bp}$ & Basenpaare \\
\hline bzw. & beziehungsweise \\
\hline ca. & circa \\
\hline $\mathrm{cm}$ & Zentimeter \\
\hline DNA & Desoxyribonukleinsäure \\
\hline d. h. & das heißt \\
\hline $\mathrm{dt}$ & Dezitonnen \\
\hline EDTA & Ethylendiamintetraacetat \\
\hline et al. & et alteri \\
\hline etc. & et cetera \\
\hline F-Blatt & Fahnenblatt \\
\hline f. sp. & formae specialis \\
\hline $\mathrm{g}, \mathrm{kg}, \mu \mathrm{g}$ & Gramm, Kilo-, Mikro- \\
\hline ha & ha \\
\hline $\mathrm{H}_{2} \mathrm{O}$ & Wasser \\
\hline $1, \mathrm{ml}, \mu \mathrm{l}$ & Liter, Milli-, Mikro- \\
\hline $\mathrm{m}, \mathrm{cm}, \mathrm{mm}, \mathrm{nm}$ & Meter, Zenti-, Milli-, Nano- \\
\hline $\mathrm{MgCl}_{2}$ & Magnesiumchlorid \\
\hline $\mathrm{M}, \mathrm{mM}, \mathrm{nM}$ & Mol, Milli-, Nano- \\
\hline $\min$. & Minute \\
\hline Mitt. & Mitteilung \\
\hline Mittl. & Mittlere(r) \\
\hline o. g. & oben genannt \\
\hline $\mathrm{P}$ & Irrtumswahrscheinlichkeit \\
\hline PCR & Polymerasekettenreaktion \\
\hline$r^{2}$ & Korrelationskoeffizient \\
\hline sec. & Sekunde \\
\hline SNK & Student Newman Keuls Test \\
\hline
\end{tabular}


sog.

Std.

Tab.

Taq-Poly.

$\mathrm{U}$

UV

Var.

W

z. B

${ }^{\circ} \mathrm{C}$

$\%$ sogenannt (e)

Stunde(n)

Tabelle

Taq-Polymerase

Unit

Ultraviolett

Variante

Watt

zum Beispiel

Grad Celsius

Prozent 


\section{Einleitung}

Getreide und Getreideprodukte sind weltweit von großer Bedeutung. In den letzten Jahrzehnten wuchs der Bedarf an Grundnahrungsmitteln durch Zuwachs der Weltbevölkerung. Gleichzeitig stiegen die erzielten Getreideerträge der Regionen gemäßigter Klimaten, insbesondere in Europa, zur Deckung des wachsenden Bedarfs deutlich an (VERRET et al. 1990a). Die Steigerung der Erträge wurde durch zunehmende Intensivierung der Landwirtschaft erreicht, die aus phytopathologischer und ökologischer Sicht nicht unproblematisch ist. Zum einen bewirkt Intensivierung von Agrarmaßnahmen das vermehrte Auftreten monotoner Landschaften, deren Vegetation von wenigen Nutzpflanzen dominiert wird. Daraus resultiert die Zerstörung und Fragmentierung natürlicher Lebensräume und führt zu einer Verminderung von Biodiversität (SAUNDERS et al. 1991). Zum anderen fördert intensive Landwirtschaft die Spezialisierung von Pathogenen, z. B. in Form von Resistenzen gegenüber Pflanzenschutzmitteln. Daraus lässt sich ableiten, dass die Wirkung landwirtschaftlicher Nutzung auf Biodiversität wesentlich durch die räumliche Komplexität einer Landschaft beeinflusst wird, z. B. von der Verfügbarkeit von Nahrungsquellen.

Erhaltung und Förderung der Biodiversität in Agrarlandschaften stellt laut ALTIERI (1995) ein essentielles Element im Zuge der nachhaltigen Landwirtschaft dar. Sowohl die Extensivierung der Agrarbewirtschaftungsmaßnahmen durch verringerten Einsatz chemischer Pflanzenschutzmittel, als auch die Diversifizierung von Agrarökosystemen durch Erhöhung der Landschaftskomplexität unterliegen dabei besonderer Beachtung (BIGNAL \& McCRACKEN 1996). In der Europäischen Gemeinschaft sind nachhaltige Landwirtschaft und Landschaftsmanagement aktuelle Themen zur Verbesserung des biologischen Pflanzenschutzes und Erhaltung ökologischer Funktionen. Die diskutierte „Unwägbarkeits“- oder „Zukunftssicherungs“-Hypothese besitzt aufgrund der geringen Kenntnisse über den Einfluss von Biodiversität auf ökologische Funktionen in Agrarökosystemen einen hohen Stellenwert in der EU-Agrarpolitik. Laut dieser Hypothese ist die Artenvielfalt wegen ihres unbekannten Stellenwertes bei nicht prognostizierbaren Veränderungen zu schützen (BENGTSSON et al. 1997). 
Diese Arbeit ist in das interdisziplinäre Projekt Bioplex eingegliedert, dass sich mit dem Zusammenhang zwischen Biodiversität und räumlicher Komplexität in Agrarlandschaften beschäftigt. An diesem Projekt sind insgesamt fünf verschiedene Arbeitsgruppen der Universitäten Göttingen und Giessen beteiligt.

Die übergeordnete Hypothese des Projektes lautet, dass die biologische Vielfalt in der europäischen Kulturlandschaft eng mit dem Komplexitätsgrad der Landschaft verknüpft ist. Im Rahmen dieses Projektes werden die wichtigsten funktionellen Tiergruppen (Schadinsekten, Prädatoren, Parasitoide, Bestäuber, Samenräuber, Bodenwühler, Zersetzer, Bodenmikroorganismen) sowie phytopathogene Pilze untersucht. Die erforderlichen Analysen zur Bewertung des Zusammenhangs zwischen Biodiversität und Landschaftsstruktur werden auf lokaler und regionaler Skalenebene durchgeführt. Die Struktur einer Landschaft wird dabei hinsichtlich ihrer Komplexität differenziert. Ein hoher Anteil an Hecken, Wiesen und Wäldern in unmittelbarer Umgebung des Untersuchungsfeldes beschreibt eine divers strukturierte Landschaft. Im Gegensatz dazu ist eine monotone, wenig komplex strukturierte Landschaft durch weiträumige Ackerflächen in der Umgebung des Untersuchungsfeldes charakterisiert. Die ausgewählten Landschaften bilden dabei einen Gradienten, der von einfach strukturierten Raumeinheiten bis hin zu komplexen Systemen aus Hecken, Brachen Grünland etc. reicht. Abb. 1 verdeutlicht den Unterschied zwischen einer komplex strukturierten und einer monotonen Landschaft.
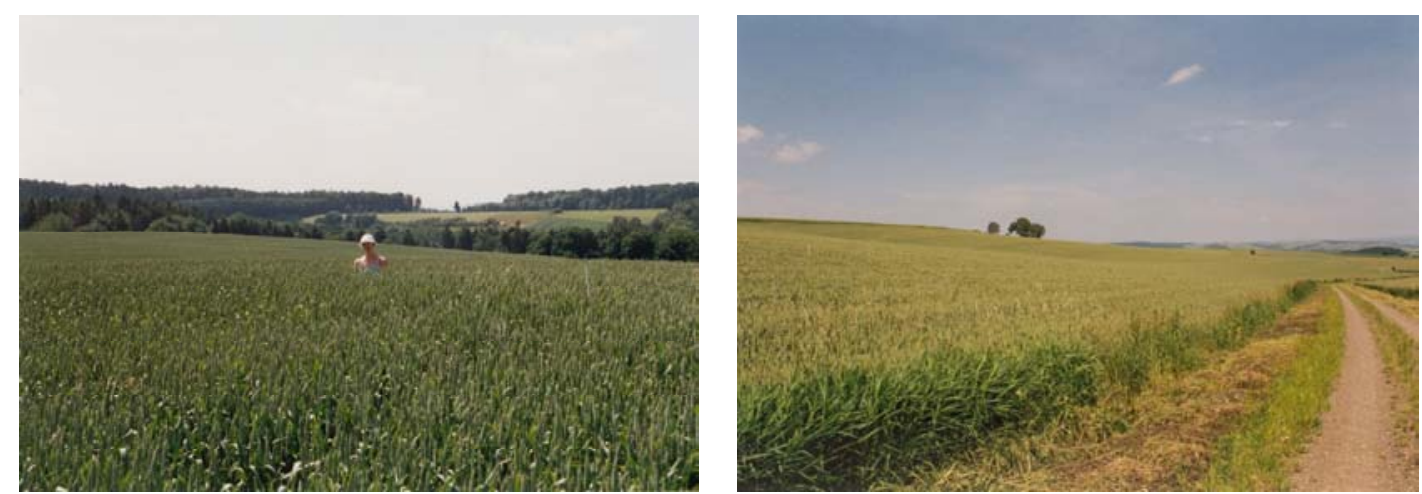

Abb. 1: Photographische Aufnahmen unterschiedlich strukturierter Landschaften

Bild links: komplex strukturierte Landschaft Bild rechts: monotone, wenig strukturierte Landschaft

Neben naturwissenschaftlichen fließen auch sozioökonomische Aspekte in die Untersuchungen des Projektes ein. Dies dient der Erfassung der Wertstellung der 
Biodiversität, sowie deren Bedeutung für die landwirtschaftliche Produktion. Ziel des Bioplex-Projektes ist, die Ergebnisse naturwissenschaftlicher und sozioökonomischer Analysen zur Entwicklung gebietsspezifischer Agrarumweltprogramme im Rahmen der EU-Agrarpolitik zu nutzen.

Phytopathogene Pilze sind auf die entsprechende Kulturpflanze spezialisiert, dennoch vertreten BURDON und SHATTOCK (1980) die Hypothese, dass ein geringeres Vorkommen von Pathogenen in natürlichen Ökosystemen im Vergleich zu Agrarökosystemen zu verzeichnen ist. Obwohl in zahlreichen Studien der positive Einfluss von Ackerbrachen auf die Diversität von Nützlingen gezeigt wurde, gab es bislang keine vergleichbaren Untersuchungen an Pathogenen. Monotone Landschaften stellen durch permanente Anwesenheit von Wirtspflanzen und eingeschränkte Begrenzungsfaktoren durch Gegenspieler optimale Bedingungen für eine epidemiologische Ausbreitung von Pathogenen dar.

Weiterhin übt die Veränderung der ackerbaulichen Praxis direkten Einfluss auf getreidepathogene Pilze aus. Die wendende Bodenbearbeitung wurde in den letzten Jahrzehnten in zunehmendem Maße durch reduzierte Bodenbearbeitung ersetzt und der Getreideanteil der Fruchtfolge, insbesondere der Winterweizenanteil, wurde aus ökonomischen Gründen erhöht (REIMANN \& DEISING 2000, WEHRMANN et al. 2000). Diese Weizendominanz begünstigt die Entwicklung ertragsrelevanter Weizenpathogene, wie z. B. Septoria tritici, Septoria nodorum, Drechslera triticirepentis, Blumeria graminis f. sp. tritici, Puccinia recondita und Puccinia strifformis. Besonders der Erreger der Blattdürre, Septoria tritici (Teleomorph Mycosphaerella graminicola), gewinnt seit einigen Jahren zunehmend an Bedeutung und kann zu Ertragsverlusten von bis zu 30 Prozent führen (EYAL 1999, MÜLLER \& HABERMEYER 2001). Zurückzuführen ist dies auf den verbreiteten Anbau anfälliger Weizensorten, frühe Saatzeiten, hohe Stickstoffdüngung, zunehmend verregnete Sommer und den Einsatz von Fungiziden (LOVELL et al. 1997, MEIEN-VOGELER et al. 1994, PALMER \& SKINNER 2002, POLLEY \& THOMAS 1991). Septoria tritici trat 1983 erstmals in Europa deutlich in Erscheinung (ROYLE et al. 1986). Daraufhin vergrößerten sich die Befallsgebiete zunächst entlang der Küste Frankreichs und Hollands bis zum norddeutschen Küstenraum (SILFHOUT 1989). Bereits 1993 konnte 
dieser Schaderreger in den gesamten Anbaugebieten Deutschlands nachgewiesen werden (OBST 1993).

Seit 1997 gewinnt zudem der Pilz Drechslera tritici-repentis (DTR) an wirtschaftlicher Bedeutung im Weizenanbau und kann laut KREYE et al. (1999) zu Ertragsverlusten von bis zu 50 Prozent führen. In der Praxis wurde diesem Erreger bis zum Jahr 1997 im Vergleich zu Mehltau- oder Septoria-Arten nur wenig Bedeutung beigemessen (WOLF 1998). Bis zu diesem Zeitpunkt trat der Erreger vereinzelt vornehmlich in den wärmeren Anbaugebieten Süddeutschlands auf (RODEMANN \& BARTELS 2000). Erst im Jahr 1997 trat der Pilz in vielen Regionen Deutschlands, erstmals auch im Norden, in ungewöhnlich großem Ausmaß auf und wurde zur „Krankheit des Jahres“ erklärt (KRÖCHER 1998a, WOLF 1998). Echter Weizenmehltau, Septoria nodorum, sowie Gelb- und Braunrost sind ebenfalls wichtige blattpathogene Pilze an Winterweizen, jedoch nicht von so hoher wirtschaftlicher Bedeutung wie $S$. tritici und DTR.

Der Einfluss von Landschaftsstrukturen lässt sich nicht unabhängig von Bewirtschaftungsparametern betrachten. Wichtige Einflussgrößen sind u. a. Sortenwahl, Bodenbearbeitung, Fruchtfolge und Fungizideinsatz. Klimatische Bedingungen stellen ebenfalls einen wichtigen Einflussfaktorenkomplex dar. Aufgrund des komplexen Zusammenspiels zwischen Klima-, Bewirtschaftungs- und Landschaftsfaktoren im Kulturpflanze-Pathogen-Komplex ist eine Bewertung der Zusammenhänge schwierig.

Durch verschiedene Landschaftsstrukturen und das dadurch entstehende Mosaik unterschiedlicher Habitate ist ein direkter Einfluss auf die genetische Variabilität von Pathogenen vorstellbar. Die genetische Variabilität verschiedener Pathogene wird seit vielen Jahren eingehend untersucht (u. a. CATEN \& NEWTON 2000, CHEN \& McDONALD 1996, McDONALD et al. 1995, SCHNIEDER et al. 2001). Untersuchungen dieser Art dienen meist der Unterscheidung verschiedener Pathotypen, der Identifizierung resistenter Isolate einer Population oder der Differenzierung von Populationen verschiedener Felder, Länder oder Kontinente. Direkte Einflüsse von Landschaftsstrukturen auf die genetische Variabilität phytopathogener Pilze wurden bisher noch nicht untersucht. 
Ziel dieser Arbeit, entsprechend der übergeordneten Hypothese von Bioplex, ist es, den Einfluss von Landschaftsstrukturen am Beispiel der Regionen Göttingen und Giessen auf das Auftreten der blattpathogenen Pilze Septoria tritici, Septoria nodorum, Drechslera tritici-repentis, Blumeria graminis f. sp. tritici, Puccinia recondita und Puccinia striiformis zu untersuchen. Ungeklärt ist zudem, ob durch das beschriebene komplexe Zusammenspiel von Bewirtschaftungs-, Klima- und Landschaftsfaktoren eine unabhängige Betrachtung sowie ein unabhängiger Einfluss der einzelnen Faktoren auf blattpathogene Pilze möglich ist. Aufgrund der oben beschriebenen weltweiten Verbreitung und der großen wirtschaftlichen Bedeutung von Septoria tritici wird zusätzlich die Aggressivität und genetische Variabilität von Populationen dieses Pilzes in Abhängigkeit von der Landschaftsdiversität analysiert.

Eine der zugrunde liegenden Arbeitshypothesen lautet, dass mit zunehmender Komplexität einer Landschaft die Biodiversität, und damit das Spektrum blattpathogener Pilze innerhalb des untersuchten Feldes größer, das Befallsausmaß hingegen geringer wird. Weiterhin besteht die Annahme, dass sowohl die Aggressivität verschiedener Isolate von Septoria tritici, als auch die genetische Variabilität der Feldpopulationen des Pilzes mit abnehmender Diversität der umgebenden Landschaft zunimmt. 


\section{Material und Methoden}

\subsection{Chemikalien}

Sämtliche hier aufgeführten Chemikalien stammen, wenn nicht anders erwähnt, aus Deutschland.

Agar Agar (Roth, Karlsruhe)

Agarose NEEO (Roth, Karlsruhe)

Borsäure (Merck, Darmstadt)

dNTP-“Mixture” (TaKaRa, Shiga, Japan)

DNeasy Plant Mini Kit (Qiagen, Hilden)

EDTA (Serva, Heidelberg)

Ethanol (Merck, Darmstadt)

Ethidiumbromid (Fluka, Neu-Ulm)

Glucose (Merck, Darmstadt)

Hefeextrakt (Roth, Karlsruhe)

Loading Dye Solution (Fermentas, St. Leon-Rot)

Lösung 1, Acrylamid/Bisacrylamid (Amersham Biosciences Europe, Freiburg)

Lösung 2, TBE, „denaturing agent“, „UV-initiator (Amersham Biosciences Europe, Freiburg)

Malzextrakt (Merck, Darmstadt)

$\mathrm{MgCl}_{2}, 25 \mathrm{mM}$ (TaKaRa, Shiga, Japan)

Paraffin (Merck, Darmstadt)

PCR-Puffer, 10 x, $\mathrm{MgCl}_{2}$-frei (TaKaRa, Shiga, Japan)

Streptomycinsulfat (Serva, Heidelberg)

Taq-Polymerase (TaKaRa, Shiga, Japan)

TRIS; Tris-(hydroxymethyl)-aminomethan (Roth, Karlsruhe)

Tween 80 (Merck, Darmstadt) 


\subsection{Nährmedien, Puffer und Trenngele}

Alle benötigten Nährmedien wurden mit normalem Leitungswasser angesetzt und 20 Minuten bei $120{ }^{\circ} \mathrm{C}$ autoklaviert. Die Medien wurden zunächst in einer geringen Menge Wasser gelöst und anschließend mit den im Folgenden angegebenen Mengen Wasser aufgefüllt. Zur Herstellung der Puffer und Trenngele wurde doppelt-destilliertes Wasser verwendet.

\section{Malz-Hefeextrakt-Agar (Malt Yeast Agar; MYA):}

Dieses Medium wurde zur Anzucht der Isolate von $S$. tritici verwendet.

- Agar Agar

- Malzextrakt

- Hefeextrakt

- Glucose

$-\mathrm{H}_{2} \mathrm{O}$
$12 \mathrm{~g}$

$8 \mathrm{~g}$

$3,2 \mathrm{~g}$

$3,2 \mathrm{~g}$

ad $1000 \mathrm{ml}$

Streptomycin (200 ppm Endkonzentration im Medium) wurde nach dem Autoklavieren und Abkühlen des Mediums auf ca. $50{ }^{\circ} \mathrm{C}$ unter sterilen Bedingungen hinzupipettiert.

Hafermehl-Agar:

Dieses Medium wurde für das Anlegen der Dauerkulturen der Isolate von S. tritici, die mit Paraffin-Öl überschichtet wurden, eingesetzt.

- Agar Agar

- gemahlene Haferflocken

- $\mathrm{H}_{2} \mathrm{O}$
$7,5 \mathrm{~g}$

$10 \mathrm{~g}$

ad $500 \mathrm{ml}$ 


\section{TBE-Puffer (TRIS-Borat-EDTA-Puffer):}

Dieser Puffer wurde für die Agarose-Gel-Elektrophorese und für die PolyacrylamidGel-Elektrophorese genutzt.

- TRIS

- Borsäure

- 0,5 M EDTA (pH 8,0)

$-\mathrm{H}_{2} \mathrm{O}$
$108 \mathrm{~g}$

$55 \mathrm{~g}$

$40 \mathrm{ml}$

ad $1000 \mathrm{ml}$

Agarose-Trenngel:

Die Trennung der PCR-Produkte erfolgte in 1,5 \%igen Agarosegelen. Die Lösung der Agarose erfolgte in 0,5 x TBE-Puffer.

- Agarose

- TBE-Puffer
$1,5 \mathrm{~g}$

ad $100 \mathrm{ml}$

Polyacrylamid-Trenngel (ReproGel ${ }^{\mathrm{TM}}$ Long Read):

Dieses Trenngel wurde für die Polyacrylamid-Gel-Elektrophorese genutzt. Lösung 1 besteht aus $21 \%$ Acrylamid/Bisacrylamid, Lösung 2 besteht aus 1 x TBE-Puffer, einem „denaturing agent“ und einem „UV-initiator“. Mit diesem Gel wurden mittels PCRamplifizierte, fluoreszenzmarkierte Mikrosatelliten analysiert.

$\begin{array}{ll}\text { - Lösung } 1 & 10 \mathrm{ml} \\ \text { - Lösung } 2 & 20 \mathrm{ml}\end{array}$

Durch die Mischung der Lösungen ergab sich ein 7 \%iges Polyacrylamid-Gel. In späteren Untersuchungen wurde zur besseren Auftrennung der Banden ein 8 \%iges Gel verwendet. Entsprechend wurden die Mengen verändert:

- Lösung 1

$11,42 \mathrm{ml}$

- Lösung 2

$18,58 \mathrm{ml}$ 


\subsection{Feldversuche}

Für die Untersuchung des Einflusses von Landschaftsstrukturen wurden im Rahmen dieser Arbeit 19 verschiedene Felder untersucht. Es handelte sich bei allen Feldern nicht um Universitätsversuchsflächen, sondern um praxisüblich bewirtschaftete Felder. Zehn davon lagen in der Region um Göttingen, neun zwischen Giessen und Marburg im Lahn-Dill-Bergland. Diese Felder unterschieden sich sowohl im Komplexitätsgrad, als auch der Landnutzungsdiversität der umgebenden Landschaft und in ihrer Bewirtschaftungsweise. Der Komplexitätsgrad einer Landschaft wurde im Rahmen dieses Projektes im Wesentlichen durch drei Parameter definiert, die im Folgenden näher beschrieben werden. Die Landnutzungsdiversität wurde im Raum Göttingen durch Kartierungen und die Bewirtschaftungsweise der Felder in Datenerhebungsbögen erfasst.
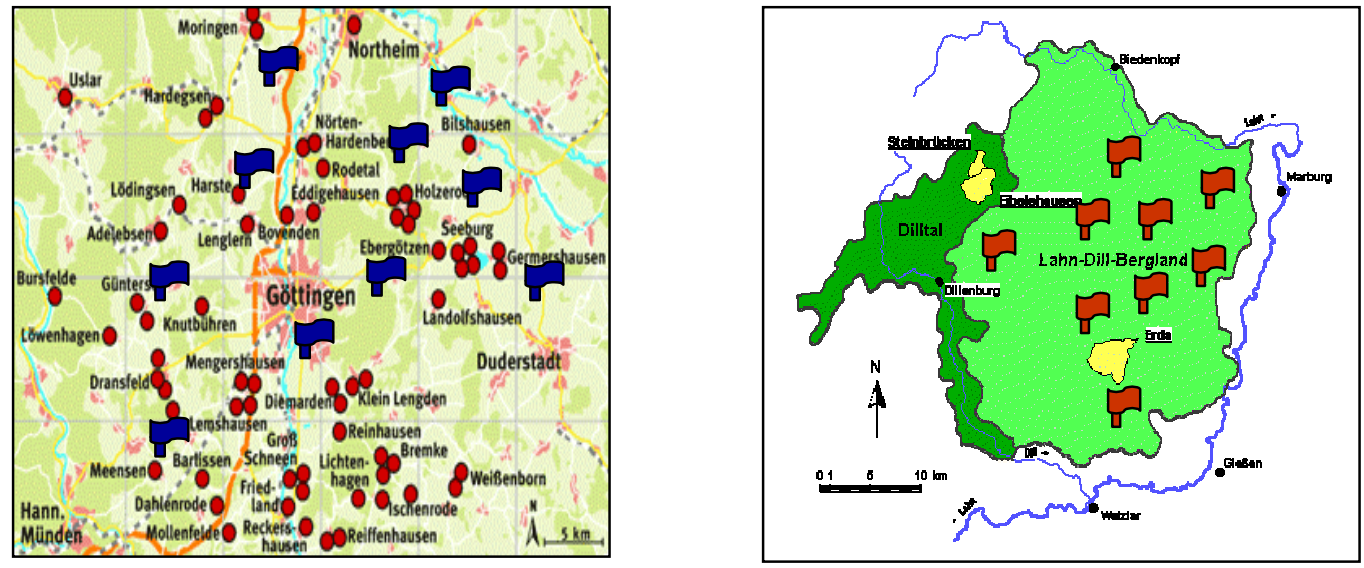

Abb. 2: Region um Göttingen und Giessen (Lahn-Dill-Bergland)

Fähnchen kennzeichnen ungefähre Lage der untersuchten Felder

\subsubsection{Landschaftsparameter der untersuchten Felder}

Im Projekt Bioplex sollten Landschaften anhand eines einheitlichen Formates verglichen werden. In einer GIS- (Geographic Information System) gestützten Faktorenanalyse wurden daher unterschiedliche Parameter (Ackeranteil, Grünlandanteil, Gehölzanteil etc.) der räumlichen Komplexität in Agrarlandschaften untersucht. Diese Analysen wurden von der Arbeitsgruppe des Teilprojektes 1 (TP1, AG Köhler, Modellierung und Geostatistik, Universität Giessen) durchgeführt. Als struktursteuernde 
Parameter erwiesen sich Ackeranteil, Umfang-Flächen-Quotient (Perimeter-Area-Ratio; PAR) und mittlere Hangneigung (SLOPE) der Landschaftsausschnitte. Ein Landschaftsausschnitt bezeichnet die Region innerhalb eines Radius von drei Kilometern um das Untersuchungsfeld herum. Im Rahmen der Untersuchungen dieser Arbeit erwies sich der Ackeranteil als Hauptparameter; er gibt den prozentualen Anteil ackerbaulich genutzter Flächen im Verhältnis zur gesamten Fläche an. Der UmfangFlächen-Quotient beschreibt die Relation eines Flächenumfangs $\mathrm{zu}$ dessen Flächeninhalt und macht eine Aussage über die Form einer Fläche, während die Hangneigung die geographische Lage wiedergibt.

Insbesondere anhand des Parameters Ackeranteil lassen sich die untersuchten Felder in Landschaftsklassen, von komplex strukturiert (Wiesen, Bäume, Hecken u. a. Saumstrukturen in der Umgebung) bis hin $\mathrm{zu}$ monoton bzw. wenig strukturiert (weiträumig umgebende Ackerflächen) einteilen. In Tab. 1 sind der prozentuale Ackeranteil, die Perimeter-Area-Ratio (PAR) und die Hangneigung (SLOPE) der zehn untersuchten Felder in der Region Göttingen dargestellt. In Tab. 2 sind gleichermaßen die neun untersuchten Felder der Region Giessen dargestellt. Die grau unterlegten Felder wurden in Rahmen der genetischen und physiologischen Untersuchungen von Septoria tritici näher untersucht.

Tab. 1: Ackeranteil, PAR und SLOPE der zehn untersuchten Felder der Region Göttingen

\begin{tabular}{|c|c|c|c|c|}
\hline $\begin{array}{c}\text { Ort des Feldes } \\
\text { in der Region } \\
\text { Göttingen }\end{array}$ & $\begin{array}{c}\text { Flächen- } \\
\text { bezeichnung }\end{array}$ & $\begin{array}{c}\text { Ackeranteil } \\
{[\%]}\end{array}$ & PAR & SLOPE \\
\hline Meensen & 4.1 & 41,62 & 1,974 & 7,607 \\
\hline Rüdershausen & 14.1 & 42,49 & 1,498 & 3,486 \\
\hline Bratental & 18.1 & 46,89 & 2,234 & 5,603 \\
\hline Wulften & 13.2 & 55,91 & 1,979 & 5,500 \\
\hline Spanbeck & 11.2 & 59,13 & 1,582 & 4,271 \\
\hline Reinshof & 1.2 & 76,67 & 1,026 & 0,658 \\
\hline Berensen & 9.1 & 79,87 & 1,195 & 1,769 \\
\hline Güntersen & 5.1 & 89,67 & 0,689 & 2,742 \\
\hline Bodensee & 12.1 & 91,71 & 0,747 & 2,618 \\
\hline Harste & 8.1 & 91,82 & 0,884 & 1,154 \\
\hline
\end{tabular}


Tab. 2: Ackeranteil, PAR und SLOPE der neun untersuchten Felder der Region Giessen

\begin{tabular}{|c|c|c|c|c|}
\hline $\begin{array}{c}\text { Ort des Feldes } \\
\text { in der Region } \\
\text { Giessen }\end{array}$ & $\begin{array}{c}\text { Flächen- } \\
\text { bezeichnung }\end{array}$ & $\begin{array}{c}\text { Ackeranteil } \\
{[\%]}\end{array}$ & PAR & SLOPE \\
\hline Elnhausen & 10 & 12,50 & 1,476 & 8,077 \\
\hline Günterrod & 18 & 19,48 & 2,237 & 7,573 \\
\hline Eisemroth & 17 & 22,54 & 2,724 & 7,805 \\
\hline Wilsbach & 20 & 23,98 & 1,128 & 5,638 \\
\hline Bottenhorn & 4 & 30,71 & 2,263 & 3,462 \\
\hline Nesselbrunn & 9 & 35,76 & 1,767 & 6,513 \\
\hline Frohnhausen & 6 & 43,52 & 1,826 & 5,923 \\
\hline Gladenbach & 5 & 49,74 & 2,268 & 4,788 \\
\hline Niederwalgern & 12 & 54,71 & 1,855 & 2,241 \\
\hline
\end{tabular}

Die Auswahl der untersuchten Flächen beider Regionen erfolgte anhand des Parameters Ackeranteil, so dass sich ein Landschaftsgradient ergab. Die folgende Abbildung 3 zeigt diesen Gradienten.

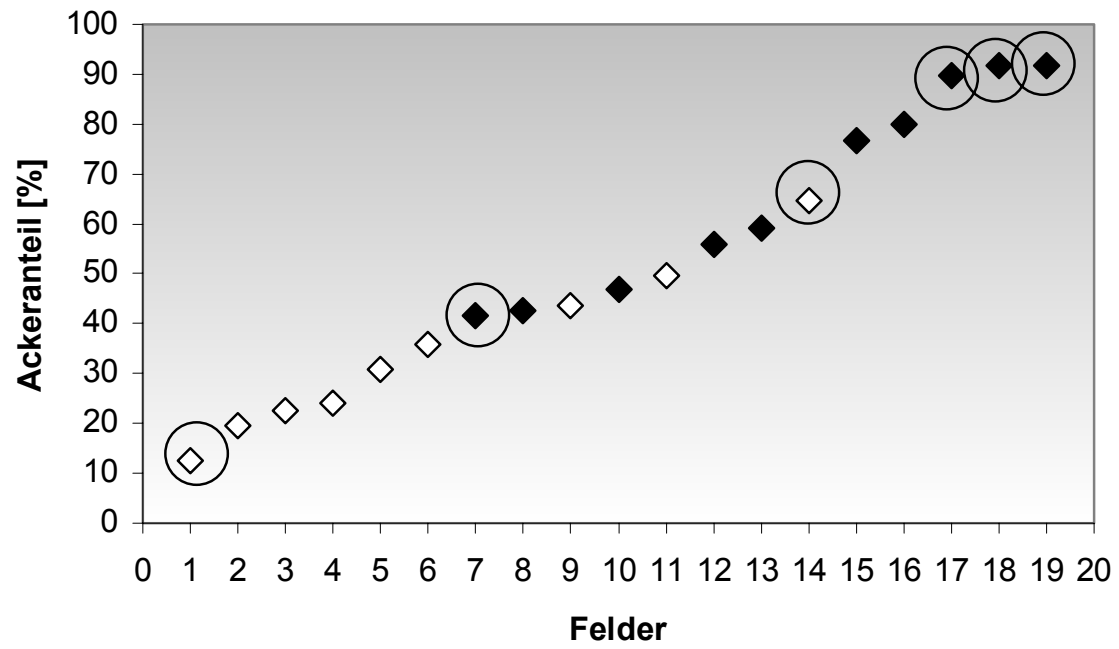

Abb. 3: Landschaftsgradient der 19 Felder der Regionen Giessen und Göttingen

Legende: weiße Rauten: 9 Felder der Region Giessen; schwarze Rauten: 10 Felder der Region Göttingen; Kreise kennzeichnen die sechs für die physiologischen und genetischen Untersuchungen von Septoria tritici näher untersuchten Felder 
Es handelte sich in einigen Fällen aufgrund der Fruchtfolge nicht in beiden Jahren um die gleichen Felder in den entsprechenden Landschaften. Allerdings wurden sie im zweiten Versuchsjahr so ausgewählt, dass es sich meist um das direkte Nachbarfeld des Vorjahresfeldes handelte. Durch diese Auswahl konnte gewährleistet werden, dass der hauptsächliche Landschaftsparameter Ackeranteil gleich blieb.

Die Landnutzungsdiversität ist ebenfalls ein wichtiger Parameter bei der Untersuchung des Landschaftseinflusses auf Pathogene. Die Landnutzungsdiversität gibt den Anteil der angebauten Feldfrüchte innerhalb des untersuchten Ausschnittes (3 km Radius) an. Diese Erhebungen wurden in beiden Versuchsjahren (2001 und 2002) in der Region Göttingen von den Projekt-Arbeitsgruppen der Universität Göttingen vorgenommen. Für die Region Giessen fehlen diese Untersuchungen.

In beiden Versuchsjahren wurden Kartierungen aller Göttinger Felder innerhalb der Landschaftssausschnitte durchgeführt. Folgende Feldfrüchte bzw. Landschaftsindikatoren wurden dabei kartiert:

- Getreide

- Raps

- Zuckerrüben

- Mais

- Kartoffeln

- Leguminosen

○ Bohnen

○ Erbsen

- $\quad$ Andere (z. B. Phacelia)

- Saatbrache

- Natürliche Brache

- Grasland

- Hecken

Diese Daten wurden von der Arbeitsgruppe des Teilprojektes 1 (TP1, AG Köhler, Modellierung und Geostatistik, Universität Giessen) mit Hilfe des Programms ATKIS (Amtliches Topographische-Kartographisches Informationssystem) verrechnet und die Ergebnisse für alle Arbeitsgruppen freigestellt. 


\subsubsection{Bewirtschaftungsparameter der untersuchten Felder}

In Datenerhebungsbögen, die von den Landwirten der 19 untersuchten Felder ausgefüllt wurden, wurden sämtliche Kulturmaßnahmen, sowie die Fruchtfolgegestaltung der untersuchten Felder während der Vegetationsperiode 2000/2001 und 2001/2002 erfragt. In diesen Erhebungsbögen wurden Informationen der folgenden Kategorien erfasst:

- Weizensorte

- Saatstärke

- Erwarteter Ertrag

- Fruchtfolge

- Bodenbearbeitung

- Bodentiefe

- Bodengüte

- Stickstoffdüngung (inkl. Angaben über die Anzahl der Düngungsmaßnahmen)

- Eingesetzte Fungizide (inkl. Anzahl der Applikationen)

- Eingesetzte Herbizide (inkl. Anzahl der Applikationen)

- Eingesetzte Insektizide (inkl. Anzahl der Applikationen)

- Eingesetzte Wachstumsregler (inkl. Anzahl der Applikationen)

\subsubsection{Design der Probenahme}

Die Feldversuchsjahre 2001 und 2002 unterschieden sich im Design der Probenahme. Daher werden beide Methoden im Folgenden getrennt aufgeführt.

\subsubsection{Design der Probenahme 2001}

Im Jahr 2001 erfolgte die Probenahme an zwei Terminen (BBCH 47-51 und 65-69) auf den 19 Flächen im Raum Göttingen und Giessen. Zur Erfassung des Befalls mit blattpathogenen Pilzen wurden pro Feld auf einem diagonalen Transekt 50 Pflanzen beprobt. Dabei wurde pro Pflanze auf einem Blatt (F-3 zum ersten und F-2 zum zweiten 
Termin) der Befall mit Septoria tritici, Septoria nodorum, Drechslera tritici-repentis, Blumeria graminis f. sp. tritici, Puccinia striiformis und Puccinia recondita qualitativ und quantitativ ermittelt und das Blatt anschließend zur weiteren Bearbeitung entnommen. Die Blätter wurden direkt auf dem Feld bonitiert, anschließend in Papiertüten gelegt und bei $-20^{\circ} \mathrm{C}$ gelagert.

\subsubsection{Design der Probenahme 2002}

Abweichend zum vorherigen Versuchsjahr 2001 wurde während der Vegetationsperiode 2002 auf den 19 ausgewählten Winterweizenflächen ein fungizidfreies Spritzfenster $(20 \times 20 \mathrm{~m})$ eingerichtet. Innerhalb dieses Spritzfensters wurden an zwei Terminen (BBCH 39-42 und BBCH 65) Blattproben genommen. Pro Fläche wurden an acht verschiedenen Stellen jeweils acht Blätter einer definierten Blattetage entnommen. Außerdem wurden auf den Göttinger Flächen auch im behandelten Teil der Felder in der gleichen Weise Proben genommen (Abb. 4).

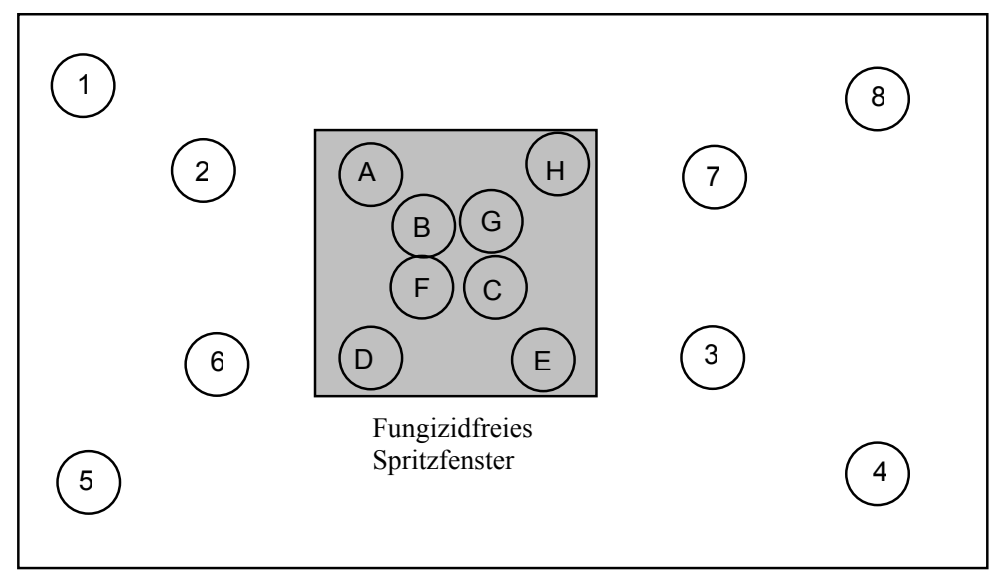

Abb. 4: Design der Probenahme 2002 auf den untersuchten Winterweizenflächen

Legende: 1-8: Plots im fungizidbehandelten Teil des Feldes; A-H: Plots im fungizidfreien Spritzfenster (nicht maßstabsgetreu)

Die Blattentnahme erfolgte, wie in Abb. 4 dargestellt, an acht diagonal zum Feld bzw. zum fungizidfreien Spritzfenster liegenden Entnahmestellen. Der Radius innerhalb einer Blattentnahmestelle betrug einen Meter. In den späteren Untersuchungen ist so zusätzlich ein Vergleich der Isolate von unterschiedlichen Blattentnahmestellen innerhalb eines Feldes möglich. Am ersten Probenahmetermin (BBCH 39-42) wurde in 
den Plots des behandelten Feldteiles das F-3 Blatt und beim zweiten Termin (BBCH 65) das F-2 Blatt entnommen. In den Plots des fungizidfreien Bereiches wurde zum ersten Entnahmetermin das F-2 Blatt und zum zweiten Termin das F-1 Blatt entnommen. Die Blätter wurden in Plastiktüten gelegt und bei $-20^{\circ} \mathrm{C}$ gelagert. In diesem Versuchsjahr erfolgte die Bonitur nicht direkt auf dem Feld sondern im Labor mit Hilfe eines Binokulars.

\subsubsection{Befallserhebung blattpathogener Pilze}

In beiden Feldversuchsjahren wurde der qualitative (Befallshäufigkeit) und quantitative (Befallsstärke) Anteil der sechs untersuchten, blattpathogenen Pilze (Septoria tritici, $S$. nodorum, Blumeria graminis f. sp. tritici, Drechslera tritici-repentis, Puccinia striiformis und Puccinia recondita) aller entnommenen Blätter der zwei Probenahmetermine prozentual bestimmt. Die Befallsbestimmung erfolgte nicht anhand eines Boniturschemas, sondern durch visuelle Schätzung (Prozent befallene Blattfläche).
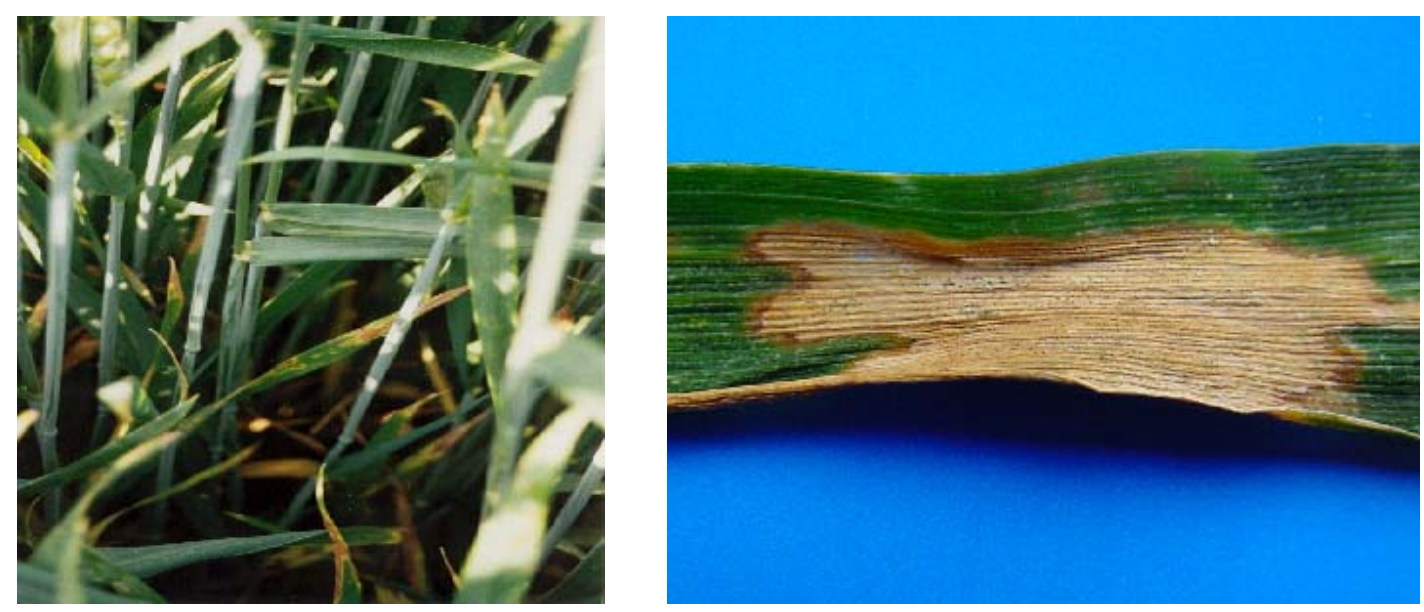

Abb. 5: Befallssymptome von Septoria tritici. (Bild links: Septoria tritici-Blattflecken in einem Winterweizenbestand; Bild rechts: Blattläsion von Septoria tritici mit linear angeordneten, schwarzen Pyknidien

Die Boniturergebnisse der einzelnen Blattproben einer Fläche wurden in der weiteren Auswertung durch Mittelwertbildung zusammengefasst. Allerdings mussten die Boniturergebnisse der verschiedenen Entnahmetermine separat betrachtet werden, da je nach Entnahmetermin Blätter unterschiedlicher Blattetagen entnommen wurden. 
Wie bereits in Kapitel 2.3.3.1. erwähnt, wurden die entnommenen Blätter des Versuchsjahres 2001 direkt auf dem Feld bonitiert und mit Nummern versehen. Bei Unsicherheiten in der Bestimmung des Befalls wurden die entsprechenden Blätter im Labor mit Hilfe eines Binokulars erneut bonitiert, um Fehler zu vermeiden. Im Versuchsjahr 2002 wurden alle Blätter im Labor bonitiert. Die Nummerierung erfolgte, um die Herkunft der verschiedenen Isolate der im Folgenden beschriebenen genetischen und physiologischen Untersuchungen genau bestimmen zu können.

\subsubsection{Auswertung}

Die Versuchsdaten wurden mit Hilfe von Microsoft Excel 2000 tabellarisch erfasst und graphisch dargestellt. Für die statistischen Erhebungen (Berechnung von Regression, Bestimmtheitsmaß und Irrtumswahrscheinlichkeit; Student Newman Keuls Test) wurde das Programmpaket SAS (Statistical Analysis System; Release 6.12) verwendet.

\subsection{Gewinnung der Isolate von Septoria tritici}

Die auf den einzelnen Feldern gesammelten Blätter wurden in Tüten bei $-20{ }^{\circ} \mathrm{C}$ gelagert. Ohne vorhergehende Inkubationszeit wurde unter der Sterilbank mit einer sterilen Impfnadel von jedem Blatt der Sporenschleim von drei verschiedenen Pyknidien abgenommen und auf Malz-Hefeextrakt-Agar in Petri-Schalen übertragen. Anschließend wurden diese für zwei Tage unter UV-nahem Licht („,blacklight blue“; Wellenlängenbereich 350-400 nm; F36W-BLB, Osram, Sylvania, München), einem Tag- / Nacht- Rhytmus von 16/8 Stunden bei $20^{\circ} \mathrm{C}$ inkubiert. Die Herstellung von Einzelspor-Isolaten war nicht nötig, da sich in einer Pyknidie klonale, genetisch gleiche Sporen befinden. Auch eine Oberflächensterilisation der Blätter wurde vor dem Abnehmen des Sporenschleims nicht durchgeführt, weil dadurch zu viele Sporenranken mit abgespült würden (MEIEN-VOGELER 1994). Septoria tritici zeigt auf MalzHefeextrakt-Agar rosafarbenes, hefeartiges Wachstum; es handelt sich dabei um durch Knospung wachsende Sporen. Nach zwei Tagen hatte sich an allen drei Entnahmestellen ausreichend Sporenmaterial gebildet, so dass es von einer der drei 
Stellen auf insgesamt vier Petri-Schalen mit Malz-Hefeextrakt-Agar mit Hilfe einer Impföse ausgestrichen wurde. Nach erneuter Inkubation unter den genannten Bedingungen (UV-nahes Licht, $20^{\circ} \mathrm{C}$ ) für fünf bis sechs Tage, waren die Platten nahezu voll bewachsen. Von einer der vier Schalen wurde ein Stück sporenhaltiger Agar in Plastikröhrchen die Hafermehl-Agar enthielten übertragen. Diese Röhrchen wurden für ca. eine Woche unter normalen Raumbedingungen (ca. $20{ }^{\circ} \mathrm{C}$ ) inkubiert, anschließend unter sterilen Bedingungen mit Paraffinöl befüllt und bei $4{ }^{\circ} \mathrm{C}$ im Kühlraum gelagert. Unter diesen Bedingungen können Pilzisolate zwei bis vier Jahre aufbewahrt und wieder verwendet werden.

Von den übrigen drei Schalen wurde das Pilzmaterial mit einem sterilen Spatel vorsichtig abgekratzt und in einem Mörser unter Zugabe von flüssigem Stickstoff zerkleinert, um anschließend die DNA zu isolieren.

\subsubsection{Bezeichnung der Isolate von Septoria tritici}

Die Bezeichnung der Pilzisolate erfolgte anhand der Feld- und Blattnummerierung. Beispielsweise wird ein Isolat des Feldes 4.1, aus dem Plot A im fungizidfreien Spritzfenster des zweiten (2) von acht gesammelten Blättern als 4.1A2 bezeichnet. Von den sechs untersuchten Feldern $(4.1,12.1,8.1,5.1,12$ und 10) wurden aus den unbehandelten Spritzfenstern, sowie zusätzlich von Feld 4.1 und 12.1 aus dem behandelten Teil des Feldes insgesamt 301 verschiedene Isolate von Septoria tritici gewonnen. Davon wurden 290 hinsichtlich ihrer genetischen Variabilität und 172 hinsichtlich ihrer Aggressivität untersucht. 


\subsection{Untersuchungen zur Aggressivität von Septoria tritici}

Die Populationen von Septoria tritici der verschiedenen Felder wurden anhand der bereits beschrieben Methoden durch ihre Befallshäufigkeit und -stärke charakterisiert. Ein weiteres Charakteristikum einer Population stellt die Aggressivität der Isolate dar, die in Gewächshausversuchen näher betrachtet wurde.

\subsubsection{Anzucht der Wirtspflanzen}

Als Wirtspflanzen dienten in diesen Versuchen zwei Winterweizensorten, die sich laut „Beschreibende Sortenliste des Bundessortenamtes“ (2001) in ihrer Anfälligkeit gegenüber $S$. tritici unterscheiden. Bei der anfälligen Sorte handelte es sich um Monopol mit der Anfälligkeitsstufe 7, die weniger anfällige Sorte Cardos ist hingegen mit 4 eingestuft. Das Saatgut beider Sorten war mit Landor CT gebeizt und verfügte über eine Keimfähigkeit von 92-94 \%. Das Beizmittel Landor CT enthält drei Wirkstoffe aus der Gruppe der Triazol- und Pyrrolderivate und ist in Weizen, Roggen und Triticale gegen samenbürtige, pilzliche Krankheitserreger zugelassen. Die Anzuchterde der Pflanzen bestand aus einem Gemisch aus gedämpfter Einheitserde und Komposterde im Verhältnis 1:1, dem etwas Sand zugefügt und anschließend in Plastiktöpfe (Länge und Breite $7 \mathrm{~cm}$ ) gefüllt wurde. Das Saatgut wurde zu je 4 Samen pro Topf ausgelegt und mit Erde bedeckt. Um für jedes getestete Pilzisolat 32 Wiederholungen $\mathrm{zu}$ erhalten, wurden vier Töpfe pro Sorte und Isolat in der beschriebenen Weise befüllt. Die Pflanzen wurden im Gewächshaus (unter Weißlicht, 16/8 Stunden Licht/Dunkel, Temperatur $20^{\circ} \mathrm{C}$ ) angezogen. Dabei konnten die Töpfe in Schalen bewässert werden, ohne die jungen Blätter durch den Gießdruck zu beschädigen. Nach ca. 14 Tagen wurden pro Topf vier dünne Holzstäbe in die Topfecken gesteckt, durch einen schmalen Bastfaden verbunden und die Blätter vorsichtig darüber gelegt, damit sie nicht umknickten. Nach 21 Tagen erreichten die Weizenpflanzen das Dreiblatt-Stadium und wurden für die Pilzinokulation bereitgestellt. 


\subsubsection{Herstellung der Sporensuspension}

Steriles Arbeiten war für die Gewinnung der Sporensuspensionen nicht erforderlich. Für jedes der 172 getesteten Isolate von $S$. tritici wurde eine dicht mit rosafarbenen Sporen bewachsene MYA-Agar enthaltende Petrischale (5 Tage alt) verwendet. Die Sporen wurden mit $10 \mathrm{ml}$ Leitungswasser übergossen und mit der schmalen Seite eines Objektträgers behutsam abgekratzt. Die Suspension wurde durch einen engmaschigen Gazefilter in einen Erlemeyer-Kolben $(50 \mathrm{ml})$ überführt. Durch den Filter wurden eventuell ebenfalls entfernte Agarstücke aus der Suspension zurückgehalten. Die Sporendichte der Suspension wurde anhand der Fuchs-Rosenthal-Apparatur bestimmt und auf eine Dichte von $2 * 10^{5}$ Sporen pro ml Wasser eingestellt. Für die Inokulation der acht Töpfe mit je vier Pflanzen wurden für jedes Pilzisolat $40 \mathrm{ml}$ Sporensuspension verwendet, die zuvor mit zwei Tropfen Tween 80 versetzt wurden.

\subsubsection{Inokulation}

Die Inokulation der beiden Weizensorten mit den 172 verschiedenen Isolaten von $S$. tritici erfolgte anhand einer Sprühinokulation. Dabei wurde die Suspension (je $40 \mathrm{ml}$ ) mit einem an einem Kompressor angeschlossenen Pulverzerstäuber appliziert. Der Zerstäuber erzeugte ein sehr feines Tropfenbild und somit eine uniforme Verteilung der Sporensuspension auf den Blättern. Die verwendete Suspensionsmenge gewährleistete, dass alle Blätter der 32 Pflanzen pro Isolat gleichermaßen mit einer dünnen Tropfenschicht bedeckt waren. Nach der Inokulation wurden die Pflanzen mit je 5 Körnern Kalk-Ammon-Salpeter (KAS) pro Topf gedüngt (VORBECK, persönliche Mitteilung). Bei einer Stickstoffmenge von 270 g pro kg KAS entsprechen 5 Körner einer Menge von ca. 9,45 mg reinen Stickstoffes pro Topf.

\subsubsection{Inkubation}

Die Inkubation der inokulierten Pflanzen erfolgte in einer Klimakammer, bei der die Parameter Licht-/Dunkelphase, Temperatur und Luftfeuchte gleichmäßig und spezifisch 
eingestellt werden. Zunächst wurden die Pflanzen für vier Tage bei $18{ }^{\circ} \mathrm{C}$, einem Licht/Dunkel Rhythmus von 14/10 Stunden und einer permanenten Luftfeuchtigkeit von $90 \%$ inkubiert. Anschließend erfolgte eine Inkubation für 17 Tage bei $18{ }^{\circ} \mathrm{C}$, Licht/Dunkel Rhythmus von 14/10 Stunden und einer Luftfeuchtigkeit von $70 \%$ während der Licht- und einer Feuchte von $60 \%$ während der Dunkelphase. Die Pflanzen wurden mindestens ein Mal täglich bewässert. Nach Ablauf von 21 Tagen wurde die Befallsstärke von $S$. tritici bonitiert.

\subsubsection{Bonitur}

Zur Bewertung der Befallsstärke der Pflanzen mit Septoria tritici wurde die befallene Blattfläche in Prozent bestimmt. Dabei wurden nur zwei der ehemals drei inokulierten Blätter bonitiert, da das älteste Blatt zum Zeitpunkt der Bonitur gänzlich seneszent war. Die Befallsstärken der vier Pflanzen pro Topf wurden als Mittelwert für die weiteren Auswertungen zusammengefasst.

\subsection{Genetische Untersuchungen}

Um die genetische Variabilität von Septoria tritici in Abhängigkeit von Landschaftsstrukturen bestimmen zu können, wurden zwei unterschiedliche Methoden getestet, die auf der Polymerase-Ketten-Reaktion (polymerase chain reaction, PCR) basieren. Mit Hilfe der PCR wird ein Gen oder Genabschnitt in drei verschiedenen, sich in mehreren Zyklen wiederholenden, temperaturabhängigen Schritten vermehrt. Dies erfolgt mit Hilfe von Oligonukleotiden, sog. Primern, und einer Polymerase. Im ersten Schritt, der so. Denaturierung, wird die doppelsträngige DNA in zwei Einzelstränge aufgeschmolzen. Anschließend erfolgt die Bindung der einzelsträngigen Primer (,annealing“) an spezifische Bindungsstellen der nun ebenfalls einzelsträngigen DNA. Im dritten Schritt (Elongation) synthetisiert und amplifiziert die Polymerase die DNABereiche zwischen den gebundenen Primern. Allgemein wird diese Abfolge in 30 bis 40 Zyklen wiederholt, so dass am Ende eine große Menge des gewünschten Gens vorliegt. 
In dieser Arbeit wurde zunächst mit einer MP-PCR-Fingerprinting-Methode (microsatellite-primed-PCR) gearbeitet und anschließend wurde eine MikrosatellitenMethode für diesen Pilz etabliert. Beide Methoden werden im Folgenden getrennt voneinander dargestellt.

Die Gewinnung der Isolate und die Extraktion der genomischen DNA wurde für beide o.g. Methoden in gleicher Weise vorgenommen und daher nicht gesondert aufgeführt.

\subsubsection{DNA-Extraktion}

Zur DNA-Gewinnung wurden $100 \mathrm{mg}$ des zermörserten, trockenen Pilzmaterials (Kap. 2.4.) in 1,5 ml Plastikröhrchen („E-Cups“) eingewogen. Die Extraktion der DNA erfolgte mit Hilfe des „DNeasy Plant Mini Kits“ der Firma Qiagen. Die zugrunde liegende Methode basiert auf der Trennung der genomischen DNA vom Zellbestand mittels Zentrifugation und Bindung an Silica-Säulen. Im Folgenden ist die Methode (nachzulesen im Handbuch S. 15-17) kurz dargestellt:

$400 \mu \mathrm{l}$ des vom Hersteller mitgelieferten Puffers AP1 und $4 \mu \mathrm{l}$ der RNAse A Stammlösung $(100 \mathrm{mg} / \mathrm{ml})$ wurden dem eingewogenen Material zugefügt und gemischt. Die Lyse der Zellen erfolgte für $10 \mathrm{~min}$ bei $65^{\circ} \mathrm{C}$. Anschließend wurden dem Lysat 130 $\mu 1$ des Puffers AP2 zugegeben und 5 min auf Eis inkubiert, so dass Detergenzien, Proteine und Polysaccharide präzipitiert wurden. Durch Zentrifugation im „Quiashredder“ wurden Zellbruchstücke entfernt. Das gereinigte Lysat wurde mit 1,5 Volumenteilen des Puffers AP3/E vermischt und auf eine silica-haltige Säulenmembran gegeben und anschließend erneut zentrifugiert. Die DNA wurde an die Säule gebunden und mit dem Waschpuffer AW gereinigt. Durch Zugabe von 2 x $100 \mu 1$ des auf $65{ }^{\circ} \mathrm{C}$ erhitzten Elutionspuffers AE wurde die DNA von der Säule gelöst und konnte anschließend bis zur Weiterverwendung bei $-20{ }^{\circ} \mathrm{C}$ gelagert werden. (Die Inhaltsstoffe der eingesetzten Puffer sind nicht vom Hersteller angegeben.)

Die Bestimmung der DNA-Konzentration erfolgte durch Vergleich der Auftragsmenge mit einem Standard $(\lambda$-Eco $91 \mathrm{I})$ in einem 1,5 \% Elektrophorse-Agarosegel. Dieser Standard besitzt die definierten Fragmentgrößen 8453, 7242, 6369, 5687, 4822, 4324, $3675,2323,1929,1371,1264,702,224,117$ [bp]. 


\subsubsection{Quantifizierung der extrahierten DNA}

Die Quantifizierung der extrahierten DNA erfolgte durch visuelle Schätzung. Auf einem Agarosegel $(1,5 \%)$ wurden die DNA-Proben in definiertem Volumen neben dem Größenmarker Lambda Eco91I (MBI Fermentas, St. Leon-Roth) in definiertem Volumen aufgetragen. Nach erfolgter Elektrophorese und Anfärben der Gele mit Ethidiumbromid wurden Helligkeit und Stärke von Referenzbanden des Markers bekannter Menge mit denen der Proben verglichen. Ethidiumbromid interkaliert zwischen den Basen der Nukleinsäuren, absorbiert im ultravioletten Wellenlängenbereich Licht und emittiert im Wellenlängenbereich von $590 \mathrm{~nm}$. Dadurch konnte die extrahierte DNA-Menge anhand der erzeugten Lichtstärke mit ausreichender Genauigkeit bestimmt und das Pipettiervolumen für die anschließende Amplifikation mittels PCR berechnet werden. Zusätzlich konnte durch Nutzung dieser Methode die Qualität der DNA (z. B. Verunreinigung mit RNA, Degradierung der DNA etc.) kontrolliert werden.

\subsubsection{Amplifikation der DNA mittels PCR}

\subsubsection{Amplifikation der DNA mittels MP-PCR}

Zur Bestimmung der genetischen Variabilität von Septoria tritici wurde zunächst die Methode „microsatellite-primed polymerase chain reaction“ (MP-PCR) getestet. Diese Methode ist ebenfalls als „,random amplified microsatellites polymerase chain reaction“ (RAMS-PCR) bekannt (CZEMBOR \& ARSENIUK 1999). In vielen Genomen kommen einfache, sich wiederholende Basensequenzen (SSR, simple sequence repeats), auch Mikrosatelliten genannt, vor. Anzahl und Ort dieser Mikrosatelliten auf dem Genom sind unbekannt und können pilzart- und isolatspezifisch sein. $\mathrm{Zu}$ diesen im Genom vorkommenden verschiedenen Mikrosatelliten wurden Primer mit komplementärer Basensequenz in unterschiedlichen Größen entwickelt und eingesetzt. Diese Primer binden im Mikrosatellitenmotiv und amplifizieren die Region zwischen zwei identischen, invertiert angeordneten Mikrosatelliten. 
Diese Methode wurde in mehreren Vorversuchen mit insgesamt 15 verschiedenen Primern getestet (s. Anhang ATab. 3). Es wurden Annealing-Temperatur der Primer, Anzahl der PCR-Zyklen, $\mathrm{MgCl}_{2}$-Konzentration, Konzentration der Polymerase etc. variiert. Für die Untersuchungen wurde schließlich ein AC-Primer mit sich neun Mal wiederholender Sequenz $[\mathrm{AC}]_{9}$ zur genetischen Differenzierung der Isolate genutzt. Die Amplifikation der DNA-Fragmente erfolgte in einem $25 \mu 1$ Ansatz. Die PCR-Ansätze wurden dabei nach folgendem Pipettierschema zusammengestellt:

Tab. 3: Pipettierschema der MP-PCR-Ansätze

\begin{tabular}{|c|c|c|c|c|c|c|}
\hline $\begin{array}{c}\mathbf{1 0} \mathbf{x} \\
\text { Puffer }\end{array}$ & $\begin{array}{c}\mathbf{2 5} \mathbf{~ m M} \\
\mathbf{M g C l}_{\mathbf{2}}\end{array}$ & $\begin{array}{c}\text { Taq-Pol. } \\
\mathbf{1} \mathbf{U} / \boldsymbol{\mu l}\end{array}$ & $\begin{array}{c}\mathbf{2 , 5} \mathbf{~ m M} \\
\mathbf{d N T P} \text { s }\end{array}$ & $\begin{array}{c}\mathbf{1 0} \boldsymbol{\mu M} \\
\text { Primer }\end{array}$ & $\begin{array}{c}\text { DNA } \\
\varnothing \mathbf{2 5} \mathbf{~ n g} / \boldsymbol{\mu l}\end{array}$ & $\begin{array}{c}\text { Bidest } \\
\mathbf{H}_{\mathbf{2}} \text { O steril }\end{array}$ \\
\hline $2,5 \mu \mathrm{l}$ & $1,7 \mu \mathrm{l}$ & $1 \mu \mathrm{l}$ & $2,5 \mu \mathrm{l}$ & $3 \mu \mathrm{l}$ & $3 \mu \mathrm{l}$ & $11,3 \mu \mathrm{l}$ \\
\hline
\end{tabular}

Die Polymerasekettenreaktion lässt sich in drei Phasen untergliedern: Denaturierung, Annealing und Elongation (Kap. 2.6.). Diese Phasen besitzen ein spezifisches Temperaturoptimum und werden in einer definierten Anzahl Zyklen wiederholt. Die Denaturierung der DNA erfolgt bei $94-95{ }^{\circ} \mathrm{C}$ und die hier verwendete Taq-Polymerase erreicht ihr Reaktionsoptimum bei $72{ }^{\circ} \mathrm{C}$. Primer besitzen spezifische Temperaturoptima, der hier verwendete $[\mathrm{AC}]_{9}$-Primer besitzt eine AnnealingTemperatur von $54{ }^{\circ} \mathrm{C}$. Die entsprechenden Temperaturschritte und Zyklen sind in der folgenden Tabelle angegeben.

Tab. 4: PCR-Kontur für die DNA-Amplifikation mit dem Primer $[\mathrm{AC}]_{9}$

\begin{tabular}{|c|c|c|}
\hline Temperatur $\left[{ }^{\circ} \mathbf{C}\right]$ & Zeit $[\mathbf{m i n}]$ & Anzahl Zyklen \\
\hline 95 & 4 & \\
54 & 1 & $\mathbf{1}$ \\
72 & 1 & \\
\hline 95 & 1 & $\mathbf{2 9}$ \\
54 & 1 & \\
72 & 1 & \\
\hline
\end{tabular}




\subsubsection{Amplifikation der DNA mittels Mikrosatelliten-PCR}

Wie bereits in Kapitel 2.6.3.1. erwähnt, sind Mikrosatelliten einfache, sich wiederholende Basensequenzen in vielen Genomen. $\mathrm{Zu}$ einigen auf dem Genom von Septoria tritici vorkommenden Mikrosatelliten wurden Primer entwickelt, die direkt an spezifische Sequenzen rechts und links des entsprechenden Mikrosatelliten binden und das Mikrosatellitenmotiv amplifizieren (OWEN et al. 1998). In diesen Untersuchungen wurden neun bekannte Primer (ST1A2, ST1A4, ST1B3, ST2E4, ST1E3, ST2C10, ST1G7, ST1E7, ST1D7) ebenfalls in einer Reihe von Vorversuchen getestet (s. Kap. 2.6.3.1.) und drei davon zur Bestimmung der genetischen Variabilität von S. tritici verwendet. Die Auswahl dieser Primer erfolgte aufgrund der hohen Reproduzierbarkeit. Der Primer ST1A4 verfügt über das Motiv $[\mathrm{CGG}]_{7}$, der Primer ST1E7 über das Motiv $[\mathrm{CGG}]_{5}$ und der Primer ST2E4 über $[\mathrm{GGC}]_{5}$. Jeder der eingesetzten Primer fungierte sowohl als „Forward“'-Primer (Primer F), der in 5'-3'-Richtung der DNA bindet, als auch als „Backward“'-Primer (Primer B), der in 3'-5'-Richtung der DNA bindet, vor. Die Primer-Sequenzen sind im Anhang (ATab. 3) aufgeführt. Die DNA jeder der 301 Isolate von $S$. tritici wurde in drei Ansätzen mit jedem der drei Primer in einem $25 \mu 1$ Ansatz amplifiziert. Das entsprechende Pipettierschema ist in der folgenden Tabelle dargestellt.

Tab. 5: Pipettierschema der Mikrosatelliten-PCR-Ansätze

\begin{tabular}{|c|c|c|c|c|c|c|c|}
\hline $\begin{array}{c}\mathbf{1 0} \mathbf{x} \\
\text { Puffer }\end{array}$ & $\begin{array}{c}\mathbf{2 5} \mathbf{~ m M} \\
\mathbf{M g C l}_{\mathbf{2}}\end{array}$ & $\begin{array}{c}\text { Taq-Pol. } \\
\mathbf{1} \mathbf{U} / \boldsymbol{\mu l}\end{array}$ & $\begin{array}{c}\mathbf{2 , 5} \mathbf{~ m M} \\
\mathbf{d N T P} \text { 's }\end{array}$ & $\begin{array}{c}\mathbf{1 0} \boldsymbol{\mu M} \\
\text { Primer } \mathbf{F}\end{array}$ & $\begin{array}{c}\mathbf{1 0} \boldsymbol{\mu M} \\
\text { Primer } \mathbf{B}\end{array}$ & $\begin{array}{c}\text { DNA } \\
\varnothing \mathbf{2 5} \mathbf{~ n g} / \boldsymbol{\mu l}\end{array}$ & $\begin{array}{c}\text { Bidest } \\
\mathbf{H}_{\mathbf{2}} \mathbf{O} \text { steril }\end{array}$ \\
\hline $2,5 \mu \mathrm{l}$ & $1,7 \mu \mathrm{l}$ & $1 \mu \mathrm{l}$ & $2,5 \mu \mathrm{l}$ & $3 \mu \mathrm{l}$ & $3 \mu \mathrm{l}$ & $3 \mu \mathrm{l}$ & $8,3 \mu \mathrm{l}$ \\
\hline
\end{tabular}

Die drei eingesetzten Primer besitzen unterschiedliche Temperaturoptima, daher werden die eingesetzten PCR-Konturen für die drei Primer in den folgenden Tabellen gesondert aufgeführt. Die „Annealing“-Temperatur ist abhängig vom GC-Gehalt (Anteil Guanin und Cytosin) in der Primer-Struktur. Je höher dieser Gehalt, desto höher ist die optimale Temperatur zur spezifischen Bindung an der DNA.

Bei dem Primer ST1A4 wurde mit der „Touch Down“-Methode gearbeitet, die in Vorversuchen für eine spezifische Amplifikation des Mikrosatellitenmotivs etabliert wurde. Bei dieser Methode wird im ersten Zyklus der PCR mit einer hohen 
„Annealing“-Temperatur gestartet. In den folgenden Zyklen wird diese Temperatur schrittweise gesenkt, bis die optimale Temperatur erreicht wird. Mit dieser Optimumtemperatur werden anschließend die weiteren Zyklen der PCR durchgeführt. Ein Vorteil dieser Methode ist, dass eventuell auftretende falsche Bindungen („mismatching“) der Primer an der DNA verhindert und so das Auftreten von sog. „Nebenbanden“ im Polyacrylamid-Gel gemindert wird.

Tab. 6: „Touch Down“ PCR-Kontur für die DNA-Amplifikation mit dem Primer ST1A4

\begin{tabular}{|c|c|c|}
\hline Temperatur $\left[{ }^{\circ} \mathbf{C}\right]$ & Zeit $[\mathbf{m i n}]$ & Anzahl Zyklen \\
\hline 94 & 4 & $\mathbf{1}$ \\
56 & 1 & \\
72 & 1 & $\mathbf{1}$ \\
\hline 95 & 1 & \\
55,5 & 1 & $\mathbf{1}$ \\
72 & 1 & \\
\hline 95 & 1 & \\
55 & 1 & $\mathbf{1}$ \\
72 & 1 & \\
\hline 95 & 1 & $\mathbf{2 6}$ \\
54,5 & 1 & \\
72 & 1 & \\
\hline 95 & 1 & \\
$\mathbf{5 4}$ & 1 & \\
72 & & \\
\hline
\end{tabular}

Die Amplifikation der DNA mit den Primern ST1E7 und ST2E4 wurde ebenfalls in Vorversuchen getestet. Dabei stellte sich heraus, dass hier nicht mit der „Touch Down“ Methode gearbeitet werden musste, da die Anzahl unerwünschter Nebenbanden im Gel gering war. Zudem konnte für beide Primer die gleiche PCR-Kontur verwendet werden, da sie über dasselbe Temperaturoptimum verfügen. Die PCR-Kontur ist der folgenden Tabelle zu entnehmen. 
Tab. 7: PCR-Kontur für die DNA-Amplifikation mit dem Primer ST1E7 und ST2A4

\begin{tabular}{|c|c|c|}
\hline Temperatur $\left[{ }^{\circ} \mathbf{C}\right]$ & Zeit $[\mathbf{m i n}]$ & Anzahl Zyklen \\
\hline 96 & 2 & \\
58 & 1 & $\mathbf{1}$ \\
72 & 0,5 & \\
\hline 94 & 1 & $\mathbf{3 5}$ \\
$\mathbf{5 8}$ & 1 & \\
72 & 0,5 & \\
\hline
\end{tabular}

\subsubsection{Agarose-Gelelektrophorese}

Die Elektrophoresetechnik wurde genutzt, um DNA-Fragmente ihrer Größe nach zu trennen und um die extrahierte Gesamt-DNA zu quantifizieren. Bei der AgaroseGelelektrophorese wurde ein 1,5 \%iges Agarosegel und 0,5 x TBE als Laufpuffer verwendet. Die angelegte Spannung zwischen den Elektroden betrug drei Volt pro Zentimeter mit einer Laufzeit von drei Stunden. Zur Quantifizierung der extrahierten DNA wurde neben den Proben der Größenmarker Lambda Eco91I (MBI Fermentas, ST. Leon-Roth) aufgetragen (Fragmentgrößen s. Kap. 2.6.1.).

Für die Gelauswertung der MP-PCR-Produkte, d. h. zur Bestimmung auswertbarer Banden und Festlegung gleicher bzw. ungleicher Banden, wurde der Größenmarker GeneRuler ${ }^{\mathrm{TM}}$ 100bp Ladder Plus (MBI Fermentas, St. Leon-Roth) neben den Proben aufgetragen. Dieser Größenmarker besitzt die definierten Fragmente 3000, 2000, 1500, 1200, 1031, 900, 800, 700, 600, 500, 400, 300, 200, 100 [bp].

\subsubsection{Polyacrylamid-Gelelektrophorese}

Um die Mikrosatelliten-PCR-Produkte auszuwerten, wurden Polyacrylamid-Gele verwendet. Dazu wurde der ALFexpress II DNA Analyser (Amersham Biosciences Europe, Freiburg) verwendet. Die Polyacrylamid-Gele wurden aus Standard-Lösungen zusammengesetzt. Zunächst wurden 7 \%ige Gele verwendet, später wurde die Konzentration auf $8 \%$, aufgrund der verbesserten Trennung der Banden, erhöht. Als Laufpuffer diente erneut 0,5 x TBE. Die Spannung betrug 1000V, bei einer Leistung 
von 25W und einer Stromstärke von 60mA. Diese Parameter stellen Maximalwerte dar; sie verändern sich während des Gel-Laufs fortwährend. Die Laufzeit betrug 4 Stunden. Neben den Proben wurde als Größenmarker der Standardmarker ALFexpress ${ }^{\mathrm{TM}}$ Sizer $^{\mathrm{TM}}$ 50-500 (Amersham Biosciences Europe, Freiburg) mit den definierten Fragmentgrößen 50, 100, 150, 200, 250, 300, 350, 400, 450, 500 [bp] aufgetragen. Zusätzlich wurde in jeder neunten Spur ein sog. Interner Standard, ein PCR-Produkt einer bekannten Größe aufgetragen. Es wurden insgesamt drei interne Standards verwendet, die jeweils PCRProdukte eines Isolates von $S$. tritici waren. Einer dieser Standards besaß das Allel 1 des Primers ST1A4, der zweite die Allele 1 und 2 des Primers ST1E7 und der dritte Standard besaß die Allele 1 und 2 des Primers ST2E4.

\subsubsection{Geldokumentation}

Die Dokumentation der beiden Gel-Arten erfolgte mit Hilfe unterschiedlicher Techniken, die im Folgenden separat aufgeführt sind.

\subsubsection{Dokumentation der Agarose-Gele}

Zunächst wurden die Agarose-Gele in einem Ethidiumbromid-Wasserbad ( $2 \mu \mathrm{g} / \mathrm{ml})$ für zehn bis 15 Minuten bei Raumtemperatur angefärbt. Anschließend wurden die Gele, um eine bessere Kontrastierung zu erreichen, in einem Wasserbad für 15 Minuten entfärbt. Die Gele wurden über eine Videokamera mit Filter und der integrierten Geldokumentationssoftware Multi-Analyst dokumentiert (Gel Doc Sytstem BioRad, München).

\subsubsection{Dokumentation der Polyacrylamid-Gele}

Die Polyacrylamid-Gele mussten nach erfolgter Elektrophorese nicht angefärbt werden. Aufgrund der fluoreszenz-markierten Primer (Cy5-Markierung am 5'-Ende der Primer) wurden die entsprechenden Fragmente im Gel bei Passieren der Photozelle nach 
Anregung der Fluoreszenzmarkierung durch einen Laserstrahl des ElektrophoreseGerätes detektiert und in einem speziellen Computerprogramm ALFwin Fragment Analyser 1.00 (Amersham Biosciences Europe, Freiburg) als Chromatogramm dargestellt. Dieses Computerprogramm ermöglicht gleichzeitig die Umformatierung der Kurvendarstellung in Gel-Bandenmuster wie bei Agarose-Gelen. Diese Bandenmuster können mit Hilfe der Software Adobe Photoshop (6.0) dokumentiert werden.

\subsubsection{Datenerfassung und Auswertung molekularer Daten}

\subsubsection{Gelauswertung}

Mit Hilfe der Software GelComparII (Applied Maths, Kortrijk, Belgien) wurden die Agarose- und Polyacrylamid-Gele ausgewertet. Zunächst wird das PCR-Bandenmuster eingelesen und Anordnung und Anzahl der Banden bestimmt. Das Programm ordnet jeder Bande anhand des aufgetragenen, definierten Standards ein Molekulargewicht zu. Durch das Auftragen des Größenmarkers ALFexpress ${ }^{\mathrm{TM}}$ Sizer $^{\mathrm{TM}}$ und des internen Standards bei den Polyacrylamid-Gelen und GeneRuler ${ }^{\mathrm{TM}} 100 \mathrm{bp}$ Ladder Plus bei den Agarose-Gelen ist durch Normalisierung (Stauchung bzw. Streckung der unterschiedlichen Gele) ein Vergleich der Agarose-Gele einerseits und der Polyacrylamid-Gele andererseits möglich. Die eingelesenen Bandenmuster dienen als Grundlage zur Berechnung genetischer Ähnlichkeiten.

\subsubsection{Genetische Ähnlichkeiten und multivariate Statistiken}

Zur Berechnung genetischer Ähnlichkeiten und Durchführung multivariater Statistiken wurde wie bei der Gelauswertung die Software GelComparII (Applied Maths, Kortrijk, Belgien) verwendet. Die Berechnung der genetischen Ähnlichkeit zweier Isolate erfolgte sowohl bei der MP-PCR-Untersuchung, als auch bei der Mikrosatelliten-PCRUntersuchung anhand des Ähnlichkeitskoeffizienten $S_{x y}$ (Dice-Index, DICE 1945). Der Dice-Index ist ein quantitatives Ähnlichkeitsmaß, dessen Wertebereich zwischen null (keine gemeinsamen Banden) und eins (alle Banden gemeinsam) liegt. Dieser 
Ähnlichkeitskoeffizient $S_{x y}$ wurde für jedes Isolatpaar im Programm GelComparII mit der folgenden Formel berechnet:

$S_{\mathrm{xy}}=2 n_{\mathrm{xy} 1 / 1} /\left(2 n_{\mathrm{xy} 1 / 1}+n_{\mathrm{yx} 1 / 0}+n_{\mathrm{xy} 0 / 1}\right)$

wobei: $\mathbf{x}$ und $\mathbf{y}=\mathrm{zu}$ vergleichende Isolate

$\mathbf{n}_{\mathbf{x y} \mathbf{1} / \mathbf{1}}=$ Anzahl der im Paarvergleich gemeinsam vorkommenden Banden

$\mathbf{n}_{\mathbf{x y} 1 / \mathbf{0}}=$ Anzahl der Banden, die im Paarvergleich nur bei Isolat $\mathrm{x}$ vorhanden sind

$\mathbf{n}_{\mathbf{x y 0} \mathbf{1}}=$ Anzahl der Banden, die im Paarvergleich nur bei Isolat y vorkommen

Diese genetischen Ähnlichkeiten wurden anhand einer Clusteranalyse verglichen und gruppiert. Die Clusteranalyse erfolgte nach dem UPGMA-Algorithmus (unweigthed pair group method with arithmetic mean, SNEATH \& SOKAL 1973). Es handelt sich dabei um ein hierarchisches Verfahren, in dem die Ähnlichkeitswerte der einzelnen Isolate zueinander als Grundlage dienen. Die in der Matrix einander ähnlichsten Isolate werden sukzessive gruppiert, anschließend werden die genetischen Distanzen zu den verbleibenden Isolaten oder Fusionsgruppen durch Mittelwertbildung (average linkage) so lange neu generiert und in einer Datenmatrix zusammengefasst, bis alle Isolate zu einem gemeinsamen Cluster fusioniert sind. Die Position der Cluster innerhalb des Dendrogramms beschreibt die genetische Ähnlichkeit der Isolate der untersuchten Population zueinander.

\subsubsection{Populationsgenetische Analyse von Septoria tritici}

Die Bestimmung des Ähnlichkeitskoeffizienten und die Cluster-Analyse wurden sowohl mit den Daten der Isolate aus der MP-PCR-Analyse, als auch aus der MikrosatellitenAnalyse durchgeführt. Weitergehende populationsgenetische Studien wurden allerdings nur mit den Daten der Isolate des Versuchsjahres 2002 aus der Mikrosatelliten-Analyse unternommen.

Auf Grundlage der Daten der genetische Ähnlichkeitsbestimmung mit GelComparII wurde anhand des Bandenmusters von allen drei verwendeten Primern bei den 290 untersuchten Isolaten von S. tritici mit Hilfe der Software eine binäre sog. 0/1-Matrix 
erstellt. Die Bandenmuster wurden hinsichtlich der An- oder Abwesenheit der entsprechenden Banden ausgewertet. Das Vorhandensein eines Allels wurde mit 1 kodiert, fehlte das Allel wurde eine 0 angegeben. Anschließend wurden die Ergebnisse der 0/1-Matrix mit Hilfe des Statistikprogramms ARLEQUIN Vers. 2.00 (SCHNEIDER et al. 2000) auf populationsgenetischer Ebene analysiert. Mit Hilfe dieser Software wurde eine Varianzanalyse der molekularen Daten (Analysis of molecular variance, AMOVA) durchgeführt, die zur Bestimmung genetischer Variabilität innerhalb und zwischen Populationen dient. Als Resultat wird die Gesamtvarianz in Varianzkomponenten unterteilt (WRIGHT 1951, COCKERHAM 1973). Mit Hilfe einer „Bootstrap“-Prozedur, bei der die Daten 1000-fach randomisiert werden, wird die Signifikanz der einzelnen Varianzkomponenten getestet. Bei dieser Methode wird eine neue Stichprobe aus den Ursprungsdaten mit der gleichen Anzahl an Datenelementen durch Zufallswahl zusammengestellt. Anhand dieser Stichproben werden erneut die Werte berechnet, mit denen anschließend ein Vertrauensbereich angegeben werden kann.

Eine dieser Varianzkomponenten ist der Fixierungs-Index F $_{\text {ST }}$ (WRIGHT 1965), der als $\mathrm{Maß}$ für die genetische Differenzierung zwischen Populationen gilt. Der $\mathrm{F}_{\mathrm{ST}}$-Wert berechnet sich wie folgt:

$F_{S T}=\left(H_{T}-H_{S}\right) / H_{T}$

wobei: $\mathbf{H}_{\mathbf{T}}=$ erwartete Heterozygotenrate in der Gesamtpopulation

$\mathbf{H}_{\mathbf{S}}=$ erwartete Heterozygotenrate in einer Subpopulation.

Eine weitere Varianzkomponente ist die genetische Diversität (,gene diversity“), die auf Grundlage haploider Daten berechnet wird (NEI 1987). Die genetische Diversität berechnet sich folgendermaßen:

$$
\begin{aligned}
& \hat{\mathbf{H}}=(\mathbf{n} / \mathbf{n}-\mathbf{1}) *\left(\mathbf{1}-\sum_{\mathbf{i}=\mathbf{1}}^{\mathbf{k}} \mathbf{p}_{\mathbf{i}}{ }^{\mathbf{2}}\right) \\
& \begin{aligned}
\text { wobei: } \mathbf{n} & =\text { Anzahl Individuen } \\
\mathbf{k} & =\text { Anzahl Haplotypen (Genotypen) } \\
\mathbf{p}_{\mathbf{i}} & =\text { Frequenz des } \mathbf{i}^{\text {ten }} \text { Haplotypen }
\end{aligned}
\end{aligned}
$$




\subsubsection{Statistische Auswertung}

Wie bei den Felderhebungen wurden die Versuchsdaten mit Hilfe von Microsoft Excel 2000 tabellarisch erfasst und graphisch dargestellt. Für die statistischen Erhebungen (Berechnung von Regression, Bestimmtheitsmaß und Irrtumswahrscheinlichkeit; Student Newman Keuls Test) wurde das Programmpaket SAS (Statistical Analysis System; Release 6.12) verwendet.

\subsection{Mikroskopie und Fotographie}

Die mikroskopischen Untersuchungen (Auszählung der Sporen mittels FuchsRosenthal-Apparatur) wurden mit einem Leica Leitz DMRB Mikroskop durchgeführt. Die Bonituren des Pilzbefalls der entnommenen Blätter der untersuchten Felder erfolgte mittels eines Binokulars (Leica Wild M 10).

Die photographischen Aufnahmen wurden mit einer Canon EOS 500N Spiegelreflexkamera (Objektiv 28-80 mm) gemacht. Als Film wurde ein Elite Selekt 200 ASA der Firma Kodak verwendet. 


\section{Ergebnisse}

\subsection{Ergebnisse der Feldversuche}

Im Rahmen der Feldversuche wurde der Einfluss von Landschaftsstrukturen auf das Auftreten blattpathogener Pilze an Weizen näher untersucht. Als Hintergrunddaten dienten zum einen die Landnutzungsdiversität der umgebenden Region jeden Untersuchungsfeldes, zum anderen die Bewirtschaftungsparameter der untersuchten Felder.

\subsubsection{Ergebnisse zur Landnutzungsdiversität}

Die Landnutzungsdiversität gibt das Verhältnis der angebauten Feldfrüchte und Saumstrukturen zueinander innerhalb des untersuchten Ausschnittes (3 km Radius) um das Untersuchungsfeld herum an. Diese Erhebungen wurden in beiden Versuchsjahren (2001 und 2002) ausschließlich in der Region Göttingen vorgenommen, für die Region Giessen fehlen diese Untersuchungen. Es wurden Kartierungen aller Felder innerhalb der Landschaftssausschnitte der Region Göttingen durchgeführt. In der folgenden Tabelle ist der prozentuale Anteil der wichtigsten Kulturen (Getreide, Raps, Zuckerrüben), des Graslandes und der Anteil sonstiger Strukturen innerhalb der untersuchten Ausschnitte angegeben. Die übrigen sieben kartierten Feldfrüchte und Saumstrukturen (Mais, Kartoffeln, Leguminosen, Saatbrache, natürliche Brache, Hecken, Andere (z. B. Phacelia)) kamen in beiden Versuchsjahren nur zu einem sehr geringen Anteil in der Region Göttingen vor, so dass sie in der Tabelle unter „Sonstige“ zusammengefasst und nicht in die Untersuchungen mit einbezogen wurden. 
Tab. 8: Landnutzungsdiversität innerhalb der 10 untersuchten Landschaftsausschnitte in der Region Göttingen in den Anbaujahren 2001 und 2002

\begin{tabular}{|c|c|c|c|c|c|c|c|c|c|c|}
\hline & \multicolumn{1}{|c|}{ Fruchtartenanteil [\%] im Anbaujahr 2001 } & \multicolumn{3}{c|}{ Fruchtartenanteil [\%] im Anbaujahr 2002 } \\
\hline Fläche & Getreide & Raps & $\begin{array}{c}\text { Z- } \\
\text { Rüben }\end{array}$ & Grasland & Sonstige & Getreide & Raps & $\begin{array}{c}\text { Z- } \\
\text { Rüben }\end{array}$ & Grasland & Sonstige \\
\hline $\mathbf{4 . 1}$ & 21,30 & 6,90 & 0,89 & 19,11 & 51,80 & 24,16 & 6,48 & 0,44 & 18,12 & 50,80 \\
\hline $\mathbf{1 4 . 1}$ & 34,47 & 8,37 & 3,28 & 20,62 & 33,26 & 36,96 & 6,83 & 3,16 & 20,64 & 32,41 \\
\hline $\mathbf{1 8 . 1}$ & 12,99 & 4,17 & 0,00 & 12,69 & 70,15 & 10,54 & 5,87 & 0,00 & 12,39 & 71,20 \\
\hline $\mathbf{1 3 . 2}$ & 43,57 & 10,12 & 1,11 & 15,47 & 29,73 & 40,41 & 9,58 & 3,43 & 15,58 & 31,00 \\
\hline $\mathbf{1 1 . 2}$ & 16,40 & 2,60 & 0,36 & 16,14 & 79,50 & 14,17 & 3,11 & 0,30 & 17,14 & 65,28 \\
\hline $\mathbf{1 . 2}$ & 47,23 & 3,28 & 14,64 & 9,05 & 25,80 & 48,05 & 3,61 & 15,07 & 9,57 & 23,70 \\
\hline $\mathbf{9 . 1}$ & 56,51 & 4,27 & 7,13 & 5,96 & 26,13 & 44,50 & 10,03 & 12,55 & 6,13 & 26,79 \\
\hline $\mathbf{5 . 1}$ & 24,82 & 4,22 & 4,24 & 11,92 & 54,80 & 39,33 & 8,97 & 4,83 & 9,98 & 36,89 \\
\hline $\mathbf{1 2 . 1}$ & 51,73 & 9,15 & 5,04 & 8,44 & 25,64 & 45,89 & 13,24 & 4,97 & 8,22 & 27,68 \\
\hline $\mathbf{8 . 1}$ & 30,70 & 3,38 & 6,90 & 7,91 & 51,11 & 43,12 & 5,79 & 8,44 & 7,83 & 34,82 \\
\hline
\end{tabular}

Legende: Z-Rüben = Zuckerrüben; Sonstige $=$ Mais, Kartoffeln, Leguminosen, Saatbrache, natürliche Brache, Hecken, Andere (Phacelia etc.); Sortierung der Felder von oben nach unten mit steigendem Ackeranteil

Der Tabelle ist zu entnehmen, dass sich die beiden Versuchsjahre 2001 und $2002 \mathrm{im}$ Hinblick auf das Verhältnis der angebauten Feldfrüchte und Saumstrukturen zueinander kaum unterschieden. Vermutlich verändern sich die charakterisierten Landschaften demnach über einen längeren Zeitraum nicht. Unabhängig vom Untersuchungsjahr unterschieden sich die untersuchten Landschaftsausschnitte dagegen stark. Die folgenden Abbildungen veranschaulichen die Daten der Tabelle am Beispiel zweier Felder. Feld 12.1 (Abb. 6) lag im Zentrum einer monotonen, wenig strukturierten Landschaft, während Feld 18.1 (Abb. 7) in eine sehr divers strukturierte Landschaft eingebettet war. 
Feld $12.1(2002)$

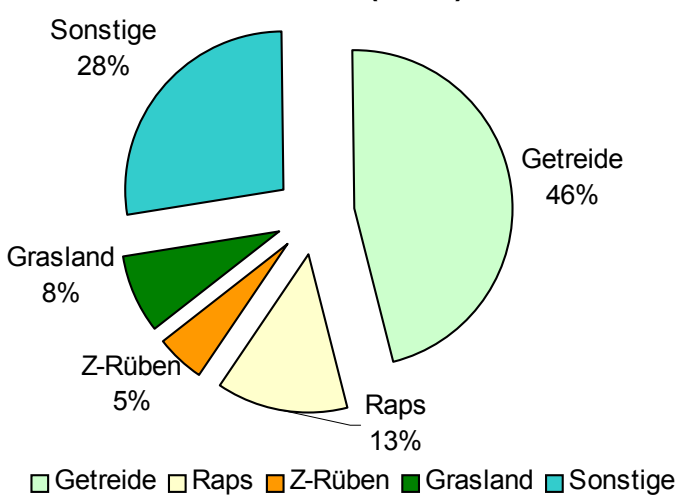

Abb. 6: Landnutzungsdiversität des das Feld 12.1 in $3 \mathrm{~km}$ umgebenden Landschaftsausschnittes im Jahr 2002

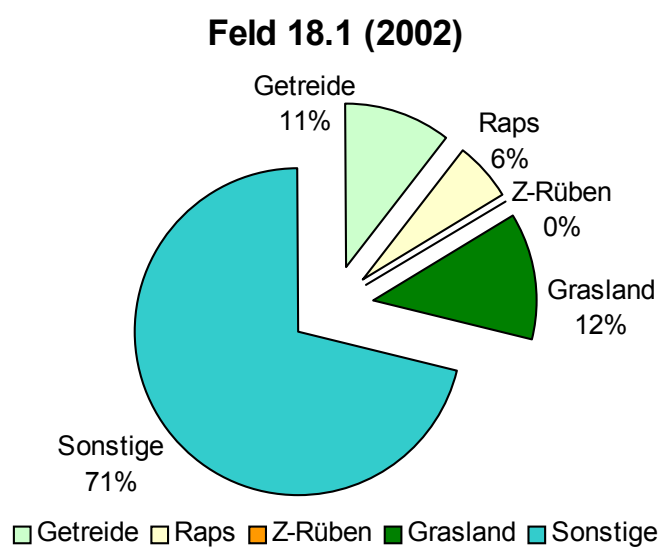

Abb. 7: Landnutzungsdiversität des das Feld 18.1 in $3 \mathrm{~km}$ umgebenden Landschaftsausschnittes im Jahr 2002

Feld 12.1 war durch einen hohen Ackeranteil, eine monotone Landschaft und einen entsprechend hohen Getreide- und Rapsanteil in der Umgebung charakterisiert, während der Anteil an Grasland mit ca. 8 \% vergleichsweise gering war (Abb. 6). Feld 18.1 lag hingegen in einer komplex strukturierten Landschaft und wurde durch einen geringen Ackeranteil charakterisiert, der Getreide- und Rapsanteil in der Umgebung war niedrig und der Anteil an Grasland und insbesondere an Saumstrukturen mit 71 \% (,Sonstige“) vergleichsweise hoch (Abb. 7).

Diese beiden Abbildungen veranschaulichen zwei extreme Landschaftsausschnitte des Gradienten (s. Kap. 2.3.1., Abb. 3), in dem die Flächen der Region Göttingen vermehrt den monotonen Landschaftsbereich abdecken, während die Giessener Flächen die komplex strukturierten Landschaften beinhalten. Leider fehlen jedoch die 
Landnutzungsdaten der Giessener Flächen, daher konnte an dieser Stelle nur eine eingeschränkte Darstellung der Landnutzungsdiversität erfolgen.

\subsubsection{Unterschiede der Bewirtschaftungsweise der untersuchten Felder}

In Datenerhebungsbögen, die von den Landwirten der 19 untersuchten Felder ausgefüllt wurden, wurden sämtliche Kulturmaßnahmen, sowie die Fruchtfolgegestaltung der Felder während der Vegetationsperiode 2000/2001 und 2001/2002 erfragt. Im Folgenden sind die wichtigsten Bewirtschaftungsparameter tabellarisch aufgeführt. Die in den physiologischen und genetischen Untersuchungen mit Septoria tritici näher betrachteten Felder sind grau unterlegt. Angaben zum Einsatz von Wachstumsreglern, Herbiziden und Insektiziden sind nicht dargestellt (s. Anhang, ATab. 1 und ATab. 2). Die Datensätze liegen nicht für alle Felder über beide Anbaujahre vollständig vor, da die Resonanz der befragten Landwirte trotz mehrmaliger Nachfrage nicht sehr hoch war.

Tab. 9: Kulturmaßnahmen der untersuchten Felder der Region Göttingen und Giessen im Jahr 2001

\begin{tabular}{|c|c|c|c|c|c|}
\hline Fläche & Weizensorte & Saatstärke & $\begin{array}{c}\text { Erwarteter } \\
\text { Ertrag (ca.) }\end{array}$ & Fruchtfolge & Bodenbearbeitung \\
\hline Gi 17 & k. A. & $250 \mathrm{~kg} / \mathrm{ha}$ & $40 \mathrm{dt} / \mathrm{ha}$ & WW-H+G-H-WG-H+G & Pf \\
\hline Gi 20 & Drifter & $150 \mathrm{~kg} / \mathrm{ha}$ & $60 \mathrm{dt} / \mathrm{ha}$ & WW-WR-WG & Pf-Ke \\
\hline Gö 4.1 & Ritmo & $220 \mathrm{~kg} / \mathrm{ha}$ & $95 \mathrm{dt} / \mathrm{ha}$ & WR-WW-WW*-WG & Pf+Pf-Ke \\
\hline Gi 5 & Contur & $180 \mathrm{~kg} / \mathrm{ha}$ & $60 \mathrm{dt} / \mathrm{ha}$ & WW-WG-T-Öllein & Pf-Ke \\
\hline Gi 6 & Contur & $160 \mathrm{~kg} / \mathrm{ha}$ & $70 \mathrm{dt} / \mathrm{ha}$ & WR-WW-T-WG & G \\
\hline Gö 11.2 & k. A. & $220 \mathrm{~kg} / \mathrm{ha}$ & $70 \mathrm{dt} / \mathrm{ha}$ & WW-B-WW-WW* & Pf-Ke \\
\hline Gi 12 & Drifter & $150 \mathrm{~kg} / \mathrm{ha}$ & $85 \mathrm{dt} / \mathrm{ha}$ & WW-T-ZR & Pf-Ke \\
\hline Gö 1.2 & Drifter & $195 \mathrm{~kg} / \mathrm{ha}$ & $90 \mathrm{dt} / \mathrm{ha}$ & ZR-WW-WW* & Pf-Ke \\
\hline Gö 9.1 & Ritmo & $158 \mathrm{~kg} / \mathrm{ha}$ & $90 \mathrm{dt} / \mathrm{ha}$ & B-B-WW-WW* & G+Pf-Ke \\
\hline Gö 5.1 & Drifter & $220 \mathrm{~kg} / \mathrm{ha}$ & $70 \mathrm{dt} / \mathrm{ha}$ & WW-Monokultur & G-Ke \\
\hline Gö 12.1 & Drifter & $130 \mathrm{~kg} / \mathrm{ha}$ & $107 \mathrm{dt} / \mathrm{ha}$ & WW Monokultur & Pf-Ke \\
\hline Gö 8.1 & Contur & $250 \mathrm{~kg} / \mathrm{ha}$ & $98 \mathrm{dt} / \mathrm{ha}$ & WW-WG-ZR & Pf+Pf-Ke \\
\hline
\end{tabular}

Legende: Pf: Pflug; Ke: Kreiselegge ; G: Grubber; WW: Winterweizen; WG: Wintergerste; WR: Winterraps; ZR: Zuckerrüben; H: Hafer; T: Triticale; SG: Sommergerste; B: Brache; * kennzeichnet die Weizenbestände 2001 der Fruchtfolge; Gö: Felder der Region Göttingen; Gi: Felder der Region Giessen; Sortierung der Felder von oben nach unten mit steigendem Ackeranteil 
Wie Tab. 9 zu entnehmen ist, fehlten für die Vegetationsperiode 2000/2001 die Daten der Göttinger Felder 13.2, 14.1 und 18.1, sowie die Daten der Giessener Felder 4, 9, 10 und 18. Saatstärke, erwarteter Ertrag, Fruchtfolge und Bodenbearbeitung wiesen deutliche Unterschiede zwischen den Feldern auf. Eine Zunahme von Saatstärke und erwartetem Ertrag mit abnehmender Diversität der Landschaftsausschnitte der aufgeführten Felder war nicht zu erkennen. Weiterhin ist Tab. 9 eine Verengung der Fruchtfolge sowie intensivierte Bodenbearbeitung mit abnehmender Landschaftsdiversität nicht $\mathrm{zu}$ entnehmen. Deutlich $\mathrm{zu}$ erkennen ist hingegen, dass in beiden Regionen im Wesentlichen die drei Weizensorten Drifter, Ritmo und Contur dominierten. Die Einstufung der Anfälligkeit, laut Bundessortenliste 2003, dieser drei Sorten gegenüber den untersuchten blattpathogenen Pilzen ist in der folgenden Tabelle dargestellt.

Tab.10: Anfälligkeit laut Bundessortenliste 2003 der Winterweizensorten der Felder des Jahres 2001 gegenüber blattpathogenen Pilzen

\begin{tabular}{|c|c|c|c|c|c|c|}
\hline Weizensorte & $\begin{array}{c}\text { Septoria } \\
\text { tritici }\end{array}$ & $\begin{array}{c}\text { Septoria } \\
\text { nodorum }\end{array}$ & $\begin{array}{c}\text { Blumeria } \\
\text { graminis f. } \\
\text { sp. tritici }\end{array}$ & $\begin{array}{c}\text { Drechslera } \\
\text { tritici- } \\
\text { repentis }\end{array}$ & $\begin{array}{c}\text { Puccinia } \\
\text { striformis }\end{array}$ & $\begin{array}{c}\text { Puccinia } \\
\text { recondita }\end{array}$ \\
\hline Ritmo & 6 & 6 & 5 & 6 & 5 & 8 \\
\hline Drifter & 6 & 4 & 3 & 6 & 3 & 4 \\
\hline Contur & 6 & 5 & 5 & 6 & 9 & 6 \\
\hline
\end{tabular}

Legende: 3-9: Anfälligkeitseinstufung von gering bis hoch

Diese Einstufung zeigt, dass es sich bei Ritmo und Contur um sehr anfällige Sorten gegenüber blattpathogenen Pilzen handelt. Die Sorte Drifter besitzt eine relativ hohe Anfälligkeit gegenüber $S$. tritici und Drechslera tritici-repentis (DTR), bei vergleichsweise geringer Anfälligkeit gegenüber den vier weiteren Pilzen.

In der folgenden Tabelle sind Düngung und Fungizidstrategie der in Tab. 9 bereits beschriebenen Felder dargestellt. 
Tab. 11: Düngung und Fungizidstrategie der untersuchten Felder der Region Göttingen und Giessen im Jahr 2001

\begin{tabular}{|c|c|c|c|c|c|c|c|c|c|}
\hline \multirow[b]{2}{*}{ Fläche } & \multicolumn{6}{|c|}{ N-Düngung [reines $\mathrm{N}$ kg/ha] } & \multicolumn{3}{|c|}{ Fungizide [l/ha] } \\
\hline & N Ges. & Gabe1 & 2 & 3 & 4 & 5 & 1. Applikation & 2. Applikation & 3. Applikation \\
\hline Gi 17 & 81 & 81 & 0 & 0 & 0 & 0 & 0 & 0 & 0 \\
\hline Gi 20 & 145 & 65 & 30 & 50 & 0 & 0 & $\begin{array}{c}1,5 \\
\text { Opus Top }\end{array}$ & 0 & 0 \\
\hline Gö 4.1 & 250 & 55 & 45 & 50 & 50 & 50 & $\begin{array}{c}0,5+0,5 \\
\text { Unix+Juwel Forte }\end{array}$ & $\begin{array}{c}0,3+0,3 \\
\text { Gladio+Fortress } \\
\text { Top } \\
\end{array}$ & $\begin{array}{c}0,5+0,5 \\
\text { Amistar+Gladio }\end{array}$ \\
\hline Gi 5 & 170 & 120 & 50 & 0 & 0 & 0 & $\begin{array}{c}1,5 \\
\text { Opus Top }\end{array}$ & 0 & 0 \\
\hline Gi 6 & 185 & 70 & 46 & 69 & 0 & 0 & $\begin{array}{c}0,5+0,5 \\
\text { Amistar+Gladio }\end{array}$ & 0 & 0 \\
\hline Gö 11.2 & 94 & 40 & 27 & 27 & 0 & 0 & $\begin{array}{c}1 \\
\text { Simbo } \\
\end{array}$ & 0 & 0 \\
\hline Gi 12 & 140 & 40 & 40 & 60 & 0 & 0 & $\begin{array}{c}0,8 \\
\text { Gladio } \\
\end{array}$ & 0 & 0 \\
\hline Gö 1.2 & 209 & 50 & 60 & 29 & 70 & 0 & $\begin{array}{c}0,7 \\
\text { Juwel Forte }\end{array}$ & $\begin{array}{c}0,2+0,3 \\
\text { Amistar+Agent }\end{array}$ & $\begin{array}{c}\text { je } 0,3 \\
\text { Amistar+Gladio }\end{array}$ \\
\hline Gö 9.1 & 230 & 46 & 12 & 81 & 51 & 40 & $\begin{array}{c}0,5+0,5 \\
\text { Unix+Juwel Forte }\end{array}$ & $\begin{array}{c}0,2+0,2 \\
\text { Agent+Amistar }\end{array}$ & $\begin{array}{c}0,5+0,4 \\
\text { Amistar+Gladio }\end{array}$ \\
\hline Gö 5.1 & 222 & 70 & 36 & 36 & 80 & 0 & $\begin{array}{c}0,5 \\
\text { Juwel }\end{array}$ & $\begin{array}{c}0,4 \\
\text { Amistar }\end{array}$ & 0 \\
\hline Gö 12.1 & 210 & 60 & 60 & 90 & 0 & 0 & $\begin{array}{c}0,7 \\
\text { Juwel }\end{array}$ & $\begin{array}{c}0,3 \\
\text { Amistar } \\
\end{array}$ & 0 \\
\hline Gö 8.1 & 193 & 42 & 60 & 60 & 31 & 0 & $\begin{array}{c}0,5 \\
\text { Amistar }\end{array}$ & $\begin{array}{c}0,6 \\
\text { Gladio }\end{array}$ & $\begin{array}{c}1,5 \\
\text { Caramba }\end{array}$ \\
\hline
\end{tabular}

Legende: Gö: Felder der Region Göttingen; Gi: Felder der Region Giessen; Sortierung der Felder von oben nach unten mit steigendem Ackeranteil

Auch bei diesen Parametern zeigten sich deutliche Unterschiede zwischen den Feldern. Während die Felder 1.2, 4.1 und 8.1 eine dreimalige Fungizidbehandlung erfuhren, wurde Feld 17 überhaupt nicht, die Felder 11.2, 5, 6, 12 und 20 nur einmalig und die Felder 5.1 und 12.1 zweimal mit Fungiziden behandelt. Es wurde ein breites Spektrum an Fungiziden eingesetzt, zudem differierten die Aufwandmengen stark. Bei der Düngung zeigte sich ein ähnliches Bild. Es wurde zwischen ein und fünf Mal gedüngt und die eingesetzten Stickstoffmengen unterschieden sich mit einer Schwankungsbreite von $81-250 \mathrm{~kg} / \mathrm{ha}$ deutlich voneinander. Mit abnehmender Landschaftskomplexität ließ sich dennoch eine leichte Zunahme der Fungizidmaßnahmen und eine ebenso leichte Erhöhung der Stickstoffmengen erkennen.

Für das Jahr 2002 fehlen die Daten der Bewirtschaftungsparameter der Felder 13.2, 14.1 und 18.1 der Region Göttingen und in der Region Giessen die Daten der Felder 4, 18 und 20 aufgrund der oben beschriebenen geringen Resonanz der Landwirte. Die Anzahl angebauter Weizensorten stieg von drei auf acht. 
Tab. 12: Kulturmaßnahmen der untersuchten Felder der Region Göttingen und Giessen im Jahr 2002

\begin{tabular}{|c|c|c|c|c|c|}
\hline Fläche & Weizensorte & Saatstärke & $\begin{array}{c}\text { Erwarteter } \\
\text { Ertrag (ca.) }\end{array}$ & Fruchtfolge & Bodenbearbeitung \\
\hline Gi 10 & Ritmo & $220 \mathrm{~kg} / \mathrm{ha}$ & $90 \mathrm{dt} / \mathrm{ha}$ & WG-SG-WR-WW & Pf \\
\hline Gi 17 & K. A. & $240 \mathrm{~kg} / \mathrm{ha}$ & $50 \mathrm{dt} / \mathrm{ha}$ & $\begin{array}{c}\text { WW-H+G-WG-H- } \\
\text { WW }\end{array}$ & Pf \\
\hline Gi 9 & Jubilar & $200 \mathrm{~kg} / \mathrm{ha}$ & $52 \mathrm{dt} / \mathrm{ha}$ & WW-WG-H & Pf-Ke-W \\
\hline Gö 4.1 & Biscay & $240 \mathrm{~kg} / \mathrm{ha}$ & $90 \mathrm{dt} / \mathrm{ha}$ & WR-WW*-WW-WG & $2 \times G+S E-K e$ \\
\hline Gi 5 & Contur & $180 \mathrm{~kg} / \mathrm{ha}$ & $55 \mathrm{dt} / \mathrm{ha}$ & WW-WG-Öllein & Pf+Ke \\
\hline Gi 6 & Drifter & $180 \mathrm{~kg} / \mathrm{ha}$ & $80 \mathrm{dt} / \mathrm{ha}$ & WG-WR-WW*-WW & Pf+Ke \\
\hline Gö 11.2 & Ludwig & $220 \mathrm{~kg} / \mathrm{ha}$ & $70 \mathrm{dt} / \mathrm{ha}$ & WW-WG-WR & Pf+Ke \\
\hline Gi 12 & Dekan & $260 \mathrm{~kg} / \mathrm{ha}$ & $85 \mathrm{dt} / \mathrm{ha}$ & WW-T-ZR-WW- & Wf \\
\hline Gö 1.2 & Xanthos & $195 \mathrm{~kg} / \mathrm{ha}$ & $90 \mathrm{dt} / \mathrm{ha}$ & WW*-ZR-WW-WG & Pf-Ke \\
\hline Gö 9.1 & Dekan & $190 \mathrm{~kg} / \mathrm{ha}$ & $92 \mathrm{dt} / \mathrm{ha}$ & WW*-WW-ZR & G-Ke \\
\hline Gö 5.1 & Ritmo & $220 \mathrm{~kg} / \mathrm{ha}$ & $70 \mathrm{dt} / \mathrm{ha}$ & WW-Monokultur & G-Ke \\
\hline Gö 12.1 & Biscay & $155 \mathrm{~kg} / \mathrm{ha}$ & $120 \mathrm{dt} / \mathrm{ha}$ & WW-Monokultur & Pf+Pf-Ke \\
\hline Gö 8.1 & Drifter & $150 \mathrm{~kg} / \mathrm{ha}$ & $85 \mathrm{dt} / \mathrm{ha}$ & WW-WG-ZR & G-Pf-Ke \\
\hline
\end{tabular}

Legende: Pf: Pflug; Ke: Kreiselegge ; G: Grubber; SE: Spatenrollegge ; W: Walze; WW: Winterweizen; WG: Wintergerste; WR: Winterraps; ZR: Zuckerrüben; H: Hafer; T: Triticale; SG: Sommergerste; * kennzeichnet die Weizenbestände 2002 der Fruchtfolge; Gö: Felder der Region Göttingen; Gi: Felder der Region Giessen; Sortierung der Felder von oben nach unten mit steigendem Ackeranteil

Wie Tab. $12 \mathrm{zu}$ entnehmen ist, waren auch in diesem Jahr Saatstärke, erwarteter Ertrag, Fruchtfolge und Bodenbearbeitung der einzelnen Felder sehr unterschiedlich. Die in Tab. 10 charakterisierten Weizensorten Ritmo, Drifter und Contur wurden auch im Jahr 2002 angebaut. In der folgenden Tabelle sind die Einstufungen der Anfälligkeit laut Bundessortenliste 2003 bzw. 2002 (für Xanthos) der im zweiten Versuchsjahr neu hinzu gekommenen 5 Sorten gegenüber blattpathogenen Pilzen aufgeführt. 
Tab.13: Anfälligkeit laut Bundessortenliste 2003 der Winterweizensorten der Felder des Jahres 2002 gegenüber blattpathogenen Pilzen

\begin{tabular}{|c|c|c|c|c|c|c|}
\hline Weizensorte & $\begin{array}{c}\text { Septoria } \\
\text { tritici }\end{array}$ & $\begin{array}{c}\text { Septoria } \\
\text { nodorum }\end{array}$ & $\begin{array}{c}\text { Blumeria } \\
\text { graminis f. } \\
\text { sp. tritici }\end{array}$ & $\begin{array}{c}\text { Drechslera } \\
\text { tritici- } \\
\text { repentis }\end{array}$ & $\begin{array}{c}\text { Puccinia } \\
\text { striformis }\end{array}$ & $\begin{array}{c}\text { Puccinia } \\
\text { recondita }\end{array}$ \\
\hline Biscay & 6 & 5 & 4 & 6 & 5 & 3 \\
\hline Dekan & 4 & 3 & 1 & 4 & 4 & 8 \\
\hline Xanthos & 4 & k. A. & 3 & k. A. & k. A. & k. A. \\
\hline Ludwig & 5 & 4 & 4 & 5 & 3 & 5 \\
\hline Jubilar & k. A. & k. A. & k. A. & k. A. & k. A. & k. A. \\
\hline
\end{tabular}

Legende: 1-8: Anfälligkeitseinstufung von gering bis hoch; k. A.: keine Angabe

Bei der Sorte Xanthos handelt es sich um eine ältere Sorte, die in der Bundessortenliste 2003 nicht weiter aufgeführt ist. Gegenüber Septoria tritici und Echten Weizenmehltau besitzt diese Sorte eine relativ geringe Anfälligkeit, während für die anderen untersuchten Pilze die Anfälligkeit relativ hoch ist und daher hier nicht näher aufgeführt ist. Die Sorte Jubilar ist noch älter als die Sorte Xanthos. Angaben zur Anfälligkeit dieser Sorte konnte weder in der Bundessortenliste, noch im Internet gefunden werden. Generell gilt diese Sorte jedoch als anfällig und wird teilweise in Befallsversuchen eingesetzt (WEINERT, pers. Mitteilung 2003). Die hier aufgeführten Sorten Biscay, Dekan und Ludwig zeigen eine mittlere Anfälligkeit gegenüber Blattpathogenen. Während Biscay, außer gegenüber Puccinia recondita, hochanfällig ist, ist Dekan nur gegen $P$. recondita anfällig und gegenüber den anderen Pilzen widerstandsfähiger. Ludwig ist gegenüber $P$. striiformis weniger sensibel und weist gegenüber den anderen Pathogenen eine mittlere Anfälligkeit auf.

In der folgenden Tabelle sind Düngung und Fungizidstrategie der untersuchten Felder im Jahr 2002 dargestellt. 
Tab. 14: Düngung und Fungizidstrategie der untersuchten Felder der Region Göttingen und Giessen im Jahr 2002

\begin{tabular}{|c|c|c|c|c|c|c|c|c|c|}
\hline \multirow[b]{2}{*}{ Fläche } & \multicolumn{6}{|c|}{ N-Düngung [reines $\mathrm{N} \mathrm{kg/ha]}$} & \multicolumn{3}{|c|}{ Fungizide $[\mathrm{l} / \mathrm{ha}]$} \\
\hline & N Ges. & Gabe 1 & 2 & 3 & 4 & 5 & 1. Applikation & 2. Applikation & 3. Applikation \\
\hline Gi 10 & 182 & 56 & 54 & 8 & 64 & 0 & $\begin{array}{c}0,6 \\
\text { Amistar } \\
\end{array}$ & $\begin{array}{c}1,2 \\
\text { Opus Top } \\
\end{array}$ & 0 \\
\hline Gi 17 & 60 & 60 & 0 & 0 & 0 & 0 & 0 & 0 & 0 \\
\hline Gi 9 & 360 & 360 & 0 & 0 & 0 & 0 & 0 & 0 & 0 \\
\hline Gö 4.1 & 231 & 21 & 55 & 54 & 55 & 46 & $\begin{array}{c}0,7 \\
\text { Juwel Forte }\end{array}$ & $\begin{array}{c}0,3 \\
\text { Opera }\end{array}$ & $\begin{array}{c}0,8 \\
\text { Opera }\end{array}$ \\
\hline Gi 5 & 158 & 108 & 50 & 0 & 0 & 0 & $\begin{array}{c}1 \\
\text { Juwel Top }\end{array}$ & 0 & 0 \\
\hline Gi 6 & 180 & 80 & 40 & 60 & 0 & 0 & $\begin{array}{c}0,5+0,5 \\
\text { Unix+Juwel }\end{array}$ & $\begin{array}{c}0,6 \\
\text { Gladio }\end{array}$ & 0 \\
\hline Gö 11.2 & 104 & 40 & 27 & 27 & 10 & 0 & $\begin{array}{c}0,7 \\
\text { Juwel Top }\end{array}$ & $\begin{array}{c}0,5 \\
\text { Juwel Top }\end{array}$ & $\begin{array}{c}0,5 \\
\text { Taspa }\end{array}$ \\
\hline Gi 12 & 170 & 60 & 50 & 60 & 0 & 0 & $\begin{array}{c}1,5 \\
\text { Sportak Alpha }\end{array}$ & $\begin{array}{c}0,4+0,3 \\
\text { Amistar+Stratego }\end{array}$ & 0 \\
\hline Gö 1.2 & 222 & 20 & 54 & 68 & 20 & 60 & $\begin{array}{c}0,75 \\
\text { Juwel Forte }\end{array}$ & $\begin{array}{c}0,5+0,4 \\
\text { Amistar+Gladio } \\
\end{array}$ & 0 \\
\hline Gö 9.1 & 225 & 50 & 90 & 85 & 0 & 0 & $\begin{array}{c}0,75 \\
\text { Juwel Forte }\end{array}$ & \begin{tabular}{|c|}
1 \\
Opera \\
\end{tabular} & 0 \\
\hline Gö 5.1 & 253 & 60 & 18 & 81 & 47 & 47 & $\begin{array}{c}0,8 \\
\text { Acanto Duo }\end{array}$ & $\begin{array}{c}1+0,3 \\
\text { Opera+Opus Top }\end{array}$ & 0 \\
\hline Gö 12.1 & 220 & 50 & 50 & 50 & 70 & 0 & $\begin{array}{c}0,6+0,3 \\
\text { Unix+Juwel Top }\end{array}$ & $\begin{array}{c}0,4+0,4 \\
\text { Acanto Duo }\end{array}$ & $\begin{array}{c}0,3+0,5 \\
\text { Amistar+Gladio }\end{array}$ \\
\hline Gö 8.1 & 255 & 40 & 20 & 95 & 50 & 50 & $\begin{array}{l}0,7 \\
\text { Unix }\end{array}$ & $\begin{array}{c}0,6+0,6 \\
\text { Amistar+Gladio }\end{array}$ & 0 \\
\hline
\end{tabular}

Legende: Gö: Felder der Region Göttingen; Gi: Felder der Region Giessen; Sortierung der Felder von oben nach unten mit steigendem Ackeranteil

Im Jahr 2002 zeigten sich erneut deutliche Unterschiede in Menge und Anzahl der Düngungsgaben und Fungizidapplikationen. Auf Feld 17 und auch auf Feld 9 wurden, wie im Vorjahr, keine Fungizide ausgebracht, während auf Feld 4.1, 11.2 und 21.1 dreimal Fungizidspritzungen durchgeführt wurden. Wie im Jahr 2001 wurde ein breites Fungizidspektrum, sowie differierende Aufwandmengen eingesetzt. Erkennbar war jedoch erneut eine leichte Zunahme der Fungizidmaßnahmen sowie eine leichte Erhöhung der Stickstoffmengen mit abnehmender Landschaftskomplexität.

Abweichend zum Vorjahr wurden, wie bereits erwähnt, die Probenahmen im fungizidunbehandelten (in der Region Giessen und Göttingen) und im behandelten Teil der Felder (nur in der Region Göttingen) durchgeführt, so dass der Einfluss der Fungizide auf Befallsstärke und - häufigkeit der Pilze näher betrachtet werden konnte. 


\subsubsection{Auftreten blattpathogener Pilze in unterschiedlichen Landschaften}

In beiden Versuchsjahren wurden Befallshäufigkeit und -stärke von den sechs blattpathogenen Pilzen Septoria tritici, Septoria nodorum, Drechslera tritici-repentis, Blumeria graminis f. sp. tritici, Puccinia striiformis und Puccinia recondita durch visuelle Schätzung des prozentualen Blattbefalls bonitiert. Die Ergebnisse aus beiden Versuchsjahren werden im Folgenden getrennt aufgeführt. Wie bereits in Kapitel 2.3.1. erwähnt, konnte aufgrund der Fruchtfolge nicht in beiden Jahren die Probenahme aus identischen Feldern erfolgen. Sie wurden im zweiten Versuchsjahr so ausgewählt, dass es sich meist um das direkte Nachbarfeld des Vorjahresfeldes handelte. Durch diese Auswahl konnte gewährleistet werden, dass der Landschaftsparameter Ackeranteil gleich blieb.

\subsubsection{Ergebnisse des Jahres 2001}

Im Versuchsjahr 2002 wurden auf jedem Feld entlang eines diagonalen Transektes im Abstand weniger Meter 50 Blätter verschiedener Pflanzen zu je zwei Terminen (BBCH 47-51 und 65-69) gesammelt. Die Befallsstärke (befallene Blattfläche in Prozent) sowie die Befallshäufigkeit wurde für alle sechs Pilze ermittelt. Anhand dieser Bonituren konnte anschließend das Auftreten der Pilze innerhalb eines Feldes, Unterschiede zwischen Feldern und Unterschiede zwischen den Regionen Giessen und Göttingen ermittelt werden. Wie in Abb. 3 in Kapitel 2.3.1. bereits dargestellt, wies die Region Giessen komplexer strukturierte Landschaften mit geringerem Ackeranteil als die Landschaften der Region Göttingen auf. Die folgende Abbildung 8 zeigt Unterschiede in der Befallsstärke der untersuchten Pilze zwischen den beiden Regionen am zweiten Boniturtermin (BBCH 65-69). 


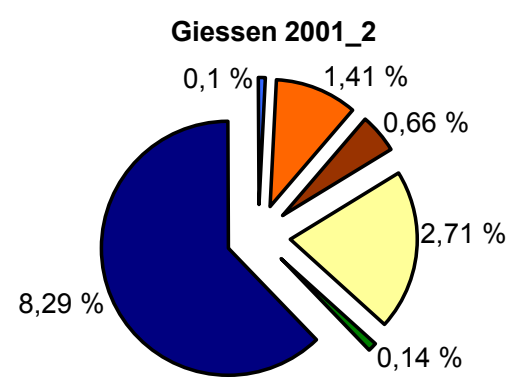

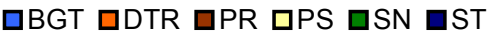

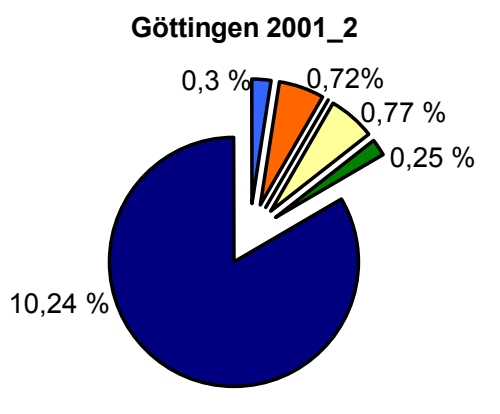

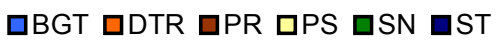

Abb. 8: Mittlere Befallsstärke (\% befallene Blattfläche des F-2 Blattes) verschiedener Pilze in den Regionen Giessen und Göttingen zum Wachstumsstadium BBCH 65-69 im Versuchsjahr 2001 Legende: BGT: Blumeria graminis f. sp. tritici; DTR: Drechslera tritici-repentis; PR: Puccinia recondita, PS: Puccinia striiformis; SN: Septoria nodorum; ST: Septoria tritici

In Abb. 8 wird deutlich, dass sowohl in der Region Göttingen, als auch in der Region Giessen S. tritici als Hauptschaderreger auftrat. Allerdings war dieser Pilz in der Region Göttingen dominanter, während die anderen fünf untersuchten blattpathogenen Pilze verstärkt in der Region Giessen auftraten. Neben der Befallsstärke wurde auch die Befallshäufigkeit der Pilze ermittelt. Abb. 9 zeigt die Befallshäufigkeit von S. tritici an beiden Boniturterminen 2001 auf den 19 Untersuchungsflächen der beiden Regionen.

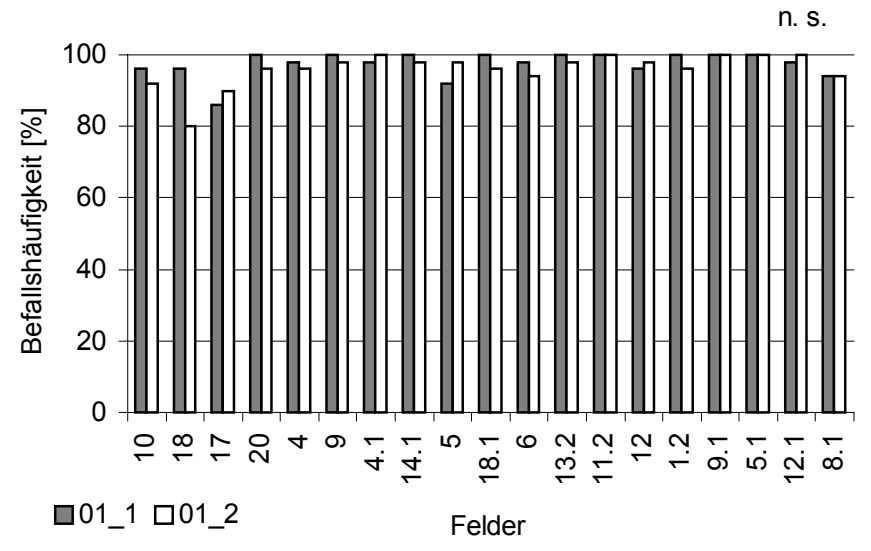

Abb. 9: Befallshäufigkeit [\%] von Septoria tritici auf den 19 Feldern der Regionen Göttingen und Giessen zu BBCH 47-51 und 65-69 im Jahr 2001

Legende: 01_1: 1. Boniturtermin (BBCH 47-51); 01_2: 2. Boniturtermin (BBCH 65-69); n. s.: nicht signifikant nach „Student Newman Keuls“ Test (SNK)

Die Befallshäufigkeit von Septoria tritici unterschied sich auf den 19 untersuchten Flächen kaum. Wie Abb. 9 zeigt, war die Befallshäufigkeit von S. tritici auf jedem Feld an beiden Boniturterminen auf einem gleichen Niveau von 80-100 \% zu klassifizieren. 
Diese hohen Befallshäufigkeiten auf allen Untersuchungsflächen belegen die Sonderstellung des Pilzes Septoria tritici. Im Folgenden werden die übrigen fünf untersuchten blattpathogenen Pilze daher immer differenziert von Septoria tritici betrachtet.

Die folgende Abb. 10 zeigt die mittlere Befallsstärke der untersuchten Pilze zu beiden Boniturterminen in den Regionen Giessen und Göttingen im Versuchsjahr 2001. Die Befallsstärke von Septoria tritici wird in Abb. 11 gesondert dargestellt. Am ersten Boniturtermin (BBCH 47-51) wurde die Befallsstärke des F-3 Blattes, am zweiten Boniturtermin die des F-2 Blattes ermittelt. Standardabweichungen wurden in diesem Diagramm nicht dargestellt, um eine bessere Anschaulichkeit der Unterschiede zu erreichen, für beide Boniturtermine lagen die Standardabweichungen zwischen 0 und 4,7 .

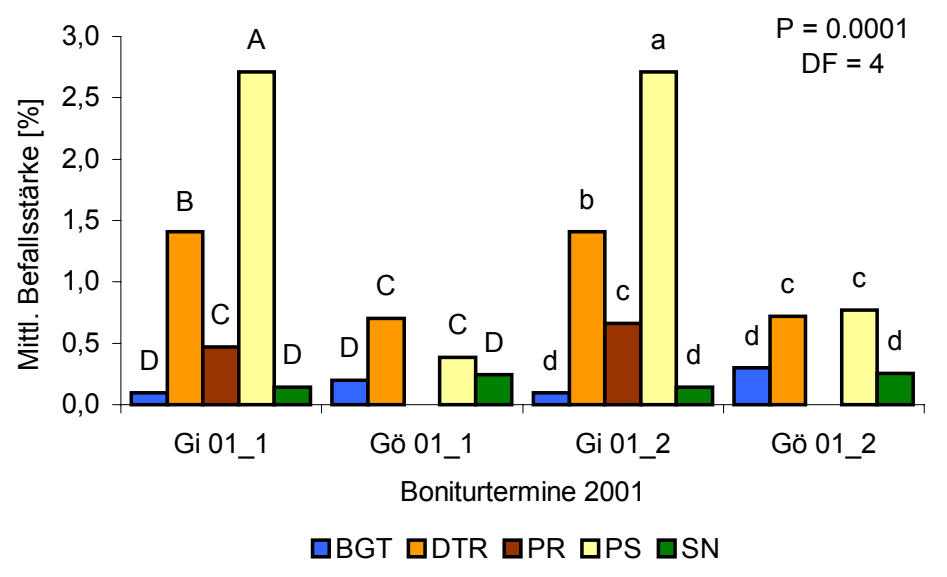

Abb. 10: Mittlere Befallsstärke (\% befallene Blattfläche des F-3 und F-2 Blattes) von Blumeria graminis f. sp. tritici (BGT), Drechslera tritici-repentis (DTR),:Puccinia recondita (PR), Puccinia striiformis (PS) und Septoria nodorum (SN) in den Regionen Giessen und Göttingen zu BBCH 47-51 und 65-69 im Jahr 2001

Legende: 01_1: 1. Boniturtermin (BBCH 47-51); 01_2: 2. Boniturtermin (BBCH 65-69) P: Irrtumswahrscheinlichkeit; DF: „Degrees of Freedom“, Freiheitsgrade; A-D: Signifikanzen des 1. Boniturtermins nach „Student Newman Keuls“ Test (SNK); a-d: Signifikanzen des 2. Boniturtermins nach SNK-Test

Vor allem Drechslera tritici-repentis (DTR) und Gelbrost (PS) waren in der Region Giessen signifikant stärker vertreten als in der Region Göttingen $(P=0,0001$, bei einer Signifikanzgrenze von $\mathrm{P} \leq 0,05)$. Braunrost $(\mathrm{PR})$ trat an beiden Boniturterminen in der Region Göttingen überhaupt nicht auf, und alle fünf Pilze zeigten eine signifikant geringere mittlere Befallsstärke auf den untersuchten Feldern in Göttingen im Vergleich 
zu den Giessener Feldern. Die mittleren Befallsstärken beider Boniturtermine jeweils einer Region unterschieden sich nicht signifikant voneinander, obwohl nicht dieselbe Blattetage entnommen wurde und zwischen den beiden Probenahmen in den meisten Fällen eine Fungizidmaßnahme stattfand. Die Befallsstärke von Septoria tritici war auf den meisten der untersuchten Felder deutlich höher als die der oben aufgeführten Pilze, daher wurde in der folgenden Abbildung eine andere Skalierung verwendet. Auch hier wurde zum ersten Boniturtermin das F-3 Blatt und zum zweiten Termin das F-2 Blatt bonitiert.

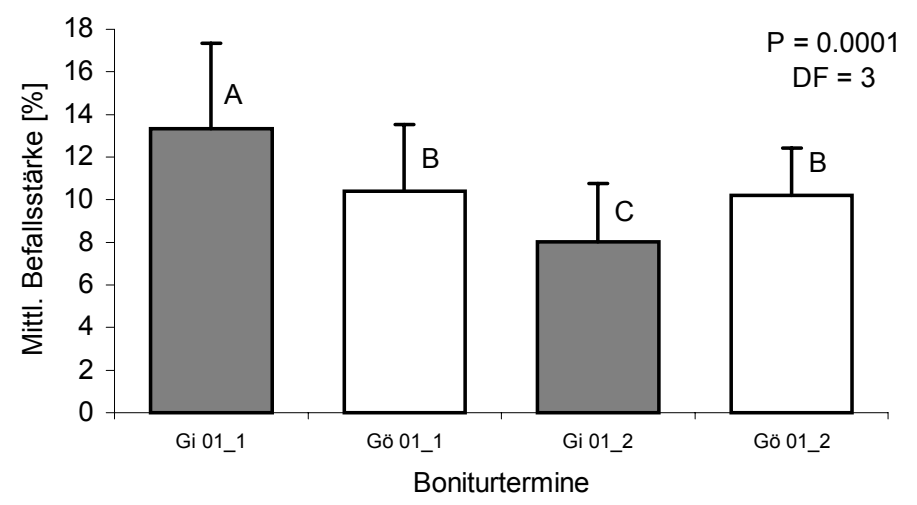

Abb. 11: Mittlere Befallsstärke (\% befallene Blattfläche des F-3 und F-2 Blattes) von Septoria tritici in den Regionen Giessen und Göttingen zu BBCH 47-51 und 65-69 im Jahr 2001 Legende: 01_1: 1. Boniturtermin (BBCH 47-51); 01_2: 2. Boniturtermin (BBCH 65-69); P: Irrtumswahrscheinlichkeit; DF: „Degrees of Freedom“, Freiheitsgrade; A, B, C: Signifikanzen nach „Student Newman Keuls“ Test (SNK)

Wie Abb. 11 zeigt, konnten hoch signifikante Unterschiede in der mittleren Befallsstärke von S. tritici in den beiden untersuchten Regionen festgestellt werden $(\mathrm{P}=0,0001)$. Am ersten Boniturtermin war die mittlere Befallsstärke in der Region Giessen (ca. $13 \%$ ) etwas höher als in der Region Göttingen (ca. 10 \%), während ein umgekehrter Effekt am zweiten Probenahmetermin zu verzeichnen war (Giessen ca. $8 \%$, Göttingen ca. $10 \%$ ). Die Befallsstärke blieb in der Region Göttingen während der Vegetationsperiode relativ gleich.

Wie bereits erwähnt, wurden in dieser Arbeit nicht nur Regionsunterschiede in der Befallsstärke der sechs blattpathogenen Pilze, sondern auch Unterschiede zwischen Feldern einzelner Landschaften untersucht. Abb. 12 zeigt die mittlere Befallsstärke zum BBCH-Stadium 65-69 der sechs untersuchten Pilze auf dem Feld 10 in der Region 
Giessen. Dieses Feld befand sich in einer komplex strukturierten Landschaft, die durch einen sehr geringen Ackeranteil charakterisiert war.

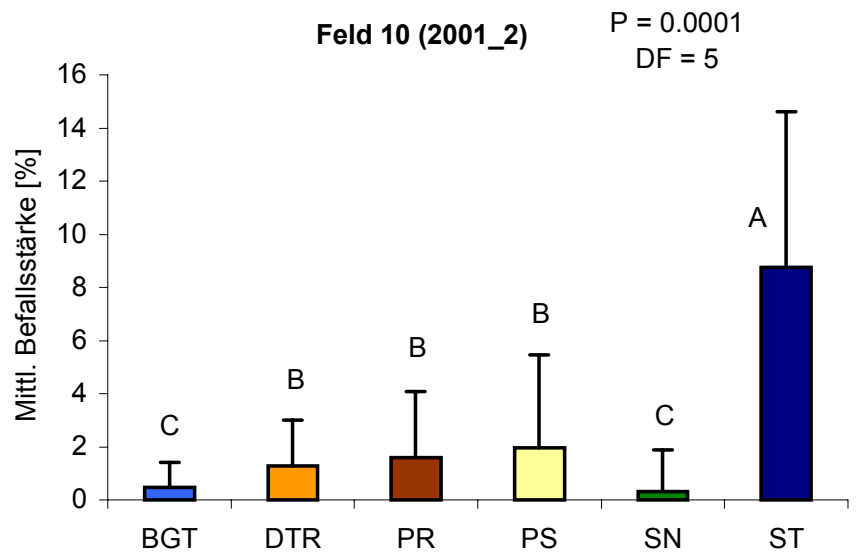

Abb. 12: Mittlere Befallsstärke (\% befallene Blattfläche F-2 Blattes) von Blumeria graminis f. sp. tritici (BGT), Drechslera tritici-repentis (DTR),:Puccinia recondita (PR), Puccinia striiformis (PS) Septoria nodorum (SN) und Septoria tritici (ST) auf dem Feld 4 der Region Giessen zu BBCH 65-69 im Jahr 2001

Legende: P: Irrtumswahrscheinlichkeit; DF: „Degrees of Freedom“, Freiheitsgrade; A, B, C: Signifikanzen nach „Student Newman Keuls“ Test (SNK)

Septoria tritici konnte auf diesem Feld, ähnlich der übrigen Felder, als Hauptpathogen mit einer signifikant höheren Befallsstärke als die übrigen Pilze $(\mathrm{P}=0,0001)$ identifiziert werden. Alle weiteren untersuchten Pathogene, wie Septoria nodorum, Drechslera tritici-repentis, Blumeria graminis f. sp. tritici, Puccinia recondita und Puccinia striiformis konnten zwar ebenfalls nachgewiesen werden, allerdings mit einer geringen Befallsstärke. Im Vergleich dazu zeigt die folgende Abbildung die mittlere Befallsstärke der Pilze auf dem Feld 12.1 der Region Göttingen zum gleichen BBCHStadium. 


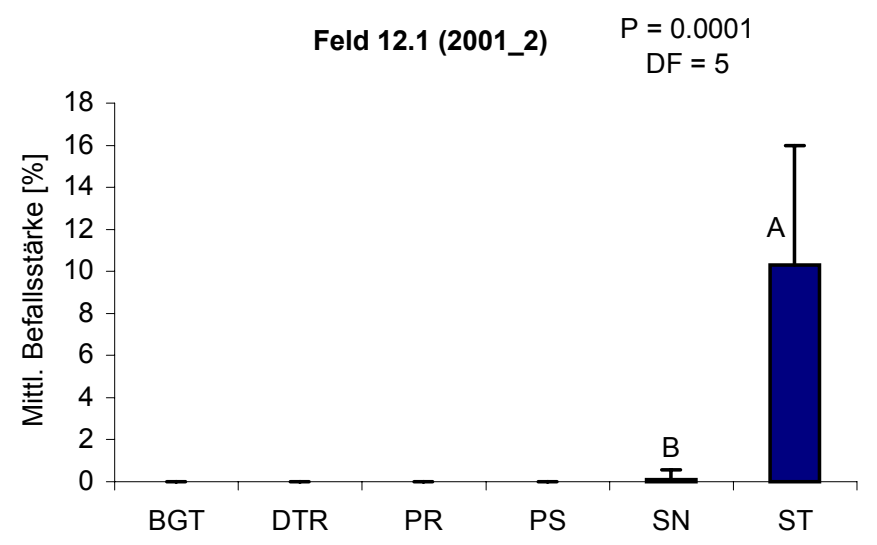

Abb. 13: Mittlere Befallsstärke (\% befallene Blattfläche F-2 Blattes) von Blumeria graminis f. sp. tritici (BGT), Drechslera tritici-repentis (DTR),:Puccinia recondita (PR), Puccinia striiformis (PS) Septoria nodorum (SN) und Septoria tritici (ST) auf dem Feld 12.1 der Region Göttingen zu BBCH 65-69 im Jahr 2001

Legende: P: Irrtumswahrscheinlichkeit; DF: „Degrees of Freedom“, Freiheitsgrade; A, B: Signifikanzen nach SNK-Test

Dieses Feld wurde durch eine sehr wenig strukturierte Landschaft mit einem hohen Ackeranteil charakterisiert. Hier war nur $S$. tritici mit einer signifikant höheren Befallsstärke vertreten $(\mathrm{P}=0,0001)$. Die anderen Pilze traten überhaupt nicht bzw. $S$. nodorum nur mit einer äußerst geringen Befallsstärke auf.

Der Parameters Ackeranteil stellte im Rahmen dieser Arbeit den hauptsächlichen Indikator für Landschaftsdiversität dar. Aus diesem Grund wurden die ermittelten mittleren Befallsstärken und die Befallshäufigkeiten der einzelnen Pilze auf den 19 Feldern der Regionen Giessen und Göttingen in Abhängigkeit vom Ackeranteil der die Felder umgebenden Landschaften in einer linearen Regressionsanalyse ausgewertet. Als Resultat ergaben sich hoch signifikante Unterschiede zwischen den 19 Feldern in der Befallsstärke mit $S$. tritici $(\mathrm{P}=0,0001)$, eine Abhängigkeit zum Ackeranteil zeigte sich allerdings nicht. 


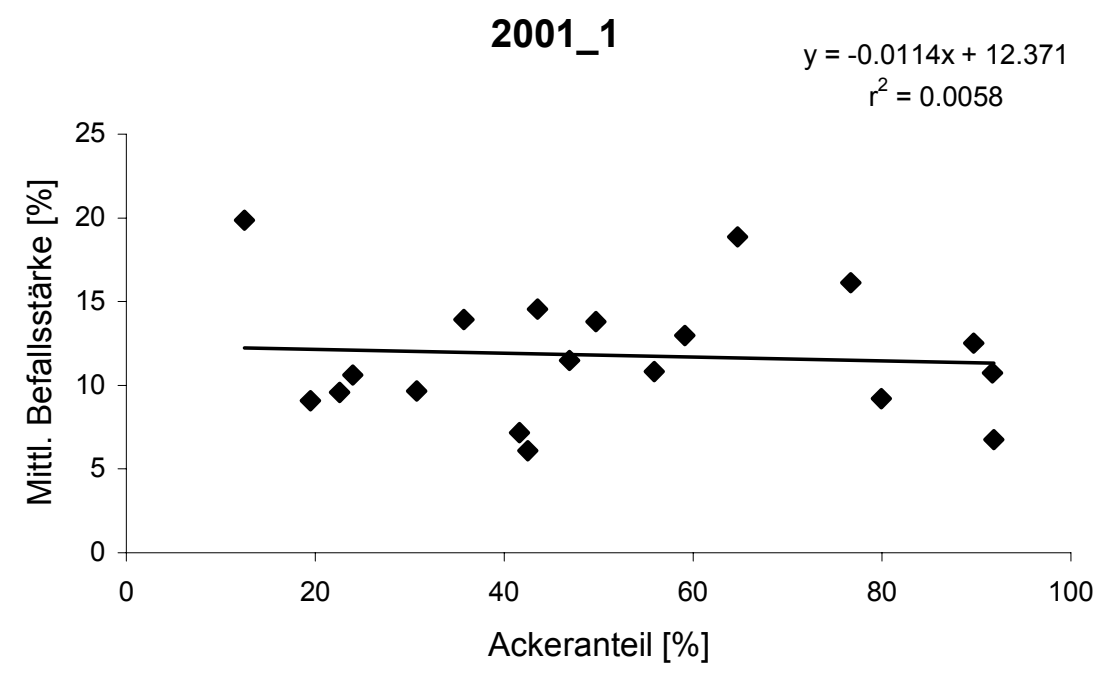

Abb. 14: Mittlere Befallsstärke (\% befallene Blattfläche F-3 Blattes) von Septoria tritici im Verhältnis zum prozentualen Ackeranteil der Landschaften der Regionen Göttingen und Giessen zu BBCH 47-51 im Jahr 2001

Legende: $\mathrm{y}$ : Regressionsgleichung; $\mathrm{r}^{2}$ : Bestimmtheitsmaß

Wie Abb. $14 \mathrm{zu}$ entnehmen ist, blieb die mittlere Befallsstärke der Felder mit steigendem Ackeranteil relativ konstant. Auch am zweiten Boniturtermin (BBCH 6569) konnte keine bzw. nur eine geringe Abhängigkeit der Befallsstärke von S. tritici vom Landschaftsparameter Ackeranteil festgestellt werden.

\section{1_2}

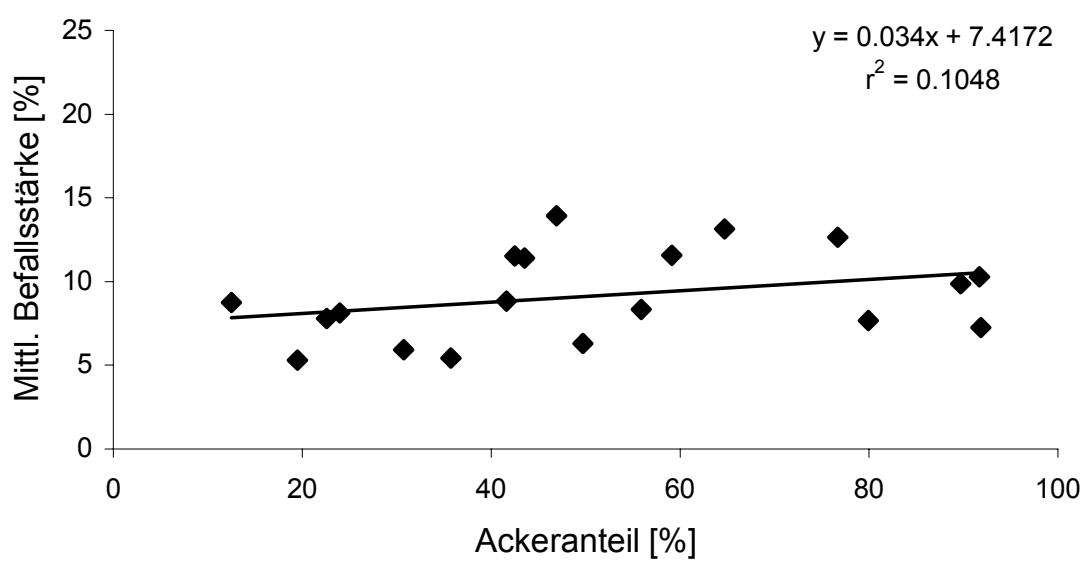

Abb. 15: Mittlere Befallsstärke (\% befallene Blattfläche F-2 Blattes) von Septoria tritici im Verhältnis zum prozentualen Ackeranteil der Landschaften der Regionen Göttingen und Giessen zu BBCH 65-69 im Jahr 2001

Legende: y: Regressionsgleichung; $r^{2}$ : Bestimmtheitsmaß 
Die mittlere Befallsstärke war am zweiten Boniturtermin auf allen Untersuchungsflächen geringer als am ersten Termin, nahm jedoch mit steigendem Ackeranteil leicht zu (Abb. 15).

Wie die beschriebenen Ergebnisse für das Hauptpathogen S. tritici zeigen, ist weder bei der mittleren Befallsstärke, noch der Befallshäufigkeit der einzelnen Felder eine Abhängigkeit zum Landschaftsparameter Ackeranteil zu verzeichnen. Betrachtet man die Befallsstärken des Pilzes auf den einzelnen Feldern im Box Plot (Abb. 16 und 17), lässt sich vor allem zum zweiten Boniturtermin eine höhere Befallsstärke auf Feldern erkennen, die in weniger komplexen Landschaften liegen. Im Box Plot werden fünf verschiedene Datenpunkte pro Feld dargestellt. Der Median gibt die Befallsstärke des Pilzes an, bei der $50 \%$ der untersuchten Blätter oberhalb und $50 \%$ unterhalb dieses Wertes liegen. Das untere Quartil gibt den Wert an, bei dem $25 \%$ der bonitierten Blätter unterhalb und $75 \%$ oberhalb dieses Wertes liegen. Beim oberen Quartil verhält es sich umgekehrt, $25 \%$ der untersuchten Blätter liegen oberhalb und $75 \%$ unterhalb dieses Wertes. Außerdem werden sowohl der Maximal-, als auch der Minimalwert der Befallsstärken je Feld angegeben. Anhand dieser Darstellung wird in den folgenden Abbildungen zum einen die große Streubreite der Befallsstärken von S. tritici auf den einzelnen Feldern deutlich, andererseits zeigt sich, dass die Niveaus der Befallsstärken der Felder erhebliche Unterschiede aufweisen.

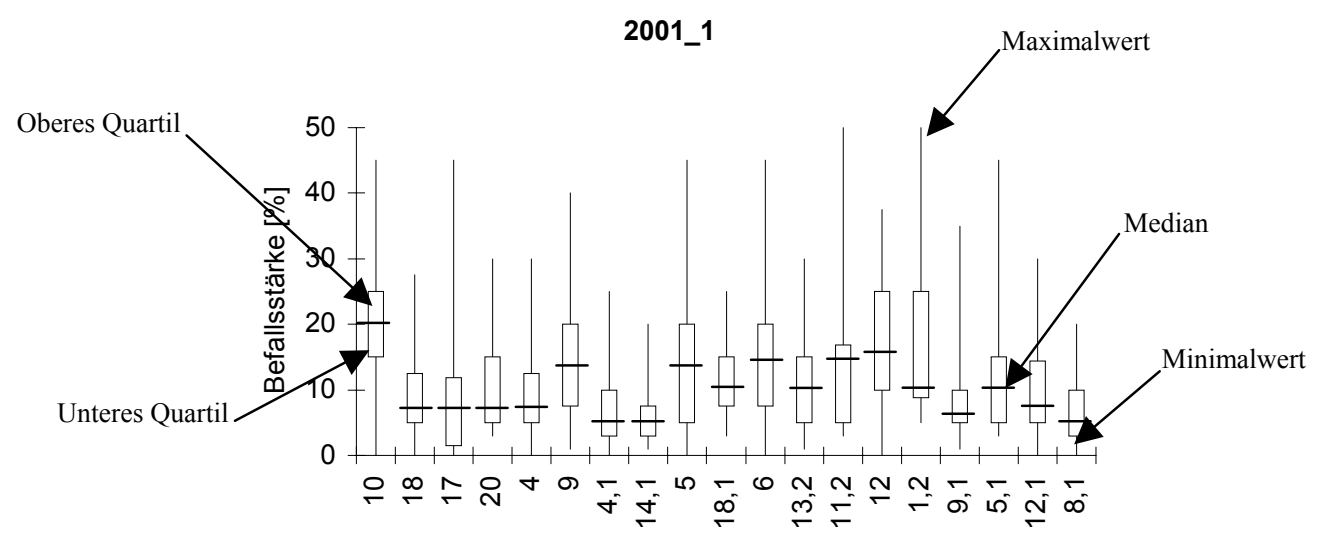

Abb. 16: Darstellung der Befallsstärke in \% befallener Blattfläche von Septoria tritici auf den 19 untersuchten Feldern der Regionen Göttingen und Giessen zu BBCH 47-51 im Jahr 2001 Legende: Aufgetragen sind Median, unteres und oberes Quartil, sowie Maximal und Minimalwert; Anordnung der Felder von links nach rechts: geringer bis hoher Ackeranteil 


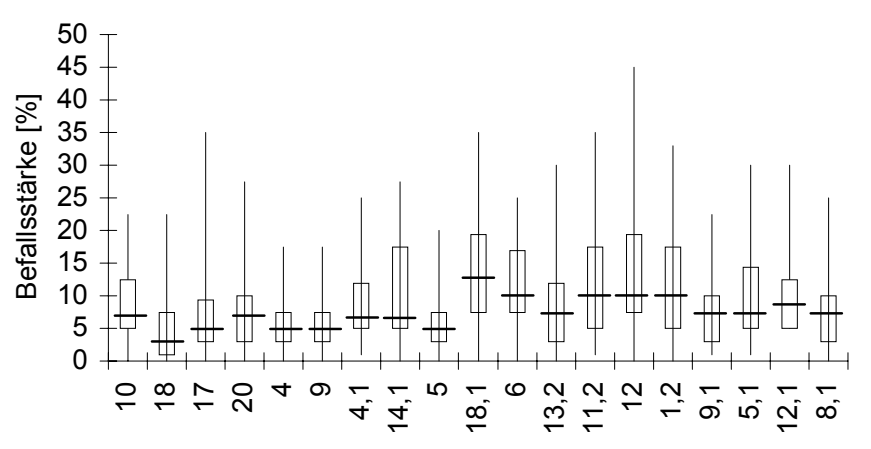

Abb. 17: Darstellung der Befallsstärke in \% befallener Blattfläche von Septoria tritici auf den 19 untersuchten Feldern der Regionen Göttingen und Giessen zu BBCH 65-69 im Jahr 2001 Legende: Aufgetragen sind Median, unteres und oberes Quartil, sowie Maximal und Minimalwert; Anordnung der Felder von links nach rechts: geringer bis hoher Ackeranteil

Den beiden Abbildungen ist $\mathrm{zu}$ entnehmen, dass die Befallsstärkeniveaus des ersten Boniturtermins deutlich höher lagen, als die des zweiten Termins, während die Differenzen zwischen den Medianwerten der Befallsstärken des zweiten Termins geringer waren als die des ersten. Das Niveau der mittleren Befallsstärken von S. tritici war auf Feldern wenig strukturierter Landschaften mit einem hohen Ackeranteil höher, als auf Feldern komplex strukturierter Landschaften (Abb. 17).

Die Befallsstärken und -häufigkeiten der ebenfalls untersuchten fünf blattpathogenen Pilzen, Septoria nodorum, Blumeria graminis f. sp. tritici, Drechslera tritici-repentis, Puccinia striiformis und Puccinia recondita auf den 19 Feldern verhielten sich gegenüber dem Parameter Ackeranteil indifferent. Die Befallsstärken und -häufigkeiten der beiden Roste und DTR zeigten eine negative Abhängigkeit vom Parameter Ackeranteil. Der Echte Weizenmehltau wies an beiden Terminen keine Abhängigkeit zum Ackeranteil auf, nur Septoria nodorum zeigte, wie Septoria tritici, eine schwache Abhängigkeit der Befallsstärke vom Parameter Ackeranteil (Abb. 18). 


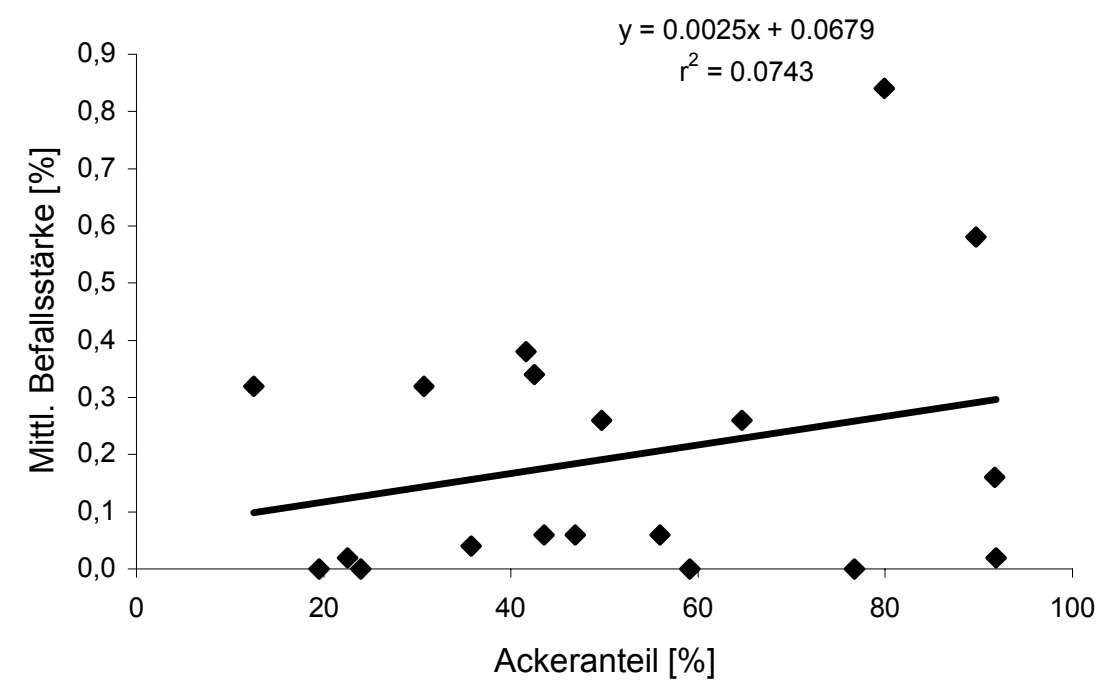

Abb. 18: Mittlere Befallsstärke (\% befallene Blattfläche des F-3 Blattes) von Septoria nodorum im Verhältnis zum prozentualen Ackeranteil der Landschaften der Regionen Göttingen und Giessen zu BBCH 47-51 im Jahr 2001

Legende: $\mathrm{y}$ : Regressionsgleichung; $\mathrm{r}^{2}$ : Bestimmtheitsmaß

Wie der Abbildung zu entnehmen ist, stieg die mittlere Befallsstärke von $S$. nodorum auf den einzelnen Feldern mit steigendem Ackeranteil. In komplex strukturierten Landschaften war die Befallsstärke von Septoria nodorum also geringer als in monotonen Landschaften. Der Echte Weizenmehltau (Blumeria graminis f. sp. tritici) wies an beiden Terminen keine Abhängigkeit vom Landschaftsparameter Ackeranteil auf. Braunrost (Puccinia recondita), Gelbrost (Puccinia striiformis) und DTR (Drechslera tritici-repentis) zeigten eine leicht negative Abhängigkeit vom Ackeranteil. Aufgrund der schwachen Regressionen sind die Ergebnisse an dieser Stelle nicht aufgeführt (s. Anhang, Abb. A1-A5).

\subsubsection{Ergebnisse des Jahres 2002}

Wie bereits in Kapitel 2.3.3.2. beschrieben, unterschied sich das Design der Probenahme im zweiten Versuchsjahr vom Design des ersten Jahres. Es wurden auf allen 19 Feldern in den Regionen Giessen und Göttingen fungizidfreie Spritzfenster eingerichtet, in denen in zwei diagonalen Transekten an acht Entnahmestellen, im Folgenden „Plot“ genannt, jeweils acht Blätter verschiedener Pflanzen an zwei 
Terminen (BBCH 39-42 und 65) entnommen wurden. Zusätzlich wurden auf den 10 Göttinger Feldern im behandelten Teil in gleicher Weise Blattproben gezogen. Wie im Vorjahr wurde die Befallsstärke (befallene Blattfläche in Prozent) und die Befallshäufigkeit für alle sechs Pilze ermittelt, so dass anschließend das Auftreten der Pilze innerhalb eines Feldes, Unterschiede zwischen Feldern und Unterschiede zwischen den Regionen Giessen und Göttingen dargestellt und verglichen werden konnte. In der folgenden Abbildung sind Unterschiede in der Befallsstärke der untersuchten Pilze innerhalb der beiden Regionen am zweiten Boniturtermin (BBCH 65) dargestellt (Abb. 19).

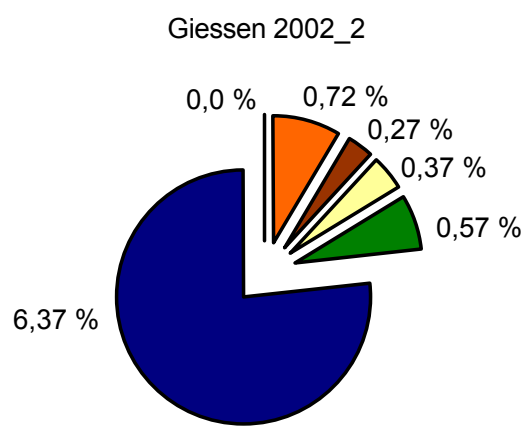

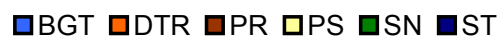

Göttingen 2002_2

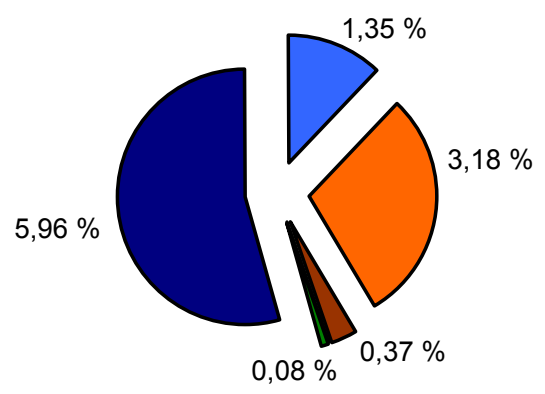

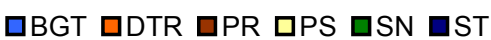

Abb. 19: Anteil der Pilze (mittlere Befallsstärke [\%] des F-1 Blattes) in den Regionen Giessen und Göttingen zum Wachtumstadium BBCH 65 (2002)

Legende: BGT: Blumeria graminis f. sp. tritici; DTR: Drechslera tritici-repentis; PR: Puccinia recondita, PS: Puccinia striiformis; SN: Septoria nodorum; ST: Septoria tritici

Für diesen Vergleich wurden nur die Daten aus den unbehandelten Spritzfenstern verrechnet. Auch im Jahr 2002 trat S. tritici sowohl in der Region Göttingen, als auch in der Region Giessen als Hauptschaderreger auf. Allerdings war der Pilz abweichend zum Vorjahr in der Region Giessen (6,37\%) etwas dominanter vertreten, als in der Region Göttingen (5,96\%). Gelbrost (PS) trat in diesem Versuchsjahr nur in der Region Giessen auf, Echter Weizenmehltau (BGT) hingegen fast ausschließlich in der Region Göttingen. An dieser Stelle bestätigt sich erneut der Eindruck, dass das Spektrum blattpathogener Pilze in der Region Giessen größer, der Befallsdruck aber geringer als in der Region Göttingen war. Auf den untersuchten Göttinger Feldern wurde der Befallsdruck im Winterweizen hauptsächlich durch die drei Pathogene S. tritici, Echter Weizenmehltau und DTR hervorgerufen. 
Auch im Versuchsjahr 2002 wurde nicht nur die Befallsstärke, sondern auch die Befallshäufigkeit der Pilze ermittelt. Die folgende Abbildung zeigt die Befallshäufigkeit von S. tritici an beiden Boniturterminen 2002 auf den 19 Untersuchungsflächen der beiden Regionen.

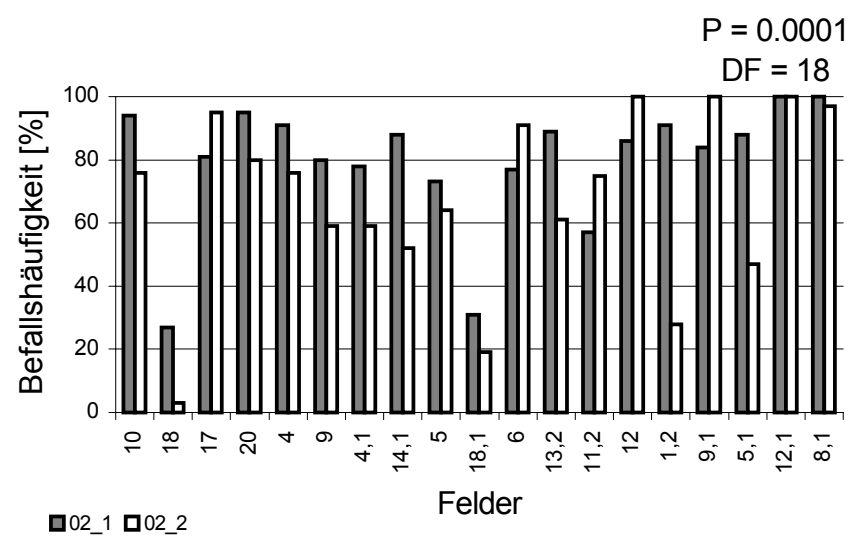

Abb. 20: Befallshäufigkeit [\%] von Septoria tritici auf den 19 Feldern der Regionen Göttingen und Giessen zu BBCH 39-42 und 65 im Jahr 2002

Legende: 01_1: 1. Boniturtermin (BBCH 39-42); 01 2: 2. Boniturtermin (BBCH 65); P: Irrtumswahrscheinlichkeit; DF: „Degrees of Freedom“, Freiheitsgrade

In diesem Diagramm (Abb. 20) sind die 19 Felder von links nach rechts mit steigendem Ackeranteil sortiert dargestellt. Die Befallshäufigkeit von Septoria tritici auf den verschiedenen Feldern unterschied sich im Gegensatz zum Versuchsjahr 2001 hoch signifikant $(\mathrm{P}=0.0001)$. Während die Befallshäufigkeit im Jahr 2001 auf allen Flächen an beiden Boniturterminen etwa gleich hoch war, unterschieden sich im Jahr 2002 sowohl die Felder, als auch die Termine signifikant voneinander. Generell lässt sich feststellen, dass im Versuchsjahr 2002 die Befallshäufigkeit von S. tritici, wie bereits im Vorjahr, sehr hoch war (im Mittel über 60\%). Eine Abhängigkeit der Befallshäufigkeit vom Landschaftsparameter Ackeranteil ließ sich nur als leichte Tendenz, besonders am zweiten Boniturtermin, feststellen. Der drastische Rückgang der Befallshäufigkeit am zweiten Boniturtermin auf den Göttinger Flächen 1.2 und 5.1 ließ auf den Einsatz von Fungiziden auch im fungizidfreien Spritzfenster schließen.

In Abb. 21 ist die mittlere Befallsstärke (im unbehandelten Spritzfenster) der untersuchten Pilze zu beiden Boniturterminen in den Regionen Giessen und Göttingen 
im Versuchsjahr 2002 dargestellt. Die Befallsstärke von Septoria tritici wird in Abb. 22 gesondert dargestellt.

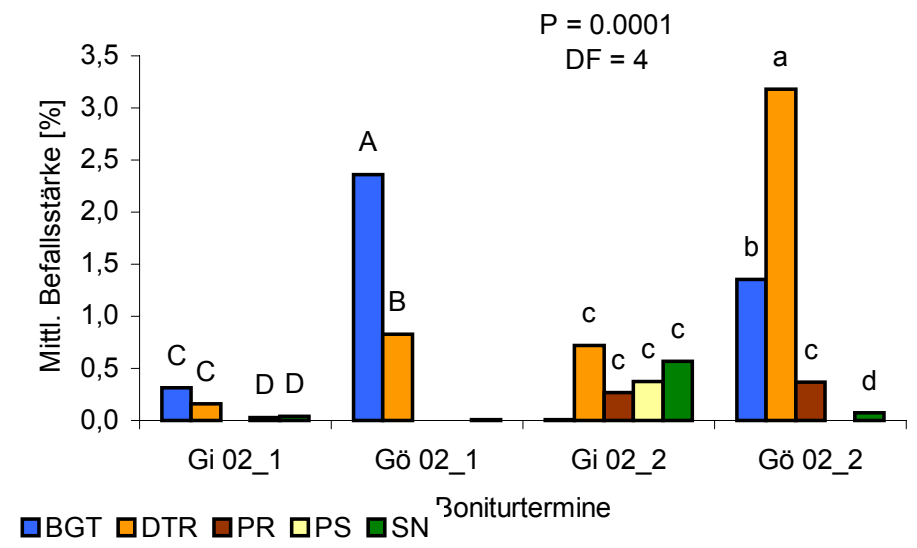

Abb. 21: Mittlere Befallsstärke (\% befallene Blattfläche des F-2 und F-1 Blattes) von Blumeria graminis f. sp. tritici (BGT), Drechslera tritici-repentis (DTR), Puccinia recondita (PR), Puccinia striiformis (PS) und Septoria nodorum (SN) in den Regionen Giessen und Göttingen zu BBCH 39-42 und 65 im Jahr 2002

Legende: 01_1: 1. Boniturtermin (BBCH 39-42); 01_2: 2. Boniturtermin (BBCH 65) P: Irrtumswahrscheinlichkeit; DF: „Degrees of Freedom“, Freiheitsgrade; A-D: Signifikanzen des 1. Boniturtermins nach „Student Newman Keuls“ Test (SNK); a-e: Signifikanzen des 2. Boniturtermins nach SNK-Test

Am ersten Boniturtermin (BBCH 39-42) wurde die Befallsstärke des F-2 Blattes, am zweiten Boniturtermin die des F-1 Blattes ermittelt. Standardabweichungen wurden in diesem Diagramm nicht mit dargestellt, um eine bessere Anschaulichkeit der Unterschiede zu erreichen. Für beide Boniturtermine lagen die Standardabweichungen, wie im Vorjahr, zwischen 0 und 4,7. Vor allem Drechslera tritici-repentis (DTR) und Echter Weizenmehltau (BGT) waren in der Region Göttingen in diesem Versuchsjahr signifikant stärker vertreten als in der Region Giessen $(\mathrm{P}=0,0001)$. Gelbrost (PS) trat an beiden Boniturterminen in der Region Göttingen überhaupt nicht auf. Obwohl am zweiten Boniturtermin eine höhere Blattetage entnommen wurde, stieg die mittlere Befallsstärke der Pathogene zum zweiten Termin an, während sie im ersten Versuchsjahr konstant blieb (s. Abb. 10). Die Befallsstärke von Septoria tritici war auf den meisten der untersuchten Felder deutlich höher als die der oben aufgeführten Pilze, daher wurde im folgenden Diagramm eine andere Skalierung verwendet, auch hier wurde zum ersten Boniturtermin das F-2 Blatt und zum zweiten Termin das F-1 Blatt bonitiert. 


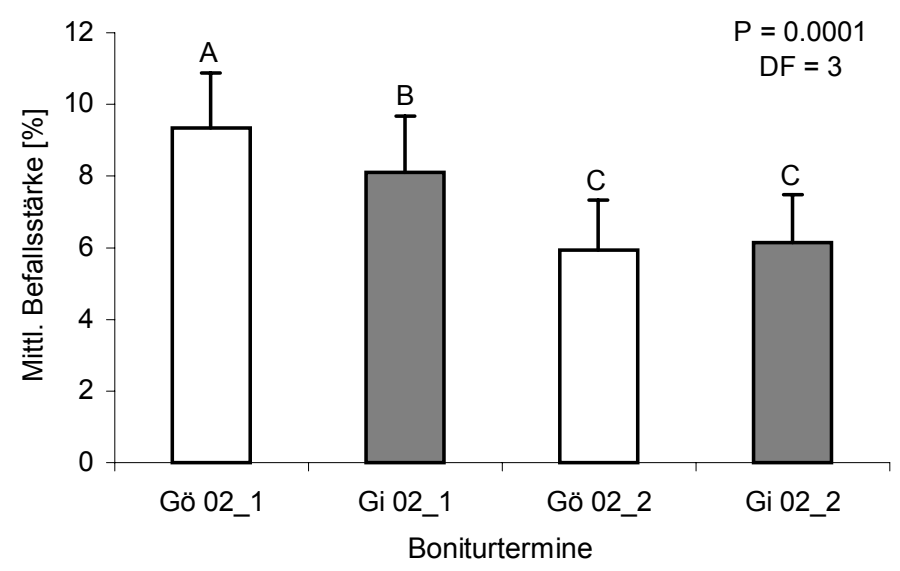

Abb. 22: Mittlere Befallsstärke (\% befallene Blattfläche des F-2 und F-1 Blattes) von Septoria tritici in den Regionen Giessen und Göttingen zu BBCH 39-42 und 65 im Jahr 2002

Legende: 01 1: 1. Boniturtermin (BBCH 39-42); 01 2: 2. Boniturtermin (BBCH 65); P: Irrtumswahrscheinlichkeit; DF: „Degrees of Freedom“, Freiheitsgrade; A-C: Signifikanzen nach „Student Newman Keuls“ Test (SNK)

Die mittlere Befallsstärke von Septoria tritici in der Region Göttingen war am ersten Boniturtermin noch signifikant höher als in der Region Giessen, während die mittlere Befallsstärke am zweiten Boniturtermin keinen signifikanten Unterschied mehr aufwies. In beiden Regionen war die Befallsstärke am zweiten Boniturtermin geringer als am ersten (Abb. 22).

Wie im Vorjahr wurden nicht nur Regionsunterschiede in der Befallsstärke der sechs blattpathogenen Pilze, sondern auch Abweichungen zwischen Feldern einzelner Landschaften untersucht. Abb. 23 zeigt die mittlere Befallsstärke am BBCH-Stadium 65 der sechs untersuchten Pilze auf dem Feld 9 in der Region Giessen. Dieses Feld befand sich in einer komplex strukturierten Landschaft, die durch einen geringen Ackeranteil charakterisiert wurde. 


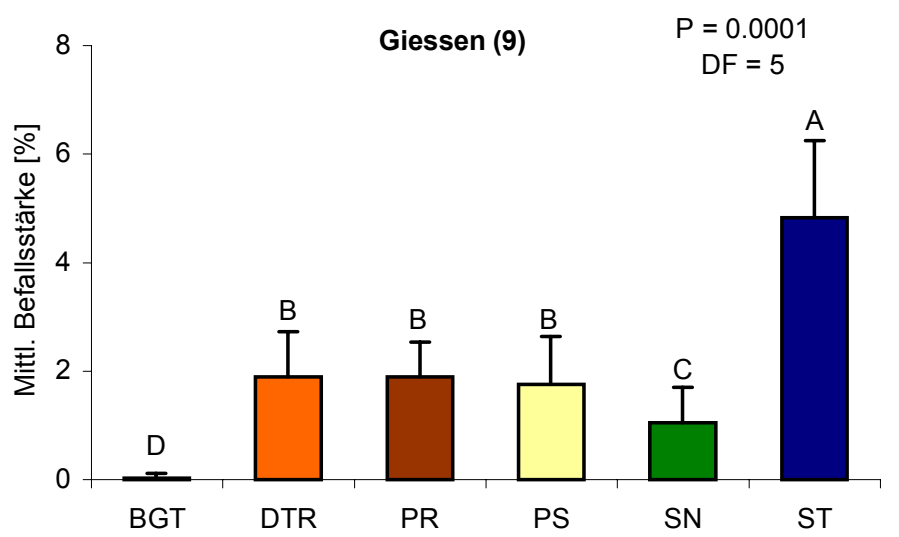

Abb. 23: Mittlere Befallsstärke (\% befallene Blattfläche des F-1 Blattes) von Blumeria graminis f. sp. tritici (BGT), Drechslera tritici-repentis (DTR), Puccinia recondita (PR), Puccinia striiformis (PS) Septoria nodorum (SN) und Septoria tritici (ST) auf dem Feld 4 der Region Giessen zu BBCH 65 im Jahr 2002

Legende: P: Irrtumswahrscheinlichkeit; DF: „Degrees of Freedom“, Freiheitsgrade; A-D: Signifikanzen nach „Student Newman Keuls“ Test (SNK)

Septoria tritici war auf diesem Feld erneut das Hauptpathogen mit einer signifikant höheren Befallsstärke als die übrigen Pilze $(P=0,0001)$. Alle weiteren untersuchten Pathogene konnten zwar ebenfalls nachgewiesen werden, allerdings mit einer geringen Befallsstärke. Im Vergleich dazu zeigt die folgende Abbildung die mittlere Befallsstärke der Pilze auf dem Feld 12.1 der Region Göttingen zum gleichen BBCH-Stadium.
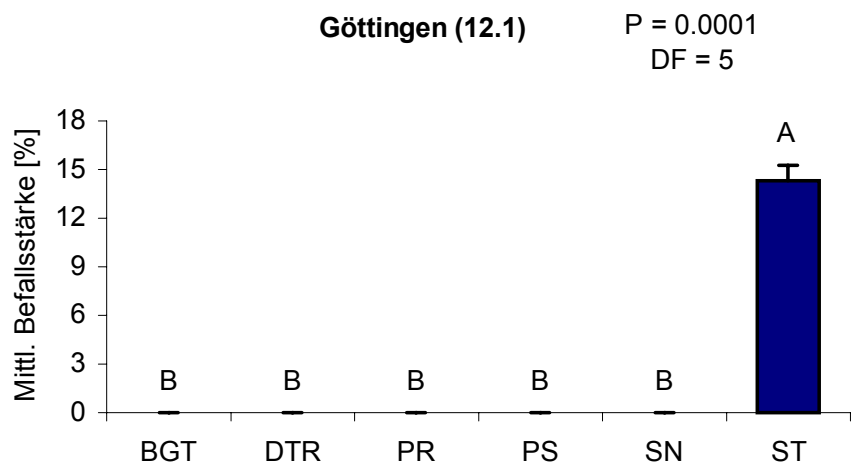

Abb. 24: Mittlere Befallsstärke (\% befallene Blattfläche des F-1 Blattes) von Blumeria graminis f. sp. tritici (BGT), Drechslera tritici-repentis (DTR), Puccinia recondita (PR), Puccinia striiformis (PS) Septoria nodorum (SN) und Septoria tritici (ST) auf dem Feld 4 der Region Giessen zu BBCH 65 im Jahr 2002

Legende: P: Irrtumswahrscheinlichkeit; DF: „Degrees of Freedom“, Freiheitsgrade; A, B: Signifikanzen nach „Student Newman Keuls“ Test (SNK) 
Dieses Feld wurde durch eine sehr wenig strukturierte Landschaft mit einem hohen Ackeranteil charakterisiert, hier war ausschließlich $S$. tritici mit einer signifikant höheren Befallsstärke vertreten $(\mathrm{P}=0,0001)$. Die anderen Pilze ließen sich auf diesem Feld überhaupt nicht nachweisen.

Die nächsten beiden Abbildungen zeigen die Abhängigkeit (lineare Regression) der Befallsstärke von $S$. tritici auf den untersuchten Flächen vom Ackeranteil an den beiden Boniturterminen (BBCH 39-42 und 65). Wie bereits erwähnt, wurden auch im Jahr $2002 \mathrm{zu}$ den Probenahmen unterschiedliche Blattetagen entnommen (am ersten Termin F-2 und F-1 am zweiten Termin). Erneut unterschieden sich die mittleren Befallsstärken der 19 Felder an beiden Terminen signifikant voneinander $(\mathrm{P}=0,0001)$. Abweichend zum Vorjahr zeigte sich eine eindeutigere Abhängigkeit der Befallsstärke vom Parameter Ackeranteil.

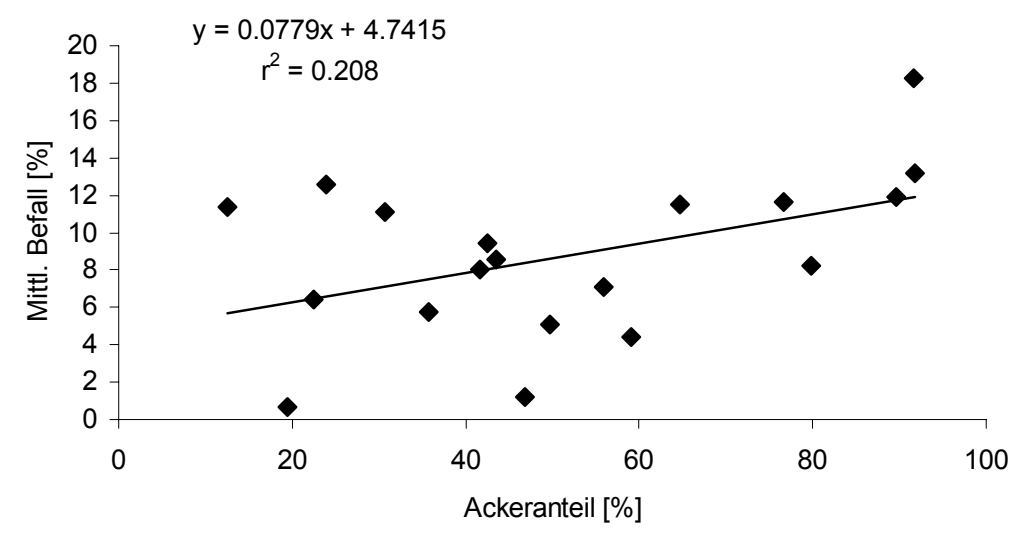

Abb. 25: Mittlere Befallsstärke (\% befallene Blattfläche des F-2 Blattes) von Septoria tritici im Verhältnis zum prozentualen Ackeranteil der Landschaften der Regionen Göttingen und Giessen zu BBCH 39-42 im Jahr 2002

Legende: $\mathrm{y}$ : Regressionsgleichung; $\mathrm{r}^{2}$ : Bestimmtheitsmaß 


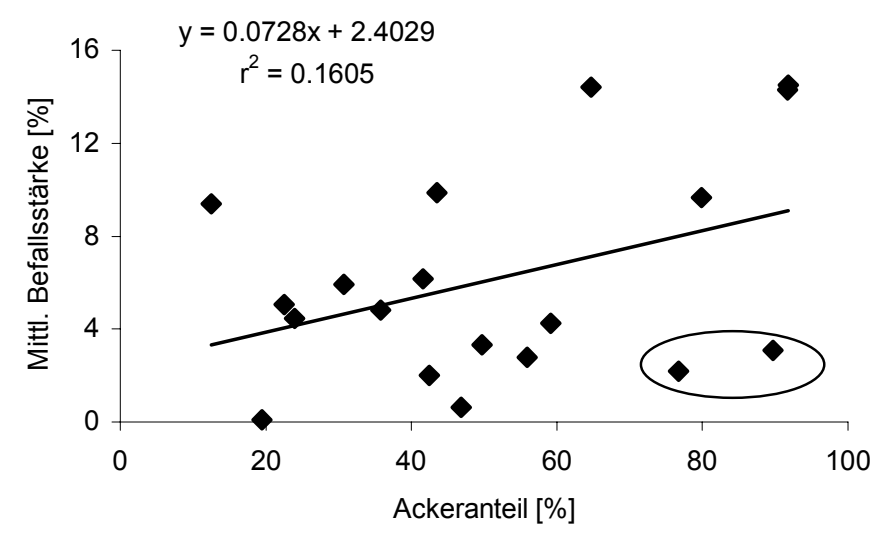

Abb. 26: Mittlere Befallsstärke ( $\%$ befallene Blattfläche des F-1 Blattes) von Septoria tritici im Verhältnis zum prozentualen Ackeranteil der Landschaften der Regionen Göttingen und Giessen zu BBCH 65 im Jahr 2002

Legende: y: Regressionsgleichung; $\mathrm{r}^{2}$ : Bestimmtheitsmaß; Punkte im Kreis: Werte von Feld 5.1 und 1.2

Abb. 25 und 26 ist zu entnehmen, dass die Befallsstärke des Pilzes mit steigendem Ackeranteil zu beiden Terminen leicht zunahm. Außerdem wird in Abb. 26 deutlich, dass die Befallsstärke der Göttinger Felder 5.1 und 1.2 (Punkte im Kreis) am zweiten Termin (BBCH 65) deutlich geringer war, als am ersten. Wie bereits erwähnt, war eine Fungizidmaßnahme im Spritzfenster daher als Ursache anzunehmen (s. Abb. 20).

Die Ergebnisse der Befallsstärken aus dem behandelten Teil der zehn Göttinger Felder, die im Versuchsjahr 2002 zusätzlich bonitiert wurde, wiesen ebenfalls eine leichte Abhängigkeit vom Parameter Ackeranteil auf. Auch hier unterschieden sich die mittleren Befallsstärken der zehn Göttinger Felder an beiden Terminen signifikant voneinander $(\mathrm{P}=0,0001)$. Am ersten Termin wurde das F-3 Blatt und am zweiten Termin das F-2 Blatt entnommen, in der folgenden Abbildung ist das Ergebnis der zweiten Probenahme zusammenfassend dargestellt. Die Werte für die Felder 5.1 und 1.2 sind entsprechend markiert. 


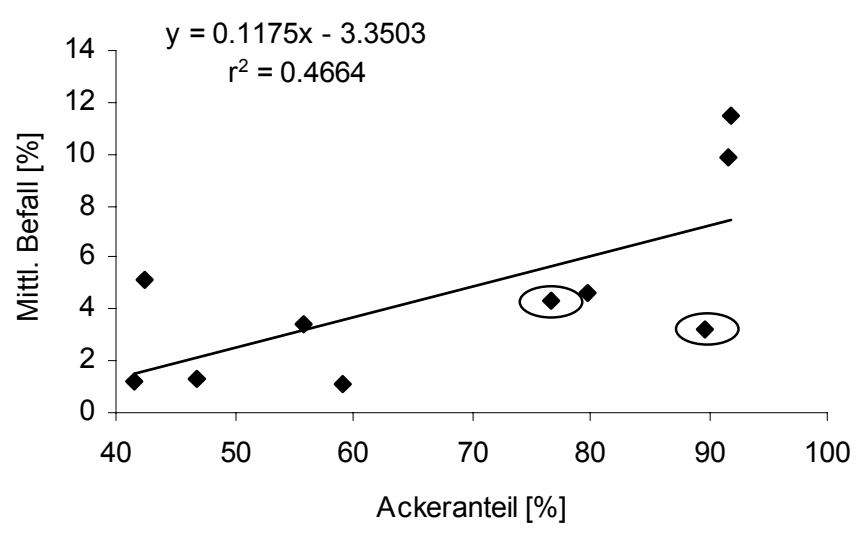

Abb. 27: Mittlere Befallsstärke ( $\%$ befallene Blattfläche des F-1 Blattes) von Septoria tritici im fungizidbehandelten Teil der Felder im Verhältnis zum prozentualen Ackeranteil der Landschaften der Regionen Göttingen und Giessen zu BBCH 65 im Jahr 2002

Legende: y: Regressionsgleichung; $\mathrm{r}^{2}$ : Bestimmtheitsmaß; Punkte im Kreis: Werte von Feld ,5.1 und 1.2

Anhand des Diagramms lässt sich in erwarteter Weise erkennen, dass die mittlere Befallsstärke, obwohl eine niedrigere Blattetage entnommen wurde (F-2 statt F-1), im behandelten Teil der Felder deutlich geringer war als im unbehandelten Teil. Außerdem zeigte sich erneut der deutlich niedrigere Befall auf den Flächen 5.1 und 1.2, die vor diesem Boniturtermin einer wirksamen Fungizidbehandlung unterzogen wurden. Auffällig ist außerdem, dass die Abhängigkeit vom Ackeranteil im Vergleich der Befallsstärken der behandelten Flächen deutlich enger war, als im Vergleich zu den unbehandelten Flächen. Diese engere Korrelation zeigte sich, wenn die zehn Göttinger Flächen getrennt von den Giessener Flächen dargestellt wurden. Die Giessener Felder waren durch einen umgebenden Ackeranteil von 12-65 \% charakterisiert, während die Göttinger Flächen durch einen Ackeranteil von 42-92 \% charakterisiert wurden. Eine enge Beziehung zum Ackeranteil ergab sich folglich dann, wenn dieser Parameter an Wert zunahm. Die entsprechenden Abbildungen sind hier nicht näher aufgeführt (s. Anhang, Abb. A6-A9).

Wie im Versuchsjahr 2001 wurden auch in diesem Jahr die Befallsstärken von S. tritici der 19 Felder, diesmal aus dem unbehandelten Teil, im Box Plot dargestellt (Abb. 28 und 29). 


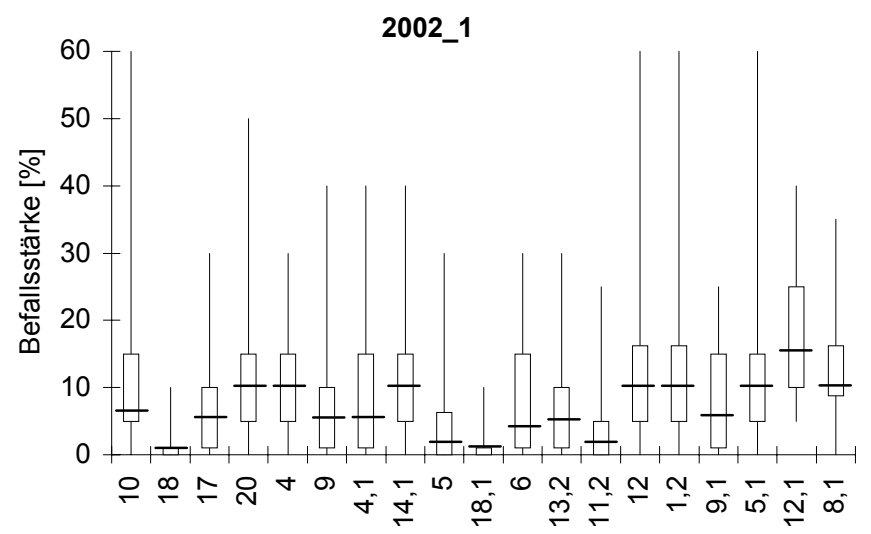

Abb. 28: Darstellung der Befallsstärke in \% befallener Blattfläche von Septoria tritici auf den 19 Feldern der Regionen Göttingen und Giessen zu BBCH 39-42 im Jahr 2002; Anordnung der Felder von links nach rechts: geringer bis hoher Ackeranteil

Legende: Aufgetragen sind Median, unteres und oberes Quartil, sowie Maximal und Minimalwert

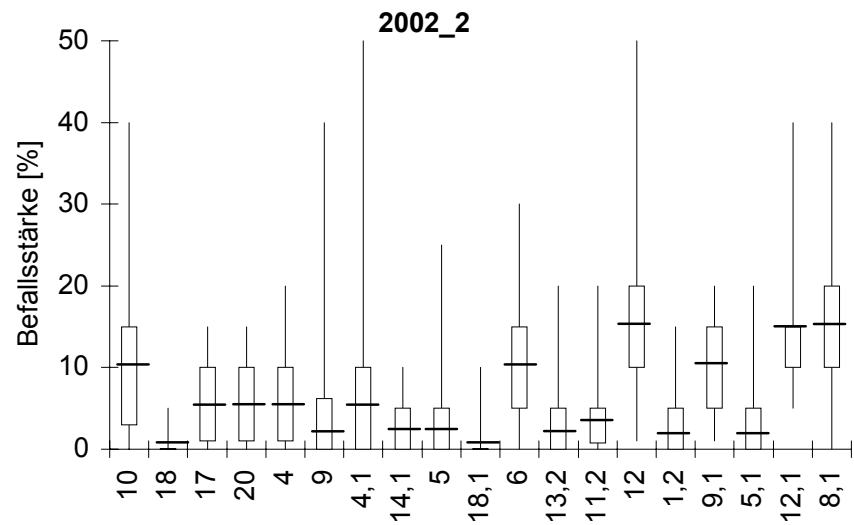

Abb. 29: Darstellung der Befallsstärke in \% befallener Blattfläche von Septoria tritici auf den 19 Feldern der Regionen Göttingen und Giessen zu BBCH 65 im Jahr 2002; Anordnung der Felder von links nach rechts: geringer bis hoher Ackeranteil

Legende: Aufgetragen sind Median, unteres und oberes Quartil, sowie Maximal und Minimalwert

Wie den beiden Abbildungen zu entnehmen ist, war im Jahr 2002 das Niveau der Befallsstärken von S. tritici auf Feldern monotoner Landschaften deutlich höher als auf Feldern komplex strukturierter Landschaften. In Abb. 29 wird zudem erneut das geringere Befallsniveau der Felder 5.1 und 1.2 der Region Göttingen deutlich. Auffällig ist das vergleichsweise hohe Befallsniveau des Feldes 10 der Region Giessen, das durch einen sehr geringen Ackeranteil der umgebenden Landschaft charakterisiert wurde. 
Neben der Befallsstärke und - häufigkeit von Septoria tritici wurden auch die der weiteren fünf blattpathogenen Pilze, Septoria nodorum, Blumeria graminis f. sp. tritici, Drechslera tritici-repentis, Puccinia striiformis und Puccinia recondita näher betrachtet. Ähnlich wie bei Septoria tritici konnten hoch signifikante Unterschiede in Befallsstärke und - häufigkeit zwischen den 19 Feldern $(\mathrm{P}=0,0001)$ an beiden Probenahmeterminen nachgewiesen werden. Abweichend zum Vorjahr zeigte $S$. nodorum in diesem Jahr an beiden Terminen eine negative Abhängigkeit der mittleren Befallsstärken vom Ackeranteil (Abb. 30).

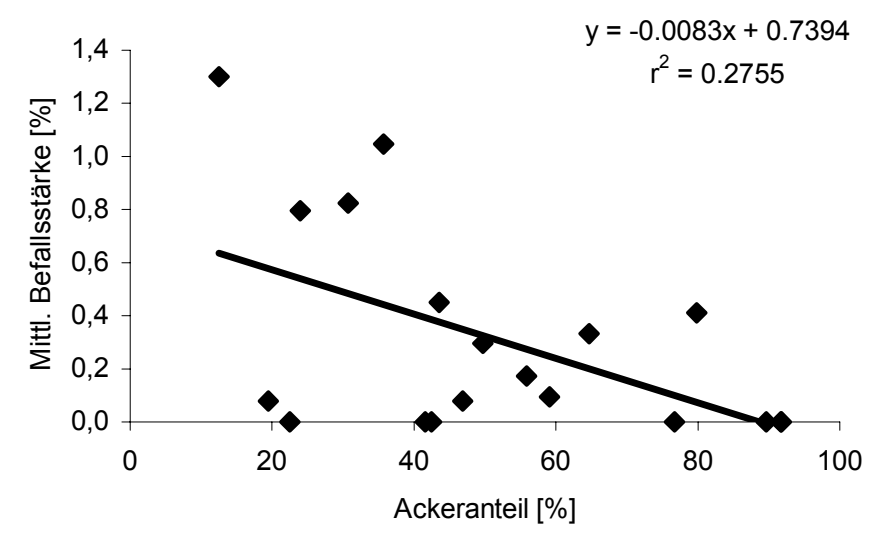

Abb. 30: Mittlere Befallsstärke (\% befallene Blattfläche des F-1 Blattes) von Septoria nodorum im Verhältnis zum prozentualen Ackeranteil der Landschaften der Regionen Göttingen und Giessen zu BBCH 65 im Jahr 2002

Legende: $y$ : Regressionsgleichung; $r^{2}$ : Bestimmtheitsmaß

Im Gegensatz dazu konnte für DTR im zweiten Versuchsjahr zu beiden Terminen eine positive Abhängigkeit der mittleren Befallsstärke zum Landschaftsparameter Ackeranteil festgestellt werden, während dieser Pilz 2001 eine negative Abhängigkeit aufwies (s. Kap. 3.1.3.1.). Die mittleren Befallsstärken des Echten Weizenmehltaus zeigten keine Abhängigkeit vom Parameter Ackeranteil, während Gelbrost und Braunrost am ersten Termin noch überhaupt nicht auftraten und am zweiten Termin, wie im Vorjahr eine negative Abhängigkeit aufwiesen. Aufgrund der schwachen Regressionen sind diese Ergebnisse an dieser Stelle nicht aufgeführt (s. Anhang, Abb. A10-A14). 


\subsection{Ergebnisse der Untersuchungen zur Aggressivität von Septoria tritici}

Ziel dieser zusätzlichen Analysen war es, die Populationen von S. tritici hinsichtlich ihrer Aggressivität zu charakterisieren. In Kapitel 3.1. wurden die Populationen von Septoria tritici der verschiedenen Felder durch die Aggressivität im Feld beurteilt. Die ermittelte Feldaggressivität (Befallshäufigkeit und -stärke) des Pilzes konnte aufgrund der unterschiedlichen Weizensorten nicht sortenunabhängig dargestellt werden. In den im Folgenden beschriebenen Untersuchungen wurden zur Bestimmung einer sortenunabhängigen Aggressivität zwei Weizensorten für alle untersuchten Isolate verwendet.

\subsubsection{Aggressivität gegenüber verschiedenen Weizensorten}

Bei den verwendeten Weizensorten handelt es sich, wie in Kapitel 2.5.1. beschrieben, um eine für Septoria tritici anfällige Weizensorte (Monopol) und eine weniger anfällige Sorte (Cardos). In diesen Untersuchungen wurden insgesamt 172 Isolate der ersten Probenahme (BBCH 39-42, F-2 Blatt) des Versuchsjahres 2002 der sechs Felder 4.1, 5.1, 8.1, 12.1, 10 und 12, sowie Isolate aus dem fungizidbehandelten Teil der Felder 4.1 und 12.1 hinsichtlich ihrer Aggressivität charakterisiert. Von jedem Isolat wurde eine Sporensuspension in Wasser $\left(2 * 10^{5}\right.$ Sporen pro $\mathrm{ml}$ Wasser $)$ hergestellt und auf je 16 Pflanzen (3-Blatt-Stadium) der beiden Sorten inokuliert. Nach Inkubation (Kap. 2.5.4.) für 21 Tage wurde die befallene Blattfläche in Prozent bonitiert und die Ergebnisse mit Hilfe von SAS statistisch ausgewertet.

Die folgende Abbildung zeigt den Vergleich der beiden Sorten Monopol und Cardos. Gegeneinander aufgetragen wurde der mittlere Befall in Prozent aller 172 untersuchten Isolate sowohl bei der Sorte Cardos, als auch der Sorte Monopol. Die beiden Sorten unterscheiden sich hoch signifikant $(\mathrm{P}=0,0001$, bei einer Signifikanzgrenze von $\mathrm{P} \leq 0,05)$, wobei die Sorte Monopol signifikant höher anfällig gegenüber $S$. tritici war als die Sorte Cardos. 


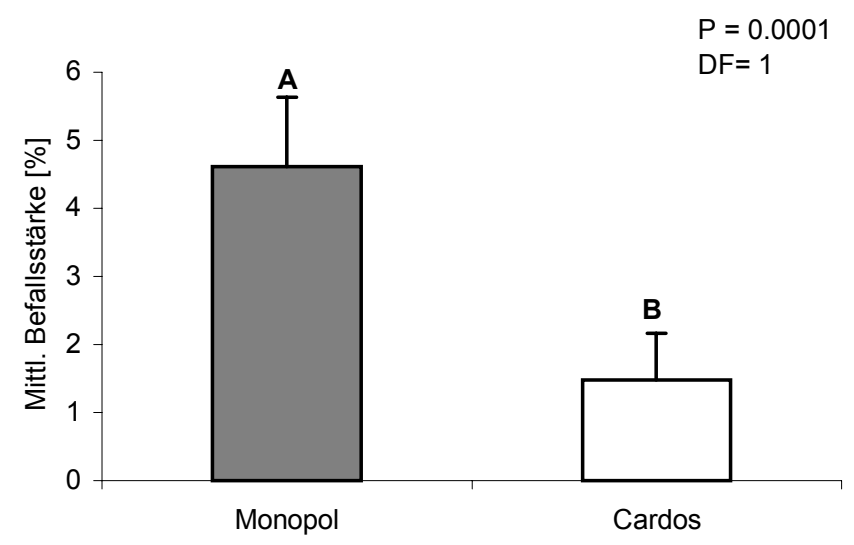

Abb. 31: Mittlere Befallsstärke (\% befallene Blattfläche des 1. und 2. Blattes) der 172 Isolate von Septoria tritici auf den Weizensorten Monopol und Cardos

Legende: P: Irrtumswahrscheinlichkeit; DF: „Degrees of Freedom“, Freiheitsgrade; A, B: Signifikanzen nach „Student Newman Keuls“ Test

In diesem Diagramm ist die deutlich höhere Befallsstärke des Pilzes auf der anfälligen Sorte Monopol im Vergleich zur weniger anfälligen Sorte Cardos ersichtlich. Diese höhere Anfälligkeit der Sorte Monopol war nach Einstufung der Bundessortenliste 2003 zu erwarten. In dieser Liste wird die Anfälligkeit von Monopol gegenüber S. tritici mit 7, die Anfälligkeit von Cardos mit 4 eingestuft.

\subsubsection{Unterschiede der Aggressivität der Isolate verschiedener Felder}

Die in Kap. 3.2.1. beschriebene generell geringere Anfälligkeit der Sorte Cardos gegenüber $S$. tritici im Vergleich zur Sorte Monopol erfordert eine differenzierte Betrachtung der Aggressivität der Isolate einzelner Felder auf beiden Sorten. Wie bereits erwähnt, wurden in diesen Untersuchungen insgesamt 172 Isolate der ersten Probenahme (BBCH 39-42, F-2 Blatt) des Versuchsjahres 2002 der sechs Felder 4.1, 5.1, 8.1, 12.1, 10 und 12, sowie Isolate aus dem fungizidbehandelten Teil der Felder 4.1 und 12.1 hinsichtlich ihrer Aggressivität charakterisiert. In Abb. 32 ist der mittlere Befall der Isolate der einzelnen Felder der Sorte Monopol dargestellt. 


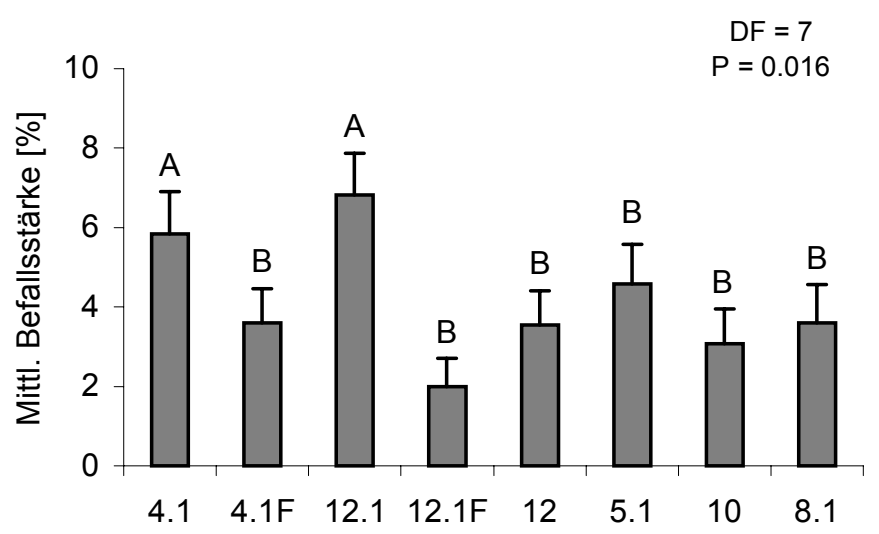

Abb. 32: Mittlere Befallsstärke (\% befallene Blattfläche des 1. und 2. Blattes) der 172 Isolate von Septoria tritici auf der Weizensorte Monopol

Legende: P: Irrtumswahrscheinlichkeit; DF: „Degrees of Freedom“, Freiheitsgrade; A, B: Signifikanzen nach SNK-Test; 4.1F und 12.1F: fungizidbehandelter Teil der Felder 4.1 und 12.1

Die mittleren Befallsstärken der Isolate der einzelnen Felder auf der Sorte Monopol unterschieden sich signifikant $(\mathrm{P}=0,016)$ voneinander. Die Aggressivität der Isolate der Felder 4.1 und 12.1 war signifikant höher als die der anderen untersuchten Felder, welche sich wiederum nicht signifikant voneinander unterschieden. Die mittlere Befallsstärke der Isolate aus dem behandelten Teil der Felder 4.1 und 12.1 war signifikant geringer als die des entsprechenden fungizidfreien Feldbereiches. Ein Bezug der Aggressivität zum Landschaftsparameter Ackeranteil ließ sich hier nicht feststellen. Feld 10 und 4.1 sind durch einen sehr geringen Ackeranteil in der Umgebung charakterisiert, während die anderen Felder durch jeweils relativ hohe Ackeranteile gekennzeichnet sind.

Der Vergleich der Befallsstärken der Isolate auf der weniger anfälligen Sorte Cardos bestätigt das beschriebene Bild. 


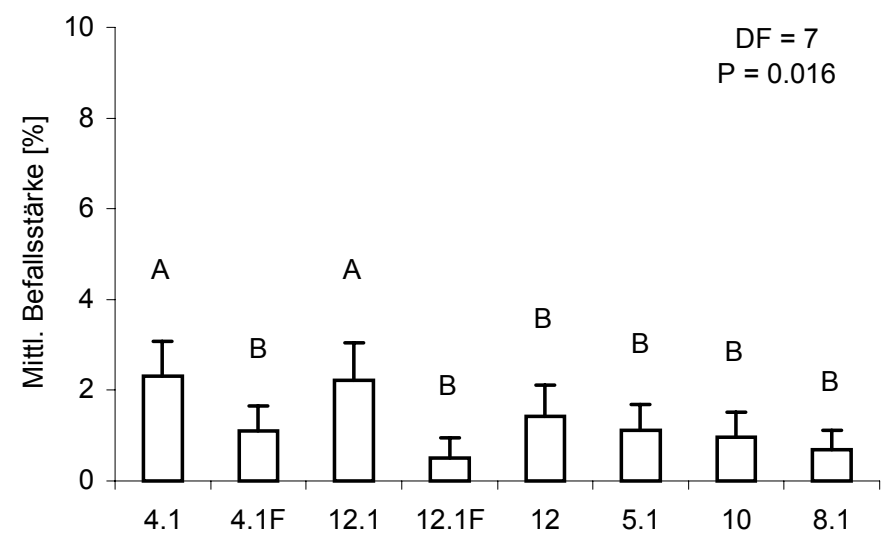

Abb. 33: Mittlere Befallsstärke (\% befallene Blattfläche des 1. und 2. Blattes) der 172 Isolate von Septoria tritici auf der Weizensorte Cardos

Legende: P: Irrtumswahrscheinlichkeit; DF: „Degrees of Freedom“, Freiheitsgrade; A, B: Signifikanzen nach SNK-Test; 4.1F und 12.1F: fungizidbehandelter Teil der Felder 4.1 und 12.1

Abb. 33 zeigt den signifikant höheren $(\mathrm{P}=0,016)$ Befall der $S$. tritici Isolate der Felder 4.1 und 12.1 auf der Sorte Cardos. Die Befallsstärken im fungizidbehandelten Teil dieser Felder waren, wie bei der Sorte Monopol, signifikant geringer, ein Bezug zum Ackeranteil ließ sich nicht herstellen. Um dies zu verdeutlichen, ist in der folgenden Abbildung der mittlere Befall des Pilzes auf den beiden Sorten im Bezug zum Ackeranteil der Felder dargestellt (lineare Regression).

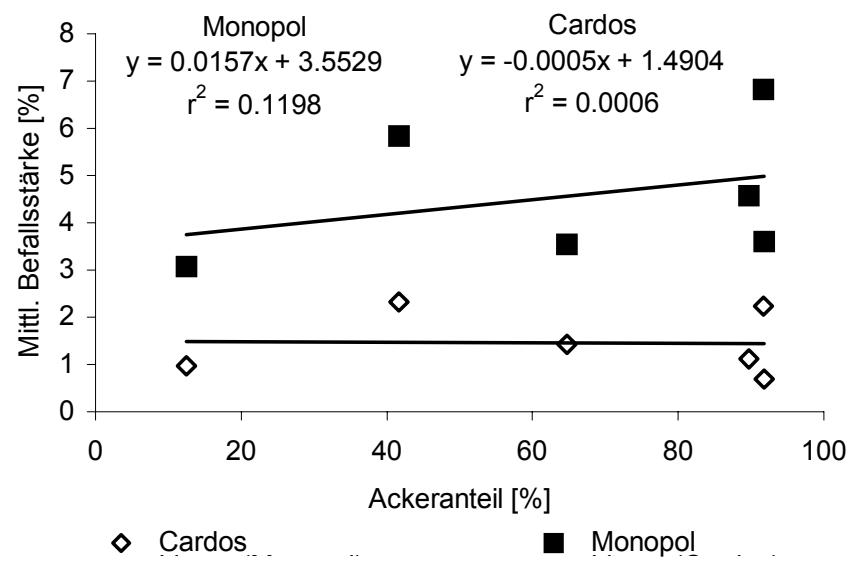

Abb. 34: Mittlere Befallsstärke (\% befallene Blattfläche des 1. und 2. Blattes) der 172 Isolate von Septoria tritici auf der Weizensorte Monopol und Cardos im Verhältnis zum Ackeranteil der Felder

Legende: $\mathrm{y}$ : Regressionsgleichung; $\mathrm{r}^{2}$ : Bestimmtheitsmaß 
In diesem Diagramm sind die Werte der behandelten Teile der Felder nicht mit aufgetragen, um die Vergleichbarkeit der Ergebnisse zu erhalten. Der Abbildung lässt sich entnehmen, dass bei der Befallsstärke der Isolate auf der Sorte Monopol nur eine vernachlässigbare Tendenz einer Abhängigkeit vom Ackeranteil zu sehen war, während die Befallsstärken auf der Sorte Cardos überhaupt keine Abhängigkeit vom Parameter Ackeranteil aufwiesen.

\subsubsection{Unterschiede der Aggressivität verschiedener Isolate von $S$. tritici}

Um dennoch eine Einschätzung der Aggressivität der $S$. tritici Isolate der einzelnen Felder auf den untersuchten Weizensorten zu erreichen, wurden die Befallsstärken der Isolate im Box Plot dargestellt.

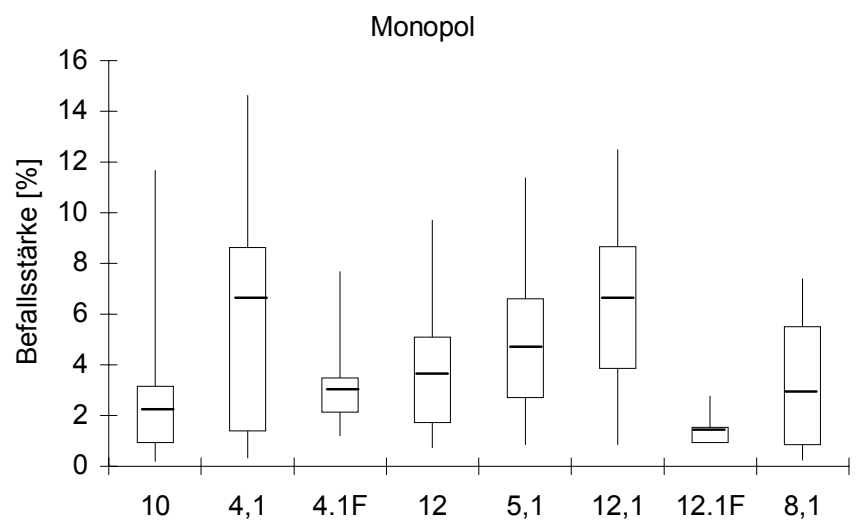

Abb. 35: Darstellung der Befallsstärke in \% befallener Blattfläche der Sorte Monopol von Septoria tritici auf den sechs untersuchten Feldern; Anordnung der Felder von links nach rechts: geringer bis hoher Ackeranteil

Legende: 4.1F und 12.1F: fungizidbehandelter Teil der Felder 4.1 und 12.1; Aufgetragen sind Median, unteres und oberes Quartil, sowie Maximal und Minimalwert

Abb. 35 zeigt das breite Spektrum der Befallsstärken der S. tritici Isolate der einzelnen Felder auf der anfälligen Weizensorte Monopol. Die Felder sind in diesem Diagramm von links nach rechts mit steigendem Ackeranteil sortiert. Deutlich zu erkennen ist der Anstieg der Befallsstärken der Felder 10, 4.1F, 12, 5.1 und 12.1 mit steigendem Ackeranteil. Die hohe Befallsstärke des Feldes 4.1 und die vergleichsweise geringen Stärken der Felder 12.1F und 8.1 bestätigen jedoch, dass keine Abhängigkeit des Befallsniveaus vom Landschaftsparameter Ackeranteil besteht. 


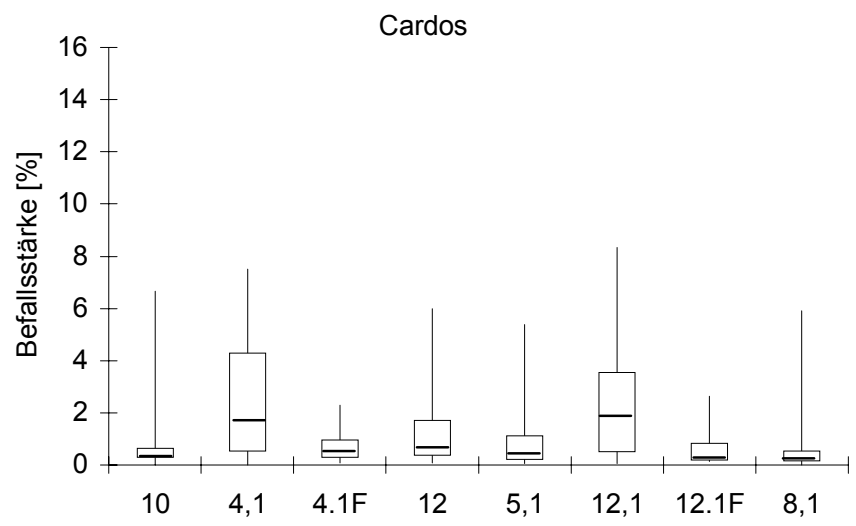

Abb. 36: Darstellung der Befallsstärke in \% befallener Blattfläche der Sorte Cardos von Septoria tritici auf den sechs untersuchten Feldern; Anordnung der Felder von links nach rechts: geringer bis hoher Ackeranteil

Legende: 4.1F und 12.1F: fungizidbehandelter Teil der Felder 4.1 und 12.1; Aufgetragen sind Median, unteres und oberes Quartil, sowie Maximal und Minimalwert

In Abb. 36 sind die Niveaus der Befallsstärken von S. tritici der untersuchten Felder auf der weniger anfälligen Weizensorte Cardos dargestellt. Im Gegensatz zu den Befallsniveaus der Sorte Monopol waren die der Sorte Cardos generell sehr gering und zeigten keine deutlichen Unterschiede. Eine Abhängigkeit vom Landschaftsparameter Ackeranteil lässt sich auch hier nicht erkennen. 


\subsection{Ergebnisse der genetischen Untersuchungen von Septoria tritici}

Die Erfahrungen der Praxis der letzten Jahre und die in Kapitel 3.1. beschriebenen Ergebnisse verdeutlichen, dass es sich bei Septoria tritici um den hauptsächlichen Schaderreger im Weizenanbau handelt. In beiden Versuchsjahren wurden daher von den Feldern 10 und 12 der Region Giessen, sowie 4.1, 5.1, 8.1 und 12.1 der Region Göttingen Septoria tritici Isolate im Labor hergestellt, die eine Stichprobe der jeweiligen Feldpopulation darstellen. Pro Feld wurden zwischen 30 und 50 Isolate gewonnen. Im zweiten Versuchsjahr wurden diese Isolate aus den unbehandelten Spritzfenstern und auf Feld 4.1 und 12.1 zusätzlich aus dem fungizidbehandelten Teil gewonnen. Zum Vergleich der Pilzpopulationen aus dem unbehandelten gegenüber dem behandelten Feldteil wurden die Felder 4.1 und 12.1 ausgewählt, da zum einen auf diesen Feldern im Jahr 2002 dieselbe Sorte (Biscay) angebaut wurde und sie sich andererseits durch die umgebende Landschaftsstruktur unterschieden. Während Feld 4.1 in einer komplex strukturierten Landschaft lag, die über einen geringen Ackeranteil verfügte, war die Landschaft von Feld 12.1 sehr monoton und durch einen hohen Ackeranteil charakterisiert (s. Kap. 2.3.1., Tab. 1).

Die DNA wurde mit Hilfe des „DNeasy Plant Mini Kits“ der Firma Quiagen extrahiert und im Rahmen zweier unterschiedlicher Methoden populationsgenetisch charakterisiert. Vor der Amplifikation der DNA anhand der Polymerase-KettenReaktion (PCR) wurde die Reinheit der aus den Pilzen extrahierten Gesamt-DNA anhand einer Agarose-Gel-Elektrophorese überprüft und quantifiziert, wie in Kapitel 2.6.1. und 2.6.2. beschrieben. Die Extraktionen mit Hilfe des o. g. Kits lieferten für jedes Isolate eine gute Ausbeute ungescherter, reiner DNA.

\subsubsection{Ergebnisse und Beurteilung der MP-PCR}

Wie bereits in Kapitel 2.6.3.1. beschrieben, wurde zu Beginn dieser Arbeit zur Bestimmung der genetischen Variabilität von $S$. tritici zunächst die Methode „microsatellite-primed polymerase chain reaction“ (MP-PCR) getestet. Nach entsprechenden Vorversuchen wurde in diesen Untersuchungen ein AC-Primer mit sich 
neun Mal wiederholender Sequenz $[\mathrm{AC}]_{9}$ zur genetischen Differenzierung der Isolate genutzt. Nach erfolgter Amplifikation mittels PCR, anschließender Agarose-GelElektrophorese und Färbung mit Ethidiumbromid konnten die amplifizierten Bereiche der DNA in Form von Banden sichtbar gemacht werden. Die folgende Abbildung zeigt diese amplifizierten Bereiche von 28 verschiedenen Isolaten des F-3 Blattes der ersten Probenahme (BBCH 47-51) des Feldes 12 aus dem Jahr 2001. Als Größenmarker wurde hier GeneRuler ${ }^{\mathrm{TM}} 100 \mathrm{bp}$ DNA Ladder Plus neben den Proben aufgetragen.

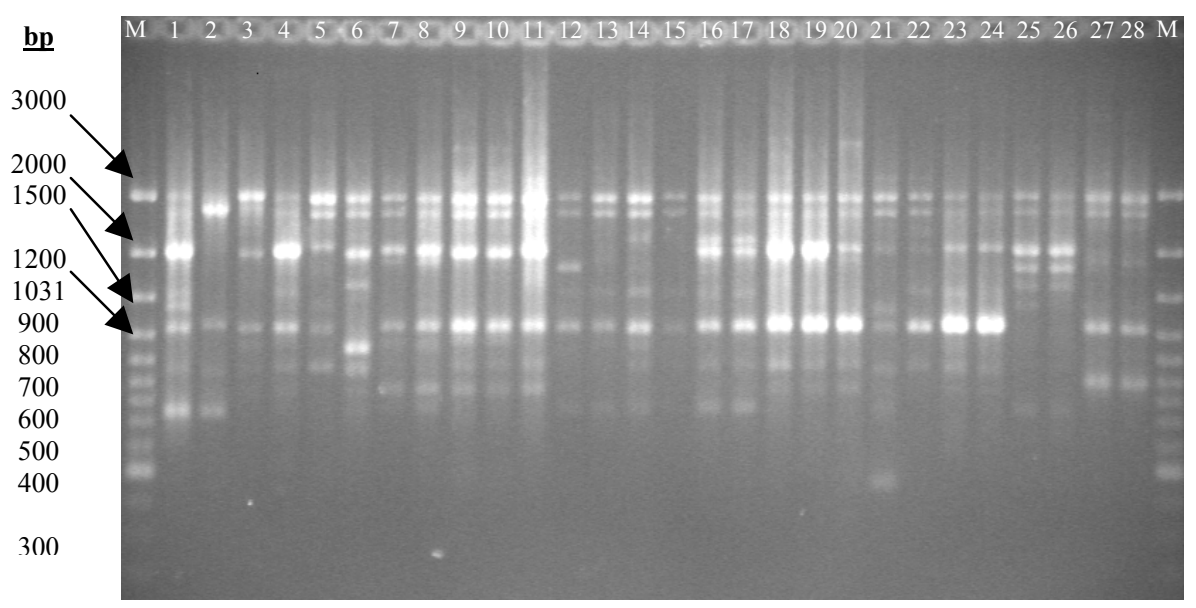

Abb. 37: Amplifizierte Banden (MP-PCR) von 28 verschiedenen Isolaten (F-3 Blatt, BBCH 47-51) des Feldes 12 des Jahres 2001

In Abb. 37 wird deutlich, dass sich die aufgetragenen Isolate in ihrem Bandenmuster erheblich voneinander unterschieden. Diese hohe Diversität zeigte sich bei allen getesteten Isolaten, nur wenige, die versuchsweise vom selben Blatt aus derselben Läsion isoliert wurden (Isolat 9 und 10, 18 und 19, sowie 23 und 24), waren genetisch gleich. Dies bestätigte sich auch in Clusteranalysen zur Bestimmung der genetischen Diversitätsindices, die hier nicht näher aufgeführt sind. Die Methode der MP-PCR wurde gewählt, da sie relativ einfach durchführbar und vergleichsweise kostengünstig ist. Nachteilig an dieser Methode ist allerdings die hohe Unspezifität der amplifizierenden Primer. Aufgrund der hohen Diversität der Isolate und der damit unmöglichen Vergleichbarkeit populationsgenetischer Daten von Septoria tritici vor dem Hintergrund unterschiedlicher Landschaften wurde diese Methode nach kurzer Zeit nicht weiter verfolgt. Stattdessen wurde die im Folgenden dargestellte MikrosatellitenMethode für $S$. tritici etabliert. 


\subsubsection{Genetische Diversität von Septoria tritici in Abhängigkeit von verschiedenen Landschaftsstrukturen}

Für die populationsgenetischen Untersuchungen wurden ausschließlich Septoria tritici Isolate des ersten Probenahmetermins (BBCH 39-42) des Jahres 2002 untersucht. Diese stammen von F-2 Blättern verschiedener Pflanzen aus den fungizidfreien Spritzfenstern der o. g. Felder 10 und 12 der Region Giessen, sowie 4.1, 5.1, 8.1 und 12.1 der Region Göttingen. Zusätzlich wurden Isolate des F-3 Blattes aus dem fungizidbehandelten Teil der Göttinger Felder 4.1 und 12.1 in die Untersuchung mit einbezogen. Es wurden 301 Pilzisolate gewonnen und davon 290 populationsgenetisch untersucht.

Die entsprechenden Mikrosatelliten der Pilzisolate wurden mit drei verschiedenen fluoreszenzmarkierten Primern und zwei verschiedenen PCR-Konturen amplifiziert. Die Mobilität der Amplifikate wurde mittels Laseranregung über eine Messzelle im unteren Bereich einer Polyacrylamid-Gel-Elektrophoreseeinheit erfasst. Die Primer ST1A4 $[\mathrm{CGG}]_{7}$, ST1E7 $[\mathrm{CGG}]_{5}$ und ST2E4 $[\mathrm{GGC}]_{5}$ wurden für die Amplifikation verschiedener Mikrosatellitenmotive verwendet, sie fungierten als „forward“ wie „reverse“ Primer (s. Kapitel 2.6.3.2.).

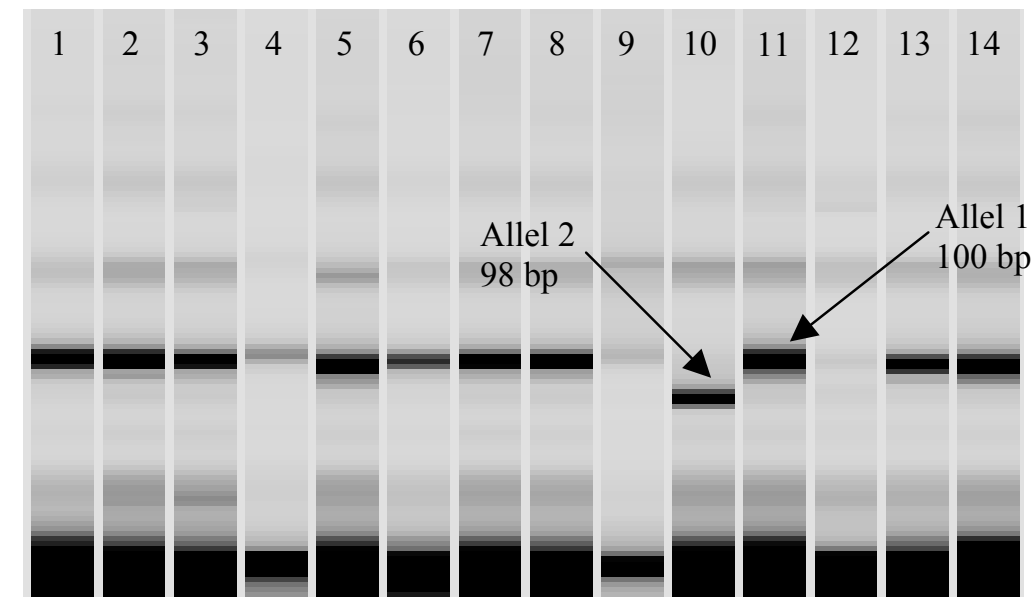

Abb. 38: Bandenmuster im Polyacrylamid-Gel von zwei der drei vorkommenden Allele verschiedener Isolate (1-14) von $S$. tritici nach Amplifikation des Mikrosatellitenmotivs mit Hilfe des Primers ST1A4

Legende: Schwarzer Bereich am unteren Bildrand: Primerwolken; zusätzliche schwache Banden im Gel sind bei Mikrosatellitenamplifikation immer vorhanden und vernachlässigbar

Die einzelnen Mikrosatellitenmotive verschiedener Isolate von S. tritici können in unterschiedlicher Wiederholungszahl vorliegen, wodurch unterschiedliche Amplifikatgrößen (angegeben als $b p=$ Basenpaare) zustande kommen. Die 
unterschiedlichen Amplifikatgrößen der jeweiligen Mikrosatelliten können als „Allele“ aufgefasst werden. Mit Hilfe der verwendeten Primer konnten sowohl Mikrosatelliten amplifiziert werden, die offenbar in Einzelkopie oder aber in zwei Kopien im Genom vorliegen. Der Primer ST1A4 amplifiziert einen Mikrosatellitenlocus von dem drei Allele im Genom von S. tritici nachgewiesen werden konnten (Abb. 38). Für die beiden anderen Primer ST1E7 und ST2E4 wurde stets die parallele Amplifikation zweier Banden festgestellt (Abb.39). Dabei waren die entsprechenden Merkmale nicht gekoppelt, sondern z. B. auch Allel 1 und 3 kombinierbar. Die Koamplifikation zweier Produkte deutet auf die physikalische Existenz zweier Kopien des Mikrosatelliten hin, dies wird als „diallelisch“ bezeichnet. Diese beiden Primer amplifizieren daher vier Allele des entsprechenden Mikrosatteliten. In der folgenden Abbildung sind die vier Allele des Primers ST1E7 exemplarisch für sechs Isolate von S. tritici dargestellt.

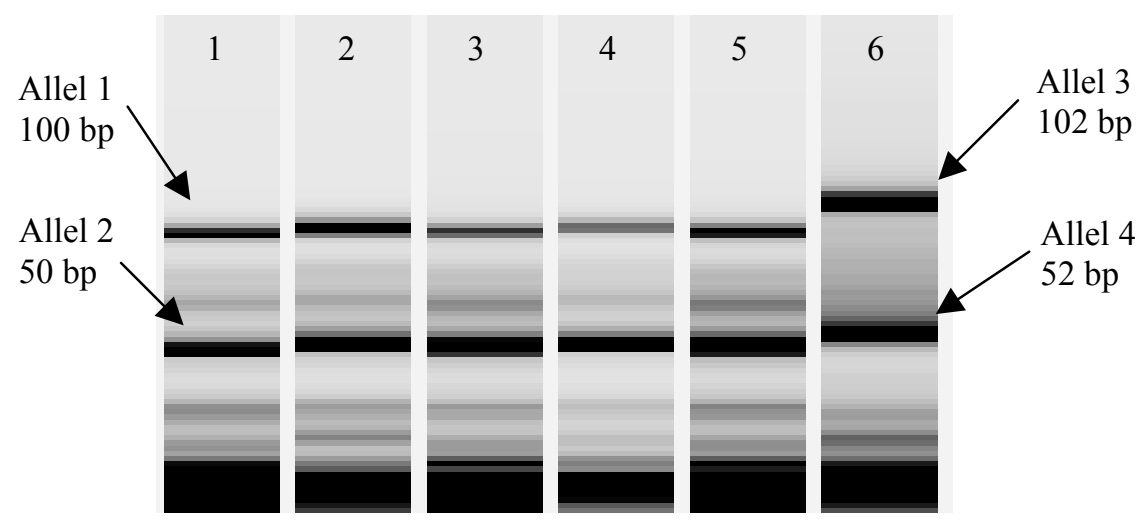

Abb. 39: Bandenmuster im Polyacrylamid-Gel von zwei von drei Allelen verschiedener Isolate (1-14) von $S$. tritici nach Amplifikation des Mikrosatellitenmotivs mit Hilfe des Primers ST1E7 Legende: Schwarzer Bereich am unteren Bildrand: Primerwolken; zusätzliche schwache Banden im Gel sind bei Mikrosatellitenamplifikation immer vorhanden und vernachlässigbar

Für jedes Isolat von $S$. tritici konnten also mit dieser Methode 11 verschiedene Allele amplifiziert und so die 290 Isolate verglichen werden. Nach erfolgter Amplifikation und Geldokumentation wurde mit Hilfe des Programms GelComparII (Applied Maths, Kortrijk, Belgien) die genetischen Ähnlichkeit berechnet. Diese Berechnung erfolgte, wie bereits in Kapitel 2.6.7.2. beschrieben, anhand des Ähnlichkeitskoeffizienten $S_{x y}$ (Dice-Index, DICE, 1945). Dieser Ähnlichkeitskoeffizient $\mathrm{S}_{\mathrm{xy}}$ wurde für jedes Isolatpaar im Programm GelComparII berechnet. Die genetischen Ähnlichkeiten wurden anhand einer Clusteranalyse nach dem UPGMA-Algorithmus (unweigthed pair group method with arithmetic mean, SNEATH \& SOKAL 1973) verglichen. Die 
Position der Cluster innerhalb des Dendrogramms beschreibt die genetische Ähnlichkeit der Isolate der untersuchten Population zueinander.

Außerdem wurde mit Hilfe des Programms GelComparII eine binäre sog. 0/1Matrix erstellt (s. Kap. 2.6.7.2.) und anschließend mit Hilfe des Statistikprogramms ARLEQUIN Vers. 2.00 (SCHNEIDER et al. 2000) auf populationsgenetischer Ebene analysiert of molecular variance, AMOVA).

Eine dieser Varianzkomponenten ist der Fixierungs-Index $F_{\text {ST }}$ (WRIGHT 1965), der als Maß für die genetische Differenzierung zwischen Populationen gilt. Die Berechnung des $\mathrm{F}_{\mathrm{ST}}$-Wertes wurde bereits in Kapitel 2.6.7.3. dargestellt. Beträgt der $\mathrm{F}_{\mathrm{ST}}$-Wert Null, liegt eine panmiktische Population ohne Substrukturierung vor. Ein Wert von eins bedeutet, dass eine gänzliche Substrukturierung der Population mit vollständiger $(100 \%)$ genetischer Differenzierung besteht. Der $\mathrm{F}_{\mathrm{ST}}$-Wert leitet außerdem Aussagen über das Ausmaß des Genflusses zwischen Populationen ab. Ein F $_{\mathrm{ST}}$-Wert von Eins zeigt an, dass kein Genfluss besteht, $\mathrm{F}_{\mathrm{ST}}=0$ zeigt Genfluss zwischen Populationen an. Eine weitere Varianzkomponente ist die genetische Diversität (,gene diversity“), die auf Grundlage haploider Daten berechnet wird (NEI 1987). Diese Varianzkomponente trifft ähnliche Aussagen wie der beschriebene Dice-Index, mit dem Unterschied, dass nicht Isolate paarweise betrachtet werden, sondern alle Individuen einer Population.

Auf Grundlage dieser Berechnungen konnten die im Folgenden dargestellten Aussagen über die genetische Variabilität der Populationen von Septoria tritici getroffen werden. Verglichen wurde dabei die Variabilität von Populationen der Regionen Giessen und Göttingen, Variabilität der Populationen verschiedener Felder, innerhalb eines Feldes und innerhalb eines Untersuchungsplots in einem Feld.

In Abb. 40 ist die genetische Distanz (berechnet nach DICE 1945) der 290 Isolate der sechs Felder (auch aus dem fungizidbehandelten Teil der Felder 4.1 und 12.1) als Clusterdiagramm (erstellt nach UPGMA-Algorithmus) dargestellt. 


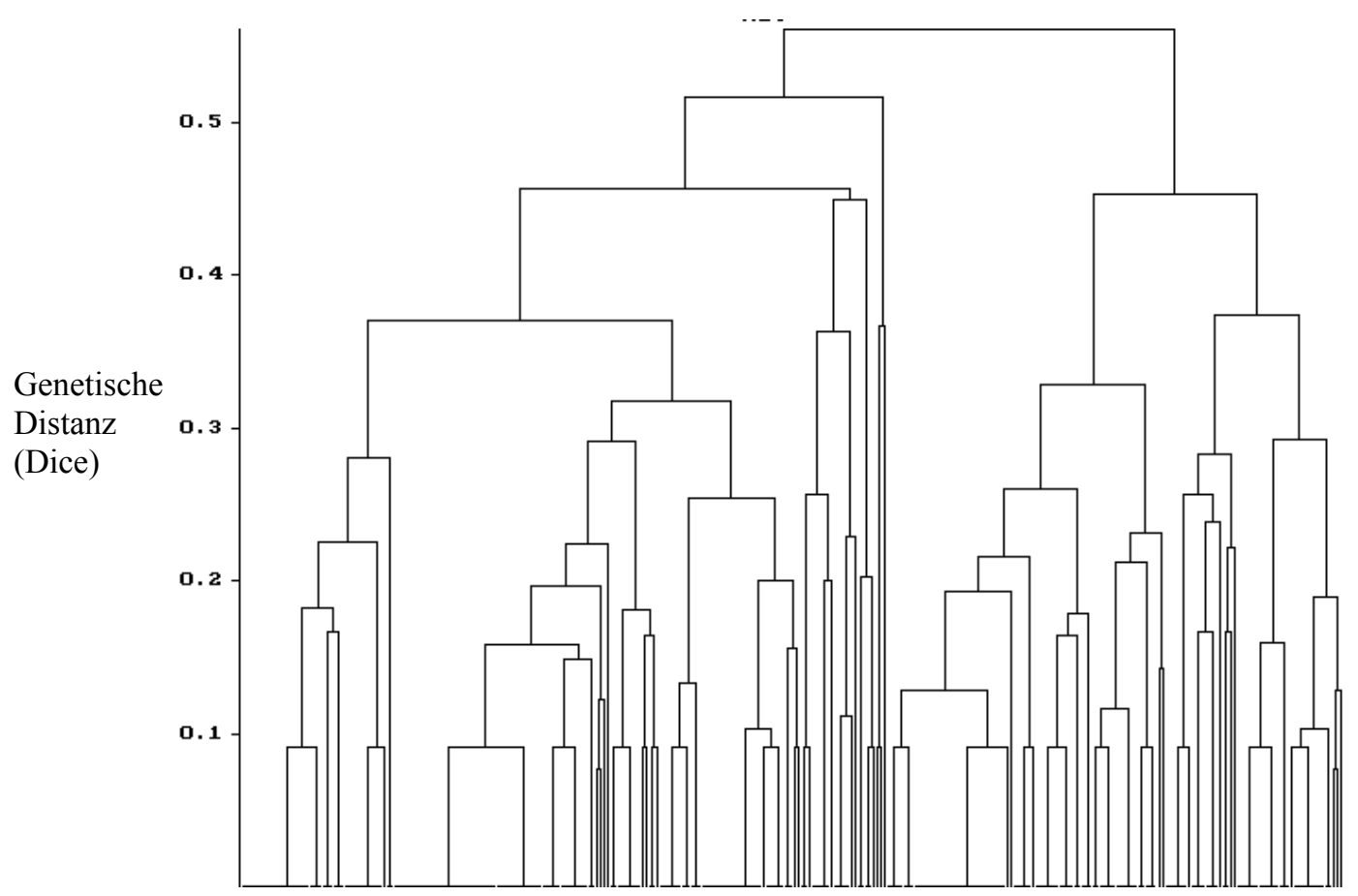

Septoria tritici Isolate (290)

Abb. 40: Clusterdiagramm (UPGMA-Algorithmus) zur genetischen Distanz der 290 Isolate von Septoria tritici

Diese Abbildung verdeutlicht die genetische Variabilität der untersuchten Gesamtpopulation von S. tritici. Unter den 290 Isolaten gab es 79 verschiedene Genotypen von insgesamt 108 Möglichkeiten bei freier Kombination der jeweils drei bzw. vier Allele der drei eingesetzten Marker, die auf Grundlage der 0/1-Matrix berechnet wurden. Demnach waren 73 \% der möglichen Genotypen in den untersuchten Pilzpopulationen wiederzufinden. Dies spiegelt die, in Kapitel 3.3.1. beschriebene, hohe Variabilität des untersuchten Pilzes wider.

Ein weiterer Aspekt bei der Untersuchung der genetischen Variabilität von Septoria tritici ist das Vorkommen gemeinsamer Genotypen innerhalb der Populationen der untersuchten Felder. In der folgenden Tabelle ist die Anzahl gemeinsamer Genotypen der sechs Felder (und der fungizidbehandelten Teile der Felder 4.1 und 12.1) dargestellt. 
Tab. 15: Anzahl gemeinsamer von insgesamt 79 verschiedenen Genotypen von Septoria tritici innerhalb der Populationen der untersuchten Felder

\begin{tabular}{|c|cccccccc|}
\hline $\begin{array}{c}\text { Felder } / \\
\text { Genotypen }\end{array}$ & $\mathbf{1 0}$ & $\mathbf{4 . 1}$ & $\mathbf{4 . 1} \mathbf{~ F}$ & $\mathbf{1 2}$ & $\mathbf{5 . 1}$ & $\mathbf{1 2 . 1}$ & $\mathbf{1 2 . 1} \mathbf{F}$ & $\mathbf{8 . 1}$ \\
\hline $\mathbf{1 0}$ & $*$ & $*$ & $*$ & $*$ & $*$ & $*$ & $*$ & $*$ \\
$\mathbf{4 . 1}$ & keine & $*$ & $*$ & $*$ & $*$ & $*$ & $*$ & $*$ \\
$\mathbf{4 . 1} \mathbf{F}$ & 2 & 5 & $*$ & $*$ & $*$ & $*$ & $*$ & $*$ \\
$\mathbf{1 2}$ & keine & 4 & 2 & $*$ & $*$ & $*$ & $*$ & $*$ \\
$\mathbf{5 . 1}$ & keine & 5 & 2 & 2 & $*$ & $*$ & $*$ & $*$ \\
$\mathbf{1 2 . 1}$ & keine & 1 & keine & 2 & 4 & $*$ & $*$ & $*$ \\
$\mathbf{1 2 . 1} \mathbf{F}$ & 2 & 6 & 8 & 2 & 1 & 1 & $*$ & $*$ \\
$\mathbf{8 . 1}$ & 2 & keine & 1 & keine & keine & keine & 1 & $*$ \\
\hline
\end{tabular}

Legende: $4.1 \mathrm{~F}$ und $12.1 \mathrm{~F}$ : fungizidbehandelte Teile der Felder 4.1 und 12.1; *: Wertangabe unnötig oder doppelt

Bei der Auswertung kristallisierten sich vier häufige Genotypen heraus, die auf den meisten der untersuchten Feldern vorkamen: Genotyp 1 (4.1, 5.1, 4.1F, 12.1F), Genotyp $8(4.1,12.1,5.1,12,12.1 \mathrm{~F})$, Genotyp $47(4.1,5.1,4.1 \mathrm{~F}, 12.1 \mathrm{~F})$ und Genotyp 50 (4.1, 12, 4.1F, 12.1F) (s. Anhang, ATab. 4). Diese häufigen Genotypen kamen weder auf Feld 10 noch Feld 8.1 vor. Diese beiden Felder hatten nur zwei gemeinsame Genotypen, die ausschließlich auf diesen beiden Feldern vorkamen. Außerdem teilten Feld 8.1 und die fungizidbehandelten Teile der Felder 4.1 und 12.1 (4.1F und 12.1F) jeweils einen gemeinsamen Genotyp, Genotyp 52, der nur auf diesen drei Feldern zu finden war. Feld 10 teilte mit den beiden Feldern $4.1 \mathrm{~F}$ und $12.1 \mathrm{~F}$ je zwei gemeinsame Genotypen, Genotyp 53 und 59 (12.1F) bzw. 60 (4.1F), die ebenfalls nur auf diesen Feldern zu finden waren.

Um Interaktionen zwischen Landschaftsstruktur und genetischer Struktur von Septoria tritici zu untersuchen, wurden die Genotypen der Isolate der Populationen mittels Varianzanalyse (AMOVA) näher betrachtet. Der genetische Diversitätindex nach NEI (1987) der Populationen der untersuchten sechs Felder ist in der folgenden Tabelle dargestellt. 
Tab. 16: Genetischer Diversitätsindex (NEI, 1978) der Septoria tritici Populationen auf den untersuchten Feldern, berechnet mittels AMOVA

\begin{tabular}{|c|c|c|c|c|c|c|c|c|}
\hline Feld & $\mathbf{4 . 1}$ & $\mathbf{1 2 . 1}$ & $\mathbf{8 . 1}$ & $\mathbf{5 . 1}$ & $\mathbf{1 2}$ & $\mathbf{1 0}$ & $\begin{array}{c}\mathbf{4 . 1} \\
(\mathrm{F})\end{array}$ & $\begin{array}{c}\mathbf{1 2 . 1} \\
(\mathrm{F})\end{array}$ \\
\hline $\begin{array}{c}\text { Gen. } \\
\text { Diversität }\end{array}$ & 0,91 & 0,90 & 0,91 & 0,89 & 0,81 & 0,92 & 0,87 & 0,92 \\
\hline
\end{tabular}

Legende: 4.1 (F) und 12.1 (F): fungizidbehandelter Teil der Felder 4.1 und 12.1

Die Diversitätsindices der Populationen von S. tritici der einzelnen Felder waren alle gleichermaßen auf hohem Niveau zu klassifizieren (0,81-0,92). Das bedeutet, dass die genetische Variabilität bereits innerhalb der Felder sehr hoch war, während die verbleibende Variabilität die zwischen den Feldern zu beobachten ist nur sehr gering ausfiel. Zur Spezifikation des Ausmaßes der Populationsstrukturierung und des Genflusses zwischen Populationen wurde der sog. Fixierungsindex ( $\mathrm{F}_{\mathrm{ST}}$-Wert) berechnet. Nach HARTL \& CLARK (1989) werden F $_{\mathrm{ST}^{-}}$-Werte zwischen null und 0,05 als keine, $\mathrm{F}_{\mathrm{ST}}$-Werte über 0,25 dagegen als sehr große genetische Differenzierung zwischen Populationen gewertet. In der folgenden Tabelle sind die Varianzkomponenten, sowie die prozentuale Variabilität der einzelnen Populationen aufgeführt. 
Tab. 17: Genetische Variabilität zwischen Regionen, Feldern, innerhalb von Feldern und innerhalb von Untersuchungsplots der untersuchten Populationen von Septoria tritici, berechnet mittels AMOVA

\begin{tabular}{|c|c|c|c|}
\hline Variabilitätsquelle & DF & Varianzkomponenten & Variabilität [\%] \\
\hline $\begin{array}{c}\text { Zwischen } \\
\text { Regionen }\end{array}$ & 1 & 0,13960 & $\mathbf{5 , 3 7}$ \\
\hline $\begin{array}{c}\text { Zwischen } \\
\text { Populationen } \\
\text { innerhalb der } \\
\text { Regionen }\end{array}$ & 6 & 0,68695 & $\mathbf{2 6 , 4 4}$ \\
\hline $\begin{array}{c}\text { Innerhalb von } \\
\text { Populationen }\end{array}$ & 281 & 1,77118 & $\mathbf{6 8 , 1 8}$ \\
\hline $\begin{array}{c}\text { Innerhalb von } \\
\text { Plots }\end{array}$ & 222 & 1,59347 & $\mathbf{6 3 , 8 1}$ \\
\hline
\end{tabular}

Legende: DF: „Degrees of Freedom“, Freiheitsgrade

Der Tabelle lässt sich entnehmen, dass zwischen den Regionen Giessen und Göttingen nur eine sehr geringe genetische Variabilität herrschte $(5,37 \%)$. Zwischen den einzelnen Populationen innerhalb der Regionen herrschte eine Variabilität von 26,44 \% bei einem $\mathrm{F}_{\mathrm{ST}}$-Wert von 0,32. Das bedeutet, dass die genetische Differenzierung zwischen den Populationen groß und signifikant war. Die größte genetische Variabilität war allerdings innerhalb der Populationen (68,18\%), bzw. innerhalb eines Untersuchungsplots $(63,81 \%)$ zu finden, d. h. über $2 / 3$ der gesamten genetischen Variabilität von $S$. tritici bestand innerhalb einer Feldpopulation. Die Ergebnisse der Berechnung der genetischen Diversität nach NEI (1978) (Tab. 16) können somit bestätigt werden. Die Resultate der Varianzanalyse sind demnach ein Hinweis darauf, dass es sich bei den untersuchten Populationen nicht um voneinander getrennte Subpopulationen handelt, die sich aufgrund unterschiedlicher Landschaftsstrukturen entwickelt haben. 


\section{Diskussion}

Im Rahmen des Bioplex-Projektes wurde der Einfluss von Landschaftsstrukturen auf die Biodiversität der wichtigsten funktionellen Tiergruppen, sowie phytopathogener Pilze untersucht. Die erforderlichen Analysen zur Bewertung des Zusammenhangs zwischen Biodiversität und Landschaftsstruktur wurden auf unterschiedlichen räumlichen Skalenebenen durchgeführt; auf lokaler und regionaler Ebene. Als Datengrundlage wurden 19 Weizenfelder gewählt, die in Landschaftsausschnitten lagen, die ein Kontinuum von einfach, monoton strukturierten Raumeinheiten bis hin zu komplexen Systemen aus Hecken, Wäldern, Brachen, Grünland etc. abdeckten. Der sich ergebende Gradient wurde bereits in Kap. 2.3.1. in Abb. 3 dargestellt. Zur Vermeidung von Verzerrungseffekten wurden in dieser Arbeit weitere Einflussfaktoren wie Agrarbewirtschaftungsmaßnahmen der Weizenfelder und landwirtschaftliche Nutzung innerhalb der Landschaftsausschnitte in die Bewertung mit einbezogen, da diese sich nicht getrennt von möglichen Einflüssen verschiedener Landschaftsstrukturen betrachten lassen.

Zunehmende Intensivierung der Landwirtschaft ist aus phytopathologischer und ökologischer Sicht nicht unproblematisch, da sie zum einen das vermehrte Auftreten monotoner Landschaften fördert, deren Vegetation von wenigen Nutzpflanzen dominiert wird. Daraus resultiert die Zerstörung und Fragmentierung natürlicher Lebensräume und führt zu einer Verminderung von Biodiversität (SAUNDERS et al. 1991). Zum anderen fördert intensive Landwirtschaft die Spezialisierung von Pathogenen, z. B. in Form von Resistenzen gegenüber Pflanzenschutzmitteln. Daraus lässt sich ableiten, dass die Wirkung landwirtschaftlicher Nutzung auf Biodiversität wesentlich durch die räumliche Komplexität einer Landschaft beeinflusst wird, z. B. von der Verfügbarkeit von Nahrungsquellen. GUTSCHE \& ENZIAN (2002) vertreten die Hypothese, dass zum Schutz der Biodiversität und für einen geringen Einsatz chemischer Pflanzenschutzmittel Naturräume über eine gewisse „Mindestausstattung“ verfügen müssen. 


\subsection{Einfluss der Landschaftsstruktur auf blattpathogene Pilze an Weizen unter Einbeziehung von Bewirtschaftungsparametern}

Die zunehmende Weizendominanz in der europäischen Kulturlandschaft begünstigt die Entwicklung ertragsmindernder Weizenpathogene, wie z. B. Septoria tritici, Septoria nodorum, Drechslera tritici-repentis, Blumeria graminis f. sp. tritici, Puccinia recondita und Puccinia striiformis. Seit einigen Jahren gewinnt der Blattdürre-Erreger Septoria tritici zunehmend an Bedeutung (EYAL 1999, MÜLLER \& HABERMEYER 2001) und kann zu Ertragsverlusten von bis zu 30 Prozent führen (s. Kap. 1.).

Auch Drechslera tritici-repentis (DTR) gewinnt zunehmend an wirtschaftlicher Bedeutung im Weizenanbau (s. Kap. 1.). Echter Weizenmehltau, Septoria nodorum, sowie Gelb- und Braunrost sind ebenfalls wichtige blattpathogene Pilze an Winterweizen, jedoch nicht von so hoher wirtschaftlicher Bedeutung wie $S$. tritici und DTR.

Um dem Befall des Weizens mit den o. g. sechs Pilzen vorzubeugen, werden vor allem tolerante/resistente Sorten, Fungizide, mehrgliedrige Fruchtfolgen und Bodenbearbeitungsmaßnahmen eingesetzt. Zusätzlich werden für einen angemessenen Fungizideinsatz im integrierten Pflanzenschutzkonzept Warndienste (z. B. IPSWeizenmodell) und Prognosemodelle (z. B. SIMSEPT) per Internet zur Verfügung gestellt (HABERMEYER \& HOFFMANN 1994, ROBBERG et al. 2003). Diese Prognosemodelle und Warndienste werden fast ausschließlich auf der Grundlage von Wetterdaten erstellt und dienen einem gezielteren und damit wirtschaftlicheren Einsatz von Fungiziden. Der Einfluss von Landschaftsstrukturen wird nur standortbezogen in den integrierten Pflanzenschutz einbezogen (DENNERT \& FISCHBECK 2001), beispielsweise spricht man von sog. „Mehltaulagen“ in direkter Angrenzung an Waldstücke. Der Einfluss der weiträumigeren Umgebung findet hingegen keine Berücksichtigung.

Wie in Kap. 3.1.3. beschrieben, wurde die Befallshäufigkeit und die Befallsstärke der sechs blattpathogenen Pilze in Abhängigkeit verschiedener Landschaftsstrukturen untersucht. Im ersten Versuchsjahr (2001) wurden in den Regionen Göttingen und Giessen die Probenahmen an zwei Terminen (BBCH 47-51 und 65-69) auf 19 praxisüblich bewirtschafteten Feldern, die mit Fungiziden behandelt wurden, 
durchgeführt. Abweichend dazu wurden im zweiten Versuchsjahr (2002) sowohl in einem fungizidfreien Spritzfenster, als auch im fungizidbehandelten Teil der Felder (allerdings nur auf 10 Feldern in der Region Göttingen) an ebenfalls zwei Terminen (BBCH 39-42 und 65) Probenahmen vorgenommen.

Der Vergleich der mittleren Befallsstärken der sechs Pilze in den beiden untersuchten Regionen offenbarte sowohl im Jahr 2001, als auch im Jahr 2002 deutliche Unterschiede. In beiden Jahren trat sowohl in der Region Göttingen, als auch in der Region Giessen $S$. tritici als Hauptschaderreger auf, allerdings war dieser Pilz in der Region Göttingen im Jahr 2001 deutlich schwerwiegender vertreten, als in der Region Giessen, während es sich im zweiten Versuchsjahr umgekehrt verhielt. Insgesamt konnten in Bezug auf die Befallsintensität mit $S$. tritici allerdings keine regionalen Unterschiede in den beiden Untersuchungsjahren festgestellt werden. Dieses vermehrte Auftreten von $S$. tritici als Hauptschaderreger wird laut BÖTTGER et al. (2001) schon mehrere Jahre in der Praxis beobachtet.

Die anderen fünf untersuchten blattpathogenen Pilze traten in beiden Jahren verstärkt in der Region Giessen auf. Befall mit Gelbrost war im Versuchsjahr 2002 nur in der Region Giessen zu verzeichnen, Echter Weizenmehltau hingegen fast ausschließlich in der Region Göttingen. Das Spektrum blattpathogener Pilze war in der Region Giessen generell größer, der Befallsdruck aber geringer als in der Region Göttingen zu klassifizieren. In der Region Göttingen wurde der Befallsdruck im Winterweizen hauptsächlich durch die drei Pathogene S. tritici, Echter Weizenmehltau und DTR hervorgerufen.

Die beiden Regionen unterschieden sich hinsichtlich ihrer Landschaftsstruktur erheblich: während in Giessen komplex strukturierte Landschaften vorherrschten, zeichnete sich die Region Göttingen durch monotone Raumeinheiten mit wenig struktureller Vielfalt aus. Die beschriebenen Ergebnisse lassen darauf schließen, dass in komplex strukturierten Landschaften zwar eine größere Artenvielfalt an Pilzen vorkommt, der Befallsdruck dieser allerdings vergleichsweise gering ist. Im Gegensatz dazu dominieren in monotonen Landschaften nur einige wenige, dafür aber wirtschaftlich bedeutende Schaderreger ( $S$. tritici und DTR). Einschränkend ist festzustellen, dass der Hauptschaderreger an Winterweizen, S. tritici, auf allen Flächen regionsunabhängig und mit teilweise hoher Befallsstärke auftritt. Dieser 
Verzerrungseffekt lässt sich anhand der ermittelten Befallshäufigkeiten belegen, die im ersten Versuchsjahr auf allen Feldern zwischen 80 und 100 Prozent und im zweiten Versuchsjahr, abgesehen von wenigen Ausnahmen, zwischen 50 und 100 Prozent lagen.

Die Befallsstärke und -häufigkeit der untersuchten Pilze auf den Feldern einzelner Landschaftsausschnitte unterschieden sich in beiden Versuchsjahren signifikant voneinander. Außerdem trat auf Feldern komplex strukturierter Landschaftsausschnitte das gesamte Schaderregerspektrum mit geringer Befallsstärke auf, während auf Feldern wenig strukturierter Landschaftsausschnitte fast ausschließlich $S$. tritici mit hoher Befallsstärke zu finden war. Dieses Ergebnis impliziert einen deutlichen Einfluss von Landschaftsstrukturen auf das Auftreten und die Befallsstärke blattpathogener Pilze. Allerdings ergab sich in direkter Beziehung zwischen dem hauptsächlichen Landschaftsparameter Ackeranteil und der Befallsstärke und -häufigkeit der einzelnen Pilze keine signifikante Beziehung. Für $S$. tritici konnte im ersten Versuchsjahr am ersten Boniturtermin keine und am zweiten Boniturtermin nur eine leichte Abhängigkeit (Bestimmtheitsmaß $r^{2}=0,1048$; lineare Regression) zwischen mittlerer Befallsstärke des Pilzes und Ackeranteil festgestellt werden. Im zweiten Versuchsjahr war sowohl am ersten, als auch am zweiten Boniturtermin eine leichte Abhängigkeit $\left(\mathrm{r}^{2}=0,208\right.$ und 0,1605) zwischen Ackeranteil und mittlerer Befallsstärke von S. tritici festzustellen. Außerdem zeigte sich, wie bereits in Kap. 3.1.3.2. beschrieben, im zweiten Versuchsjahr ein deutlich niedrigerer Befall auf den Flächen 5.1 und 1.2 am zweiten Boniturtermin, die vor diesem Boniturtermin einer wirksamen Fungizidbehandlung unterlagen. Ohne Einbeziehung dieser Werte ergab sich eine engere Korrelation zum Ackeranteil $\left(r^{2}=0,3623\right)$.

Auffällig war außerdem, dass die Abhängigkeit vom Landschaftsparameter Ackeranteil im Vergleich der Befallsstärken der behandelten Flächen in Göttingen im Jahr 2002 deutlich größer war, als im Vergleich der unbehandelten Flächen. Dieser engere Zusammenhang konnte auch auf den unbehandelten Flächen, trotz getrennter Darstellung der zehn Göttinger Flächen von den Giessener Flächen, nachgewiesen werden. In diesem Fall stieg das Bestimmtheitsmaß am ersten Termin auf $r^{2}=0,5221$ und am zweiten Termin auf $\mathrm{r}^{2}=0,4135$. Ohne die am zweiten Termin mit Fungiziden behandelten Flächen 5.1 und 1.2 in die Berechnung mit einzubeziehen, stieg der Wert des Bestimmtheitsamßes sogar auf $r^{2}=0,8282$. Die Giessener Felder waren durch einen 
umgebenden Ackeranteil von 12 bis 65 Prozent charakterisiert, während die Göttinger Flächen durch einen Ackeranteil von 42 bis 92 Prozent gekennzeichnet waren. Es scheint daher, dass sich erst dann eine Abhängigkeit zwischen der Befallsstärke und dem Landschaftsparameter Ackeranteil ergibt, wenn dieser Parameter einen bestimmten Wert erreicht, unterhalb dieses Wertes bleibt er ohne Einfluss. Anhand der beschriebenen Ergebnisse lässt sich ein Schwellenwert von ca. 40 bis 50 Prozent postulieren, oberhalb dessen der Landschaftsparameter Ackeranteil Einfluss erhält.

Der Einfluss von Landschaftsstrukturen lässt sich nicht unabhängig von Bewirtschaftungsparametern betrachten. Eine wichtige Einflussgröße ist die angebaute Winterweizensorte und deren Einstufung in Anfälligkeits- bzw. Toleranzklassen. Im Jahr 2001 wurden nur drei verschiedene Sorten auf den untersuchten Feldern angebaut: Ritmo, Drifter und Contur. Für neun der 19 Felder fehlt die Angabe der Sorte, aufgrund der in Kap. 3.1.2 bereits erwähnten geringen Resonanz der befragten Landwirte. Drifter, Ritmo und die EU-Sorte Contur sind in der vergleichenden Sortenliste als anfällig (6) gegenüber Septoria tritici eingestuft. Aufgrund der fehlenden Daten für neun Felder lässt sich nur unter Vorbehalt folgern, dass ein Sorteneffekt auf den Pilz in diesem Versuchsjahr ausgeschlossen werden kann. Im zweiten Versuchsjahr wurden erneut die drei Sorten Drifter, Ritmo und Contur, sowie weiterhin Biscay, Ludwig, Xanthos, Dekan und Jubilar angebaut. Für sieben der 19 Felder fehlt in diesem Versuchsjahr die Angabe zur Sorte. Biscay ist in der Bundessortenliste ebenfalls mit 6, wie Ritmo, Drifter und Contur, eingestuft, Ludwig ist mit 5, Xanthos und Dekan mit 4 eingestuft. Das bedeutet, dass besonders Xanthos und Dekan, aber auch Ludwig weniger anfällig gegenüber S. tritici sind. Bei der Sorte Jubilar handelt es sich um eine veraltete Sorte, über die weder in der Bundessortenliste, noch im Internet Informationen zur Anfälligkeitseinstufung gefunden werden konnten. Generell gilt diese Sorte jedoch als anfällig und wird teilweise in Befallsversuchen eingesetzt (WEINERT, pers. Mitteilung 2003). Ein Sorteneinfluss, der sich durch geringere Befallsstärke mit $S$. tritici äußerte, konnte auch im zweiten Versuchsjahr trotz größeren Sortenspektrums nicht festgestellt werden. Beispielsweise lag die mittlere Befallsstärke des Pilzes auf dem Giessener Feld 12, auf dem die weniger anfällige Sorte Dekan angebaut wurde, zu den beiden Boniturterminen bei 11,5 und 14,4 Prozent. Dieses Feld ist durch einen Ackeranteil von 64,71 Prozent in der Umgebung charakterisiert. Im Vergleich dazu betrug die mittlere Befallsstärke von S. tritici auf dem Göttinger Feld 4.1, auf dem die anfällige Sorte 
Biscay angebaut wurde, zu den beiden Boniturterminen 8,0 und 6,2 Prozent. Dieses Feld ist durch einen Ackeranteil von 41,62 Prozent in der Umgebung gekennzeichnet.

Die anderen fünf untersuchten Pathogene verhielten sich gegenüber dem Parameter Ackeranteil indifferent. Zwischen der Befallsstärke und -häufigkeit des Echten Weizenmehltau und dem Ackeranteil konnte kein Zusammenhang festgestellt werden, während die Roste eine leicht negative Abhängigkeit zeigten. Die Befallsstärken der einzelnen Felder mit Septoria nodorum wiesen im ersten Versuchsjahr eine leicht positive, im zweiten Versuchsjahr jedoch eine negative Abhängigkeit vom Ackeranteil.

Bei DTR verhielt es sich genau umgekehrt, im ersten Versuchsjahr zeigte dieser Pilz eine negative, im zweiten Versuchsjahr eine positive Abhängigkeit vom Parameter Ackeranteil. DTR ist im wesentlichen von Bodenbearbeitung und Vorfrucht abhängig. Weizen nach Weizen und pfluglose Bodenbearbeitung fördern diesen Pilz (AMELUNG 1999, BARTELS \& RODEMANN 1998, KRÖCHER 1998b, MÜLLER et al. 2001). Dies bestätigte sich besonders im Versuchsjahr 2002 auf der Göttinger Fläche 5.1, auf der Winterweizen in Monokultur (Sorte 2002 Ritmo) bei pflugloser Bodenbearbeitung angebaut wurde. Hier trat DTR am zweiten Boniturtermin mit einer mittleren Befallsstärke von 19,7 Prozent auf, obwohl eine Fungizidbehandlung stattgefunden hatte.

Laut BARTELS (2001) stellt der Anbau von Ritmo bei pflugloser Bodenbearbeitung ein „worst-case-scenario“ dar. Diese Aussage konnte hier eindeutig bestätigt werden. Im Jahr 2001 trat dieser Erreger besonders auf dem Giessener Feld 6 nach der Vorfrucht Winterraps auf, das ebenfalls pfluglos bearbeitet wurde. Auf diesem Feld wurde die DTR-anfällige Sorte Contur angebaut, also ebenfalls ein „,worst-case-scenario“ erzeugt. Die im Jahr 2001 überwiegend angebauten Sorten Ritmo, Drifter und Contur sind gegenüber DTR mittel- bis hochanfällig. Nur die im Jahr 2002 angebauten Sorten Ludwig (4) und Dekan (5) sind weniger anfällig gegenüber DTR eingestuft. Ein deutlicher Einfluss der Sorte zeigte sich daher auf dem Göttinger Feld 9.1, auf dem die Sorte Dekan angebaut wurde. Hier betrug die mittlere Befallsstärke des Pilzes am zweiten Boniturtermin trotz pflugloser Bodenbearbeitung nur 0,2 Prozent. Zudem ist festzustellen, dass in diesem Fall auch der Einfluss der Vorfrucht Zuckerrübe hemmend auf den Befall mit DTR gewirkt hat. Insgesamt lässt sich für DTR, den Erreger der 
Blattfleckenkrankheit, der in der Literatur beschriebene große Einfluss von Bodenbearbeitung, Vorfrucht und Sorte bestätigen. Ein Landschaftseinfluss spielt in diesem Zusammenhang keine bzw. nur eine untergeordnete Rolle.

Laut KREYE et al. (1999) ist generell das Auftreten von Pilzkrankheiten bei pflugloser Bodenbearbeitung stärker von der Vorfrucht abhängig als bei wendender Bodenbearbeitung. Mehltau und Roste werden allerdings von der Bodenbearbeitung nicht beeinflusst, was im Rahmen dieser Arbeit bestätigt werden konnte. Ebenfalls zu vernachlässigen ist der Einfluss von Landschaftsstrukturen auf Echten Weizenmehltau und Roste. Diese Pilze scheinen jahres- und standortabhängig zu sein. Echter Weizenmehltau bereitet seit mehreren Jahrzehnten Probleme durch seine schnelle Anpassung an Fungizidmaßnahmen. Bereits zwei Jahre nach erstmaligem Einsatz von Strobilurinen traten bei Blumeria graminis f. sp. tritici massive Resistenzprobleme auf (BERNHARD et al. 2000, RESCHKE 1999). Die untersuchte Fragstellung nach dem Einfluss von Landschaftsstrukturen scheint für diesen Pilz jedoch vernachlässigbar zu sein. Agrarbewirtschaftungsmaßnahmen, insbesondere der sinnvolle Einsatz von Fungiziden, spielt bei diesem Erreger eine übergeordnete Rolle.

Bei den untersuchten Rostpilzen, Puccinia striiformis und P. recondita ist aufgrund des leicht negativen Zusammenhangs zwischen Befallsstärke und -häufigkeit und dem Landschaftsparameter Ackeranteil anzunehmen, dass diese Pilze in komplex strukturierten Landschaften bessere Reproduktionsmöglichkeiten auf ihren Nebenwirten vorfinden. Der Nebenwirt von $P$. recondita (Braunrost) ist Berberitze, der von $P$. striiformis (Gelbrost) ist bisher nicht bekannt. Die beiden Erreger unterscheiden sich hauptsächlich in ihren Temperaturansprüchen. Während $P$. recondita eher an wärmere Klimate angepasst ist, kommt $P$. striiformis häufiger in kühleren Regionen vor (BOSSE \& DÖLGER 2001, EVERSMEYER \& KRAMER 2000).

Agrarbewirtschaftungsmaßnahmen beeinflussen die Entwicklung und das Schadausmaß von Rostpilzen direkt. PFLEEGER \& MUNDT (1998) fanden heraus, dass eine Erhöhung der Saatstärke einen leicht signifikanten, positiven Einfluss auf die Entwicklung von Braunrost hat und dass bei Mischung von Weizen mit wildem Hafer die Befallsstärke stark erhöht wurde. Verbreitet sind auch Interaktionen zwischen konkurrierenden Schadpilzen zu beobachten. So zeigte MADARIAGA (1986), dass bei 
Anwesenheit von $S$. tritici die Entwicklung von P. striiformis gehemmt wird. Beide Pilze kommen zwar gleichzeitig auf einem Blatt vor, $S$. tritici wirkt jedoch hypostatisch auf Gelbrost. Dies liegt vermutlich daran, dass es sich bei Gelbrost um einen biotrophen, bei $S$. tritici dagegen um einen nekrotrophen Organismus handelt.

Die Bedeutung von Septoria nodorum verringerte sich in den letzten Jahren, was auf jahres- und standortabhängige Bedingungen zurückzuführen ist. Dieser Pilz wurde zunehmend von Septoria tritici verdrängt, obwohl eine Studie von NOLAN et al. (1999) einen stimulierenden Effekt von $S$. tritici auf die Sporenproduktion von $S$. nodorum belegte. Einschränkend wurde in der Studie diese Interaktion jedoch als ,isolatabhängig“ tituliert. Die zunehmende Verbreitung von S. tritici scheint daher, wie eingangs bereits beschrieben, auf den verbreiteten Anbau anfälliger Weizensorten, frühe Saatzeiten, hohe Stickstoffdüngung, zunehmend verregnete Sommer und den Einsatz von Fungiziden zurückzuführen zu sein (LOVELL et al. 1997, MEIEN-VOGELER et al., 1994 POLLEY \& THOMAS 1991).

SIMON et al. (2003) stellten bei der Untersuchung des Einflusses von Stickstoffdüngung auf $S$. tritici fest, dass erhöhte Stickstoffdüngung zwar den Befall förderte, gleichzeitig aber dieser Einflussfaktor direkt an andere agronomische Maßnahmen, Sorteneinfluss und klimatische Bedingungen gebunden ist. Dies belegt erneut das komplizierte Zusammenspiel verschiedener Faktoren im KulturpflanzePathogen-Komplex.

Der erzielte Ertrag auf einem bewirtschafteten Feld ist ein Indikator für die Bewirtschaftungsintensität (TIEDEMANN, pers. Mitteilung 2004). Je höher die Erträge, desto höher ist auch die Intensität der Bewirtschaftung. Bei den in Kapitel 3.1.2. aufgeführten Erträgen der 19 untersuchten Felder handelt es sich um erwartete und nicht um tatsächlich erzielte Erträge, zum anderen ist kein Zusammenhang zur Bewirtschaftungsintensität erkennbar. Daher scheint der Indikator in diesem Zusammenhang vernachlässigbar zu sein.

Einer der wichtigsten Bewirtschaftungsparameter ist die Applikation von Fungiziden. Um die Ergebnisse dieser Arbeit unabhängig von diesem bedeutenden Einflussfaktor analysieren zu können, wurden im zweiten Versuchsjahr fungizidfreie Spritzfenster auf den Feldern eingerichtet. Der Einfluss von Fungiziden war daraufhin bei vergleichender 
Betrachtung der Befallsstärken im zweiten Versuchsjahr deutlich zu erkennen. Erstaunlich war jedoch, dass im ersten Versuchsjahr, in dem Fungizidapplikationen stattfanden, nur ein leichter Zusammenhang zwischen den Befallsstärken von S. tritici und dem Parameter Ackeranteil zu erkennen war. Im zweiten Versuchsjahr war der Zusammenhang hingegen auch im behandelten Teil der Felder der Region Göttingen deutlich.

Auch bei der Fruchtfolge handelt es sich, wie bereits beschrieben, um einen wichtigen Bewirtschaftungsparameter. In beiden Versuchsjahren bestanden große Unterschiede in Bezug auf die Fruchtfolgegestaltung zwischen den untersuchten Feldern der beiden Regionen. Das Spektrum reichte von reiner Winterweizen-Monokultur (Feld 5.1 und 12.1) bis hin $\mathrm{zu}$ viergliedrigen Fruchtfolgen mit Anbau von Hafer und Gerste als Gemisch (Feld 17) oder Anbau von Öllein (Feld 5). Weiterhin unterschieden sich die 19 untersuchten Felder hinsichtlich ihrer Saatstärken, Bodenbearbeitungsmaßnahmen und Düngungsstrategien (Kap. 3.1.2., Tab. 9, 11, 12 und 14), sowie des Einsatzes von Wachstumsreglern, Insektiziden und Herbiziden (Anhang, ATab. 1 und 2) in beiden Jahren deutlich voneinander.

Generell ließ sich auf Grundlage dieser Daten erkennen, dass mit abnehmender Diversität einer Landschaft Bewirtschaftungsmaßnahmen wie Fungizid-, Herbizid-, Insektizid- und Wachstumsreglereinsatz intensiviert wurden. Hingegen wiesen Saatstärke, Düngung, Fruchtfolge und Bodenbearbeitungsmaßnahmen keine Abhängigkeit zur Landschaftskomplexität bzw. Bewirtschaftungsintensität auf.

Einen wichtigen Einflussfaktorenkomplex auf die Entwicklung von Pathogenen stellen klimatische Bedingungen dar. PIETRAVALLE et al. (2003) belegten, dass der Infektionszyklus von Septoria tritici wesentlich von Temperatur, Niederschlagsmenge und Windstärke abhängig ist. Während niedrige Temperaturen die Entwicklung verzögern, begünstigen hohe Windstärken eine Ausbreitung des Pilzes durch Aneinanderreiben infizierter und gesunder Blätter. Die asexuellen Pyknidiosporen des Pilzes werden durch Regenspritzer verbreitet, also direkt durch die Niederschlagsmenge beeinflusst (SHAW \& ROYLE 1993). Weitere Parameter wie Blattnässedauer und Inokulum-Menge spielen bei der Infektion des Pilzes eine entscheidende Rolle (CHUNGU et al. 2001). 
In Untersuchungen von BANNON \& COOKE (1998) konnte zudem gezeigt werden, dass durch die Untersaat von Kleegras in Weizenbeständen die Verbreitung von $S$. tritici über Regenspritzer gehemmt ist. Dies ist insbesondere darauf zurückzuführen, dass Kleegras nicht zu den Wirtspflanzen von S. tritici gehört. Bei der Verbreitung durch Regenspritzer innerhalb eines kleinen Areals landen viele Pyknidiosporen des Pilzes auf der Nicht-Wirtspflanze Kleegras und verringern so den Befall des Weizens. Dies könnte eine wirksame ackerbauliche Maßnahme zur Reduktion des Befalls mit $S$. tritici darstellen.

BRENNAN et al. (1984) und ARSENIUK et al. (1998) wiesen direkten Einfluss von Temperatur, Niederschlag und Windstärke auf die Ver- und Ausbreitung von Septoria nodorum nach. Die untersuchten Rostpilze unterliegen ebenfalls dem Einfluss verschiedener Umweltbedingungen wie Temperatur und Wind (BOSSE \& DÖLGER 2001, EVERSMEYER \& KRAMER 2000, GEAGEA et al. 1999, HOVMØLLER et al. 2002). Echter Mehltau ist bekannt für seine extreme Windverbreitung. Die Konidien dieses Erregers können mit dem Wind über Strecken von mehreren hundert Kilometern Länge verbreitet werden (FRAHM 2000). Nur für die Epidemiologie des Erregers der Blattfleckenkrankheit, DTR, scheinen in erster Linie die beschriebenen ackerbaulichen Maßnahmen ausschlaggebend zu sein (MIELKE \& REICHELT 1999, RODEMANN \& BARTELS 2002, WOLF \& HOFFMANN 1994).

Aufgrund des komplexen Zusammenspiels zwischen Klima-, Bewirtschaftungs- und Landschaftsfaktoren im Kulturpflanze-Pathogen-Komplex ist eine Bewertung der Zusammenhänge schwierig. Aus den Ergebnissen der Felderhebungen dieser Arbeit lässt sich daher insgesamt feststellen, dass der Intensität der landwirtschaftlichen Nutzung in der Region Göttingen wesentlich größere Bedeutung zukommt als in der Region Giessen. Während im Giessener Raum bzw. im Lahn-Dill-Bergland Landwirtschaft fast ausschließlich im Nebenerwerb betrieben wird, herrscht im Göttinger Raum intensive Landwirtschaft vor. Es erscheint daher im Rahmen der beobachteten Ergebnisse sinnvoll, dem Einfluss verschiedener Landschaftsstrukturen nur eine untergeordnete Rolle beizumessen. Vielmehr ergeben sich die beobachteten Differenzierungen durch unterschiedliche Bewirtschaftungsintensitäten. 
Offenbar sind Landschaftsstruktur und Intensivierungsgrad miteinander verbunden. Der Komplexitätsgrad einer Landschaft ist direkt mit der entsprechenden Nutzung verbunden. Intensive Landwirtschaft wird hauptsächlich in monoton strukturierten Landschaften betrieben, während in komplexen Landschaften die landwirtschaftliche Nutzung nur eine untergeordnete Rolle spielt bzw. vermehrt Viehwirtschaft anstelle von Ackerwirtschaft betrieben wird. Dennoch können die beschriebenen Ergebnisse genutzt werden, um in komplex strukturierten Landschaften Pflanzenschutzmaßnahmen unter ökonomischen und ökologischen Gesichtspunkten gering zu halten. Aufgrund der geringen Befallsstärken der Pilze sind überzogene Bewirtschaftungsmaßnahmen nicht sinnvoll. In wenig komplex strukturierten Landschaften mit intensiver Landwirtschaft kann der Einfluss von Landschaften vernachlässigt werden. Hier muss den Agrarbewirtschaftungsmaßnahmen eine übergeordnete Rolle beigemessen werden. 


\subsection{Einfluss der Landschaftsstruktur auf die Aggressivität von Septoria tritici}

Populationen von Pathogenen lassen sich in vielfältiger Weise charakterisieren. Im Rahmen dieser Arbeit wurde die Feldaggressivität (Befallshäufigkeit und -stärke) von S. tritici in den Versuchsjahren 2001 und 2002 beschrieben. Die ermittelte Feldaggressivität des Pilzes konnte aufgrund der unterschiedlichen Weizensorten nicht sortenunabhängig dargestellt werden, so dass in Gewächshausversuchen zusätzlich eine sortenunabhängige Aggressivität der $S$. tritici Isolate auf zwei verschiedenen Weizensorten ermittelt wurde.

Bei diesen Weizensorten handelt es sich, wie in Kapitel 2.5.1. beschrieben, um eine für Septoria tritici anfällige Weizensorte (Monopol) und eine weniger anfällige Sorte (Cardos). In diesen Untersuchungen wurden insgesamt 172 Isolate der ersten Probenahme (BBCH 39-42, F-2 Blatt) des Versuchsjahres 2002 der sechs Felder 4.1, 5.1, 8.1, 12.1, 10 und 12, sowie einige Isolate aus dem fungizidbehandelten Teil der Felder 4.1 und 12.1 hinsichtlich ihrer Aggressivität charakterisiert. Von jedem Isolat wurde eine Sporensuspension in Wasser hergestellt und auf je 16 Pflanzen der beiden Sorten inokuliert (Kap. 2.5.3.). Nach Inkubation für 21 Tage wurde die befallene Blattfläche in Prozent bonitiert (Kap. 2.5.4.). Die Versuche belegten eine deutlich höhere Anfälligkeit der Sorte Monopol im Vergleich zur Sorte Cardos, die nach Einstufung der Bundessortenliste 2003 zu erwarten war. Laut dieser Liste wird die Anfälligkeit von Monopol gegenüber $S$. tritici mit 7, die Anfälligkeit von Cardos mit 4 eingestuft.

Nach genereller Einschätzung der Anfälligkeit der beiden verglichenen Weizensorten konnten mittels Aggressivitätsvergleich der Isolate einzelner Felder signifikante Unterschiede identifiziert werden. Die Aggressivität der Isolate der Felder 4.1 und 12.1 auf der Sorte Monopol war signifikant höher als die der anderen untersuchten Felder, die sich wiederum nicht signifikant voneinander unterscheiden. Der Vergleich der Befallsstärken der Isolate auf der weniger anfälligen Sorte Cardos bestätigte das beschriebene Bild. 
Ein Bezug der Aggressivität zum Landschaftsparameter Ackeranteil ließ sich in diesen Untersuchungen nicht feststellen. Feld 4.1 war durch einen sehr geringen Ackeranteil in der Umgebung charakterisiert, während Feld 12.1 durch hohen Ackeranteil gekennzeichnet war. Ein Vergleich der Befallsniveaus der S. tritici Isolate der einzelnen Felder auf der anfälligen Weizensorte Monopol zeigte zwar einen Anstieg der Befallsstärken mit steigendem Ackeranteil, allerdings war durch die bereits beschriebene hohe Befallsstärke des Feldes 4.1 und die vergleichsweise geringen Befallsniveaus der Felder 12.1F und 8.1 ein enger Zusammenhang zum Parameter Ackeranteil nicht möglich. Im Gegensatz zu den Befallsniveaus der Sorte Monopol waren die der Sorte Cardos durchgängig sehr gering und differierten wenig. Eine Abhängigkeit vom Ackeranteil ließ sich an dieser Stelle nicht erkennen.

Insgesamt lässt sich feststellen, dass die untersuchten Isolate von Septoria tritici signifikante Unterschiede in ihrer Aggressivität aufwiesen, die allerdings nicht in direkten Bezug zu ihrer Herkunft gestellt werden konnten.

In Untersuchungen von EYAL et al. (1985) wurden 79 Isolate des Pilzes aus 22 verschiedenen Ländern hinsichtlich ihrer Virulenz untersucht. Es konnte gezeigt werden, dass Virulenz und Aggressivität von S. tritici innerhalb und zwischen verschiedenen Ländern und Regionen sehr variabel sein kann. Zudem wiesen die Isolate hohe Spezifität gegenüber den angebauten Weizensorten auf. Beispielsweise waren Isolate aus Südafrika wesentlich virulenter gegenüber Sorten dieser Region als gegenüber Sorten aus anderen Regionen. Allerdings wiesen viele Isolate verschiedener Länder eine generell hohe Aggressivität gegenüber unterschiedlichen Weizensorten auf. AHMED et al. (1995) untersuchten die Aggressivität von 14 Septoria tritici Isolaten aus drei verschiedenen Regionen (Kalifornien, Oregon und Texas) auf zwei unterschiedlichen Weizensorten. Alle Isolate waren gegenüber den getesteten Weizensorten pathogen, wiesen aber große Unterschiede in ihrer Befallsstärke auf. Dieses Ergebnis konnte anhand der eigenen Untersuchungen bestätigt werden.

Abweichend zu den hier ermittelten Ergebnissen konnten jedoch AHMED et al. (1995) eine Herkunftsspezifität des Pilzes nachweisen. In einer Studie von MAMLUK et al. (1995) wurden sowohl Unterschiede in der Aggressivität verschiedener Isolate von $S$. tritici gegenüber verschiedenen Weizensorten dargestellt, als auch Unterschiede in der Aggressivität der Isolate verschiedener Regionen. 
Weizensorten unterscheiden sich u. a. in ihrer Entwicklungszeit. Der beanspruchte Entwicklungszeitraum des Weizens stellt einen weiteren Einflussfaktor auf die Spezifität der Isolat-Sorte Beziehung von S. tritici dar. Je schneller die Entwicklung, umso anfälliger ist die Sorte und umso höher ist die Befallsstärke des Pilzes (ARAMA et al. 1999). Allerdings scheint dieses Phänomen im Lauf der Entwicklung des Weizens ausgeglichen $\mathrm{zu}$ werden.

Viele Untersuchungen postulieren eine enge Beziehung zwischen Pilzisolat und Weizensorte. BROWN et al. (2001) untersuchten in Feldversuchen die Interaktion zwischen 71 Weizensorten und sechs Isolaten von Septoria tritici über einen Zeitraum von drei Jahren. Dabei wurde eine sehr enge Beziehung zwischen einzelnen Sorten und Isolaten festgestellt, die über den gesamten Versuchszeitraum stabil blieben. Gleichzeitig kristallisierten sich jedoch auch einige Sorten mit generell geringer Anfälligkeit gegenüber den getesteten Isolaten des Pilzes heraus.

Auch ARRAIANO et al. (2001), BRADING et al. (2002), COWGER et al. (2000), sowie KEMA et al. $(1996,1997)$ beschrieben sowohl für Keimlinge, als auch fertig entwickelte Weizenpflanzen verschiedener Sorten unter Gewächshaus- und Feldbedingungen eine enge Isolat-Sorte Interaktion. Im Gegensatz $\mathrm{zu}$ diesen Ergebnissen fanden CHEN et al. (1994) keine Hinweise, die Rückschlüsse auf eine Adaptation einzelner Pathotypen von Septoria tritici an den Wirt-Genotyp schließen ließen. Vorherrschende Meinung in der Literatur ist jedoch, dass es sich bei der Interaktion Pilzisolat-Weizensorte um eine Gen-für-Gen-Interaktion handelt. Daher wird im Folgenden nicht mehr der Begriff „Aggresivität“ sondern „Virulenz“ verwendet. Aggressivität umfasst das quantitative Ausmaß eines Befalls, während Pathogenität die qualitative Eigenschaft eines Pathogens beschreibt, eine Pflanze befallen zu können. Der Begriff Virulenz wird verwendet, wenn dem Befall nachgewiesenermaßen eine Gen-für-Gen Interaktion zugrunde liegt.

Die sog. Gen-für-Gen Beziehung ist bei der Interaktion von Pathogenen und ihren Wirtspflanzen weit verbreitet. Sie dient auf Seiten der Pflanze der aktiven Abwehr eines Pathogens, auf Seiten des Pathogens zur aktiven Überwindung dieser Abwehrmechanismen (BURDON 1997). Folglich geht mit dieser Interaktion eine spezifische Entwicklung von Rassen und Resistenzmechanismen einher, die wiederum 
von Umweltbedingungen gesteuert wird. THRALL \& BURDON (2002) postulierten, dass der Anteil sich entwickelnder Resistenzen und Virulenzen direkt von der räumlichen Verbreitung und der Populationsgröße abhängen.

McDONALD \& LINDE (2002) untersuchten Resistenzrisiken verschiedener Pathogene auf populationsgenetischer Ebene. Entscheidend für die Beständigkeit einer Resistenz ist das „evolutionary potential“ der Pathogene. Dieses Potential ist abhängig von der Mutationsrate, der Populationsgröße (,genetic drift“), der Verbreitungsart (,gene flow“) und der Art der Reproduktion. Bei Septoria tritici besteht aufgrund dieser Faktoren ein relativ hohes Resistenzrisiko. Die Populationen und die Mutationsrate sind sehr groß, der Pilz vermehrt sich sowohl sexuell als auch asexuell. Daher verfügt Septoria tritici laut dieser Einteilung über eine hohes „,evolutionary potential““.

Dies leitet zu der Schlussfolgerung, dass die Entwicklung und Verbreitung von Virulenzen und Resistenzen bei diesem Pilz ein sehr hohes Level erreicht, das in den eigenen Untersuchungen bestätigt werden konnte. Die getesteten 179 Isolate des Pilzes wiesen signifikante Unterschiede in ihrer Virulenz gegenüber den eingesetzten Weizensorten auf. Direkte Unterschiede zwischen Isolatgruppen einzelner Felder konnten nicht festgestellt werden, was sich vermutlich in der $\mathrm{zu}$ geringen geographischen Entfernung begründet.

Zudem wird die Interaktion Weizensorte-Isolat durch diverse weitere Faktoren beeinflusst. Beispielsweise waren Isolate von fungizidbehandelten Blättern einer Weizensorte signifikant virulenter als Isolate unbehandelter Blätter derselben Sorte (COWGER \& MUNDT 2002a). Im Gegensatz dazu zeigten die hier untersuchten Isolate aus den fungizidbehandelten Teilen der Felder 4.1 und 12.1 eine signifikant geringere Aggressivität im Vergleich zu Isolaten aus den unbehandelten Teilen derselben Felder.

Dieser Widerspruch ist durch die Weitervermehrung auf MYA-Medium zu erklären, das einen offensichtlichen Fitnessverlust der Isolate zur Folge hatte. Isolate aus den fungizidunbehandelten Spritzfenstern vollzogen nur einen Vermehrungszyklus auf dem genannten Medium und wurden anschließend bis zur Inokulation in Dauerkulturen auf Hafermehlagar unter Paraffin gelagert. Isolate aus den fungizidbehandelten Feldbereichen wurden über einen längeren Zeitraum für zusätzliche Untersuchungen zur Fungizidsensitivität (BECKER 2004) benötigt und 
daher über eine Vielzahl von Vermehrungszyklen auf MYA-Medium angezogen. Der mit dieser Anzuchtmethode verbundene Fitnessverlust der Isolate wurde zuvor bereits bei S. tritici und anderen Pilzarten beobachtet (WEINERT, pers. Mitteilung 2003).

Resistente Weizensorten stellen ein wichtiges Bekämpfungsmittel im integrierten Pflanzenschutz dar. Abgesehen von der Gefahr des Resistenzverlustes durch Adaptation des Pilzes, sind auch die Ertragseigenschaften resistenter Sorten reduziert. PARKER et al. (2004) testeten verschiede Weizensorte hinsichtlich ihrer Resistenz- und Ertragseigenschaften. Das Ergebnis dieser Studie lieferte die Erkenntnis, dass resistente Sorten oftmals einen geringeren Ertrag einbringen, als anfällige Sorten.

Weiterhin hat der Anbau von Mischungen anfälliger und resistenter Sorten als pflanzenbauliche Maßnahme laut COWGER \& MUNDT (2002b) keinen messbaren Einfluss auf die Fitness oder Pathogenität von Septoria tritici Isolaten.

Zusammenfassend ist festzuhalten, dass innerhalb verschiedener Populationen von Septoria tritici eine hohe Variabilität der Aggressivität einzelner Isolate besteht. Die Aggressivität unterliegt dabei der Gen-für-Gen-Interaktion zwischen Pilz und Pflanze, ist isolat- und sortenspezifisch und wird demnach als Virulenz bezeichnet. Zudem unterliegt die Virulenz offenbar geographischen Einflüssen (AHMED et al. 1995, EYAL et al. 1985, MAMLUK et al. 1995), die vermutlich aufgrund der geringen geographischen Entfernung in den eigenen Untersuchungen nicht nachgewiesen werden konnten. Ein direkter Einfluss von Landschaftsstrukturen auf die Virulenz von S. tritici Isolaten konnte nicht ermittelt werden, da die komplexen und sehr spezifischen Interaktionen einzelner Isolate (Rassen) mit verschiedenen Weizensorten mögliche Landschaftseinflüsse überlagern. 


\subsection{Einfluss der Landschaftsstruktur auf die genetische Variabilität von Septoria tritici}

Die genetische Variabilität verschiedener Pathogene wird seit vielen Jahren eingehend untersucht (u. a. CATEN \& NEWTON 2000, CHEN \& McDONALD 1996, McDONALD et al. 1995, SCHNIEDER et al. 2001). Untersuchungen dieser Art dienen meist der Unterscheidung verschiedener Pathotypen, der Identifizierung resistenter Isolate einer Population oder der Differenzierung von Populationen verschiedener Felder, Länder oder Kontinente. Direkte Einflüsse von Landschaftsstrukturen auf die genetische Variabilität phytopathogener Pilze wurden bisher noch nicht analysiert.

Bei Septoria tritici handelt es sich um einen weltweit bedeutenden Schadpilz an Weizen. Aufgrund seiner Häufigkeit und weiten Verbreitung wurde dieser Pilz im Rahmen dieser Arbeit zur Untersuchung der genetischen Variabilität in Abhängigkeit von Landschaftsstrukturen ausgewählt. Populationsgenetische Studien von Septoria tritici bzw. der Hauptfruchtform Mycosphaerella graminicola werden seit über einem Jahrzehnt durchgeführt (u. a. CHEN \& McDONALD 1996, BOEGER et al. 1993, McDONALD et al. 1995, SCHNIEDER et al. 2001, ZHAN et al. 2001, 2002a). Die zu diesem Zweck am häufigsten genutzten DNA-Markertechniken stellen dabei die RFLP (restriction fragment length polymorphism) sowie die DNA-Fingerprints dar (u. a. BOEGER et al. 1993, CHEN et al. 1994, CHEN \& McDONALD 1996, LINDE et al. 2002, McDONALD \& MARTINEZ 1990a, ZAHN et al. 2001, 2002b). Populationsgenetische Untersuchungen des Pilzes Mycosphaerella graminicola mit anderen Markertechniken wie z. B. AFLP und RAPD sind dagegen in der Literatur selten zu finden (u. a. KEMA et al. 2002).

In den Untersuchungen dieser Arbeit wurde zunächst aufgrund der einfachen und vergleichsweise kostengünstigen Handhabung mit der MP-PCR-FingerprintingMethode (microsatellite-primed polymerase chain reaction) gearbeitet, um die genetische Variabilität von S. tritici innerhalb verschiedener Landschaftsstrukturen zu bestimmen. Sogenannte Mikrosatelliten sind, in vielen Genomen vorkommende, einfache, sich wiederholende Basensequenzen, deren Anzahl und Ort auf dem Genom unbekannt sind und pilzart- und isolatspezifisch sein können. Nach entsprechenden Vorversuchen wurde in diesen Untersuchungen ein AC-Primer mit sich neun Mal 
wiederholender Sequenz $[\mathrm{AC}]_{9}$ zur genetischen Differenzierung der Isolate genutzt. Nachteilig an dieser Methode ist allerdings die hohe Unspezifität der amplifizierenden Primer. Dieser Ansatz erschien aufgrund der hohen Diversität der Isolate und der damit unmöglichen Vergleichbarkeit populationsgenetischer Daten von Septoria tritici vor dem Hintergrund unterschiedlicher Landschaften nicht als geeignet und wurde daher nicht weiter verfolgt.

Stattdessen wurde eine Mikrosatelliten-Methode für $S$. tritici etabliert. Für die populationsgenetischen Untersuchungen wurden ausschließlich Septoria tritici Isolate des ersten Probenahmetermins (BBCH 39-42) des Jahres 2002 untersucht. Diese stammten von F-2 Blättern verschiedener Pflanzen aus den fungizidfreien Spritzfenstern der o. g. Felder 10 und 12 der Region Giessen, sowie 4.1, 5.1, 8.1 und 12.1 der Region Göttingen. Pro Feld wurden zwischen 30 und 50 Isolate gewonnen. Zusätzlich wurden Isolate des F-3 Blattes aus dem fungizidbehandelten Teil der Göttinger Felder 4.1 und 12.1 in die Untersuchung mit einbezogen. Während auf diesen Feldern 2002 dieselbe Sorte (Biscay) angebaut wurde, unterschieden sie sich durch die umgebende Landschaftsstruktur. Feld 4.1 lag in einer komplex strukturierten Landschaft mit einem geringen Ackeranteil, die Landschaft von Feld 12.1 war hingegen sehr monoton und durch einen hohen Ackeranteil charakterisiert.

Es wurden 301 Pilzisolate erstellt und 290 davon populationsgenetisch untersucht. Die entsprechenden Mikrosatelliten der extrahierten DNA der Pilzisolate wurden mit drei verschiedenen Primern und zwei PCR-Konturen amplifiziert und mittels PolyacrylamidGel-Elektrophorese dargestellt. Grundlagen für diese Methode lieferten OWEN et al. (1998), die neun verschiedene Primer zur Amplifikation von Mikrosatellitenmotiven des Pilzes $S$. tritici testeten. Die von OWEN et al. (1998) beschriebene Methode wurde in mehreren Schritten modifiziert, um eine optimale Vergleichbarkeit der erzielten Ergebnisse zu erhalten. In dieser Arbeit wurden nur drei der neun Primer verwendet, die hoch reproduzierbare Ergebnisse lieferten. Wie in Kapitel 2.6.3.2. detailliert erläutert, handelte es sich bei den drei Primern um ST1A4 $[\mathrm{CGG}]_{7}$, ST1E7 $[\mathrm{CGG}]_{5}$ und ST2E4 $[\mathrm{GGC}]_{5}$, die als „forward“ wie „reverse“ Primer fungierten. Mit jedem Primer wird normalerweise nur eine Bande erzeugt, die Primer ST1E7 und ST2E4 erzeugten jedoch in allen Fällen pro Isolat zwei Banden, es handelt sich also um diallelische Mikrosatellitenmotive. 
Für jedes Isolat von $S$. tritici konnten mit der Mikrosatelliten-Methode 11 verschiedene Allele amplifiziert und so die 290 Isolate miteinander verglichen werden. Mit Hilfe des Statistikprogramms ARLEQUIN Vers. 2.00 (SCHNEIDER et al. 2000) wurden die Daten auf populationsgenetischer Ebene ausgewertet. Es wurde eine AMOVA (Analysis of molecular variance) durchgeführt, die zur Bestimmung genetischer Variabilität innerhalb und zwischen Populationen dient.

Als Resultat konnte ermittelt werden, dass die 290 Isolate aus 79 unterschiedlichen Genotypen von insgesamt 108 Möglichkeiten bei freier Kombination der jeweils drei bzw. vier Allele der drei eingesetzten Marker, die auf Grundlage der binären Matrix berechnet wurden. Demnach waren 73 Prozent der möglichen Genotypen in den untersuchten Pilzpopulationen wiederzufinden. Anschließend wurden auf Grundlage dieser Berechnungen Unterschiede in der genetischen Variabilität der Populationen von Septoria tritici zwischen den beiden Regionen Göttingen und Giessen, zwischen den untersuchten Feldern sowie Variabilität innerhalb eines Feldes und innerhalb eines Untersuchungsplots bestimmt. Die beiden Regionen wiesen nur eine sehr geringe genetische Variabilität von 5,37 Prozent auf (s. Kap. 3.3.2.). Zwischen den einzelnen Populationen der Felder innerhalb der Regionen herrscht eine Variabilität von 26,44 Prozent. Die größte genetische Variabilität besteht allerdings innerhalb der Population eines Feldes $(68,18 \%)$ und eines Untersuchungsplots $(63,81 \%)$. Das bedeutet, dass über $2 / 3$ der gesamten genetischen Variabilität von $S$. tritici innerhalb einer Feldpopulation bzw. innerhalb eines Untersuchungsplots, also innerhalb eines Quadratmeters, besteht.

Als Ergebnis kann festgehalten werden, dass es sich bei den untersuchten Populationen nicht um voneinander getrennte Subpopulationen handelt, die sich aufgrund unterschiedlicher Landschaftsstrukturen entwickelt haben. Vielmehr handelt es sich um eine Gesamtpopulation des Pilzes, die selbst auf kleinstem Raum wiederzufinden ist. Zahlreiche populationsgenetische Untersuchungen zur genetischen Diversität von Septoria tritici bzw. Mycosphaerella graminicola in der Literatur bestätigen die Ergebnisse dieser Arbeit. 
In Untersuchungen von SCHNIEDER et al. (2001) betrug die genetische Gesamtvarianz innerhalb einer Feldpopulation des Pilzes nahezu 96 Prozent. Obwohl nicht dieselbe Technik verwendet wurde, sondern die genetische Variabilität des Pilzes mittels AFLP (amplified fragment length polymorphism) ermittelt wurde, konnte die hohe Variabilität dieses Pilzes eindeutig gezeigt werden. Die hohe genetische Diversität von S. tritici wurde zudem in vielen weiteren Studien, die vor allem mit RFLP (restriction fragment length polymorphism) sowie DNA-Fingerprints arbeiten, belegt (u. a. CHEN et al. 1994, McDONALD et al. 1990a, 1990b, 1995, 1999, ZHAN et al. 2003 etc.).

Sexuelle Rekombinationsvorgänge scheinen demnach großen Einfluss auf die Populationsstruktur von S. tritici auszuüben. Untersuchungen zur Rekombination bei sexueller und asexueller Vermehrung des Pilzes wurden u. a. von BOEGER et al. (1993), McDONALD \& MARTINEZ (1991) und SCHNIEDER et al. (2001) eingehend beschrieben. Es wurden Anzahl und Verteilung identischer Multi-Locus-Haplotypen (MLH) innerhalb eines eng begrenzten Areals, beispielsweise innerhalb eines Feldes oder eines Untersuchungsplots, überprüft.

Ein hoher Anteil identischer MLH's definiert eine ausgeprägte asexuelle Vermehrung innerhalb einer Population. Gleiche MLH's stammen von unteren Blattetagen oder von Nachbarpflanzen, die im Zuge der asexuellen Vermehrung durch den sog. „splash-effect“ (SHAW \& ROYLE 1993) auf höher gelegene Blätter übertragen wurden. Zudem begünstigen hohe Windstärken eine Ausbreitung des Pilzes durch Aneinanderreiben infizierter und gesunder Blätter (PIETRAVALLE et al. 2003). Gleiche MLH's wurden zumeist innerhalb einer Läsion beobachtet, hingegen konnten in keiner der o.g. Untersuchungen identische MLH'S auf Pflanzen anderer Probeentnahmestellen gefunden werden.

In einer Studie von LINDE et al. (2002) wurde die genetische Diversität innerhalb von Läsionen eines Blattes, die durch Septoria tritici verursacht wurden, bestimmt. Es wurden 158 Isolate aus 5 verschiedenen Läsionen untersucht. Die erzielten Ergebnisse zeigten, dass diese Isolate aus 15 verschiedenen Genotypen bestanden. Innerhalb einer Läsion konnten davon zwei bis sechs unterschiedliche Genotypen nachgewiesen werden. Dies deutet darauf hin, dass die durch Septoria tritici verursachten Läsionen durch gleichzeitige Infektion mehrerer genetisch unterschiedlicher Ascosporen hervorgegangen sind und belegt somit den unerwartet großen Einfluss der sexuellen 
Rekombination auf die Populationsstruktur selbst innerhalb kleinster Ausschnittsflächen. McDONALD \& LINDE (2002) postulierten, dass je nach Größe des untersuchten Ausschnittes und Anzahl der untersuchten Isolate bis $\mathrm{zu} 700.000$ verschiedene Individuen von $S$. tritici innerhalb einer Feldpopulation existieren können.

Diese Annahme impliziert, dass der sexuelle Vermehrungszyklus des Pilzes nicht ausschließlich im Herbst auf Stoppelresten stattfindet und die dabei gebildeten flugfähigen Ascosporen die Neusaat (Primärinfektion) infizieren (SANDERSON 1972 VERRET et al. 1990b), sondern vielmehr auch während der Vegetationsperiode zeitgleich zum asexuellen Zyklus stattfinden muss (HUNTER et al. 1999, KEMA \& SILFHOUT 1997, ZHAN et al. 1998, 2000). Somit dienen die Ascosporen nicht nur als Inokulum zur Primärinfektion (SHAW \& ROYLE 1989), sondern tragen neben den asexuell gebildeten Pyknidiosporen, die u. a. über Regenspritzer neue Pflanzen infizieren können, zur Sekundärinfektion höher gelegener Blattetagen bei (ZAHN et al. 1998, 2000).

Die durch asexuelle Massenvermehrung entstehende klonale Populationsstruktur von Septoria tritici wird demnach während der Vegetationsperiode durch sexuelle Rekombinationsereignisse stark beeinflusst. Nach SCHNIEDER et al. (1998) ist die asexuelle Vermehrung und die Ausbreitung identischer Individuen nur innerhalb eines kleinen Raumes von Bedeutung. Das Verhältnis von asexueller $\mathrm{zu}$ sexueller Rekombination ist direkt von der Infektionsdichte abhängig (COWGER et al. 2002). In Jahren mit hohem Infektionsdruck ist die sexuelle Reproduktionsrate höher, als in Jahren mit geringer Infektionsstärke. Dennoch finden asexuelle und sexuelle Vermehrung von $S$. tritici in jedem Fall während der gesamten Vegetationsperiode statt.

Die durchgeführten Untersuchungen, sowie die aus der Literatur angeführten Ergebnisse belegen eine generell sehr hohe genetische Variabilität von Septoria tritici, die offenbar zu einem großen Teil auf häufige sexuelle Rekombination zurückzuführen ist. Die geringe genetische Differenzierung der Populationen unterstützt die Hypothese, dass sich Populationen des Pilzes nicht getrennt voneinander entwickelt haben, sondern im ständigen genetischen Austausch zueinander stehen und daher vielmehr Teile eines gemeinsamen Genpools darstellen (LINDE et al. 2002, SCHNIEDER et al. 2001). Eine 
Beziehung zwischen unterschiedlichen Landschaftsstrukturen und der genetischen Variabilität von Septoria tritici konnte nicht nachgewiesen werden.

BOEGER et al. (1993) stellten in Untersuchungen sehr geringe Unterschiede zwischen Populationen verschiedener geographischer Herkünfte fest. Mittels RFLP wurde die genetische Variabilität von zwei geographisch getrennten Populationen von S. tritici von BOEGER et al. (1993) verglichen. Diese stammten von je einem Feld in Oregon und Kalifornien (750 km Entfernung). In beiden Populationen herrschte, wie auch bei den untersuchten Populationen dieser Arbeit, die größte genetische Diversität innerhalb des Untersuchungsfeldes. Zwischen den geographisch getrennten Feldern bestand zwar nur eine geringe Diversität der Pilzpopulationen, es gab jedoch keine gemeinsamen Genotypen.

Dieses Phänomen konnte ebenfalls anhand der eigenen durchgeführten Analysen bestätigt werden. Die hier untersuchten acht Pilzpopulationen waren über deutlich geringere Distanzen getrennt als die in BOEGER's Untersuchungen (1993), die weiteste Entfernung betrug ca. $200 \mathrm{~km}$. Dennoch konnte gezeigt werden, dass Feld 10 (Region Giessen, komplexe Landschaftsstruktur, geringer Ackeranteil) und Feld 8.1 (Region Göttingen, monotone Lanschaftsstruktur, hoher Ackeranteil) nur zwei gemeinsame Genotypen besaßen und ansonsten nur je einen bzw. zwei gemeinsame Genotypen mit den fungizidbehandelten Teilen der Felder 4.1 und 12.1 der Region Göttingen teilten. $\mathrm{Zu}$ allen anderen untersuchten Feldern bestanden keine gemeinsamen Genotypen.

Es ist $\mathrm{zu}$ vermuten, dass diese gemeinsamen Genotypen auf die gewählte Mikrosatelliten-Methode und relativ geringe Anzahl untersuchter Allele zurückzuführen ist. Bei Erhöhung der Allelanzahl würde sich entsprechend eine noch höhere Variabilität zeigen, als bereits ermittelt wurde. McDONALD \& MARTINEZ (1991) berechneten mittels RFLP, dass mit einer Wahrscheinlichkeit von weniger als 7 x $10^{-7}$ zwei Isolate von Septoria tritici zufällig identische Bandenmuster aufweisen. Dennoch war die verwendete Methode aufschlussreich und vergleichbar mit der von BOEGER (1993), da die hohe genetische Variabilität von $S$. tritici innerhalb eines Feldes und die geringe Variabilität zwischen Feldern und Regionen belegt werden konnte. 
SCHNIEDER et al. (2001) untersuchten 203 Isolate von Septoria tritici von fünf unterschiedlichen Standorten in Deutschland mittels AFLP und konnten erneut eine sehr hohe genetische Variabilität des Pilzes innerhalb eines Feldes (96\%) identifizieren, während zwischen den Feldern eine Variabilität von nur vier Prozent bestimmt werden konnte.

In einer neuen, umfassenden Studie von ZHAN et al. (2003) wurden 1673 Isolate des Pilzes von 17 Weizenfeldern aus 11 Ländern von fünf Kontinenten über einen Zeitraum von sechs Jahren (1989-1995) mittels RFLP untersucht. Ergebnisse dieser Untersuchungen ergaben, dass innerhalb eines Untersuchungsplots (1-9 $\left.\mathrm{m}^{2}\right)$ eines Feldes 80 Prozent der gesamten, globalen genetischen Variabilität von S. tritici zu finden war. Innerhalb eines Feldes wurde sogar eine Gesamtvariabilität von über 90 Prozent ermittelt. Zwischen Feldern einer Region betrug die Variabilität nur ca. fünf Prozent, zwischen Feldern unterschiedlicher Kontinente sogar lediglich drei Prozent. Die geringe genetische Variabilität zwischen Populationen unterschiedlicher Kontinente deutet auf einen signifikanten Genfluss zwischen diesen Populationen hin.

Dieses Ergebnis bestätigt die Annahme von LINDE et al. (2002), die 1098 Isolate von Septoria tritici aus sieben Populationen von vier Kontinenten mit Hilfe der RFLPMethode untersuchten. Als Resultat ergab sich eine schwache, aber signifikante Korrelation zwischen genetischer und geographischer Distanz der verschiedenen Populationen. Hohe Migrationsraten von Individuen verursachen die Zunahme genetischer Ähnlichkeit zwischen Populationen. Die errechnete Migrationsrate (,infinite island model“" nach WRIGHT 1951) dieser Untersuchungen wies auf einen signifikanten Genfluss zwischen Populationen unterschiedlicher Kontinente hin. Die Hypothese, dass es sich bei Septoria tritici um einen Pilz handelt, der über eine weltweite Gesamtpopulation verfügt, die selbst auf kleinstem Raum innerhalb eines Feldes wiederzufinden ist, kann an dieser Stelle erneut bestätigt werden.

Ganzjährig, sexuell gebildete flugfähige Ascosporen stellen, wie bereits erwähnt, neben den während der Vegetationsperiode asexuell gebildeten Pycnidiosporen die wichtigste Verbreitungsart von Septoria tritici bzw. Mycosphaerella graminicola dar (HUNTER et al. 1999, SANDERSON 1972, SCOTT et al. 1988, SHAW \& ROYLE 1989, VERRET et al. 1990b, ZHAN et al. 1998, 2000). Die Luftverbreitung der Ascosporen erklärt den 
Genfluss auf regionaler Basis (1-10 km) (LINDE et al. 2002), nicht jedoch die geringe genetische Diversität zwischen geographisch getrennten Populationen unterschiedlicher Kontinente.

Ursache für den Genfluss zwischen Kontinenten stellt laut BOEGER et al. (1993) und McDONALD et al. (1999) der interkontinentale Handel mit kontaminiertem Saatgut bzw. Getreide oder Verschleppung infizierten Pflanzenmaterials (BROKENSHIRE 1975) dar. Ausbreitung über Wind und Nebenwirte wie Poa pratensis, P. annua, $P$. trivialis, Bromus mollis, B. steriles, Holcus lanatus, Agropyron repens, Alopecurus pratensis, Agrostis-, Festuca-, Vulpia-, und Hordeum-Arten (HOFFMANN \& SCHMUTTERER 1983) ist demnach kein ausreichender Erklärungsgrund für die weltweit geringe genetische Diversität von Septoria tritici.

Die beschriebenen Untersuchungen leiten erneut $\mathrm{zu}$ dem Schluss, dass die unterschiedlichen Populationen des Pilzes einem gemeinsamen Genpool entspringen, dessen Ursprung für die Hauptfruchtform Mycosphaerella graminicola der mittlere Osten bildet (McDONALD et al. 1999). Alle Populationen des Pilzes stehen demnach in kontinuierlichem Austausch miteinander.

Aktuelle Untersuchungen von ZHAN et al. (2004) zeigen, dass im Gegensatz zur genomischen DNA des Pilzes die mitochondriale DNA verschiedener Populationen von S. tritici nur äußerst geringe Unterschiede aufweist. Dies ist laut ZHAN et al. (2004) auf Wirtsspezifität durch natürlichen Selektionsdruck der Wirtspflanzen zurückzuführen. Erstaunlich ist allerdings, dass die genomische DNA des Pilzes offenbar von natürlicher Selektion relativ unbeeinflusst bleibt und sich keine Subpopulationen einzelner Felder bilden. Eine Ausnahme bildet die künstliche Selektion durch Fungizide, die besonders in den letzten zwei Jahren zu einem Auftreten resistenter Isolate von S. tritici führten (FRAC 2002).

Der Literatur ist zu entnehmen, dass diese hohe genetische Diversität von Populationen pflanzenpathogener Pilze nicht nur bei S. tritici zu finden ist. Auch Populationen von Septoria nodorum verfügen über hohe genetische Variabilität innerhalb eines Feldes und nur geringe Variabilität zwischen Feldern (u. a. CATEN \& NEWTON 2000, KELLER et al. 1997a, 1997b, McDONALD et al. 1994). 
Desgleichen zeigt Gelbrost (Puccinia striiformis) hohe Variabilität innerhalb von Feldpopulationen und nur geringe Variabilität zwischen Feldern und sogar Kontinenten (CHEN et al. 2001, HOVM $\varnothing$ LLER et al. 2002, KOLMER 1997, McCALLUM et al. 1999, 2002, SHAN et al. 1997).

PARK et al. (2000) zeigten, dass auch verschiedene Populationen von Braunrost (Puccinia recondita) zumindest in Westeuropa sehr hohe genetische Ähnlichkeiten besitzen.

Anders verhält es sich bei dem Erreger der Kraut- und Knollenfäule der Kartoffel (Phytophthora infestans). Dieser Pilz weist deutliche geographische Substrukturierung in weiten Teilen der Welt auf (CARLISLE et al. 2001, ELANSKY et al. 2001, GRÜNWALD et al. 2001, JAIME-GARCIA et al. 2001, PEREZ et al. 2001).

Ebenso zeigt der Erreger einer bakteriellen Fäule an Reis, Xanthomonas oryzae, auf den Phillipinen sowohl eine hohe genetische Diversität innerhalb eines Feldes, als auch zwischen Feldern (ARDALES et al. 1996), was auf eine geographische Substrukturierung der Bakterienpopulationen innerhalb verschiedener Agrarökosysteme hinweist.

Fusarium-Arten verhalten sich offenbar indifferent. MIEDANER et al. (2001) belegten, dass Populationen von Fusarium graminearum aus Ungarn nur geringe genetische Diversität aufwiesen, während Populationen aus Deutschland und Russland sehr divers waren. In einer Studie von ROSEWICH GALE et al. (2002) wurde für verschiedene Populationen des Pilzes in China eine hohe genetische Diversität innerhalb und nur geringe Diversität zwischen diesen Populationen ermittelt.

Der Erreger der Blattfleckenkrankheit an Bananen, Mycosphaerella musicola, weist ebenfalls hohe genetische Diversität innerhalb einzelner Populationen auf, aber, im Gegensatz zu Mycosphaerella graminicola (Septoria tritici) zeigt dieser Pilz deutliche Einteilung in geographische Subpopulationen (HAYDEN et al. 2003a). Laut dieser Studie unterscheiden sich Populationen in Lateinamerika, der Karibik, Australien und Indonesien signifikant voneinander, so dass nicht von einem gemeinsamen Ursprung einer Gesamtpopulation ausgegangen werden kann. Geographische Einflüsse begründen eine unabhängige Strukturierung dieser Populationen. 
Auch bei Mycosphaerella fijiensis, dem Erreger der sog. „schwarzen Sigatoka“ an Bananen, lassen sich auf genetischer Ebene Subpopulationen in Australien, Papua Neu Guinea und den Pazifischen Inseln erkennen (HAYDEN et al. 2003b).

Zusammenfassend ist festzustellen, dass der Einfluss von Landschaftsstrukturen bzw. geographischer Lage bei einigen Pflanzenpathogenen offenbar mit der genetischen Diversität korreliert. Dieser Effekt konnte durch die nachgewiesene Aufspaltung in Subpopulationen, die sich auf verschiedenen Feldern einer Region oder in verschiedenen Ländern bzw. auf verschiedenen Kontinenten wiederfinden, belegt werden. Verbreiteter scheint jedoch das in dieser Arbeit ermittelte Phänomen des Auftretens einer weltweiten Gesamtpopulation verschiedener Pathogene $\mathrm{zu}$ sein. Insbesondere bei dem hier untersuchten blattpathogenen Pilz Septoria tritici ist die weltweite genetische Variabilität bereits innerhalb eines Feldausschnittes von 1-9 $\mathrm{m}^{2} \mathrm{zu}$ finden. Dies begründet sich durch die hohen sexuellen Rekombinationsraten und hohen Individuenzahlen (bis zu 700.000 Individuen) innerhalb eines Feldes (McDONALD \& LINDE 2002). Dementsprechend spielen Einflüsse von Landschaftsstrukturen auf die genetische Variabilität dieses Pilzes keine bzw. nur eine äußerst untergeordnete Rolle. 


\section{Zusammenfassung}

Diese Arbeit wurde im Rahmen des interdisziplinären Projektes Bioplex durchgeführt, dass sich mit dem Zusammenhang zwischen Biodiversität und räumlicher Komplexität in Agrarlandschaften beschäftigt. Die übergeordnete Hypothese des Projektes lautete, dass die biologische Vielfalt in der europäischen Kulturlandschaft eng mit dem Komplexitätsgrad der Landschaft verknüpft sei. Ziel der vorliegenden Arbeit entsprechend der übergeordneten Hypothese von Bioplex war es, den Einfluss von Landschaftsstrukturen am Beispiel der Regionen Göttingen und Giessen auf das Auftreten der blattpathogenen Pilze Septoria tritici, Septoria nodorum, Drechslera tritici-repentis, Blumeria graminis f. sp. tritici, Puccinia striiformis und Puccinia recondita $\mathrm{zu}$ untersuchen. Zusätzlich wurde die Aggressivität und genetische Variabilität von Septoria tritici-Populationen in Abhängigkeit von der Landschaftsdiversität analysiert.

Die Struktur einer Landschaft wurde dabei hinsichtlich ihrer Komplexität differenziert. Ein hoher Anteil an Hecken, Wiesen und Wäldern in unmittelbarer Umgebung des Untersuchungsfeldes beschrieb eine divers strukturierte Landschaft. Im Gegensatz dazu war eine monotone, wenig komplex strukturierte Landschaft durch weiträumige Ackerflächen in der Umgebung des Untersuchungsfeldes charakterisiert. Zugrundeliegender Landschaftsparameter war daher der Ackeranteil innerhalb eines Radius von drei Kilometern um jedes Versuchsfeld. Es wurden in beiden Versuchsjahren (2001 und 2002) zehn Felder der Region Göttingen sowie 9 Felder der Region Giessen untersucht.

Im Rahmen der Feldversuche wurden im ersten Versuchsjahr (2001) in den Regionen Göttingen und Giessen die Probenahmen an zwei Terminen (BBCH 47-51 und 65-69) auf 19 praxisüblich bewirtschafteten Feldern, die mit Fungiziden behandelt wurden, durchgeführt. Abweichend dazu wurden im zweiten Versuchsjahr (2002) sowohl in einem fungizidfreien Spritzfenster, als auch im fungizidbehandelten Teil der Felder (allerdings nur auf 10 Feldern in der Region Göttingen) an ebenfalls zwei Terminen (BBCH 39-42 und 65) Probenahmen vorgenommen.

Die Ergebnisse zeigten, dass das Spektrum der untersuchten blattpathogenen Pilze allgemein in der Region Giessen größer, das Befallsausmaß hingegen geringer war 
als in der Region Göttingen. Zudem nahm die Anzahl auftretender Pathogene in Feldern komplex strukturierter Landschaften ebenfalls $\mathrm{zu}$, während die Befallsstärke im Vergleich zu Feldern monotoner Landschaften abnahm. Dominantes Pathogen auf allen untersuchten Feldern beider Regionen in beiden Versuchsjahren war Septoria tritici. Dieser Pilz wies eine leichte Abhängigkeit vom Landschaftsparameter Ackeranteil auf, während sich die anderen untersuchten Pathogene gegenüber diesem Parameter indifferent verhielten.

Trotz dieses scheinbaren Zusammenhangs zwischen Landschaftsdiversität und Befallsstärke von Septoria tritici konnte dem Einfluss der Landschaft nur eine untergeordnete Rolle beigemessen werden. Insgesamt spielte die Intensität der landwirtschaftlichen Nutzung in der Region Göttingen eine wesentlich größere Rolle als in der Region Giessen. Während im Giessener Raum bzw. im Lahn-Dill-Bergland Landwirtschaft fast ausschließlich im Nebenerwerb betrieben wird, herrscht im Göttinger Raum intensive Landwirtschaft vor. Die beobachteten Differenzierungen ergaben sich demnach vielmehr durch unterschiedliche Bewirtschaftungsintensitäten.

Landschaftsstruktur und Intensivierungsgrad sind offenbar miteinander verbunden. Intensive Landwirtschaft wird hauptsächlich in monotonen Landschaften betrieben, während in komplex strukturierten Landschaften die landwirtschaftliche Nutzung nur eine untergeordnete Rolle spielt bzw. vermehrt Viehwirtschaft anstelle von Ackerwirtschaft betrieben wird. Dennoch können die beschriebenen Ergebnisse genutzt werden, um in komplex strukturierten Landschaften die Intensität von Pflanzenschutzmaßnahmen unter ökonomischen und ökologischen Gesichtspunkten gering zu halten. Aufgrund der geringen Befallsstärken der Pilze sind überzogene Bewirtschaftungsmaßnahmen nicht sinnvoll. In wenig komplex strukturierten Landschaften mit intensiver Landwirtschaft muss den Agrarbewirtschaftungsmaßnahmen eine übergeordnete Rolle beigemessen werden, während der Einfluss von Landschaftsstrukturen vernachlässigbar ist.

Bei den Untersuchungen zur Aggressivität von Septoria tritici wurde eine anfällige Weizensorte (Monopol) und eine weniger anfällige Sorte (Cardos) in Gewächshausversuchen getestet. In diesen Untersuchungen wurden insgesamt 172 Isolate hinsichtlich ihrer Aggressivität charakterisiert. Die Isolate stammten aus den 
fungizidfreien Spritzfenstern von sechs verschiedenen Feldern, sowie zusätzlich aus den fungizidbehandelten Teilen von zwei dieser Felder. Sie wurden am ersten Probenahmetermin (BBCH 39-42) des Versuchsjahres 2002 entnommen.

Die Ergebnisse dieser Analysen ergaben, dass innerhalb verschiedener Populationen von Septoria tritici eine hohe Variabilität der Aggressivität einzelner Isolate besteht. Die Aggressivität unterliegt dabei der Gen-für-Gen-Interaktion zwischen Pilz und Pflanze, ist isolat- und sortenspezifisch und wird demnach als Virulenz bezeichnet. Zudem unterliegt die Virulenz geographischen Einflüssen, die vermutlich aufgrund der geringen geographischen Entfernung in diesem Projekt nicht nachgewiesen werden konnten.

Ein direkter Einfluss von Landschaftsstrukturen auf die Virulenz von S. tritici Isolaten konnte nicht ermittelt werden, da die komplexen und sehr spezifischen Interaktionen einzelner Isolate (Rassen) mit verschiedenen Weizensorten mögliche Landschaftseinflüsse überlagern.

Im Rahmen der populationsgenetischen Untersuchungen wurden 290 Isolate von Septoria tritici mit Hilfe einer Mikrosatelliten-Methode analysiert. Diese Isolate stammten ebenfalls aus den fungizidfreien Spritzfenstern von sechs verschiedenen Feldern, sowie zusätzlich aus den fungizidbehandelten Teilen von zwei dieser Felder und wurden am ersten Probenahmetermin (BBCH 39-42) des Versuchsjahres 2002 entnommen. Pro Feld wurden zwischen 30 und 50 Isolate gewonnen. Für jedes Isolat von $S$. tritici konnten mit der Mikrosatelliten-Methode 11 verschiedene Allele amplifiziert werden.

Als Resultat konnte ermittelt werden, dass die 290 Isolate aus 79 unterschiedlichen Genotypen von insgesamt 108 Möglichkeiten bei freier Kombination der jeweils drei bzw. vier Allele der drei eingesetzten Marker bestanden. Demnach waren 73 Prozent der möglichen Genotypen in den untersuchten Pilzpopulationen wieder zu finden. Die beiden Regionen Giessen und Göttingen wiesen nur eine sehr geringe genetische Variabilität von 5,37 \% auf. Zwischen den einzelnen Populationen der Felder innerhalb der Regionen herrscht eine Variabilität von 26,44 \%. Die größte genetische Variabilität bestand allerdings innerhalb der Population eines Feldes $(68,18 \%)$ und eines Quadratmeters (63,81\%). Das bedeutet, dass über $2 / 3$ der gesamten genetischen Variabilität von $S$. tritici innerhalb einer Feldpopulation bzw. innerhalb eines Quadratmeters zu finden ist. 
Aus diesen Ergebnissen lässt sich ableiten, dass es sich bei den untersuchten Populationen nicht um voneinander getrennte Subpopulationen handelt, die sich aufgrund unterschiedlicher Landschaftsstrukturen entwickelt haben. Vielmehr handelt es sich um eine Gesamtpopulation des Pilzes, die selbst auf kleinstem Raum wieder zu finden ist. Dies ist auf den großen Einfluss von sexueller Reproduktion und entsprechend hohe Rekombinationsraten zurückzuführen. Einflüsse von Landschaftsstrukturen auf die genetische Variabilität dieses Pilzes spielen dementsprechend keine bzw. nur eine äußerst untergeordnete Rolle. 


\section{Literaturverzeichnis}

Ahmed, H. U., Mundt, C. C., Coakley, S. M. (1995): Host-pathogen relationship of geographically diverse isolates of Septoria tritici and wheat cultivars. Plant Pathology 44, 838-847

Altieri, F. (1995): Agroecology - the science of sustainable agriculture. Canadian Journal of Agricultural Economics 44, 199-201

AMELUNG, D. (1999): DTR-Blattfleckenkrankheit ist heimtückisch. Bauernzeitung 14, 34-35

Arraiano, L. S., Brading, P. A., Brown, J. K. M. (2001): A detached seedling leaf technique to study resistance to Mycosphaerella graminicola (anamorph Septoria tritici) in wheat. Plant Pathology 50, 339-346

Arama, P. F., Parlevliet, J. E., van Silfhout, C. H. (1999): Heading date and resistance to septoria tritici blotch in wheat not genetically associated. Euphytica 106, 63-68

Ardales, E. Y., Leung, H., Vera Cruz, C. M., Mew, T. W., Leach, J. E., Nelson, R. J. (1996): Hierarchical analysis of spatial variation of the rice bacterial blight pathogen across diverse agroecosystems in the Philippines. Phytopathology 86 (3), 241-252

Arseniuk, E., Góral, T., Scharen, A. L. (1998): Seasonal Patterns of spore dispersal of Phaeosphaeria spp. and Stagonospora spp. Plant Disease 82 (2), 187-194

BAnnon, F. J., Cooke, B. M. (1998): Studies on dispersal of Septoria tritici pycnidiospores in wheat-clover intercrops. Plant Pathology 47, 49-56 
BARTEls, G., Rodemann, B. (1998): Möglichkeiten der Bekämpfung von Drechslera tritici-repentis (Died.) Shoem., dem Erreger der Blattfleckenkrankheit an Weizen nach pflugloser Bestellung. Mitteilungen aus der Biologischen Bundesanstalt für Land- und Forstwirtschaft, 357, 87-88

BARTELS, G. (2001): Expertentipp - Reichen zwei Termine? DLG-Mitteilungen 2, 50

BECKER, E. (2004): Septoria tritici - Auftreten, Fungizidsensitivität und genetische Diversität in Abhängigkeit von verschiedenen Landschaftsstrukturen. Masterarbeit, Georg-August-Universität Göttingen

Bengtsson, J., Jones, H., Setälä, H. (1997): The value of biodiversity. Trends in the Ecology and Evolution 12, 334-336

Bernhard, U., Homa, U. und Green, E. (2000): Keine Kompromisse bei Echtem Mehltau. Getreide, 6 (2), 154-156

Bignal, E. M., McCracken, D. I. (1996): Low-intensity farming systems in the conservation of the countryside. Journal of Applied Ecology 33, 413-24

Boeger, J. M., Chen, R. S., McDonald, B. A. (1993): Gene flow between geographic populations of Mycospharella graminicola (anamorph Septoria tritici) detected with RFLP markers. Phytopathology 83, 1148-1154

Böttger, W., Kettel, M., Masemann, H., Kauke, J. (2001): Widerstandsfähigkeit der Sorten ist keine dauerhaft fixierte Größe. Land und Forst 15, 21-25

Bosse, W., Dölger, D. (2001): Expertentipp - Den Standort kennen. DLG-Mitteilungen 2,52

Brading, P. A., Verstappen E. C. P., Kema, G. H. J., Brown, J. K. M. (2002): A genefor-gene relationship between wheat and Mycosphaerella graminicola, the septoria tritici blotch pathogen. Phytopathology 92 (4), 439-445 
Brennan, R. M., Fitt, B. D. L., Taylor, G. S., Colhoun, J. (1984): Dispersal of Septoria nodorum pycnidiospores by simulated rain and wind. Phytopathologische Zeitung 112, 291-297

BROKENSHIRE, T. (1975): Wheat debris as an inoculum source for seedling infection by Septoria tritici. Plant Phathology 24, 202-207

Brown, J. K. M., Kema, G. H. J., Forrer, H.-R., Verstappen, E. C. P., Arraiano, L. S., Brading, P. A., Foster, E. M., Fried, P. M., Jenny, E. (2001): Resistance of wheat cultivars and breeding lines to septoria tritici blotch caused by isolates of Mycosphaerella graminicola in field trials. Plant Pathology 50, 325-338

Burdon, J. J., Shattock, R. C. (1980): Disease in plant communities. Applied Biology $5,145-219$

BuRDON, J. J. (1997): The evolution of gene-for-gene interactions in natural pathosystems. In: Crute, J. R., Holub, E. B., Burdon, J. J. (1997): The gene-forgene relationship in plant-parasite interactions. CAB International, 245-262

Carlisle, D. J., Cooke, L. R., Brown, A. E. (2001): Phenotypic and genotypic characterisation of Northern Ireland isolates of Phytophthora infestans. European Journal of Phytopathology 107, 291-303

CAten, C. E., Newton, A. C. (2000): Variation in cultural characteristics, pathogenicity, vegetative compatibility and electrophoretic karyotype within field populations of Stagonospora nodorum. Plant Pathology 49, 219-226

Chen, R. S., Boeger, J. M., McDonald, B. A. (1994): Genetic stability in a population of a plant pathogenic fungus over time. Molecular Ecology 3, 209-218

Chen, R. S., McDonald, B. A. (1996): Sexual reproduction plays a major role in the genetic structure of populations of the fungus Mycosphaerella graminicola. Genetics 142, 1119-1127 
Chen, X., Moore, M., Milus, E. A., Long, D. L., Fine, R. F., Marshall, D., Jackson, L. (2002): Wheat stripe rust epidemics and races of Puccinia striiformis f. sp. tritici in the United States in 2000. Plant Disease, 86 (1), 39-46

Chungu, C., Gilbert, J., Townley-Smith, F. (2001): Septoria tritici blotch development as affected by temperature, duration of leaf wetness, inoculum concentration and host. Plant Disease 85 (4), 430-435

Cockerham, C. C. (1973): Analysis of gene frequencies. Genetics 74, 679-700

Cowger, C., Hoffer, M. E., Mundt, C. C. (2000): Specific adaptation by Mycosphaerella graminicola to a resistant wheat cultivar. Plant Pathology 49, $445-451$

Cowger, C., McDonald, B. A., Mundt, C. C. (2002): Frequency of sexual reproduction by Mycosphaerella graminicola on partially resistant wheat cultivars. Phytopathology 92 (11), 1175-1181

Cowger, C., Mundt, C. C. (2002a): Aggressiveness of Mycosphaerella graminicola isolates from susceptible and partially resistant wheat cultivars. Phytopathology $92(6), 624-630$

Cowger, C., Mundt, C. C. (2002b): Effects of wheat cultivar mixtures on epidemic progression of septoria tritici blotch and pathogenicity of Mycosphaerella graminicola. Phytopathology 92 (6), 617-623

Czembor, P. C., Arseniuk, E. (1999): Study of genetic variability among monopycnidial and monopycnidiospore isolates derived from single pycnidia of Stagonospora spp. and Septoria tritici with the use of RAPD-PCR, MP-PCR and rep-PCR techniques. Journal of Phytopathology 147, 539-546

DENNERT, J., Fischbeck, G. (2001): Integrierter Fungizideinsatz in Winterweizen. Getreide 7 (1), 18-26 
DicE, L. R. (1945): Measures of the amount of ecological association between species. Ecology 26, 297-302

Elansky, S., Smirnov, A., Dyakov, Y., Dolgova, A., Filippov, A., Kozlovsky, B., Kozlovskaya, I., Russo, P., Smart, C., Fry, W. (2001): Genotypic analysis of Russian isolates of Phytophthora infestans from the Moscow region, Siberia and Far East. Journal of Phytopathology 149, 605-611

EversmeYer, M. G., Kramer, C. L. (2000): Epidemiology of wheat leaf and stem rust in the central great plains of the USA. Annual Review of Phytopathology 38, $491-513$

Eyal, Z., Scharen, A. L., Huffmann, M. D., Prescott, J. M. (1985): Global insights into virulence frequencies of Mycosphaerella graminicola. Phytopathology 75 (12), $1456-1462$

EYAL, Z. (1999): The septoria tritici and stagonospora nodorum blotch diseases of wheat. European Journal of Plant Pathology 105, 629-641

FrAC (2002): Mitteilungen des Fungicide Resistance Action Committee. www.frac.info/qoi/qoi_meeting2002.html

FRAHM, J. (2000): Wie Resistenz entsteht. DLG-Mitteilungen, 3, 50-54

GeageA, L., Huber, L., Sache, I. (1999): Dry-dispersal and rain-splash of brown (Puccinia recondita f. sp. tritici) and yellow (Puccinia striiformis) rust spores from infected wheat leaves exposed to simulated rain drops. Plant Pathology 48, $472-482$

GrÜnwald, N. J., Flier, W. G., Sturbaum, A. K., Garay-Serrano, E., van den Bosch, T. B. M., Smart, C. D., Matuszak, J. M., Lozoya-Saldana, H., Turkensteen, L. J., Fry, W. E. (2001): Population structure of Phytophthora infestans in the Toluca Valley region of Central Mexico. Phytopathology 91 (9), 882-890 
Gutsche, V., Enzian, S. (2002): Quantifizierung der Ausstattung einer Landschaft mit naturbetonten terrestrischen Biotopen auf der Basis digitaler topographischer Daten. Nachrichtenblatt des Deutschen Pflanzenschutzdienstes 54 (4), 92-101

HABERMeyer, J., Hoffmann, G. M. (1994): Strategie und Realisation der Einführung des Pflanzenschutz-Entscheidungsmodells („IPS Weizenmodell“) gegen Pilzkrankheiten an Weizen in die landwirtschaftliche Praxis. Journal of Plant Diseases and Protection 101 (6), 617-633

Hartl, D. L., Clark, A. G. (1989): Principles of Population Genetics. $2^{\text {nd }}$ Edition. Sinauer, Sunderland, Mass., USA

Hayden, H. L., Carlier, J., Aitken, E. A. B. (2003a): Population differentiation in the banana leaf spot pathogen Mycosphaerella musicola, examined at a global scale. Plant Pathology 52, 713-719

Hayden, H. L., Carlier, J., Aitken, E. A. B. (2003b): Genetic structure of Mycosphaerella fijiensis populations from Australia Papua New Guinea and the Pacific Islands. Plant Pathology 52, 703-712

Hunter, T., Coker, R. R., Royle, D. J. (1999): The telemorph stage, Mycosphaerella graminicola, in epidemics of septoria tritici blotch on winter wheat in the UK. Plant Pathology 48, 51-57

Hoffmann, G. M., Schmutterer, H. (1983): Parasitäre Krankheiten und Schädlinge an landwirtschaftlichen Kulturpflanzen. Verlag Eugen Ulmer, Stuttgart.

Hovm $\varnothing$ Ller, M. S., Justesen, A. F., Brown, J. K. M. (2002): Clonality and longdistance migration of Puccinia striiformis f. sp. tritici in north-west Europe. Plant Pathology 51, 24-32 
Jaime-Garcia, R., Orum, T. V., Felix-Castellum, R., Trinidad-Correa, R., VanEtten, H. D., Nelson, M. R. (2001): Spatial analysis of Phytophthora infestans genotypes and late blight severity on tomato and potatoe in the Del Fuerte valley using geostatistics and geographic information systems. Phytopathology 91 (12), $1156-1165$

Keller, S. M., McDermott, J. M., Pettway, R. E., Wolfe, M. S., McDonald, B. A. (1997a): Gene flow and sexual reproduction in the wheat glume bloth pathogen Phaeosphaeria nodorum (anamorph Stagonospora nodorum). Phytopathology $87(3), 353-358$

Keller, S. M., Wolfe, M. S., McDermott, J. M., McDonald, B. A. (1997b): High genetic similarity among populations of Phaeosphaeria nodorum across wheat cultivars and regions in Switzerland. Phytopathology 87 (11), 1134-1139

Kema, G. H. J., Annone, J. G., Sayoud, R., Silfhout, C. H. van, Ginkel, M. van, de Bree, J. (1996): Genetic variation for virulence and resistance in the wheatMycosphaerella graminicola pathosystem I. Interactions between pathogen isolates and host cultivars. Phytopathology 86 (2), 200-212

KemA, G. H. J., Silfhout, C. H. van (1997): Genetic variation for virulence and resistance in the wheat-Mycosphaerella graminicola pathosystem III. Comparative seedling and adult plant experiments. Phytopathology 87 (3), 266-272

Kema, G. H. J., Goodwin, S. B., Hamza, S., Verstappen, E. C. P., Calvaletto, J. R., Theo, A. J. Van der Lee, M., de Weerdt, P. J., Bonants, M., Waalwijk, C. (2002): A combined amplified polymorphism and randomly amplified polymorphism DNA genetic linkage map of Mycosphaerella graminicola, the septoria tritici leaf blotch pathogen of wheat. Genetics 161, 1497-1505

Kolmer, A. (1997): Virulence dynamics and genetics of cereal rust populations in North America. In: Crute, J. R., Holub, E. B., Burdon, J. J. (1997): The gene-forgene relationship in plant-parasite interactions. CAB International, 139-156 
KreYe, H., Garbe, V., Bartels, G., Hoppe, H.-H., Brunotte, J. (1999): Pflanzenschutz im Weizen bei konservierender Bodenbearbeitung. Getreide 5 (4), 180-183

KRÖCHER, C. von (1998a): Terminsache Blattdürre. DLG-Mitteilungen, 4, 26-29

KRÖCHER, C. von (1998b): DTR - eine zunehmende Gefahr für den Weizenanbau in Niedersachsen? Mitteilungen aus der Biologischen Bundesanstalt für Land- und Forstwirtschaft, 357, 86-87

LiNDE, C. C., Zhan, J., McDonald, B. A. (2002): Population structure of Mycosphaerella graminicola: From Lesions to Continents. Phytopathology 92, 946-955

Lovell D. J., Parker, S. R., Hunter, T., Royle, D. J., Coker R. R. (1997): Influence of crop growth and structure on the risk of epidemics by Mycosphaerella graminicola (Septoria tritici) in winter wheat. Plant Pathology 46, 126-138

Madariaga, R. B., Scharen, A. L. (1986): Interactions of Puccinia striiformis and Mycosphaerella graminicola on wheat. Plant Disease 70 (7), 651-654

MamLuK, O. F., Gilchrist, D. G., Singh, M. (1995): Variation in virulence in isolates of Mycosphaerella graminicola from six geographical wheat-growing regions. Phytopathologia Mediterana 34, 45-51

McCallum, B. D., Roelfs, A. P., Szabo, L. J., Groth, J. V. (1999): Comparison of Puccinia graminis f. sp. tritici from South America and Europe. Plant Pathology $48,574-581$

McDonald, B. A., Martinez, J. P. (1990a): DNA restriction fragment length polymorphism among Mycosphaerella graminicola (anamorph Septoria tritici) isolates collected from a single wheat field. Pythopathology 80, 1368-1373

McDonald, B. A., Martinez, J. P. (1990b): Restriction fragment length polymorphisms in Septoria tritici occur at a high frequency. Current Genetics 17, 133-138 
McDonald, B. A., Martinez, J. P. (1991): Chromosome length polymorphism in a Septoria tritici population. Current Genetics 19, 265-271

McDonald, B. A., Miles, J., Nelson, L. R., Pettway, R. E. (1994): Genetic variability in nuclear DNA in field populations of Stagonospora nodorum. Phytopathology $84(3), 250-255$

McDonald, B. A., Pettway, R. E., Chen, R. S., Boeger, J. M., Martinez, J. B. (1995): The population genetics of Septoria tritici (telemorph Mycospharella graminicola). Canadian Journal of Botany 71, 292-301

McDonald, B. A., Zhan, J., Yarden, O., Hogan, K., Garton, J., Pettway, R. E. (1999): The population genetics of Mycosphaerella graminicola and Stagonospora nodorum. In: Lucas, J. A., Bowyer, P., Anderson, H. M. (1999): Septoria on cereals: A study of pathosystems. CAB International, 44-69

McDonald, B. A., Linde, C. (2002): The population genetics of plant pathogens and breeding strategies for durable resistance. Euphytica, 124, 163-180

Meien-Vogeler, F., Bartels, G., Fehrmann, H. (1994): Distribution of Septoria tritici on wheat in germany and its regional importance. In:Proceedings of the $4^{\text {th }}$ International Septoria of cereals worksjop. IHAR, Radzikow, Poland, 299-300

Miedaner, T., Schilling, A. G., Geiger, H. H. (2001): Molecular genetic diversity and variation for aggressiveness in populations of Fusarium graminearum and Fusarium culmorum sampled from wheat fields in different countries. Journal of Phytopathology 149, 641-648

Mielke, H., Reichelt, A. (1999): Studien zur Biologie des Erregers Drechslera triticirepentis, zur Anfälligkeit des Weizens und verschiedener Artverwandten sowie zur Bekämpfung der DTR-Weizenblattdürre. Mitteilungen aus der Biologischen Bundesanstalt für Land- und Forstwirtschaft 366, 4-76 
MÜLLER, M., Habermeyer, J., (2001): Bewertung der Wirksamkeit moderner Fungizide gegen Septoria tritici und Drechslera tritici-repentis unter epidemiologischen Gesichtspunkten. Gesunde Pflanzen 53 (1), 7-14

Müller, M., Habermeyer, J., Petersen, H.-H. (2001): „Weizen Aktuell“- Das Infosystem für Getreidekrankheiten. Getreide 7 (2), 98-102

NEI, M. (1987): Molecular Evolutionary Genetics. Columbia University Press, New York

Nolan, S., Cooke, B. M., Monahan, F. J. (1999): Studies on the interaction between Septoria tritici and Stagonospora nodorum in wheat. European Journal of Plant Pathology 105, 917-925

OBst, A., Paul, V. H. (1993) : Krankheiten und Schädlinge des Getreides. Verlag Th. Mann, Ge-Buer

Owen, P. G., Pei, M., Karp, A., Royle, D. J., Edwards, K. J. (1998): Isolation and characterization of microsatellite loci in the wheat pathogen Mycosphaerella graminicola. Molecular Ecology 7, 1611-1612

PALMER, C.-L., Skinner, W. (2002): Mycosphaerella graminicola: latent infection, crop devastation and genomics. Molecular Plant Pathology, 3 (2), 63-70

PARK, R. F., Jahoor, A., Feslenstein, F. G. (2000): Population structure of Puccinia recondita in Western Europe during 1995, as assessed by variability in Pathogenicity and molecular markers. Journal of Phytopathology 148, 169-179

PArker, S. R., Welham, S., Paveley, N. D., Foulkes, J., Scott, R. K. (2004): Tolerance of septoria leaf blotch in winter wheat. Plant Pathology 53, 1-10

Perez, W. G., Gamboa, J. S., Falcon, Y. V., Coca, M., Raymundo, R., Nelson, R. (2001): Genetic structure of peruvian populations of Phytophthora infestans. Phytopathology 91 (10), 956-965 
Pfleeger, T. G., Mundt, C. C. (1998): Wheat leaf rust severity as affected by plant density and species proportion in simple communities of wheat and wild oats. Phytopathology, 88 (7), 708-714

Pietravalle, S., Shaw, M. W., Parker, S. R., van den Bosch, F. (2003): Modeling of relationships between weather and Septoria tritici epidemics on winter wheat: A critical approach. Phytopathology 93 (10), 1329-1339

Polley, R. W., Thomas, M. R. (1991): Surveys of diseases of winter wheat in England and Wales, 1976-1988. Annals of Applied Biology 119, 1-20

ReIMANN, S., Deising, H. B. (2000): Einschätzung der Fungizidresistenz bei Getreidepathogenen. Mitteilungen aus der Biologischen Bundesanstalt für Landund Forstwirtschaft, 376, 99

RESCHKE, M. (1999): Strobis in Gefahr. DLG-Mitteilungen, 1, 51

Rodemann, B., Bartels, G. (2000): Bekämpfung von Drechslera tritici-repentis und deren Wirtschaftlichkeit. Getreide, 1, 36-40

Rodemann, B., Bartels, G. (2002): Mit Sortenwahl und Fungizideinsatz die DTRBlattdürre bekämpfen. Getreide 1, 18-23

Rosewich Gale, L., Chen, L.-F., Hernick, C. A., Takamura, K., Kistler, H. C. (2002): Population analysis of Fusarium graminearum from wheat fields in eastern China. Phytopathology 92 (12), 1315-1322

RossBerg, D., Kluge, E., Jörg, E. (2003): SIMSEPT - ein neues Prognosemodell zum Auftreten von Septoria tritici und Septoria nodorum. Gesunde Pflanzen 55 (1), 8-12

Royle, D. J., Shaw, M. W., Cook, R. J. (1986): Patterns of development of Septoria nodorum and S. tritici in some whinter wheat crops in Western Europe 19811983. Plant Pathology 35, 466-476 
SANDERSON, F. R. (1976): Mycosphaerella graminicola (Fuckel) Sanderson comb. Nov., the ascogenous State of Septoria tritici Rob. Apud. Desm. New Zealand Journal of Botany 15 (4), 359-360

SAunders, D. A., Hobbs, R. J., Margules, C. R. (1991): Biological consequences of ecosystem fragmentation: a review. Conservation Biology 5; 18-32

ScotT, P. R., Sanderson, F. R., Bendikz, P. W. (1988): Occurence of Mycosphaerella graminicola, telemorph of Septoria tritici, on wheat debris in the UK. Plant Pathology 37, 285-290

Shan, W., Chen, S., Kang, Z., Wu, L., Li, Z. (1998): Genetic diversity in Puccinia striiformis Westend. f. sp. tritici revealed by pathogen genome-specific repetitive sequence. Canadian Journal of Botany 76, 587-595

SHAw, M. W., Royle, D. J. (1989): Airborne inoculum as a major source of Septoria tritici (Mycosphaerella graminicola) infections in winter wheat crops in the UK. Plant Pathology 38, 35-43

SHAW, M. W., Royle, D. J. (1993): Factors determining the severity of epidemics of Mycosphaerella graminicola (Septoria tritici) on winter wheat in the UK. Plant Pathology 42, 882-899

Schneider, S., Rosseli, D., Excoffier, L. (2000): Arlequin Ver. 2000: A software for population genetics analysis. Genetics and Biometry Laboratory: University of Geneva, Switzerland

SchniEder, F., Jung, C., Verreet, J. A. (1998): Untersuchungen zur Gen- und genotypischen Diversität von Septoria tritici in Deutschland durch die AFLPMarkertechnik. Mitteilungen aus der Biologischen Bundesanstalt für Land- und Forstwirtschaft, 357, 249-250 
Schnieder, F., Koch, G., Jung, C., Verreet, J. A. (2001): Genotypic diversity of the wheat leaf blotch pathogen Mycosphaerella graminicola (ananmorph Septoria tritici) in Germany. European Journal of Plant Pathology 107, 285-290

Silfhout, C. H. van, Arama, P. F., Kema, G. H. J. (1989): International survey of factors of virulence in Septoria tritici. Third Septoria workshop Zürich

Simón, M. R., Cordo, C. A., Perelló, A. E., Struik, P. C. (2003): Influence of nitrogen supply on the susceptibility of wheat to Septoria tritici. Journal of Phytopathology 151, 283-289

Sneath, P. H. A., Sokal, R. R. (1973): Numerical Taxonomy. Freeman, San Francisco

Thrall, P. H., Burdon, J. J. (2002): Evolution of gene-for-gene systems in metapopulations: the effect of spatial scale of host and pathogen dispersal. Plant Pathology 51, 169-184

Verreet, J. A., Hoffmann, G. M., Portner, J. (1990a): Zur Bekämpfung von Getreidekrankheiten in gemäßigten Klimaten. Pflanzenschutz-Nachrichten Bayer 43, 88-110

Verreet, J. A., Hoffmann, G. M., Portner, J. (1990b): Nachweis des Telemorph Mycosphaerella graminicola (Fuckel) Schroeter (Anamorph: Septoria tritici Rob. Apud Desm.) in der Bundesrepublik Deutschland. Journal of Phytophathology 130, 105-113

WehrmanN, A., Klink, H., Verreet, J.-A. (2000): Bewertung von Fungiziden zur Bekämpfung wichtiger Krankheitserreger des Weizens. Mitteilungen aus der Biologischen Bundesanstalt für Land- und Forstwirtschaft, 376, 83

Wolf, P. F. J., Hoffmann, G. M. (1994): Epidemiologisch begründetes Entscheidungsschema für eine integrierte Bekämpfung von Drechslera triticirepentis (Died.) Shoem., (teleomorph Pyrenophora tritici-repentis [Died.] Drechs.). Gesunde Pflanzen 46 (5), 164-173 
WoLF, P. (1998): DTR-Blattfleckenkrankheit des Weizens. Getreide, 1, 20-25

Wright, S. (1951): The genetical structure of populations. Annals of Eugenetics 15, 323-354

Wright, S. (1965): Evolution and the genetics of populations. The theory of gene frequencies. The University of Chicago Press, Chicago.

Zhan, J., Mundt, C. C., McDonald, B. A. (1998): Measuring immigration and sexual reproduction in field populations of Mycosphaerella graminicola. Phytophathology 88, 1330-1337

ZHAN, J., Mundt, C. C., McDonald, B. A. (2000): Estimating rates of recombination and migration in populations of plant pathogens. Phytophathology 90, 324-326

Zhan, J., Mundt, C. C., McDonald, B. A. (2001): Using RFLPs to assess temporal variation and estimate the number of ascospores that initiate epidemics in the field populations of Mycosphaerella graminicola. Phytopathology 91, 10111017

ZHAN, J., Mundt, C. C., Hoffer, M. E., McDonald, B. A. (2002a): Local adaptation and effects of host genotype on the evolution of virulence: an experimental test in a plant pathosystem. Journal of Evolutionary Biology 15, 634-647

ZhAN, J., Kema, G. H. J., Waalwijk, C., McDonald, B. A. (2002b): Distribution of mating type alleles in the wheat pathogen Mycosphaerella graminicola over spatial scales from lesions to continents. Fungal Genetics and Biology 36, 128136

ZhAn, J., Pettway, R. E., McDonald, B. A. (2003): The global genetic structure of the wheat pathogen Mycosphaerella graminicola is characterized by high nuclear diversity, low mitochondrial diversity, regular recombination and gene flow. Experimental Mycology 38 (3), 286-297 


\section{Anhang}

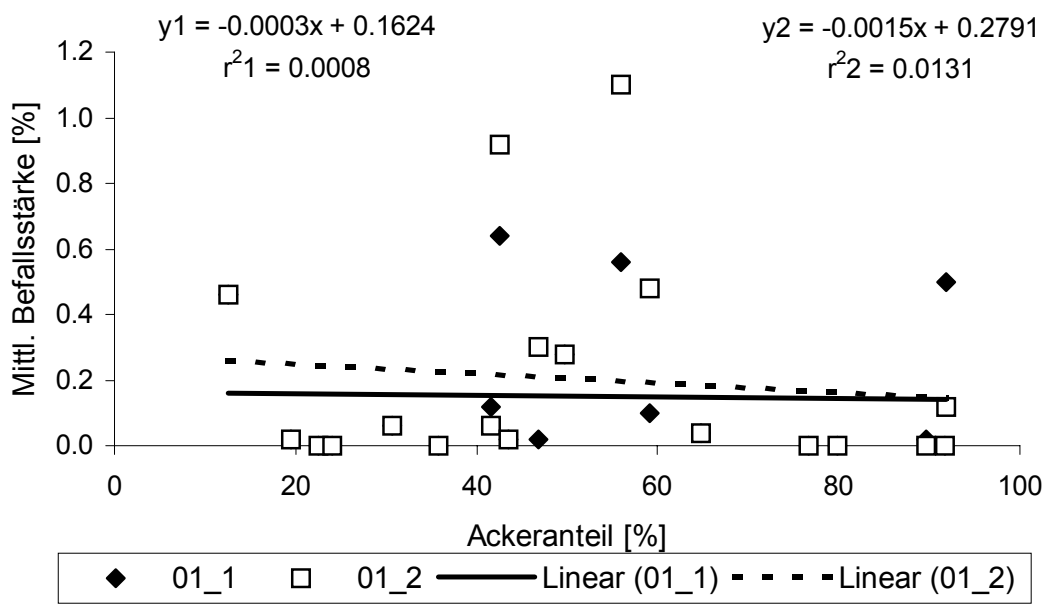

Abb. A1: Mittlere Befallsstärke (\% befallene Blattfläche des F-3 und F-2 Blattes) von Blumeria graminis f. sp. tritici im Verhältnis zum prozentualen Ackeranteil der Landschaften der Regionen Göttingen und Giessen zu BBCH 47-51 und 65-69 im Jahr 2001

Legende: 01_1: $\mathrm{BBCH}$ 47-51; 01_2: BBCH 65-69; y1: Regressionsgleichung 01_1; y2: Regressionsgleichung 01_2; $\mathrm{r}^{2} 1$ : Bestimmtheitsmaß 01_1; $\mathrm{r}^{2} 2$ : Bestimmtheitsmaß 01_2

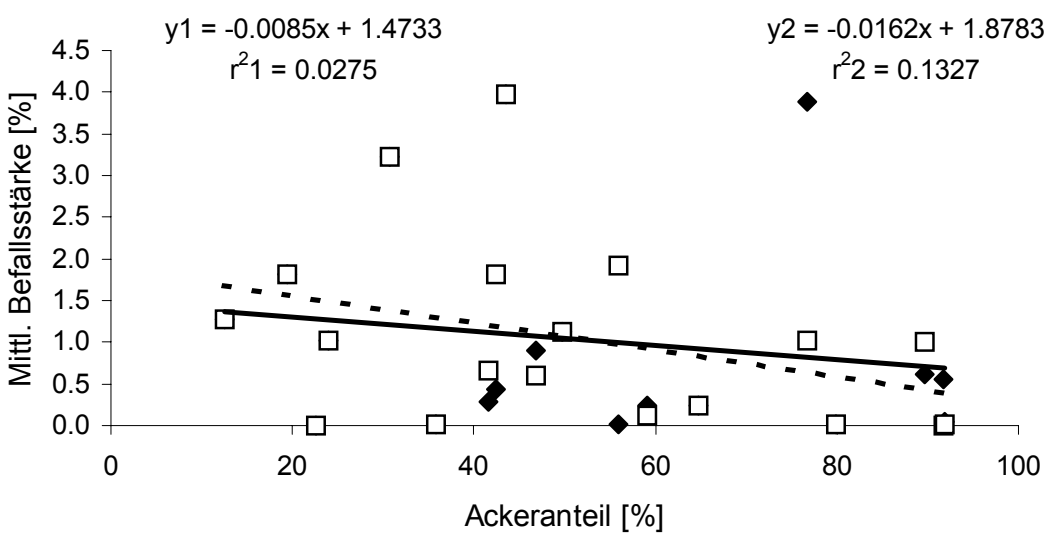

• 01_1 $\square \quad 01 \_2$ - - - Linear (01_2) Linear (01_1)

Abb. A2: Mittlere Befallsstärke (\% befallene Blattfläche des F-3 und F-2 Blattes) von Drechslera triticirepentis im Verhältnis zum prozentualen Ackeranteil der Landschaften der Regionen Göttingen und Giessen zu BBCH 47-51 und 65-69 im Jahr 2001

Legende: 01_1: BBCH 47-51; 01_2: BBCH 65-69; y1: Regressionsgleichung 01_1; y2: Regressionsgleichung 01_2; $\mathrm{r}^{2} 1$ : Bestimmtheitsmaß 01_1; $\mathrm{r}^{2} 2$ : Bestimmtheitsmaß 01_2 


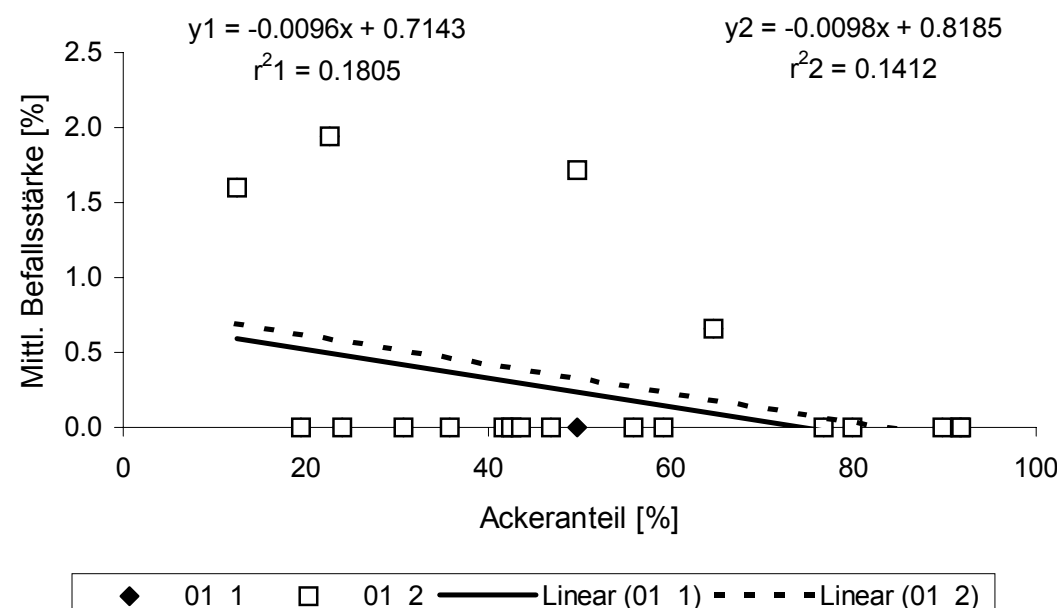

Abb. A3: Mittlere Befallsstärke (\% befallene Blattfläche des F-3 und F-2 Blattes) von Puccinia recondita im Verhältnis zum prozentualen Ackeranteil der Landschaften der Regionen Göttingen und Giessen zu BBCH 47-51 und 65-69 im Jahr 2001

Legende: 01_1: $\mathrm{BBCH}$ 47-51; 01_2: BBCH 65-69; y1: Regressionsgleichung 01_1; y2: Regressionsgleichung 01_2; $\mathrm{r}^{2} 1$ : Bestimmtheitsmaß 01_1; $\mathrm{r}^{2} 2$ : Bestimmtheitsmaß 01_2

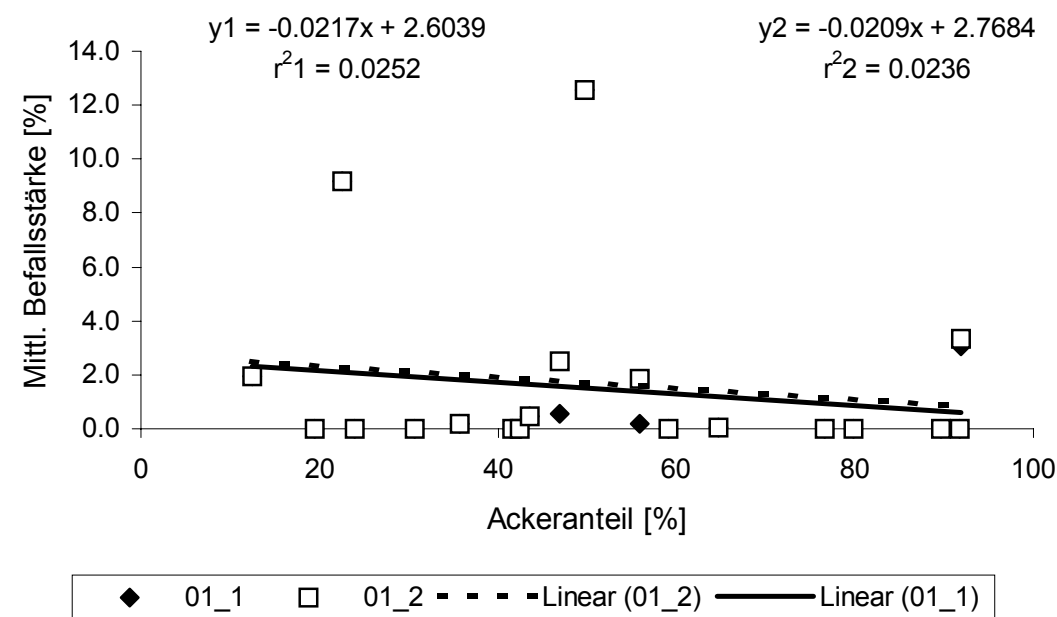

Abb. A4: Mittlere Befallsstärke (\% befallene Blattfläche des F-3 und F-2 Blattes) von Puccinia striiformis im Verhältnis zum prozentualen Ackeranteil der Landschaften der Regionen Göttingen und Giessen zu BBCH 47-51 und 65-69 im Jahr 2001

Legende: 01_1: BBCH 47-51; 01_2: BBCH 65-69; y1: Regressionsgleichung 01_1; y2: Regressionsgleichung 01_2; $\mathrm{r}^{2} 1$ : Bestimmtheitsmaß 01_1; $\mathrm{r}^{2} 2$ : Bestimmtheitsmaß 01_2 


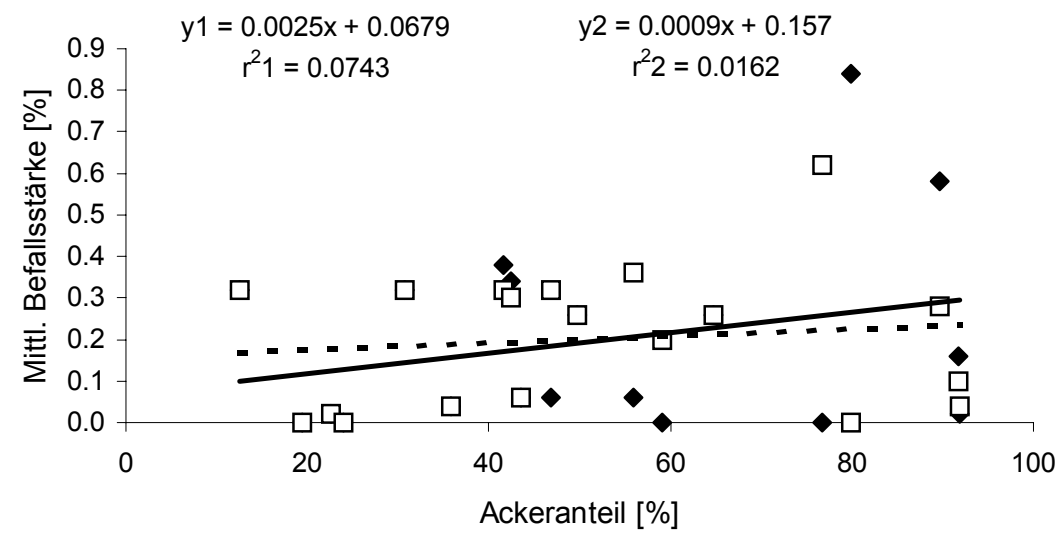

$\bullet \quad 01 \_1 \quad \square \quad 01 \_2---$ - Linear (01_2) Linear (01_1)

Abb. A5: Mittlere Befallsstärke (\% befallene Blattfläche des F-3 und F-2 Blattes) von Septoria nodorum im Verhältnis zum prozentualen Ackeranteil der Landschaften der Regionen Göttingen und Giessen zu BBCH 47-51 und 65-69 im Jahr 2001

Legende: 01_1: BBCH 47-51; 01_2: BBCH 65-69; y1: Regressionsgleichung 01_1; y2: Regressionsgleichung 01_2; $\mathrm{r}^{2} 1$ : Bestimmtheitsmaß 01_1; $\mathrm{r}^{2} 2$ : Bestimmtheitsmaß 01_2

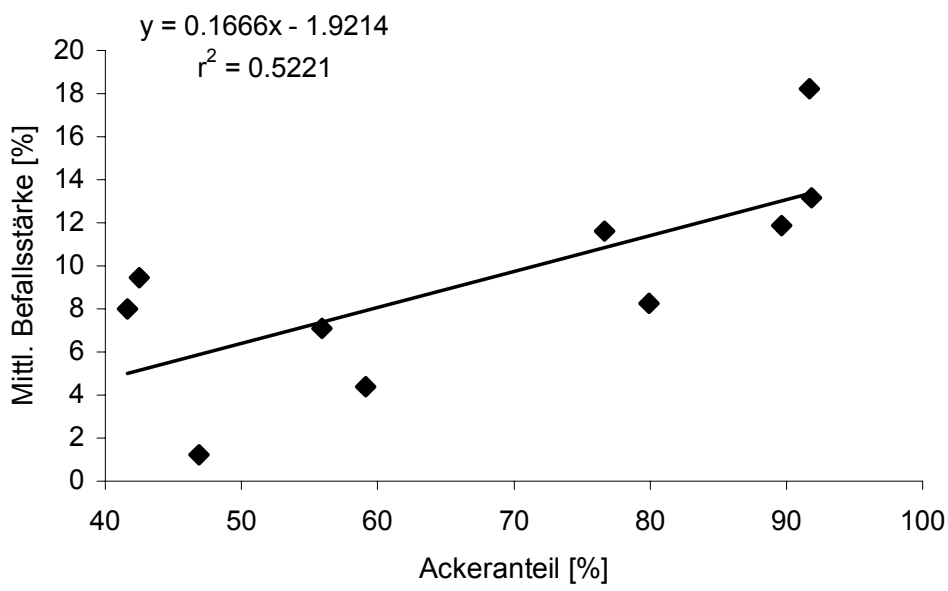

Abb. A6: Mittlere Befallsstärke (\% befallene Blattfläche des F-2 Blattes) von Septoria tritici im Verhältnis zum prozentualen Ackeranteil der Landschaften der Region Göttingen zu BBCH 3942 im Jahr 2002

Legende: y: Regressionsgleichung; ${ }^{2}$ : Bestimmtheitsmaß 


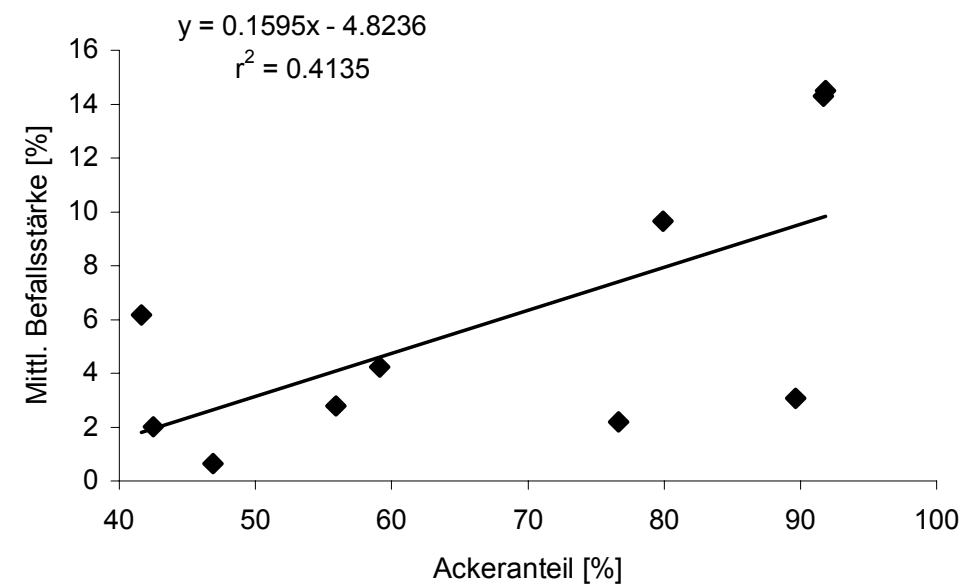

Abb. A7: Mittlere Befallsstärke (\% befallene Blattfläche des F-1 Blattes) von Septoria tritici im Verhältnis zum prozentualen Ackeranteil der Landschaften der Region Göttingen zu BBCH 65 im Jahr 2002

Legende: $y$ : Regressionsgleichung; $r^{2}$ : Bestimmtheitsmaß

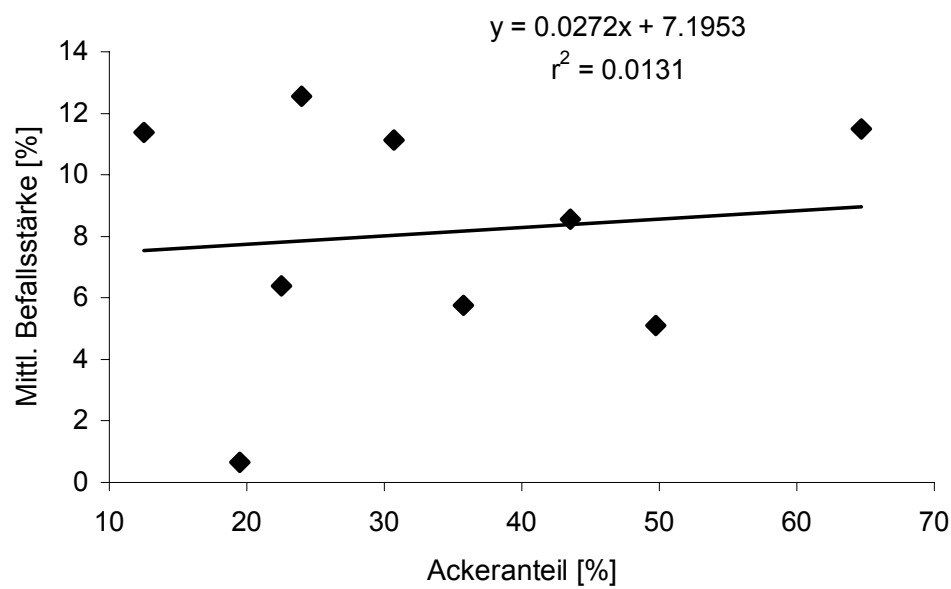

Abb. A8: Mittlere Befallsstärke (\% befallene Blattfläche des F-2 Blattes) von Septoria tritici im Verhältnis zum prozentualen Ackeranteil der Landschaften der Region Giessen zu BBCH 39-42 im Jahr 2002

Legende: $y:$ Regressionsgleichung; $r^{2}$ : Bestimmtheitsmaß 


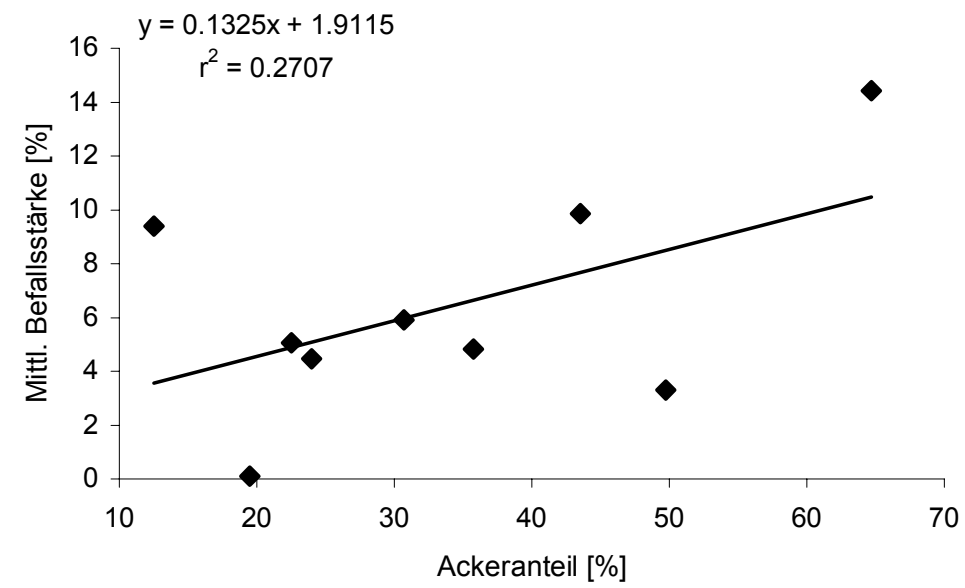

Abb. A9: Mittlere Befallsstärke (\% befallene Blattfläche des F-1 Blattes) von Septoria tritici im Verhältnis zum prozentualen Ackeranteil der Landschaften der Region Giessen zu BBCH 65 im Jahr 2002

Legende: y: Regressionsgleichung; $\mathrm{r}^{2}$ : Bestimmtheitsmaß

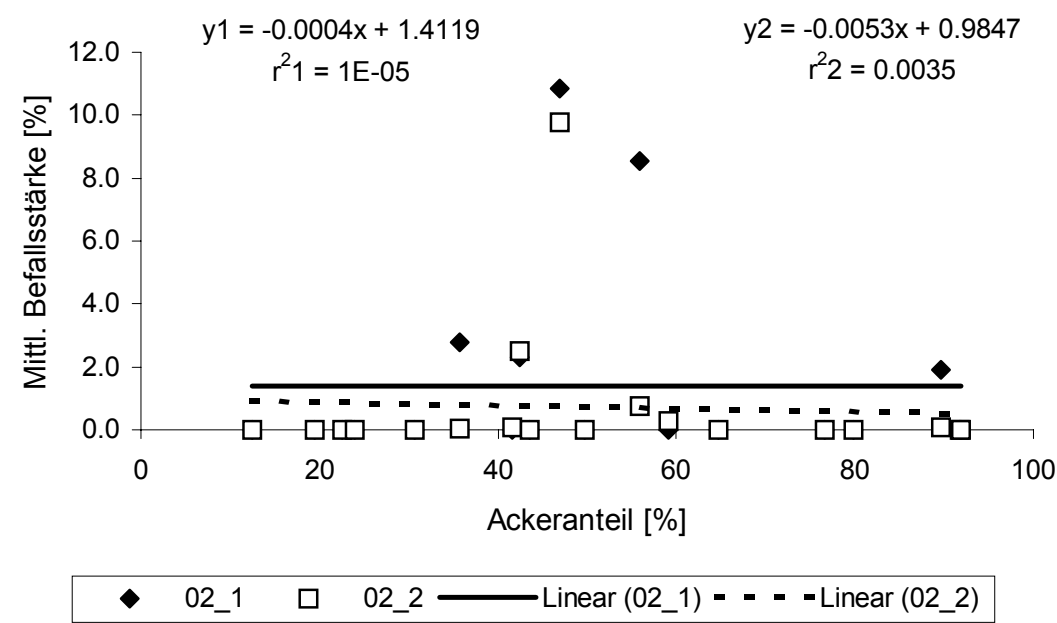

Abb. A10: Mittlere Befallsstärke (\% befallene Blattfläche des F-2 und F-1 Blattes) von Blumeria graminis f. sp. tritici im Verhältnis zum prozentualen Ackeranteil der Landschaften der Regionen Göttingen und Giessen zu BBCH 39-42 und 65-69 im Jahr 2002

Legende: 02_1: $\mathrm{BBCH}$ 39-42; 02_2: $\mathrm{BBCH}$ 65; y1: Regressionsgleichung 01_1; y2: Regressionsgleichung 01_2; $\mathrm{r}^{2} 1$ : Bestimmtheitsmaß 01_1; $\mathrm{r}^{2} 2$ : Bestimmtheitsmaß 01_2 


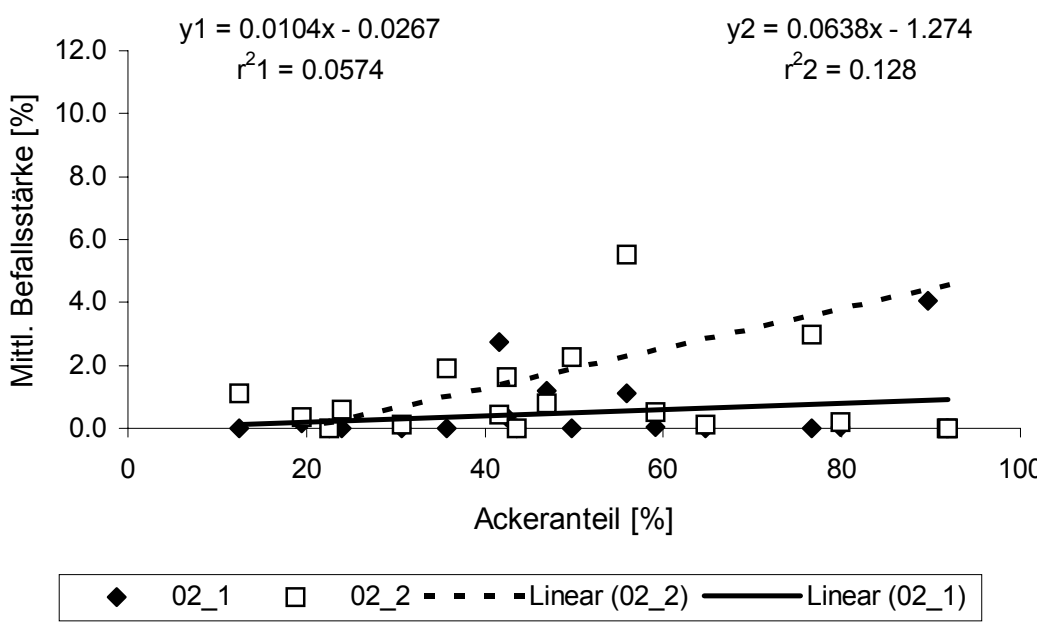

Abb. A11: Mittlere Befallsstärke (\% befallene Blattfläche des F-2 und F-1 Blattes) von Drechslera tritici-repentis im Verhältnis zum prozentualen Ackeranteil der Landschaften der Regionen Göttingen und Giessen zu BBCH 39-42 und 65-69 im Jahr 2002

Legende: 02_1: $\mathrm{BBCH}$ 39-42; 02_2: $\mathrm{BBCH}$ 65; y1: Regressionsgleichung 01_1; y2: Regressionsgleichung 01_2; $\mathrm{r}^{2} 1$ : Bestimmtheitsmaß 01_1; $\mathrm{r}^{2} 2$ : Bestimmtheitsmaß 01_2

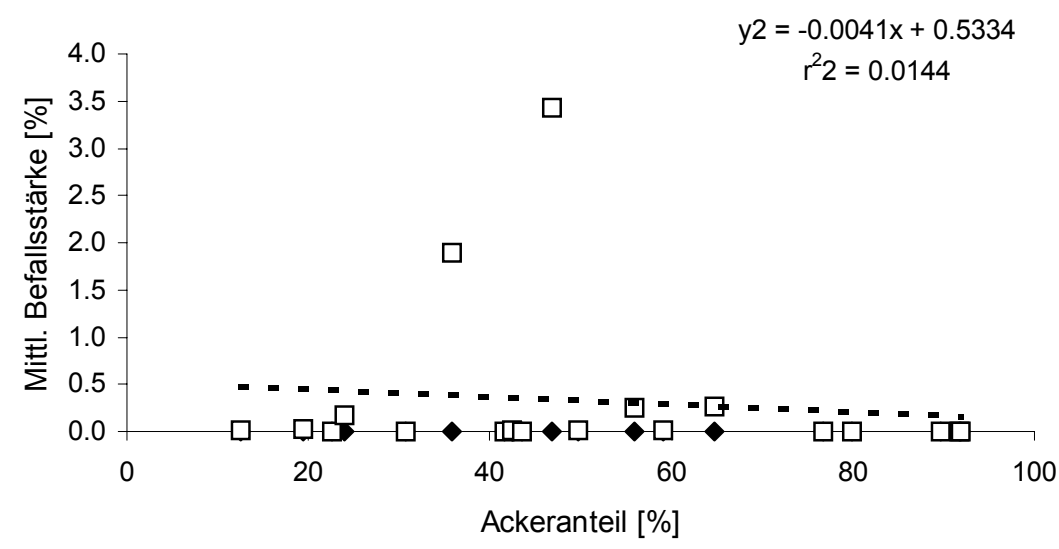

$\bullet \quad 02 \_1 \quad \square \quad 02 \_2-\cdots-\operatorname{Linear}\left(02 \_2\right)$

Abb. A12: Mittlere Befallsstärke (\% befallene Blattfläche des F-2 und F-1 Blattes) von Puccinia recondita im Verhältnis zum prozentualen Ackeranteil der Landschaften der Regionen Göttingen und Giessen zu BBCH 39-42 und 65-69 im Jahr 2002

Legende: 02_1: BBCH 39-42; $02 \_2$ : BBCH 65; y2: Regressionsgleichung 01_2; $\mathrm{r}^{2} 2$ : Bestimmtheitsmaß 01_2; (y1 und $\mathrm{r}^{2} 1$ fehlen, da zu BBCH 39-42 Befall =0) 


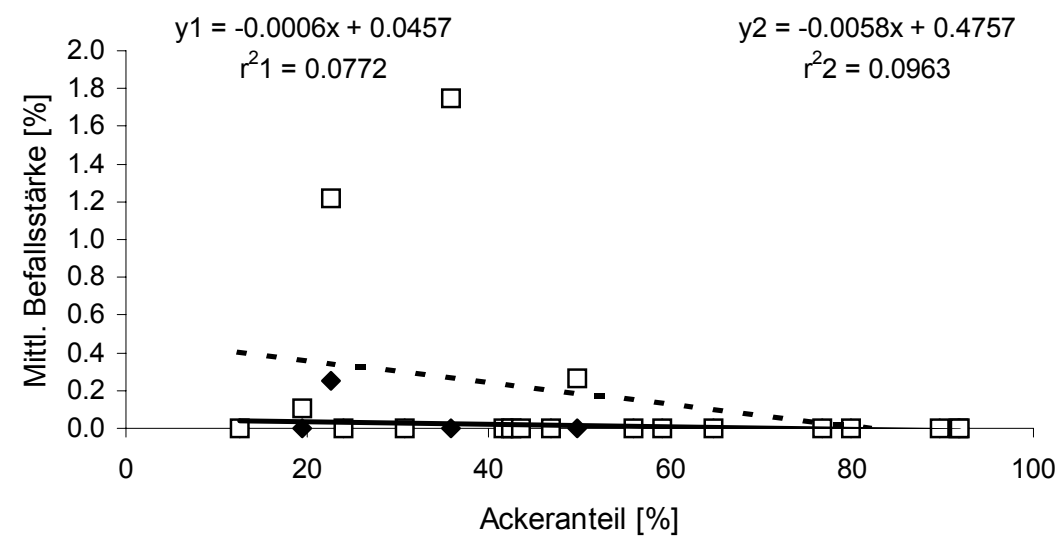

$\diamond \quad 02 \_1 \quad \square \quad 02 \_2-\operatorname{Linear}\left(02 \_1\right)$ - - - - Linear (02_2)

Abb. A13: Mittlere Befallsstärke (\% befallene Blattfläche des F-2 und F-1 Blattes) von Puccinia striiformis im Verhältnis zum prozentualen Ackeranteil der Landschaften der Regionen Göttingen und Giessen zu BBCH 39-42 und 65-69 im Jahr 2002

Legende: 02_1: $\mathrm{BBCH}$ 39-42; 02_2: $\mathrm{BBCH}$ 65; y1: Regressionsgleichung 01_1; y2: Regressionsgleichung 01_2; $\mathrm{r}^{2} 1$ : Bestimmtheitsmaß 01_1; $\mathrm{r}^{2} 2$ : Bestimmtheitsmaß 01_2

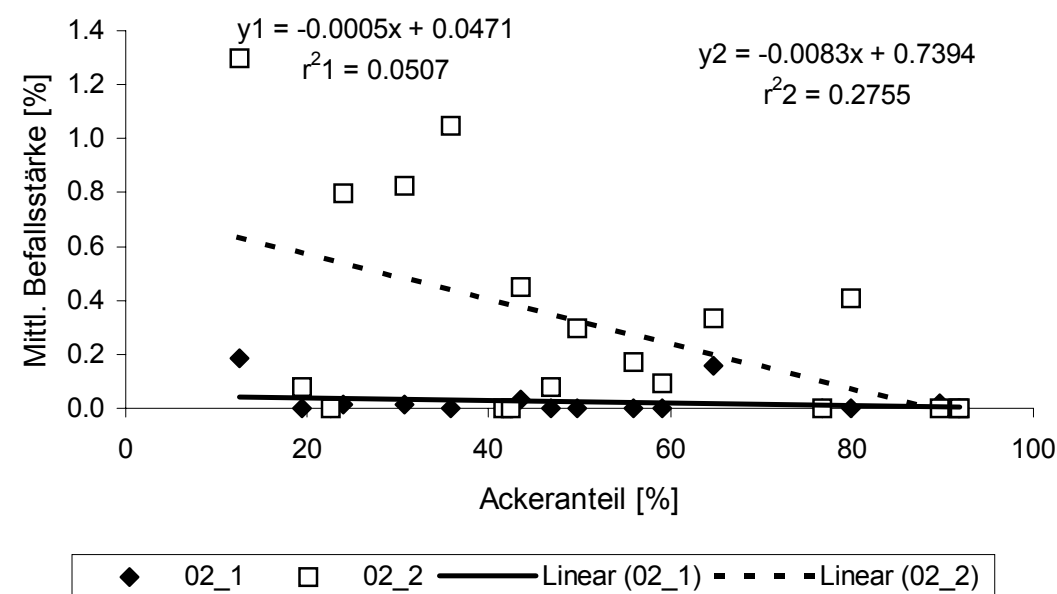

Abb. A14: Mittlere Befallsstärke (\% befallene Blattfläche des F-2 und F-1 Blattes) von Septoria nodorum im Verhältnis zum prozentualen Ackeranteil der Landschaften der Regionen Göttingen und Giessen zu BBCH 39-42 und 65-69 im Jahr 2002

Legende: 02_1: $\mathrm{BBCH}$ 39-42; 02_2: $\mathrm{BBCH}$ 65; y1: Regressionsgleichung 01_1; y2: Regressionsgleichung 01_2; $\mathrm{r}^{2} 1$ : Bestimmtheitsmaß 01_1; $\mathrm{r}^{2} 2$ : Bestimmtheitsmaß 01_2 
ATab. 1: Herbizid-, Wachstumsregler- und Insektizideinsatz auf den untersuchten Feldern der Region Göttingen und Giessen im Jahr 2001

\begin{tabular}{|c|c|c|c|c|c|c|c|c|c|}
\hline \multirow[b]{2}{*}{ Fläche } & \multicolumn{3}{|c|}{ Herbizide [l/ha] } & \multicolumn{3}{|c|}{ Wachstumsregler [l/ha] } & \multicolumn{3}{|c|}{ Insektizide [l/ha] } \\
\hline & $\begin{array}{c}1 . \\
\text { Applikation }\end{array}$ & 2. & 3. & $\begin{array}{c}1 . \\
\text { Applikation }\end{array}$ & 2. & 3. & $\begin{array}{c}1 . \\
\text { Applikation }\end{array}$ & 2. & 3. \\
\hline Gi 17 & $\begin{array}{c}1,5+2,5 \\
\text { IPU+Stomp }\end{array}$ & 0 & 0 & 0 & 0 & 0 & 0 & 0 & 0 \\
\hline Gi 20 & $\begin{array}{c}0,09 \\
\text { Concert }\end{array}$ & 0 & 0 & $\begin{array}{c}2,5 \\
\text { Terpal C }\end{array}$ & 0 & 0 & 0 & 0 & 0 \\
\hline Gö 4.1 & $\begin{array}{c}0,3 \\
\text { Herold }\end{array}$ & $\begin{array}{l}0,026 \\
\text { Hoestar }\end{array}$ & 0 & $\begin{array}{c}1,1 \\
\text { CCC }\end{array}$ & $\begin{array}{c}0,45+0,2 \\
\text { CCC+Moddus }\end{array}$ & 0 & $\begin{array}{c}0,15 \\
\text { Karate }\end{array}$ & 0 & 0 \\
\hline Gi 5 & $\begin{array}{c}2,5+0,02 \\
\text { Azur+Hoestar }\end{array}$ & 0 & 0 & $\begin{array}{l}1,25 \\
\text { CCC }\end{array}$ & 0 & 0 & 0 & 0 & 0 \\
\hline Gi 6 & $\begin{array}{c}1+2 \\
\text { IPU+Stomp }\end{array}$ & $\begin{array}{c}1,5 \\
\text { MCPA }\end{array}$ & 0 & $\begin{array}{c}1 \\
\mathrm{CCC}\end{array}$ & 0 & 0 & 0 & 0 & 0 \\
\hline $\begin{array}{c}\text { Gö } \\
11.2\end{array}$ & $\begin{array}{c}1,5+1,3+0,02 \\
\text { IPS+Bifanal } \\
+ \text { Hoestar }\end{array}$ & 0 & 0 & $\begin{array}{c}1 \\
\mathrm{CCC}\end{array}$ & $\begin{array}{c}0,5 \\
\mathrm{CCC}\end{array}$ & 0 & 0 & 0 & 0 \\
\hline Gi 12 & $\begin{array}{c}0,045 \\
\text { Concert }\end{array}$ & 0 & 0 & $\begin{array}{c}1,5 \\
\mathrm{CCC}\end{array}$ & 0 & 0 & 0 & 0 & 0 \\
\hline Gö 1.2 & $\begin{array}{c}2+0,6 \\
\text { IPU+Fox }\end{array}$ & $\begin{array}{c}0,3 \\
\text { Starane }\end{array}$ & $\begin{array}{c}1 \\
\text { MCPA }\end{array}$ & $\begin{array}{c}1 \\
\mathrm{CCC}\end{array}$ & $\begin{array}{c}0,4 \\
\text { CCC }\end{array}$ & 0 & 0 & 0 & 0 \\
\hline Gö 9.1 & $\begin{array}{c}0,5 \\
\text { Herold }\end{array}$ & $\begin{array}{c}0,7 \\
\text { Ralon S }\end{array}$ & $\begin{array}{c}0,5 \\
\text { Starane }\end{array}$ & $\begin{array}{c}1 \\
\mathrm{CCC}\end{array}$ & $\begin{array}{c}0,6+0,2 \\
\text { CCC+Moddus }\end{array}$ & $\begin{array}{c}0,5 \\
\mathrm{CCC}\end{array}$ & $\begin{array}{c}0,2 \\
\text { Sumicidin }\end{array}$ & $\begin{array}{c}0,15 \\
\text { Sumicidin }\end{array}$ & 0 \\
\hline Gö 5.1 & $\begin{array}{c}2 \\
\text { IPU }\end{array}$ & $\begin{array}{c}0,7+0,5 \\
\text { Starane+Fox }\end{array}$ & 0 & $\stackrel{1}{\mathrm{CCC}}$ & $\begin{array}{c}0,4 \\
\text { CCC }\end{array}$ & 0 & $\begin{array}{c}0,3 \\
\text { Sumicidin }\end{array}$ & 0 & 0 \\
\hline $\begin{array}{l}\text { Gö } \\
12.1\end{array}$ & $\begin{array}{l}0,025 \\
\text { Monitor }\end{array}$ & 0 & 0 & $\begin{array}{c}1 \\
\mathrm{CCC}\end{array}$ & $\begin{array}{c}0,3 \\
\text { CCC }\end{array}$ & 0 & $\begin{array}{c}0,03 \\
\text { Pirimor }\end{array}$ & 0 & 0 \\
\hline Gö 8.1 & $\begin{array}{c}0,02 \\
\text { Lexus }\end{array}$ & $\begin{array}{c}1,5 \\
\text { MCPA }\end{array}$ & 0 & $\begin{array}{c}1,5 \\
\text { CCC }\end{array}$ & $\begin{array}{c}0,5 \\
\text { CCC }\end{array}$ & 0 & $\begin{array}{c}0,2 \\
\text { Sumicidin }\end{array}$ & 0 & 0 \\
\hline
\end{tabular}

Legende: Gö : Felder der Region Göttingen ; Gi : Felder der Region Giessen 
ATab. 2: Herbizid-, Wachstumsregler- und Insektizideinsatz auf den untersuchten Feldern der Region Göttingen und Giessen im Jahr 2002

\begin{tabular}{|c|c|c|c|c|c|c|c|c|c|}
\hline & Her & de [I/ha] & & Wachst & umsregler [l/ha & & Insektiz & ide [l/ha] & \\
\hline Fläche & 1. Applikation & 2. & 3. & $\begin{array}{c}1 . \\
\text { Applikation }\end{array}$ & 2. & 3. & $\begin{array}{c}1 . \\
\text { Applikation }\end{array}$ & 2. & 3. \\
\hline Gi 10 & $\begin{array}{c}2+1 \\
\text { Stomp } \\
+ \text { IPU }\end{array}$ & 0 & 0 & $\begin{array}{c}0,5 \\
\mathrm{CCC}\end{array}$ & $\begin{array}{c}0,4 \\
\text { Moddus }\end{array}$ & 0 & 0 & 0 & 0 \\
\hline Gi 17 & $\begin{array}{c}2+1 \\
\text { Stomp } \\
+ \text { Tolkan } \\
\end{array}$ & 0 & 0 & 0 & 0 & 0 & 0 & 0 & 0 \\
\hline Gi 9 & $\begin{array}{c}5 \\
\text { Stomp }\end{array}$ & 0 & 0 & 0 & 0 & 0 & 0 & 0 & 0 \\
\hline Gö 4.1 & $\begin{array}{c}\text { 0,011+0,08 } \\
+0,014 \\
\text { Monitor } \\
+ \text { Hoestars } \\
+ \text { Pointer }\end{array}$ & 0 & 0 & $\stackrel{1}{\mathrm{CCC}}$ & $\begin{array}{c}0,4+0,2 \\
\text { CCC+Moddus }\end{array}$ & 0 & $\begin{array}{c}0,06 \\
\text { Karate } \\
\text { Zeon }\end{array}$ & $\begin{array}{c}0,1 \\
\text { Pirimor }\end{array}$ & 0 \\
\hline Gi 5 & $\begin{array}{c}\text { 2,5+0,8 } \\
\text { IPU } \\
\text { +Starane }\end{array}$ & 0 & 0 & $\begin{array}{l}1,25 \\
\mathrm{CCC}\end{array}$ & 0 & 0 & 0 & 0 & 0 \\
\hline Gi 6 & $\begin{array}{c}1+2 \\
\text { IPU } \\
+ \text { Stomp }\end{array}$ & 0 & 0 & $\begin{array}{c}1,2 \\
\mathrm{CCC}\end{array}$ & $\begin{array}{c}0,3+0,3 \\
\text { CCC+Moddus }\end{array}$ & 0 & $\begin{array}{c}0,02 \\
\text { Decio }\end{array}$ & 0 & 0 \\
\hline $\begin{array}{c}\text { Gö } \\
11.2\end{array}$ & $\begin{array}{l}\text { 1,5+1,5 } \\
\text { Arelon } \\
\text { +Bifenal }\end{array}$ & $\begin{array}{c}0,4 \\
\text { Starane }\end{array}$ & 0 & $\stackrel{1}{\mathrm{CCC}}$ & $\stackrel{1}{\mathrm{CCC}}$ & 0 & 0 & 0 & 0 \\
\hline Gi 12 & $\begin{array}{c}1,1+2,5 \\
\text { Lexus } \\
+ \text { Primus }\end{array}$ & 0 & 0 & $\stackrel{1}{\mathrm{CCC}}$ & $\begin{array}{c}\text { 0,4+0,2 } \\
\text { CCC } \\
\text { +Moddus }\end{array}$ & 0 & 0 & 0 & 0 \\
\hline Gö 1.2 & $\begin{array}{c}0,3 \\
\text { Herold }\end{array}$ & $\begin{array}{c}0,1 \\
\text { HoestarS }\end{array}$ & $\begin{array}{c}1,2 \\
\text { MCPA }\end{array}$ & $\begin{array}{c}1,2 \\
\mathrm{CCC}\end{array}$ & $\begin{array}{c}0,3+0,15 \\
\text { CCC } \\
\text { +Moddus } \\
\end{array}$ & 0 & $\begin{array}{c}0,2 \\
\text { Bulldock }\end{array}$ & 0 & 0 \\
\hline Gö 9.1 & $\begin{array}{c}2,5+1,25 \\
\text { IPU } \\
+ \text { Bifenal }\end{array}$ & $\begin{array}{c}\text { 0,5+0,8+1 } \\
\text { Starane } \\
\text { +RalonS } \\
\text { +Oleo }\end{array}$ & $\begin{array}{c}1,2 \\
\text { MCPA }\end{array}$ & $\begin{array}{c}1,2 \\
\mathrm{CCC}\end{array}$ & $\begin{array}{c}0,5+0,2 \\
\text { CCC } \\
\text { +Moddus }\end{array}$ & $\begin{array}{c}0,2 \\
\mathrm{CCC}\end{array}$ & $\begin{array}{c}0,2 \\
\text { Sumicidin }\end{array}$ & $\begin{array}{c}0,2 \\
\text { Sumicidin }\end{array}$ & 0 \\
\hline Gö 5.1 & $\begin{array}{c}2 \\
\text { IPU }\end{array}$ & $\begin{array}{c}0,4+0,2 \\
\text { Starane } \\
+ \text { Butenal } \\
\end{array}$ & $\begin{array}{c}1 \\
\mathrm{MCPA}\end{array}$ & $\begin{array}{c}0,8 \\
\mathrm{CCC}\end{array}$ & $\begin{array}{c}0,4 \\
\text { CCC }\end{array}$ & 0 & $\begin{array}{c}0,2 \\
\text { Sumicidin }\end{array}$ & $\begin{array}{c}0,2 \\
\text { Sumicidin }\end{array}$ & 0 \\
\hline $\begin{array}{c}\text { Gö } \\
12.1\end{array}$ & $\begin{array}{c}\text { 0,01+0,2 } \\
\text { Laurel Pack }\end{array}$ & 0 & 0 & $\begin{array}{c}1 \\
\mathrm{CCC}\end{array}$ & $\begin{array}{c}0,3 \\
\mathrm{CCC}\end{array}$ & 0 & 0 & 0 & 0 \\
\hline Gö 8.1 & $\begin{array}{c}0,1+0,02 \\
\text { Hoestar } \\
+ \text { Lexus }\end{array}$ & $\begin{array}{c}0,8+0,08 \\
\text { Starane } \\
\text { +Attribut }\end{array}$ & $\begin{array}{c}1,25 \\
\text { MCPA }\end{array}$ & $\begin{array}{l}1,25 \\
\mathrm{CCC}\end{array}$ & $\begin{array}{c}0,5+0,3 \\
\text { CCC } \\
+ \text { Moddus }\end{array}$ & 0 & $\begin{array}{c}0,75 \\
\text { Karate }\end{array}$ & 0 & 0 \\
\hline
\end{tabular}

Legende: Gö : Felder der Region Göttingen ; Gi : Felder der Region Giessen 
ATab 3: Verwendete Primer im Rahmen der genetischen Untersuchungen

\begin{tabular}{|c|c|c|c|}
\hline Primer & Verwendet bei & Primer Motiv & Primer Sequenz \\
\hline $\mathrm{AC}$ & MP-PCR & {$[\mathrm{AC}]_{9}$} & ACACACACACACACACAC \\
\hline GATA & MP-PCR (Vorversuch) & {$[\mathrm{GATA}]_{4}$} & GATAGATAGATAGATA \\
\hline $\mathrm{CAG}$ & MP-PCR (Vorversuch) & {$[\mathrm{CAG}]_{5}$} & CAGCAGCAGCAGCAG \\
\hline GACA & MP-PCR (Vorversuch) & {$[\mathrm{GACA}]_{4}$} & GACAGACAGACAGACA \\
\hline GACAC & MP-PCR (Vorversuch) & {$[\mathrm{GACAC}]_{3}$} & GACACGACACGACAC \\
\hline TGTC & MP-PCR (Vorversuch) & {$[\mathrm{TGTC}]_{4}$} & TGTCTGTCTGTCTGTC \\
\hline AAG & MP-PCR (Vorversuch) & {$[\mathrm{AAG}]_{6}$} & AAGAAGAAGAAGAAGAAG \\
\hline $\mathrm{AAC}$ & MP-PCR (Vorversuch) & {$[\mathrm{AAC}]_{7}$} & AACAACAACAACAACAACAAC \\
\hline ATC & MP-PCR (Vorversuch) & {$[\mathrm{ATC}]_{7}$} & ATCATCATCATCATCATCATC \\
\hline $\mathrm{AG}$ & MP-PCR (Vorversuch) & {$[\mathrm{AG}]_{9}$} & AGAGAGAGAGAGAGAGAG \\
\hline $\mathrm{AGC}$ & MP-PCR (Vorversuch) & {$[\mathrm{AGC}]_{5}$} & AGCAGCAGCAGCAGC \\
\hline GTG & MP-PCR (Vorversuch) & {$[\mathrm{GTG}]_{5}$} & GTGGTGGTGGTGGTG \\
\hline CCT & MP-PCR (Vorversuch) & {$[\mathrm{CCT}]_{5}$} & ССТССТССТССТССТ \\
\hline $\mathrm{ACG}$ & MP-PCR (Vorversuch) & {$[\mathrm{ACG}]_{5}$} & ACGACGACGACGACG \\
\hline ACT & MP-PCR (Vorversuch) & {$[\mathrm{ACT}]_{7}$} & ACTACTACTACTACTACTACT \\
\hline ST1A4 & Mikrosatelliten-PCR & {$[\mathrm{CGG}]_{7}$} & $\begin{array}{l}\text { F: 5'GGTTCGATGGAGAGATTT3' } \\
\text { R: 5'TCACCTCCTCATCGCAGA3' }\end{array}$ \\
\hline St2E4 & Mikrosatelliten-PCR & {$[\mathrm{GGC}]_{5}$} & $\begin{array}{l}\text { F: 5'GAAGATCAACAGCATGGGCGG3' } \\
\text { R: 5'CTCCAGAGGGATCACAAAGGC3' }\end{array}$ \\
\hline ST1E7 & Mikrosatelliten-PCR & {$[\mathrm{CGG}]_{5}$} & $\begin{array}{l}\text { F: 5'GATCTCGAGCAGGGCGGAAGT3', } \\
\text { R: 5'TCACACGCTGGTCTGTGAATC3' }\end{array}$ \\
\hline ST1A2 & $\begin{array}{l}\text { Mikrosatelliten-PCR } \\
\text { (Vorversuch) }\end{array}$ & {$[\mathrm{GGC}]_{7} /[\mathrm{GGT}]_{2}$} & $\begin{array}{l}\text { F: 5'TTTTCCTCTCTCCCGTGC3' } \\
\text { R: 5'CTCTCGTCAACCCCAGAC3' }\end{array}$ \\
\hline ST1B3 & $\begin{array}{c}\text { Mikrosatelliten-PCR } \\
\text { (Vorversuch) }\end{array}$ & {$[\mathrm{CCG}]_{8}$} & $\begin{array}{l}\text { F: 5'ACGTTCACATCTCATACC3' } \\
\text { R: 5'CTCTAGCTCTACCTTAAT3' }\end{array}$ \\
\hline ST1E3 & $\begin{array}{c}\text { Mikrosatelliten-PCR } \\
\text { (Vorversuch) }\end{array}$ & {$[\mathrm{CGG}]_{5}$} & $\begin{array}{l}\text { F: 5'GGTCCGCCGGTCGAAGTCG3', } \\
\text { R: 5'GCCAAGGCACTGCTGCTCC3' }\end{array}$ \\
\hline ST2C10 & $\begin{array}{l}\text { Mikrosatelliten-PCR } \\
\text { (Vorversuch) }\end{array}$ & {$[\mathrm{AGCGG}]_{4}$} & $\begin{array}{l}\text { F: 5'AGGCGAGAAACTTGCTTGCAG3', } \\
\text { R: 5'AATGAACGTCCCATGGACGTG3' }\end{array}$ \\
\hline ST1E7 & $\begin{array}{l}\text { Mikrosatelliten-PCR } \\
\text { (Vorversuch) }\end{array}$ & {$[\mathrm{TG}]_{9}$} & $\begin{array}{l}\text { F: 5'ATGCTGAGAAGTTCGGTGAGG3' } \\
\text { R: 5'CGTTCTTCCACCTCCAACACT3' }\end{array}$ \\
\hline ST1D7 & $\begin{array}{l}\text { Mikrosatelliten-PCR } \\
\text { (Vorversuch) }\end{array}$ & {$[\mathrm{AC}]_{22}$} & $\begin{array}{l}\text { F: 5'ATCCTCCATTCACTACTGCAT3' } \\
\text { R: 5'TGTGGAACAGGAATAGGCTTG3' }\end{array}$ \\
\hline
\end{tabular}

(Primer Sequenzen vgl. OWEN et al. 1998 und CZEMBOR \& ARSENIUK 1999) 
ATab. 4: Binäre 0/1 Matrix der 79 Genotypen der 290 Isolate von Septoria tritici auf Grundlage der 11 amplifizierten Allele mit den Primern ST1A4, ST1E7 und ST2E4

\begin{tabular}{|c|c|c|c|c|c|c|c|c|c|c|c|}
\hline \multirow[b]{2}{*}{ Genotyp } & \multicolumn{3}{|c|}{ Primer ST1A4 } & \multicolumn{4}{|c|}{ Primer ST1E7 } & \multicolumn{4}{|c|}{ Primer ST2E4 } \\
\hline & $\begin{array}{c}\text { Allel } \\
1\end{array}$ & $\begin{array}{c}\text { Allel } \\
2\end{array}$ & $\begin{array}{c}\text { Allel } \\
\mathbf{3}\end{array}$ & $\begin{array}{c}\text { Allel } \\
4\end{array}$ & $\begin{array}{c}\text { Allel } \\
5\end{array}$ & $\begin{array}{c}\text { Allel } \\
6\end{array}$ & $\begin{array}{c}\text { Allel } \\
7\end{array}$ & $\begin{array}{c}\text { Allel } \\
8\end{array}$ & $\begin{array}{c}\text { Allel } \\
9\end{array}$ & $\begin{array}{c}\text { Allel } \\
10\end{array}$ & $\begin{array}{c}\text { Allel } \\
11\end{array}$ \\
\hline 1 & 0 & 1 & 0 & 0 & 1 & 0 & 1 & 0 & 1 & 1 & 1 \\
\hline 2 & 0 & 1 & 0 & 0 & 1 & 0 & 1 & 0 & 1 & 0 & 1 \\
\hline 3 & 0 & 0 & 1 & 0 & 1 & 0 & 1 & 0 & 1 & 1 & 1 \\
\hline 4 & 1 & 0 & 0 & 0 & 1 & 0 & 1 & 0 & 1 & 1 & 1 \\
\hline 5 & 0 & 1 & 0 & 0 & 1 & 1 & 0 & 0 & 1 & 1 & 1 \\
\hline 6 & 0 & 1 & 0 & 0 & 1 & 1 & 0 & 0 & 1 & 1 & 0 \\
\hline 7 & 0 & 0 & 1 & 1 & 0 & 1 & 0 & 1 & 0 & 0 & 1 \\
\hline 8 & 0 & 1 & 0 & 0 & 1 & 0 & 1 & 1 & 0 & 1 & 1 \\
\hline 9 & 0 & 1 & 0 & 0 & 1 & 0 & 1 & 1 & 0 & 1 & 0 \\
\hline 10 & 0 & 1 & 0 & 1 & 0 & 1 & 0 & 1 & 0 & 1 & 1 \\
\hline 11 & 0 & 1 & 0 & 0 & 1 & 0 & 1 & 1 & 0 & 0 & 1 \\
\hline 12 & 0 & 1 & 0 & 0 & 1 & 0 & 1 & 1 & 0 & 0 & 0 \\
\hline 13 & 0 & 1 & 0 & 0 & 1 & 1 & 0 & 1 & 0 & 1 & 1 \\
\hline 14 & 0 & 1 & 0 & 0 & 1 & 1 & 1 & 1 & 0 & 1 & 1 \\
\hline 15 & 0 & 1 & 0 & 0 & 0 & 1 & 1 & 1 & 0 & 1 & 1 \\
\hline 16 & 0 & 1 & 0 & 0 & 1 & 0 & 1 & 1 & 0 & 1 & 1 \\
\hline 17 & 0 & 0 & 1 & 0 & 1 & 0 & 1 & 1 & 0 & 1 & 0 \\
\hline 18 & 0 & 0 & 1 & 0 & 1 & 0 & 1 & 1 & 0 & 1 & 1 \\
\hline 19 & 0 & 0 & 1 & 0 & 1 & 0 & 1 & 1 & 1 & 1 & 0 \\
\hline 20 & 0 & 0 & 1 & 0 & 1 & 0 & 1 & 1 & 1 & 0 & 0 \\
\hline 21 & 0 & 0 & 1 & 0 & 1 & 0 & 1 & 1 & 1 & 0 & 1 \\
\hline 22 & 0 & 0 & 1 & 0 & 1 & 0 & 1 & 1 & 0 & 0 & 1 \\
\hline 23 & 1 & 0 & 0 & 0 & 1 & 0 & 1 & 1 & 1 & 0 & 0 \\
\hline 24 & 1 & 0 & 0 & 0 & 1 & 0 & 1 & 1 & 1 & 1 & 0 \\
\hline 25 & 1 & 0 & 0 & 0 & 1 & 0 & 1 & 1 & 0 & 0 & 0 \\
\hline 26 & 1 & 0 & 0 & 0 & 1 & 0 & 1 & 1 & 0 & 1 & 1 \\
\hline 27 & 1 & 0 & 0 & 0 & 1 & 0 & 1 & 1 & 1 & 0 & 1 \\
\hline 28 & 1 & 0 & 0 & 0 & 1 & 0 & 1 & 1 & 0 & 0 & 1 \\
\hline 29 & 1 & 0 & 0 & 0 & 0 & 0 & 0 & 1 & 0 & 1 & 1 \\
\hline 30 & 1 & 0 & 0 & 0 & 1 & 1 & 0 & 1 & 0 & 1 & 1 \\
\hline 31 & 1 & 0 & 0 & 0 & 1 & 0 & 0 & 1 & 0 & 1 & 1 \\
\hline 32 & 0 & 0 & 1 & 1 & 1 & 0 & 0 & 1 & 0 & 1 & 0 \\
\hline 33 & 0 & 0 & 1 & 1 & 1 & 0 & 0 & 1 & 0 & 1 & 1 \\
\hline 34 & 0 & 1 & 0 & 1 & 1 & 0 & 0 & 1 & 0 & 1 & 0 \\
\hline 35 & 0 & 1 & 0 & 1 & 1 & 0 & 0 & 0 & 1 & 1 & 0 \\
\hline 36 & 0 & 1 & 0 & 0 & 1 & 1 & 0 & 1 & 0 & 1 & 0 \\
\hline 37 & 0 & 1 & 0 & 0 & 1 & 1 & 0 & 0 & 0 & 1 & 0 \\
\hline 38 & 0 & 1 & 0 & 0 & 1 & 1 & 0 & 0 & 0 & 0 & 0 \\
\hline 39 & 0 & 0 & 1 & 0 & 1 & 1 & 0 & 1 & 0 & 1 & 1 \\
\hline 40 & 0 & 0 & 1 & 0 & 1 & 1 & 0 & 0 & 1 & 1 & 1 \\
\hline 41 & 0 & 0 & 1 & 0 & 1 & 1 & 0 & 0 & 1 & 1 & 0 \\
\hline 42 & 1 & 0 & 0 & 0 & 1 & 1 & 0 & 1 & 1 & 0 & 0 \\
\hline 43 & 1 & 0 & 0 & 0 & 1 & 1 & 0 & 1 & 1 & 1 & 0 \\
\hline 44 & 1 & 0 & 0 & 1 & 1 & 0 & 0 & 1 & 0 & 0 & 0 \\
\hline 45 & 0 & 1 & 0 & 1 & 0 & 1 & 0 & 1 & 0 & 0 & 1 \\
\hline 46 & 0 & 1 & 0 & 1 & 0 & 1 & 0 & 1 & 1 & 0 & 1 \\
\hline 47 & 0 & 1 & 0 & 1 & 0 & 1 & 0 & 1 & 0 & 1 & 1 \\
\hline 48 & 0 & 1 & 0 & 0 & 1 & 0 & 1 & 0 & 1 & 0 & 1 \\
\hline 49 & 0 & 1 & 0 & 1 & 0 & 1 & 0 & 1 & 0 & 0 & 0 \\
\hline 50 & 1 & 0 & 0 & 1 & 0 & 1 & 0 & 1 & 0 & 1 & 1 \\
\hline 51 & 1 & 0 & 0 & 1 & 0 & 1 & 0 & 1 & 0 & 0 & 1 \\
\hline 52 & 0 & 1 & 0 & 1 & 0 & 1 & 0 & 0 & 1 & 1 & 1 \\
\hline 53 & 0 & 1 & 0 & 1 & 0 & 1 & 0 & 0 & 1 & 0 & 1 \\
\hline 54 & 0 & 1 & 0 & 1 & 0 & 1 & 0 & 0 & 1 & 0 & 0 \\
\hline 55 & 0 & 1 & 0 & 1 & 0 & 1 & 0 & 0 & 0 & 0 & 1 \\
\hline 56 & 0 & 0 & 1 & 1 & 0 & 1 & 0 & 1 & 1 & 0 & 1 \\
\hline 57 & 0 & 1 & 0 & 0 & 1 & 0 & 1 & 1 & 1 & 0 & 1 \\
\hline 58 & 0 & 0 & 1 & 1 & 0 & 1 & 0 & 1 & 0 & 1 & 1 \\
\hline 59 & 0 & 0 & 1 & 1 & 0 & 1 & 0 & 0 & 1 & 1 & 1 \\
\hline 60 & 0 & 0 & 1 & 1 & 0 & 1 & 0 & 0 & 1 & 0 & 1 \\
\hline 61 & 0 & 0 & 1 & 1 & 0 & 1 & 0 & 0 & 0 & 0 & 0 \\
\hline 62 & 0 & 0 & 1 & 1 & 0 & 1 & 0 & 0 & 0 & 0 & 1 \\
\hline 63 & 0 & 1 & 0 & 1 & 0 & 0 & 1 & 0 & 1 & 1 & 1 \\
\hline 64 & 0 & 1 & 0 & 1 & 0 & 0 & 1 & 0 & 1 & 1 & 0 \\
\hline 65 & 1 & 0 & 0 & 1 & 0 & 0 & 1 & 0 & 1 & 1 & 1 \\
\hline
\end{tabular}


Fortsetzung ATab. 4:

\begin{tabular}{|c|c|c|c|c|c|c|c|c|c|c|c|}
\hline & \multicolumn{9}{|c|}{ Primer ST1A4 } & \multicolumn{9}{c|}{ Primer ST1E7 } & \multicolumn{3}{c|}{ Primer ST2E4 } \\
\hline Genotyp & Allel & Allel & Allel & Allel & Allel & Allel & Allel & Allel & Allel & Allel \\
$\mathbf{9}$ & $\mathbf{2}$ & $\mathbf{4}$ & $\mathbf{5}$ & $\mathbf{6}$ & $\mathbf{7}$ & $\begin{array}{c}\text { Allel } \\
\mathbf{1 1}\end{array}$ \\
\hline $\mathbf{6 6}$ & 1 & 0 & 0 & 1 & 0 & 0 & 1 & 1 & 1 & 1 & 0 \\
\hline $\mathbf{6 7}$ & 1 & 0 & 0 & 1 & 1 & 0 & 0 & 0 & 1 & 1 & 1 \\
\hline $\mathbf{6 8}$ & 0 & 0 & 1 & 1 & 0 & 0 & 1 & 0 & 1 & 1 & 1 \\
\hline $\mathbf{6 9}$ & 0 & 0 & 1 & 1 & 0 & 0 & 1 & 1 & 1 & 1 & 0 \\
\hline $\mathbf{7 0}$ & 0 & 0 & 1 & 0 & 0 & 1 & 1 & 0 & 1 & 1 & 1 \\
\hline $\mathbf{7 1}$ & 1 & 0 & 0 & 1 & 0 & 1 & 0 & 0 & 1 & 1 & 1 \\
\hline $\mathbf{7 2}$ & 1 & 0 & 0 & 1 & 0 & 1 & 0 & 0 & 1 & 0 & 1 \\
\hline $\mathbf{7 3}$ & 1 & 0 & 0 & 1 & 0 & 1 & 0 & 0 & 1 & 0 & 0 \\
\hline $\mathbf{7 4}$ & 1 & 0 & 0 & 0 & 0 & 1 & 1 & 0 & 1 & 1 & 0 \\
\hline $\mathbf{7 5}$ & 1 & 0 & 0 & 0 & 0 & 1 & 1 & 0 & 1 & 1 & 1 \\
\hline $\mathbf{7 6}$ & 1 & 0 & 0 & 0 & 0 & 1 & 1 & 0 & 1 & 0 & 1 \\
\hline $\mathbf{7 7}$ & 1 & 0 & 0 & 0 & 0 & 1 & 1 & 1 & 0 & 1 & 1 \\
\hline $\mathbf{7 8}$ & 1 & 0 & 0 & 0 & 0 & 1 & 1 & 1 & 1 & 1 & 1 \\
\hline $\mathbf{7 9}$ & 1 & 0 & 0 & 0 & 0 & 1 & 1 & 1 & 0 & 0 & 1 \\
\hline
\end{tabular}




\section{Danksagung}

Mein ganz besonderer Dank gilt Herrn Prof. Dr. Andreas von Tiedemann für die herzliche Aufnahme in seine Abteilung, die Übernahme des Referats, die jederzeit angebotene Hilfe und Unterstützung bei der Fertigstellung dieser Arbeit. Außerdem bedanke ich mich für die wichtigen Diskussionen, Gespräche und Anregungen und das große Verständnis bei Problemen jeder Art.

Mein herzlicher Dank gilt Herrn Prof. Dr. Stefan Vidal für die Überlassung des Themas und die Unterstützung während der ersten acht Monate bei der Durchführung dieser Arbeit.

Ganz besonders bedanke ich mich bei Herrn Dr. Birger Koopmann für seine Unterstützung, Korrekturen bei praktischer und geistiger Arbeit, seine unermüdliche Geduld und seine Freundschaft.

Bei Evelin Vorbeck und Pia Meyer bedanke ich mich für die wichtige technische Hilfe und den großen Spaß an der Arbeit.

Bei Frau Dr. Ursula Hettwer möchte ich mich besonders für die Hilfe bei der Auswertung der molekularen Daten bedanken.

Bei Herrn Prof. Dr. Bruce McDonald bedanke ich mich herzlich für die Beratung bei populationsgenetischen Fragen.

Ich bedanke mich bei Dr. Mark Varrelmann, Sarah Dunker, Christina Eynck und Evelin Vorbeck für ihr unermüdliches Korrekturlesen.

Ganz herzlich bedanke ich mich bei meiner Arbeitsgruppe für das freundschaftliche Verhältnis und den großen Spaß im Institut und außerhalb.

Bei meinen FreundInnen bedanke ich mich für die Unterstützung und Abwechslung während der Durchführung dieser Arbeit.

Schließlich danke ich meinen Eltern für ihre Unterstützung und ihr Verständnis und dafür, dass ich mich immer auf sie verlassen kann. 


\section{Lebenslauf}

Name. Julia Morzfeld

Geburtsdatum: 24.11.1975

Geburtsort: Bochum

Schulzeit:

1981-1986 Grundschule (Gräfin-Imma-Schule, Bochum)

1986-1995 Gymnasium (Graf-Engelbert-Gymnasium, Bochum)

Studium:

$1995-1998$

Grundstudium Biologie an der Ruhr-Universität Bochum

1998- 2000

Hauptstudium Biologie an der Georg-August-Universität Göttingen

2000-2001

Diplomarbeit am Institut für Pflanzenpathologie und Pflanzenschutz an der Georg-August-Universität Göttingen

05.01 .2001

Abschluss Dipl. Biol.

2001-2004 Doktorandin am Institut für Pflanzenpathologie und Pflanzenschutz der Georg-August-Universität Göttingen 


\section{Selbstständigkeitserklärung}

Ich versichere, dass ich die vorliegende Arbeit, selbstständig verfasst und keine anderen als die angegebenen Hilfsmittel verwendet habe.

Julia Morzfeld

Göttingen, April 2004 